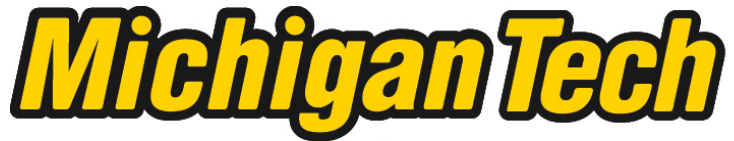 \\ Michigan Technological University Create the Future Digital Commons @ Michigan Tech
}

\section{Application of ultra high performance concrete (UHPC) as a thin- bonded overlay for concrete bridge decks}

Sarah V. Shann

Michigan Technological University

Follow this and additional works at: https://digitalcommons.mtu.edu/etds

Part of the Civil and Environmental Engineering Commons Copyright 2012 Sarah V. Shann

\section{Recommended Citation}

Shann, Sarah V., "Application of ultra high performance concrete (UHPC) as a thin-bonded overlay for concrete bridge decks", Master's Thesis, Michigan Technological University, 2012.

https://doi.org/10.37099/mtu.dc.etds/270

Follow this and additional works at: https://digitalcommons.mtu.edu/etds

3 Part of the Civil and Environmental Engineering Commons 
APPLICATION OF ULTRA HIGH PERFORMANCE CONCRETE (UHPC) AS A THIN-BONDED OVERLAY FOR CONCRETE BRIDGE DECKS

By

Sarah V. Shann

\begin{abstract}
A THESIS
Submitted in partial fulfillment of the requirements for the degree of MASTER OF SCIENCE

(Civil Engineering)

MICHIGAN TECHNOLOGICAL UNIVERSITY
\end{abstract}

2012

(C) 2012 Sarah V. Shann 
This thesis, "Application of Ultra High Performance Concrete (UHPC) as a Thin-Bonded Overlay for Concrete Bridge Decks," is hereby approved in partial fulfillment of the requirements for the Degree of MASTER OF SCIENCE IN CIVIL ENGINEERING.

Department of Civil and Environmental Engineering

Signatures:

Thesis Advisor

Dr. Devin K. Harris

Department Chair

Dr. David W. Hand

Date 


\section{Table of Contents}

Table of Contents ......................................................................................... ii

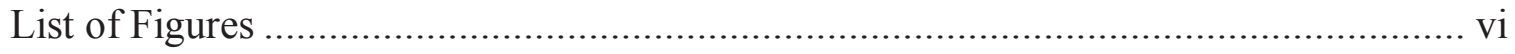

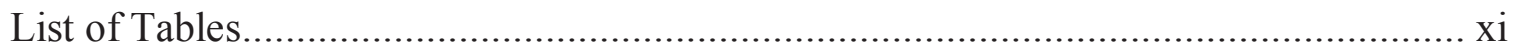

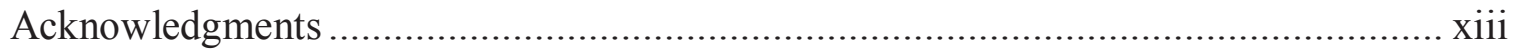

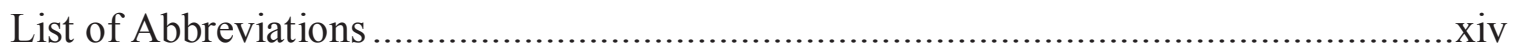

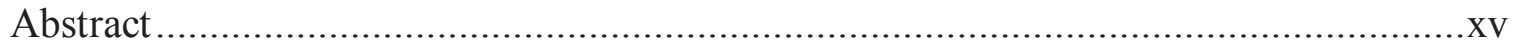

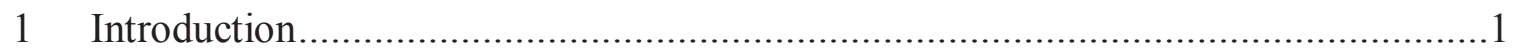

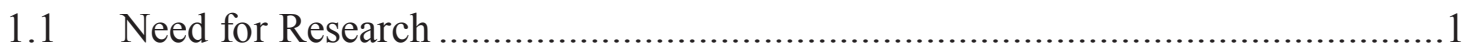

1.2 Thesis Overview and Scope....................................................................

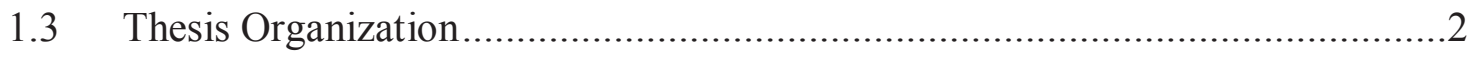

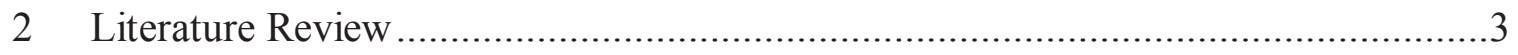

2.1 Bridge Deck Failure Mechanisms .............................................................

2.2 Repair and Maintenance Strategies ..........................................................

2.3 Overlay Failure Mechanisms ...............................................................4

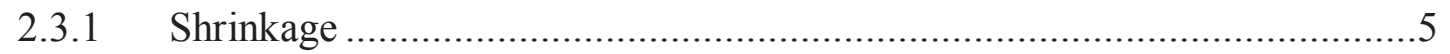

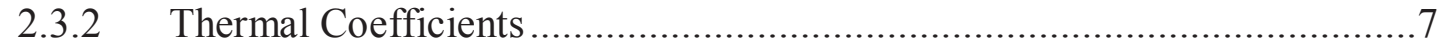

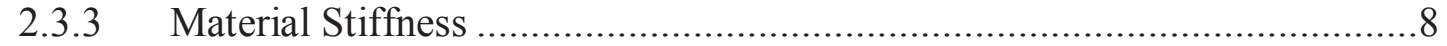

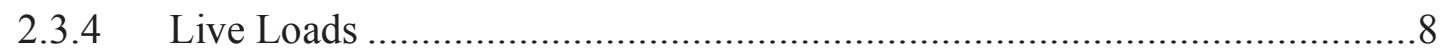

2.4 Overview of Traditional Overlays.........................................................

2.5 Modeling of Overlay Systems............................................................. 15

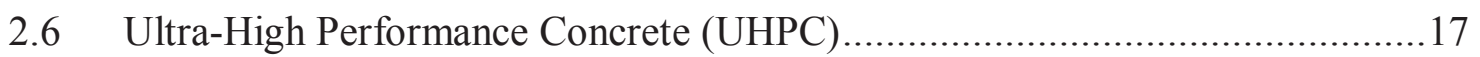

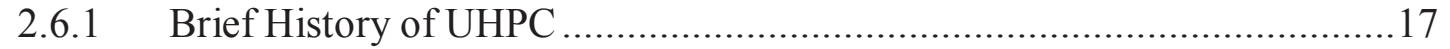

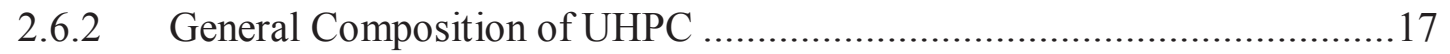

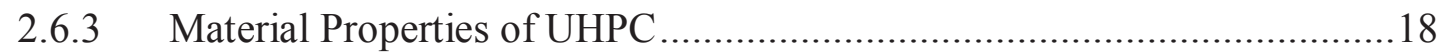

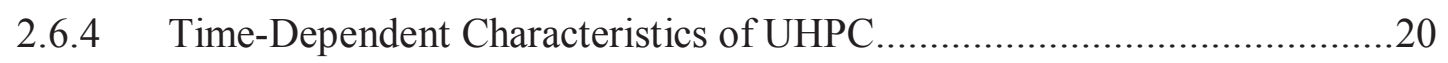

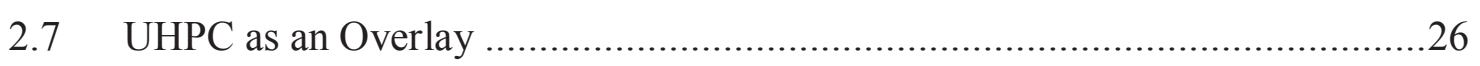




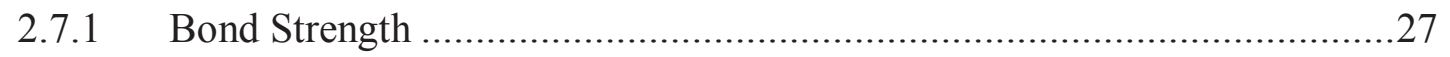

2.7.2 Summary of UHPC Applications as Bridge Deck Overlays ………….......28

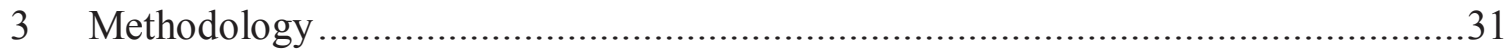

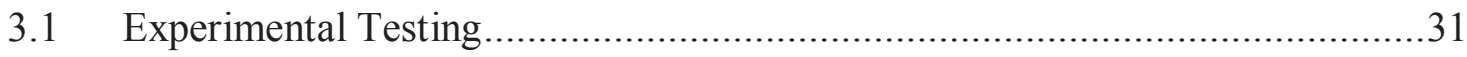

3.1.1 UHPC Batching and Mixing Procedure ....................................................

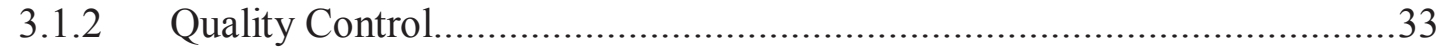

3.1.3 Curing Regimes and Demold Time........................................................33

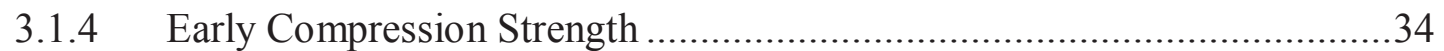

3.1.5 Restrained Shrinkage and Creep ………………......................................

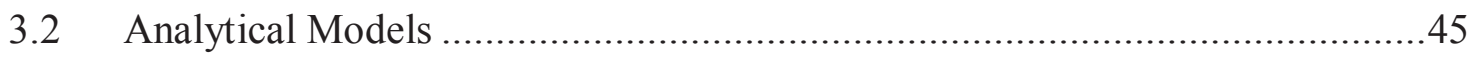

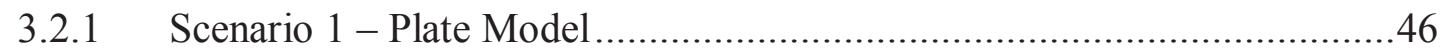

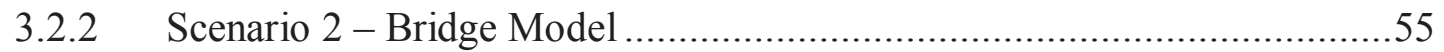

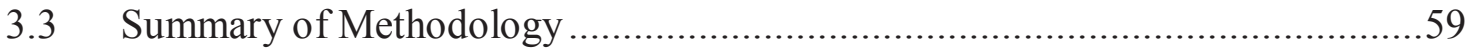

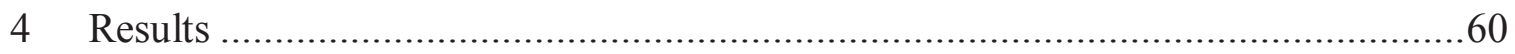

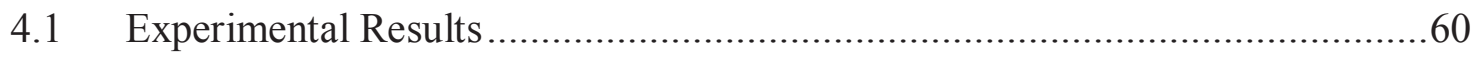

4.1.1 Early Age Compression Strength........................................................60

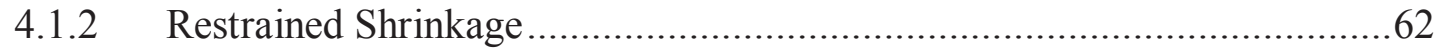

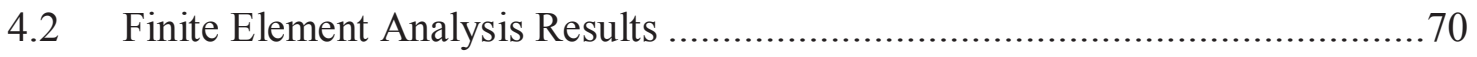

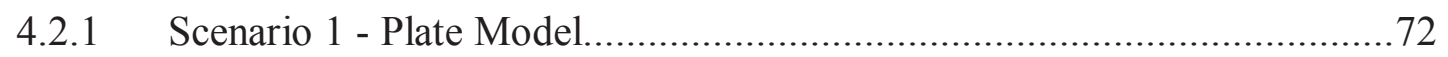

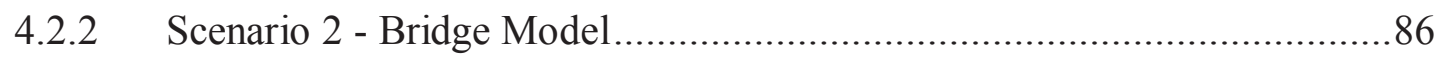

4.2.3 Comparison of Global Bridge and Plate FEM …….................................92

4.3 Shrinkage and Notional Design Truck Load ……..........................................99

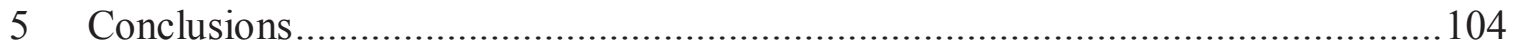

$6 \quad$ Future Work

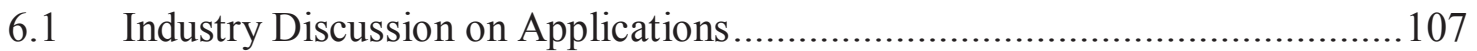

6.1.1 Mixing and Casting Sequence Discussion...............................................107

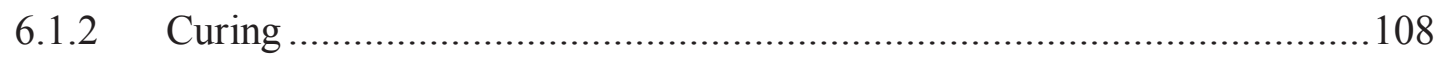

6.1.3 Bonding and Riding Surface Preparations..............................................108

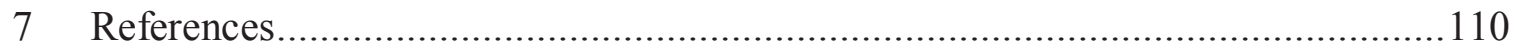




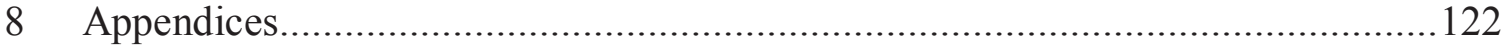




\section{List of Figures}

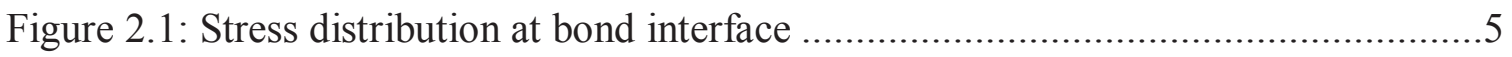

Figure 2.2: Early age compressive strength gain of Ductal ${ }^{\circledR}$ within 2 days ....................24

Figure 2.3: Compressive strength gain of Ductal ${ }^{\circledR}$ within 7 days ...................................24

Figure 2.4: Compressive strength gain of Ductal ${ }^{\circledR}$ within 30 days .................................25

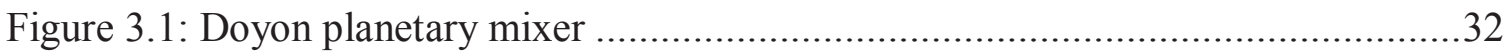

Figure 3.2: Flow test setup and spread measurement..................................................33

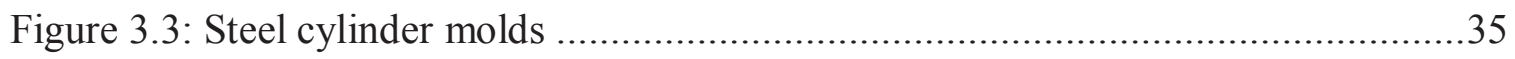

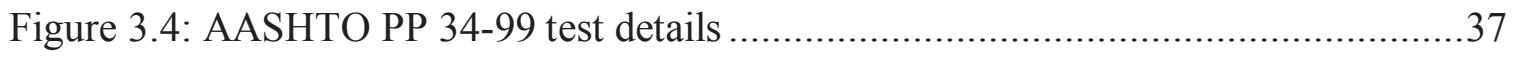

Figure 3.5: Complete strain gage installation ................................................................38

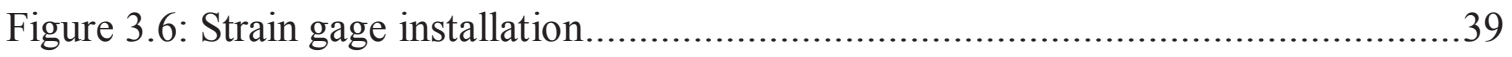

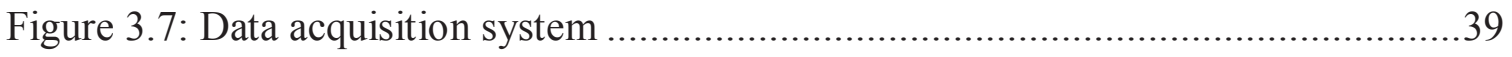

Figure 3.8: AASHTO PP34-99 cast specimen ............................................................40

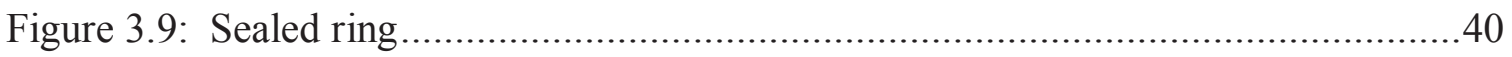

Figure 3.10: Pressure idealization for determine the residual concrete stress ...................41

Figure 3.11: Stress distribution when drying occurs from outer circumference...............41

Figure 3.12: Free body diagram of pressurized cylinder .............................................42

Figure 3.13: Horizontal interface shear stress diagram ................................................4

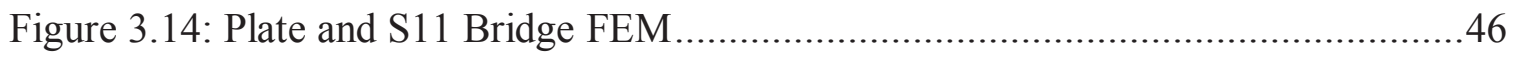

Figure 3.15: Simplified Plate Model Boundary Conditions ...............................................49

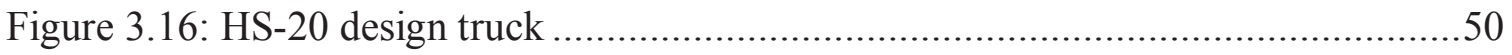

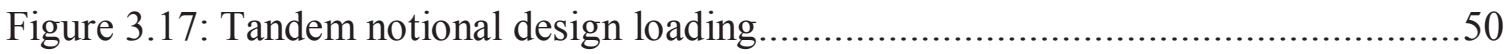

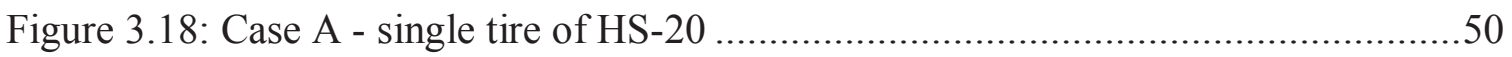

Figure 3.19: Case B - wheels from one side of HS-20 …………..............................50

Figure 3.20: Case C - middle and rear axles of HS-20 ……..........................................51

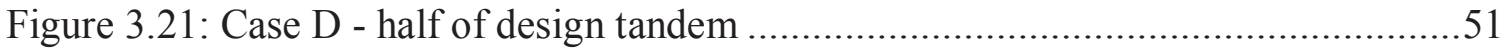




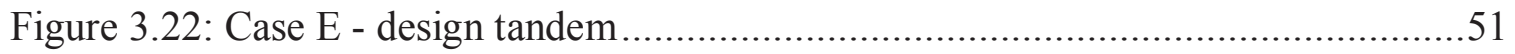

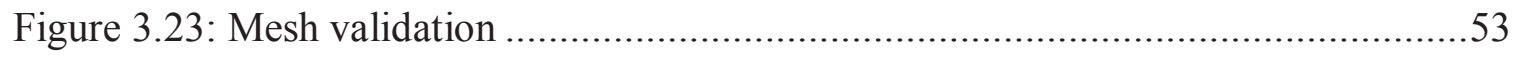

Figure 3.24: MDOT S11 Bridge over Stanley Rd...............................................56

Figure 3.25: Truck A used in MDOT loading of S11 Bridge ......................................57

Figure 3.26: Truck B used in MDOT loading of S11 Bridge ....................................57

Figure 3.27: Girder strain - one truck in one lane............................................5

Figure 3.28: Girder strain - both trucks on bridge ..............................................58

Figure 4.1: Ambient cure compressive strength test results .....................................61

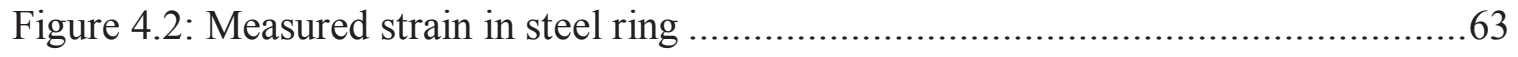

Figure 4.3: Steel ring strain resulting from MSC ...............................................64

Figure 4.4: Adjusted steel ring strain.................................................................65

Figure 4.5: Average steel strain and projected trend line .......................................65

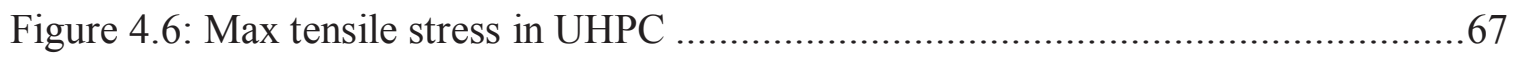

Figure 4.7: Max tensile stress in UHPC per cure regime ......................................67

Figure 4.8: Avg. hoop stress through ring depth - AMC cure.................................68

Figure 4.9: Avg. hoop stress through ring depth - MSC cure .................................69

Figure 4.10: Mohr's circle - max and min stress of 3 planes ...................................... 71

Figure 4.11: Debonding stress determination .............................................. 71

Figure 4.12: Deflected shape for fixed (left) and simple (right) girder supports.............72

Figure 4.13: Longitudinal normal stress $\left(\sigma_{\mathrm{x}}\right)$ distribution for fixed (left) and simple (right) girder supports ............................................................................ 73

Figure 4.14: Transverse normal stress $\left(\sigma_{\mathrm{y}}\right)$ distribution for fixed (left) and simple (right)

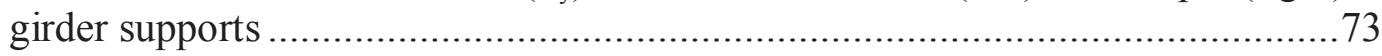

Figure 4.15: Interlaminar longitudinal shear stress (ILSXZ) distribution for fixed (left) and simple (right) girder supports..................................................... 73

Figure 4.16: Interlaminar transverse shear stress (ILSYZ) distribution for fixed (left) and simple (right) girder supports ......................................................... 74 
Figure 4.17: Influence of girder spacing, load configuration, and girder support on state of stress in overlay-UHPC system

Figure 4.18: Effect of $t_{o}$ and $E_{o} / E_{d}$ ratio on debonding stress with fixed girder supports $\left(t_{d}\right.$ constant)

Figure 4.19: Effect of $t_{o}$ and $E_{o} / E_{d}$ ratio on debonding stress with simple girder supports $\left(t_{d}\right.$ constant $)$

Figure 4.20: Effect of $t_{o}$ and $E_{o} / E_{d}$ ratio on interface shear stress with fixed girder

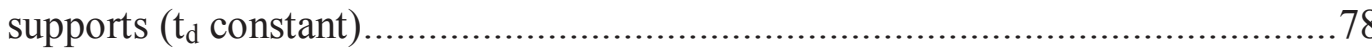

Figure 4.21: Effect of $t_{o}$ and $E_{o} / E_{d}$ ratio on interface shear stress with simple girder

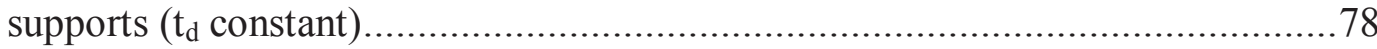

Figure 4.22: Effect of $t_{o}$ and $E_{o} / E_{d}$ ratio on tensile stress with fixed girder supports $\left(t_{d}\right.$

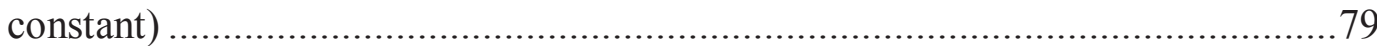

Figure 4.23: Effect of $t_{o}$ and $E_{o} / E_{d}$ ratio on tensile stress with simple girder supports $\left(t_{d}\right.$

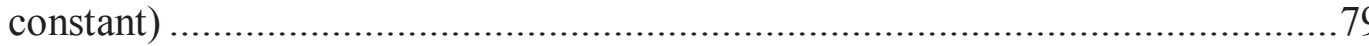

Figure 4.24: Effects of $t_{d}$ and $E_{o} / E_{d}$ ratio on debonding stress with fixed girder supports $\left(t_{0}\right.$ constant $)$

Figure 4.25: Effects of $t_{d}$ and $E_{o} / E_{d}$ ratio on debonding stress with simple girder supports $\left(\mathrm{t}_{\mathrm{o}}\right.$ constant $)$ 80

Figure 4.26: Effects of $t_{d}$ and $E_{o} / E_{d}$ ratio on interface shear stress with fixed girder supports $\left(\mathrm{t}_{\mathrm{o}}\right.$ constant $)$.......

Figure 4.27: Effects of $t_{d}$ and $E_{o} / E_{d}$ ratio on interface shear stress with simple girder supports $\left(\mathrm{t}_{\mathrm{o}}\right.$ constant $)$......

Figure 4.28: Effects of $t_{d}$ and $E_{0} / E_{d}$ ratio on tensile stress with fixed girder supports $\left(t_{o}\right.$ constant)

Figure 4.29: Effects of $t_{d}$ and $E_{o} / E_{d}$ Ratio on tensile stress with simple girder supports $\left(t_{o}\right.$ constant) 81

Figure 4.30: Tension stress and strength for AMC UHPC and fixed girder supports $\left(t_{d}=8\right.$ in.) .84

Figure 4.31: Tension stress and strength for MSC UHPC and fixed girder supports $\left(\mathrm{t}_{\mathrm{d}}=8\right.$ in.) .85

Figure 4.32: Tensile stress and strength for AMC UHPC and fixed girder supports $\left(t_{o}=1 / 2\right.$ in) .85 
Figure 4.33: Tensile stress and strength for MSC UHPC and fixed girder supports $\left(t_{0}=1 / 2\right.$ in) .86

Figure 4.34: Design tandem in bridge center - debonding stress ..............................87

Figure 4.35: Design tandem in bridge lane - debonding stress ................................87

Figure 4.36: HS-20 truck in bridge center - debonding stress ................................... 88

Figure 4.37: HS-20 truck in bridge lane - debonding stress ...................................... 88

Figure 4.38: Design tandem in bridge center - interface shear stress..........................89

Figure 4.39: Design tandem in bridge lane - interface shear stress............................89

Figure 4.40: HS-20 truck in bridge center - interface shear stress ...............................89

Figure 4.41: HS-20 truck in bridge lane - interface shear stress ...............................90

Figure 4.42: Design tandem in bridge center - tensile stress .................................90

Figure 4.43: Design tandem in bridge lane - tensile stress ................................... 91

Figure 4.44: HS-20 truck in bridge center - tensile stress ....................................91

Figure 4.45: HS-20 truck in bridge lane - tensile stress .....................................91

Figure 4.46: Plate and bridge FEM comparison - debonding stress, design tandem, fixed

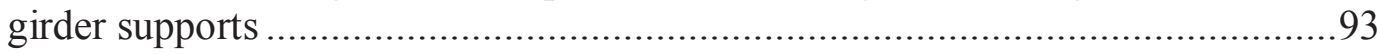

Figure 4.47: Plate and bridge FEM comparison - debonding stress, design tandem, fixed

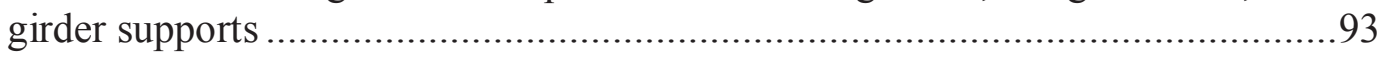

Figure 4.48: Plate and bridge FEM comparison, debonding stress, HS-20 truck, fixed

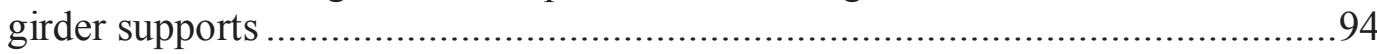

Figure 4.49: Plate and bridge FEM comparison - debonding stress, HS-20 truck, simple

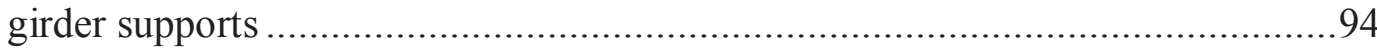

Figure 4.50: Plate and bridge FEM Comparison - interface shear stress, design tandem, fixed girder supports .......................................................................95

Figure 4.51: Plate and bridge FEM Comparison - interface shear stress, design tandem,

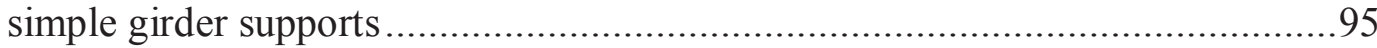

Figure 4.52: Plate and bridge FEM Comparison - interface shear stress, HS-20 truck,

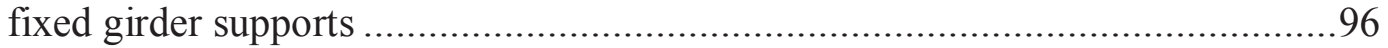

Figure 4.53: Plate and bridge FEM Comparison - interface shear stress, HS-20 truck, simple girder supports . .96 
Figure 4.54: Plate and bridge FEM Comparison - tensile stress, design tandem, fixed

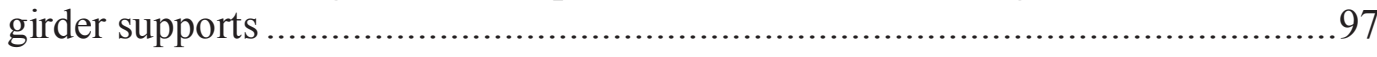

Figure 4.55: Plate and bridge FEM Comparison - tensile stress, design tandem, simple

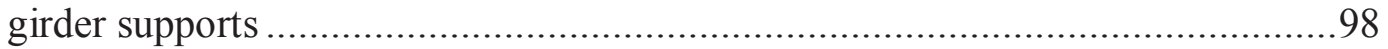

Figure 4.56: Plate and bridge FEM Comparison - tensile stress, HS-20 truck, fixed girder

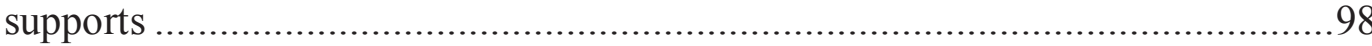

Figure 4.57: Plate and bridge FEM Comparison - tensile stress, HS-20 truck, simple

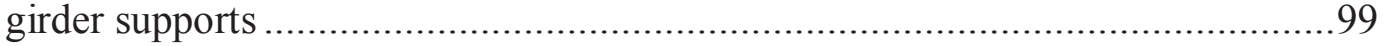

Figure 4.58: Tensile stress under combined restrained shrinkage and design tandem....101

Figure 4.59: Maximum interface shear stress for various $E_{o} / E_{d}$ and $t_{o}$ and fixed girder

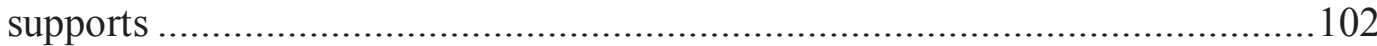

Figure 4.60: Maximum interface shear stress for various $E_{o} / E_{d}$ and $t_{o}$ and simple girder supports .102

Figure 4.61: Interface shear stress under combined restrained shrinkage and design tandem

Figure 8.1: Detailed temperature and RH data during testing ................................ 128

Figure 8.2: Temperature and RH data over test duration .................................... 128

Figure 8.3: Debonding stress under various loads, $\mathrm{s}_{\mathrm{g}}$, and support conditions..............131

Figure 8.4: Interface shear stress under various loads, $\mathrm{s}_{\mathrm{g}}$, and support conditions .........132

Figure 8.5: Tensile stress under various loads, $\mathrm{s}_{\mathrm{g}}$, and support conditions...................132 


\section{List of Tables}

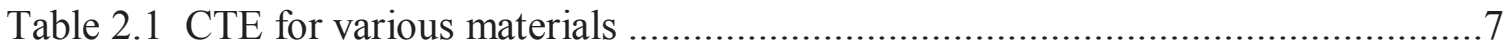

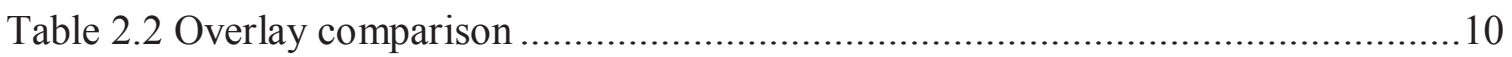

Table 2.3 General UHPC composition (Graybeal 2006a) ...............................................18

Table 2.4 Concrete comparison (Misson 2008) ………………………….................19

Table 2.5 Selected material characteristics of UHPC (Graybeal 2006a; 2006b) ..............19

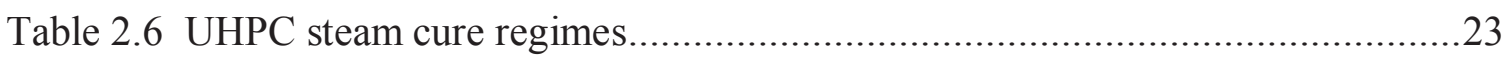

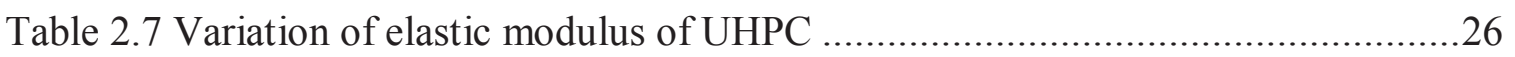

Table 2.8 UHPC bond test results (Harris et al. 2011; Carbonell et al. 2012).................28

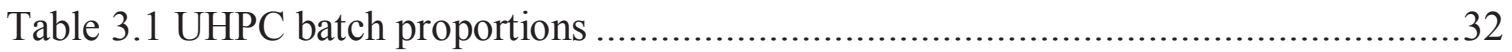

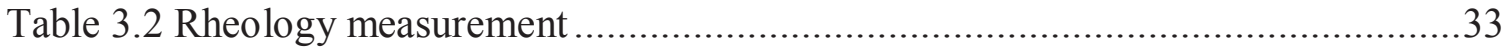

Table 3.3 Differences between ASTM and AASHTO ring test standards ........................37

Table 3.4 Summary of considered deck elements ..........................................................48

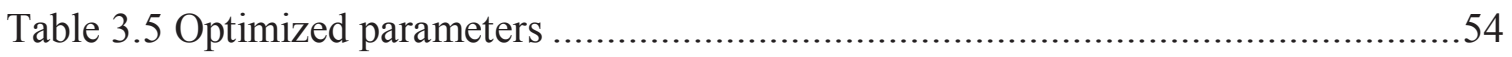

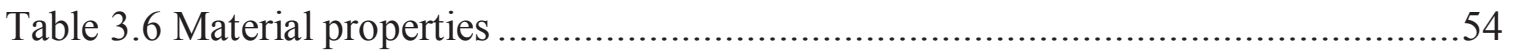

Table 3.7 Bridge member details ..............................................................................56

Table 3.8 Tested parameters for bridge model............................................................59

Table 4.1 Ambient cure compression test results........................................................60

Table 4.2 Modified steam cure compression test results ................................................61

Table 4.3 Ring specimen mix and steam details ........................................................63

Table 4.4 Shrinkage induced interface shear force and stress - AMC cure......................69

Table 4.5 Shrinkage induced interface shear force and stress - MSC cure ......................69

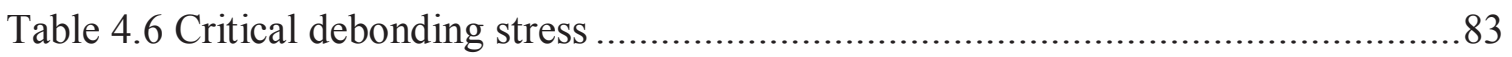

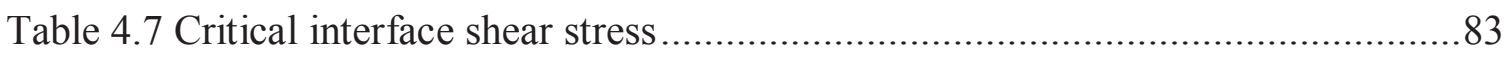

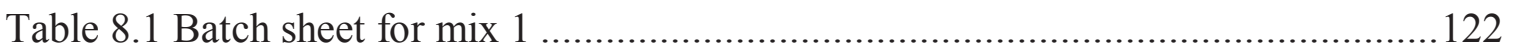

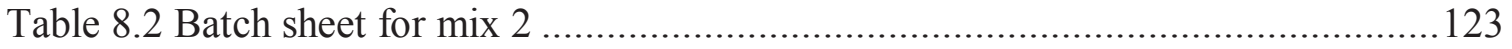


Table 8.3 Batch sheet for mix 3 .................................................................... 124

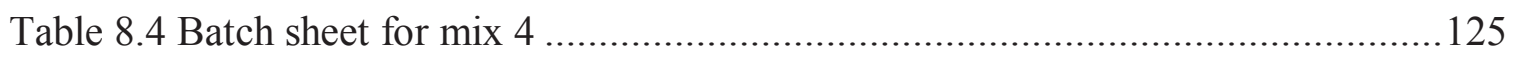

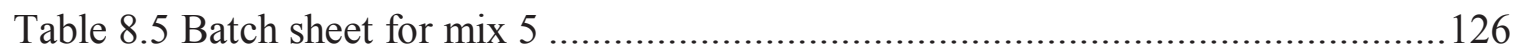

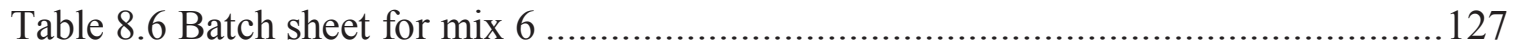

Table 8.7 Ambient cure compressive strength test results.....................................129

Table 8.8 Modified steam cure compression test data............................................130 


\section{Acknowledgments}

I am in debt to Dr. Devin K. Harris, my advisor, for his guidance, insight, constructive criticism, and encouragement in both my graduate and undergraduate careers. He has taught me so much in the last year and a half alone. I feel privileged to have been able to study under him.

I would also like to thank my committee members, Dr. Theresa (Tess) Ahlborn and Dr. Jacob Hiller, and Dr. Gregory Odegard, for their time, guidance, and input into this research. Their advice throughout my studies is extremely appreciated.

I gratefully acknowledge the University Transportation Center for Materials in Sustainable Transportation Infrastructure (UTC-MiSTI) at Michigan Tech for supporting the research activities. I would also like to extend my thanks to Lafarge North America for providing the materials for this research and their technical support.

I want to thank the Benedict Lab Staff, Henrique (Kiko) de Melo e Silva and Michael Yokie, as well as my project team members, Miguel Carbonell, Eric Krieger, and Jason Flietstra for their technical guidance, training, and patience throughout my research efforts. Thanks to David Froster and Morgan Hansen for their help in the labs and to Amir Gheitasi for answering my ANSYS questions.

My graduate work would not be as enjoyable without my officemates Khatereh Vaghefi and Merel Jackson. Thank you both for keeping me sane, lending an ear, and quite a few good laughs. Additional thanks goes out numerous friends and colleagues for their time, support, and encouragement throughout my academic career.

I would like to dedicate a special thank you to my parents who have unconditionally supported me in all of my endeavors. Their encouragement and constant support have helped me become the person and student I am today.

To my fiancé, Jon, thank you for you for all of your support, encouragement, and love over the past 6 years. I am eternally grateful. 


\section{List of Abbreviations}

\begin{tabular}{|l|l|}
\hline AASTHO. & $\begin{array}{l}\text { American Association of State Highway and Transportation } \\
\text { Officials. }\end{array}$ \\
\hline ACI. & American Concrete Institute. \\
\hline ASTM. & American Society for Testing and Materials. \\
\hline FEA. & Finite element analysis. \\
\hline FEM. & Finite element model. \\
\hline FHWA. & Federal Highway Administration. \\
\hline FRC. & Fiber reinforced concrete. \\
\hline HPC. & High performance concrete. \\
\hline LMC. & Latex modified concrete. \\
\hline LSDC. & Low slump dense concrete. \\
\hline LVDT. & Linear variable differential transducers. \\
\hline MSC. & Micro silica concrete (also referred to as SFMC). \\
\hline MSC. & Modified steam cure. \\
\hline NCHRP. & National Cooperative Highway Research Program. \\
\hline NSC. & Normal strength concrete. \\
\hline PC. & Polymer concrete. \\
\hline SCM. & Supplementary cementing materials. \\
\hline SFMC. & Silica fume modified concrete (also referred to as MSC). \\
\hline TRB. & Transportation Research Board. \\
\hline UHPC. & Ultra high performance concrete. \\
\hline UHPFRC. & Ultra high performance fiber reinforced concrete. \\
\hline W/B. & Water-to-binder ratio. \\
\hline W/C. & Water-to-cement ratio. \\
\hline
\end{tabular}




\begin{abstract}
As transportation infrastructure across the globe approaches the end of its service life, new innovative materials and applications are needed to sustainably repair and prevent damage to these structures. Bridge structures in the United States in particular are at risk as a large percentage will be reaching their design service lives in the coming decades. Superstructure deterioration occurs due to a variety of factors, but a major contributor comes in the form of deteriorating concrete bridge decks. Within a concrete bridge deck system, deterioration mechanisms can include spalling, delaminations, scaling from unsuitable material selection, freeze-thaw damage, and corrosion of reinforcing steel due to infiltration of chloride ions and moisture.

This thesis presents findings pertaining to the feasibility of using UHPC as a thin-bonded overlay on concrete bridge decks, specifically in precast bridge deck applications where construction duration and traffic interruption can be minimized, as well as in cast-inplace field applications. UHPC has several properties that make it a desirable material for this application. These properties include post-cracking tensile capacity, high compressive strength, high resistance to environmental and chemical attack, negligible permeability, negligible dry shrinkage when thermally cured, and the ability to self consolidate. The compatibility of this bridge deck overlay system was determined to minimize overlay thickness and dead load without sacrificing bond integrity or lose of protective capabilities. A parametric analysis was conducted using a 3D finite element model of a simply supported bridge under HS-20 truck and overload. Experimental tests were conducted to determine the net effect of UHPC volume change due to restrained shrinkage and tensile creep relaxation. The combined effects from numerical models and test results were then considered in determining the optimum overlay thickness for castin-place and precast applications.
\end{abstract}




\section{Introduction}

\section{$1.1 \quad$ Need for Research}

A large percentage of bridges in the United States will be reaching their design service lives in the coming decades and more than $11 \%$ are currently listed as structurally deficient and over $12 \%$ rate as functionally obsolete (FHWA 2011). Concrete bridge decks are a major contributor to the degradation of an entire bridge system, as they are often directly exposed to de-icing salts and serve as protection for the underlying superstructure (Knight et al. 2004). This degradation is critical because the deck serves not only as the riding surface, but as a protective barrier exposed to maintenance strategies such as plowing and de-icing agents, environmental conditions, and vehicle traffic, all of which contribute to the deck's degradation (Krstulovic-Opara et al. 1995; Knight et al. 2004; Krauss et al. 2009).

Degradation of a concrete bridge deck can be in the forms of spalling, delaminations, scaling due to poor material design, freeze-thaw damage, and/or corrosion of reinforcing steel due to infiltration of chloride ions and moisture or inadequate clear cover (Krauss et al. 2009). Overlays are often applied to bridge decks to protect the superstructure from these mechanisms (Knight et al. 2004; Griffin et al. 2006). However, traditional overlays have several limitations; for instance they have relatively short service lives (typically between 5-25 years) causing continuous maintenance, repair, and replacement of the system. These repetitive installation are perpetual drains of the financial resources of state and national transportation agencies (Krauss et al. 2009). Furthermore, several traditionally used overlays require experienced contractors and/or specialized equipment for correct implementation, can significantly add to the structure's dead load, and they often have compatibility challenges associated with differences in time-dependent properties between materials (Krauss et al. 2009).

This research investigates the feasibility of using Ultra-High Performance Concrete (UHPC) as a thin-bonded overlay on concrete bridge decks. UHPC has several properties which potentially make it a desirable material for this application. These properties include extremely high permeability resistance, negligible dry shrinkage when thermally cured, and post-cracking tensile capacity. UHPC also exhibits high compressive strength between 18-33 psi at 28 days depending on the cure regime; making UHPC a possible material for rehabilitation of bridge decks when added load capacity and load transfer is desired (Graybeal 2006a; Misson 2008). Furthermore, UHPC exhibits high early strength, which could help minimize construction time. These material characteristics may allow for long service lives, reduced maintenance and overall service cost, despite the high initial cost of the material. It is expected that as the industry use of UHPC increases and owners become more familiar with the material, competition will increase and the initial material costs of UHPC will decrease. 


\subsection{Thesis Overview and Scope}

Although there has been significant research regarding UHPC's material properties within the last decade by several institutions, most notably the Federal Highway Administration (FHWA), limited research exists related to the application of UHPC in bridge deck or overlay applications. The objective of this research was to explore the application of UHPC as a thin-bonded overlay on concrete bridge decks by investigating the compatibility of a UHPC-normal strength concrete (NSC) system. As part of this objective, the thickness of the overlay was optimized to reduce material quantity, cost, and dead load. Also important was to balance curing time with the bond integrity to minimize traffic interruption and precast bed turn-over time, as lower set times reduce rehabilitation or production costs. To determine this optimum thickness and conduct a parametric analysis of other bridge components, a 3-D finite element model of a standard bridge deck under a HS-20 truck and overload was developed in addition to a simplified 2-D plate model. This study is primarily a numerical investigation aimed at optimizing overlay thickness and cure duration with a complementary experimental and numerical program focused on system compatibility.

\subsection{Thesis Organization}

This thesis contains the findings of an investigation of the applications of UHPC as a thin-bonded overlay on concrete bridge decks. This report is organized as follows:

Section 2 is a literature review of previous research on UHPC, its history, composition, and mechanical and material properties, and previous investigations regarding UHPC as a bridge deck overlay. This section also includes a thorough comparison of traditional alternative overlays; along with a discussion of bridge overlay failure modes and causes. Section 3 contains the experimental and finite element modeling methodology. The results from these sections are presented and discussed in Section 4. Section 5 outlines all conclusions obtained from the test results and Section 6 discusses the future work that may be considered. The appendices include batch mix data sheets, UHPC mix sequence instructions, and detailed testing results. 


\section{Literature Review}

The following literature review discusses typical bridge deck and overlay failure mechanisms; in addition to several types of concrete bridge deck overlays used in the United States. A brief history of UHPC is included, as well as an overview of its general composition, material properties, and time-dependent properties. This is followed by a summary of previous research that investigated the potential of UHPC as an overlay.

\subsection{Bridge Deck Failure Mechanisms}

Bridge deck failures can occur from several mechanisms, such as spalling, delaminations, or cracking. Delamination between composite concrete materials is when a repair concrete separates (debonds) from the substrate material along the horizontal interfacial plane. Delamination can also occur at or near the outermost layer of reinforcing steel (FHWA 2006). Spalling is a material loss common in repair materials where the concrete completely separates from the substrate material. Delaminations and spalling occur when interfacial stress becomes greater than the interfacial strength due to moisture change, temperature change, corrosion of reinforcement, and mechanical stresses (Sun 2004; FHWA 2006). Failures caused by delaminations or spalls often expose reinforcing steel, which can lead to further degradation of the bridge superstructure. The causes of concrete cracking include volume changes when the concrete is restrained, flexural movement due to applied traffic loads and temperature differences from environmental conditions (Kosmatka and Wilson 2011). Cracking is a particular problem in northern states, which have extreme freeze-thaw cycles and high salt loads, as chloride ions are able to ingress through the depth of the slab, causing corrosion of slab reinforcement and thereby reducing the load capacity of structure over time.

\subsection{Repair and Maintenance Strategies}

There are several repair and maintenance strategies commonly used by transportation agencies to prevent and protect against these deck failures. General repair methods include patching or crack repair, asphalt overlay with waterproofing membrane, concrete or composite overlays that include scarifying damaged concrete to some depth, and lastly partial or full deck replacement. Damages to steel reinforcement are often repaired and protected when damaged concrete is removed. Polymer overlays and sealers are additional options in maintenance and protection strategies. Though these are the most common repair and maintenance strategies used by transportation agencies, decision thresholds between methods widely vary. In general, the life of a bridge deck is to be extended whenever possible and partial and full deck replacement is to be avoided, as these are costly and time consuming repairs. Patching and crack repair options are often used when minimal damaged areas are present, as they are less costly and time consuming than other repair methods. Sealers are lightweight and protect the deck from ingress of chloride ions present in deicing chemicals; however, sealers are applicable in 
maintenance situations only, as they are not able to repair severely damaged regions. For bridge decks with moderate deterioration, but do not require immediate replacement, overlays are often most appropriate. Overlays are less costly than full deck replacement and require shorter traffic closures. They provide added cover for reinforcement and increased chloride ion resistance. Depending on the overlay type, bonded overlays may also increase a bridge's load carrying capacity and load transfer, though added dead load or clearance restrictions may be an issue. (Krauss et al. 2009)

As a majority of the nation's bridge infrastructure is at or nearing the point of moderate to severe deck damage (FHWA 2011), the concentration on overlay materials and behavior is the main focus of the presented research.

\subsection{Overlay Failure Mechanisms}

Due to degradation of a deck structure, an overlay is often a primary solution used in rehabilitation, prevention, or maintenance plans. The primary function of an overlay is to protect the substrate from the ingress of chloride ions after damaged material has been removed. Other intended functions are improved wearing surface, abrasion resistance, drainage, and skid resistance, or added structural capacity in some cases. (Krauss et al. 2009)

Despite their intended use, overlays often fail in both new and old bridges much before the end of the design service lives are reached. This is often due to the same failure mechanics that cripple bridge decks, such as spalling, delamination, cracking, or poor quality of construction. Delamination and spalling in overlays occur when the tension perpendicular to the interface and/or interface shear stresses exceed an overlay's bond strength in the associated direction. Representations of the interface shear stresses $\left(\tau_{\mathrm{zx}}\right.$ and $\left.\tau_{\mathrm{zy}}\right)$ and debonding stresses $\left(\sigma_{\mathrm{zz}}\right)$ within an overlay-deck section are shown in Figure 2.1 , as well as cracking stresses $\left(\sigma_{\mathrm{xx}}\right.$ and $\left.\sigma_{\mathrm{yy}}\right)$. These stresses can be caused by shrinkage of the overlay, differing thermal properties, or differing material stiffness between the deck substrate and overlay material. Debonding can also occur due to repeated vehicle loading if the interface bond strength between the overlay and substrate is not high enough. The stresses induced by these factors are addressed in further detail in the following sections. A majority of overlay failures can be traced back in the form of poor quality of construction in terms of improper material selection or proportioning, surface preparation, placement conditions, finishing, or curing procedures (Krauss et al. 2009). 


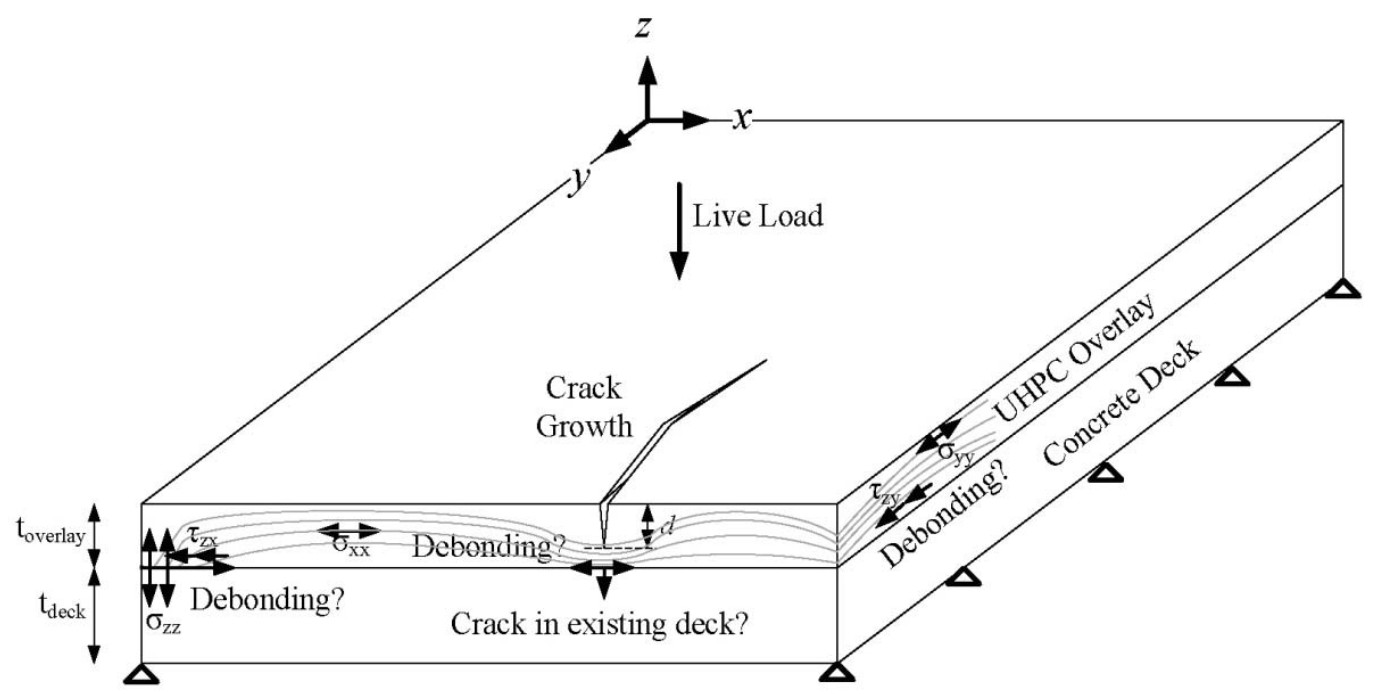

Figure 2.1: Stress distribution at bond interface

\subsubsection{Shrinkage}

Shrinkage is the time-dependent decrease in material volume due to temperature and moisture changes, which are caused by external environmental conditions or due to internal reactions. Although all concrete structures exhibit some shrinkage throughout their lives, it is a major issue for overlays and integrity of the bond between an overlay and the substrate due to the restraint which occurs between decks and overlays from differences in shrinkage rates and specimen ages. This volume change is especially an issue in early ages due to the fact that a majority of shrinkage occurs within the first few days or hours after placement when the concrete tensile strength has not developed.

The main types of shrinkage are chemical, plastic, autogenous, thermal and drying (Nassif et al. 2007; Kosmatka and Wilson 2011).

Chemical shrinkage is the internal, absolute volume change that occurs during hydration. Before setting occurs, some dimensional volume change is caused by the chemical reactions during hydration. After initial setting occurs, chemical shrinkage no longer creates dimensional change, but generates voids within the structure's volume. This shrinkage is also the driving force of autogenous shrinkage (Habel et al. 2006a; Kosmatka and Wilson 2011).

Plastic shrinkage also occurs before concrete has hardened, though it is caused when the evaporation rate at exposed surfaces exceeds the rate at which bleed water is created, causing negative pressure within the cement skeleton (Nassif et al. 2007). Autogenous 
and chemical shrinkage also affect the amount of plastic shrinkage, as the increased magnitude of chemical shrinkage will leave less bleed water to prevent drying (Kosmatka and Wilson 2011). Wet burlap or plastic covering of exposed surface are used to significantly reduce plastic shrinkage (Nassif et al. 2007; Kosmatka and Wilson 2011).

Thermal shrinkage is initiated after the heat generation from cement hydration has occurred and the concrete begins to cool. Concrete sets soon after hydration is completed, but the temperature change caused by the cooling induces residual stresses into the system. Due to the large surface area of bridge decks, the hydration heat is easier to dissipate, resulting in almost negligible thermal shrinkage (Nassif et al. 2007).

Autogenous shrinkage (also called endogeneous shrinkage) is a dimensional change attributed to chemical shrinkage and self-desiccation of the paste during cement hydration when there is not enough water for complete hydration (Kosmatka and Wilson 2011). Self desiccation is defined by ACI as "the removal of free water by chemical reaction so as to leave insufficient water to cover the solid surfaces and cause a decrease in the relative humidity of the system" (ACI 2010). This shrinkage relates to a lack of water within the concrete; therefore, if there is excess water, no autogenous shrinkage will occur (Nassif et al. 2007; Kosmatka and Wilson 2011). Insufficient water can be caused by low water-to-cement ratios, no moist curing, or a section with inadequate pore water transport through voids. Autogenous shrinkage is not affected by the amount of exposed surface area-to-volume ratio (or member thickness) as is found in drying shrinkage. Some industry professionals believe measurement of autogenous shrinkage should begin once initial setting occurs, while others believe autogenous shrinkage to begin from the time of placement. This issue is in debate primarily because before the concrete material sets, chemical and autogenous shrinkage are not distinguishable from each other. Autogenous shrinkage is a major component of the total shrinkage in concrete mixtures with low water-to-cement ratio and large quantities of fine cementious material (Kosmatka and Wilson 2011).

Drying shrinkage is the volume change due to moisture gradients of hardened concrete. In situations where excess water has not been consumed during hydration, high heat and low humidity in the surrounding environment causes this excess pore water to evaporate, causing contraction in the hardened concrete. This type of shrinkage begins from the outside of the structure to the inside and is a function of the surface area to volume of the structure, the external environmental conditions, porosity of the concrete, and the size, shape, and continuity of pores (Nassif et al. 2007; Kosmatka and Wilson 2011). Drying shrinkage is a concern for structural elements, such as bridge decks and overlays, which have large exposed surfaces and are restrained (Nassif et al. 2007).

Cracks develop when the stresses due to shrinkage exceed a material's tensile capacity. Interface debonding may also occur between an overlay-deck system or other repair situations due to these shrinkage stresses if the interface shearing bond strength is exceeded. 


\subsubsection{Thermal Coefficients}

Materials typically expand when heated and contract when cooled. These temperature changes can be caused by external environmental effects or internal cement hydration (discussed in the previous section). A material's thermal coefficient $(\alpha)$ is the extent to which it displaces due to a unit change in temperature (Kosmatka and Wilson 2011; Wight and MacGregor 2012). For concrete, the thermal coefficient is influenced by aggregate type, cement and SCM content, age, water-to-cement ratio, and external temperature range and relative humidity (Kosmatka and Wilson 2011; Wight and MacGregor 2012). Large differences or incompatibilities in thermal expansion coefficients between composite materials can cause large tensile stresses, which may lead to debonding or cracking. Therefore, it is important to take these long-term shrinkage effects into account. Table 2.1 compares the coefficient of thermal expansion (CTE) for various normal strength concretes (NSC), steel, and UHPC. UHPC has a slightly higher CTE than normal strength concrete and steel.

An example of the implications of a thin-bonded UHPC overlay on a concrete bridge deck is included here. When the environmental temperature is increased from $74^{\circ} \mathrm{F}$ to $110^{\circ} \mathrm{F}$, a composite sample of general NSC and ambient cured UHPC would experience a thermal strain of $\left(8.2 \mu \varepsilon /{ }^{\circ} \mathrm{F}-5.5 \mu \varepsilon /{ }^{\circ} \mathrm{F}\right) *\left(110^{\circ} \mathrm{F}-74^{\circ} \mathrm{F}\right)=97.2 \mu \varepsilon$. For 28 -day ambient UHPC, which has a modulus of elasticity of $6076 \mathrm{ksi}$ (Graybeal 2006a), this thermal change would cause approximately 590 psi of tensile stress.

Table 2.1

CTE for various materials

\begin{tabular}{|c|c|}
\hline & $\mathrm{CTE}, \alpha\left(\right.$ microstrain $\left./{ }^{\circ} \mathrm{F}\right)$ \\
\hline Steel (Wight and MacGregor 2012) & 6.5 \\
\hline $\begin{array}{l}\text { NSC with siliceous aggregates (Kosmatka and Wilson } \\
\text { 2011) }\end{array}$ & $5-7$ \\
\hline $\begin{array}{l}\text { NSC with limestone or calcareous aggregates } \\
\text { (Kosmatka and Wilson 2011) }\end{array}$ & $3.5-5$ \\
\hline $\begin{array}{l}\text { General NSC (Kosmatka and Wilson 2011; Wight and } \\
\text { MacGregor 2012). }\end{array}$ & 5.5 \\
\hline Reinforced Concrete (Wight and MacGregor 2012) & 6 \\
\hline $\begin{array}{l}\text { UHPC under ambient steam cure, 28-day (Graybeal } \\
\text { 2006a; Ahlborn et al. 2011) }\end{array}$ & $7.74-8.2$ \\
\hline $\begin{array}{l}\text { UHPC under tempered steam cure. 28-day (Graybeal } \\
\text { 2006a) }\end{array}$ & 8.6 \\
\hline $\begin{array}{l}\text { UHPC under steam cure, 28-day (Graybeal 2006a; } \\
\text { Ahlborn et al. 2011) }\end{array}$ & $8.18-8.7$ \\
\hline
\end{tabular}


The effects of CTE differences between NSC and UHPC are warranted, but were beyond the scope of this research project. It is important to note these differences for future research regarding this topic and account for it in design.

\subsubsection{Material Stiffness}

If overlay and deck materials have substantial differences in the stiffness, or modulus of elasticity, the strain distribution between the two materials will not be uniform. Higher material stiffness draws more of the load than lower stiffness material, causing large interfacial bond stresses (Kosmatka and Wilson 2011). If these bond stresses become large enough that they exceed the bond strength of the composite system, debonding will occur. Once materials separate, the system no longer has composite action and the load capacity of the structure will reduce. Furthermore, debonding allows water and chlorides to penetrate further into the deck, degrading steel reinforcement within. The addition of freeze thaw cycles could also increase the degradation into spalling of concrete sections.

\subsubsection{Live Loads}

As a vehicle crosses a bridge, tensile stresses are induced at the bond interface away from the vehicle tires where the overlay is put into tension. These tensile stresses pull the overlay away from the deck substrate, causing debonding. Vehicle loading also introduces shear stresses into the interface, especially in cases of breaking or acceleration, which can cause cracking along the composite interface and debonding. These modes of failure increase the exposure of reinforcement to chloride ions, decrease the load capacity of the structure, and speed degradation of the structure as a whole.

\subsection{Overview of Traditional Overlays}

As highlighted in Section 1.1, overlays are often applied to bridge decks for increased cover of reinforcement and increased chloride ion resistance, which is accomplished by selecting an overlay material with low chloride ion and water permeability. Overlays can also be applied to improve riding surface (by choosing an overlay with high skid and wearing resistance), strengthen bearing capacity (through the use of a material with high resistance to indentation), or increased load carrying capacity and load transfer of a bridge deck (by using high compressive strength materials). Furthermore, an overlay may be considered to restore riding quality or modify an existing roadway alignment or deck drainage. Overlay materials that have high bond strength with the substrate material, are able to bridge and/or fill existing substrate cracks, and have post-cracking tensile capacity are also desirable depending on their intended application. (Halvorsen 1993; Sohanghpurwala 2006)

The type of overlay selected for a given project or application can be based on one or several of the following factors (Halvorsen 1993; Knight et al. 2004; Sun 2004; Krauss et al. 2009; ACI 345 2011): 
- Substrate concrete material

- Substrate concrete condition

- Local aggregate availability

- Local construction practices/familiarity of construction crew

- Construction costs and overall economy

- Lane closure time

- Installation difficulties and complexity

- Long-term costs relating to maintenance plans

- Frequency of traffic

- Dead load and clearance restrictions

- Drainage and slope modifications

- Previous deck overlays and repairs

Overlays which are traditionally used by state and federal transportation agencies include: low slump dense concrete (LSDC), latex modified concrete (LMC), silica fume concrete (SFMC), high-performance concrete overlays (HPC), polymer concrete (PC), fiber reinforced concrete (FRC), hot-mix asphalt (HMA) concrete, and Portland cement concrete (PCC) (Halvorsen 1993; Gillum et al. 2001; Luo 2002; Sun 2004; Krauss et al. 2009; ACI 345 2011). Comparisons of these overlays are included in Table 2.2. These comparisons are derived from multiple sources and are intended to provide general characteristics of the different overlay systems such as: cost per square foot, average thickness, service lives, and bond strengths in addition to curing and construction procedures and general overlay benefits and disadvantages. Certain overlay types have more experimental data available in literature due to their use and performance since being developed or due to differences in material behavior and application of the selected ASTM parameters. 


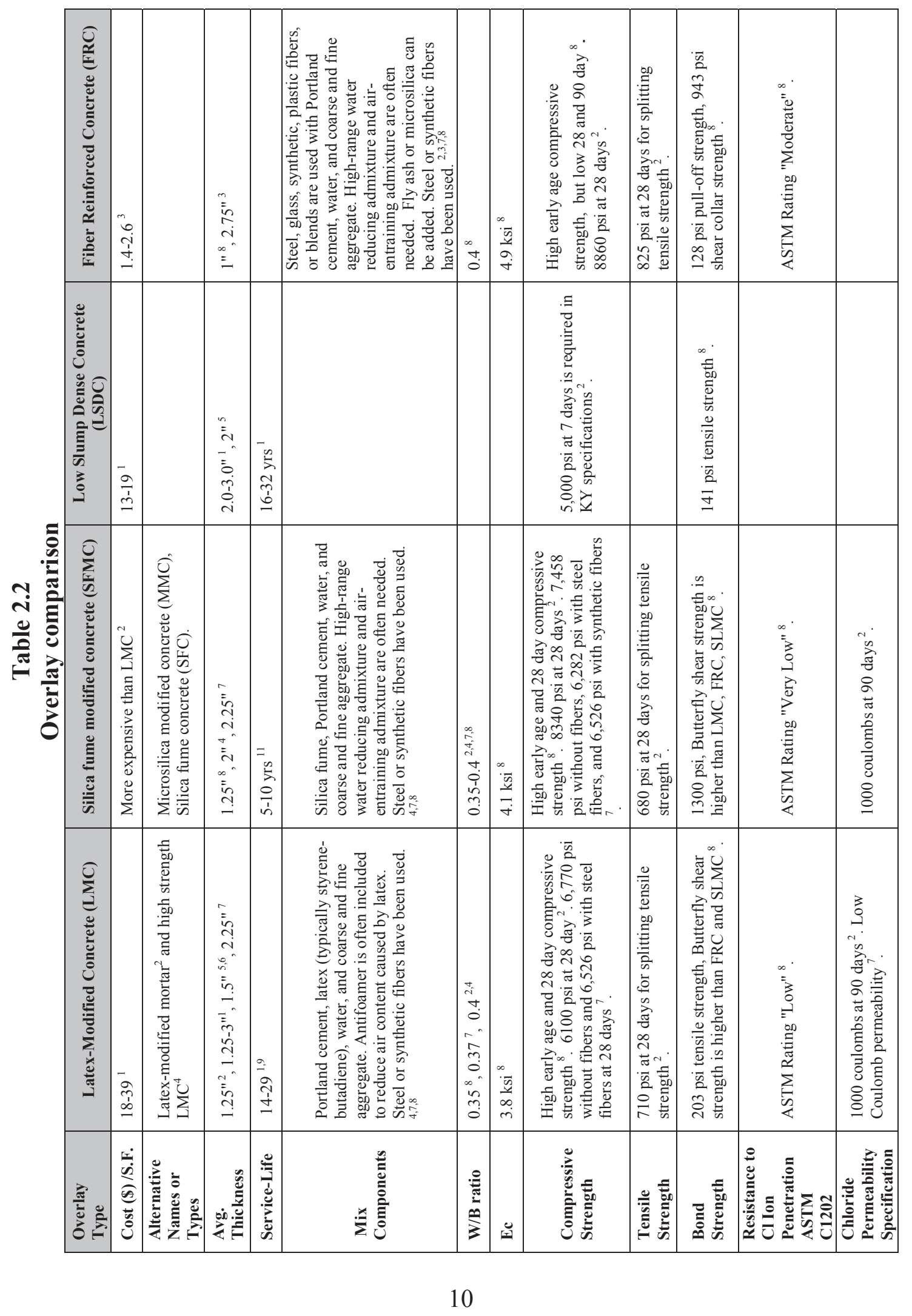




\begin{tabular}{|c|c|c|c|c|c|}
\hline & & & & 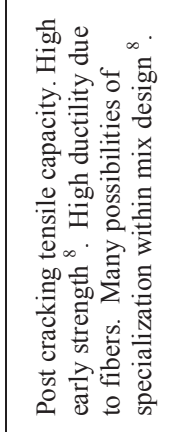 & 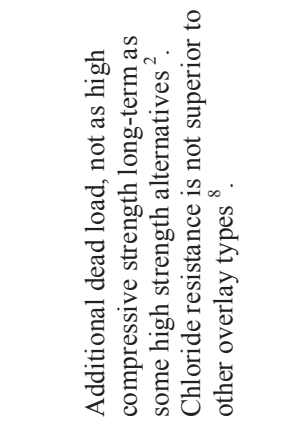 \\
\hline & 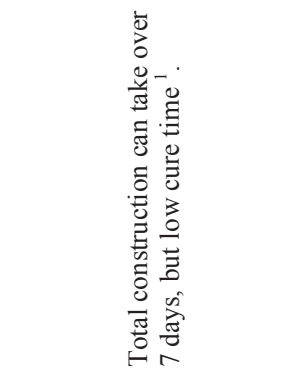 & 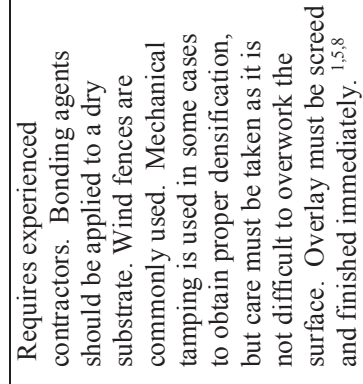 & 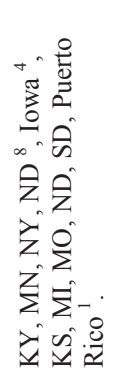 & 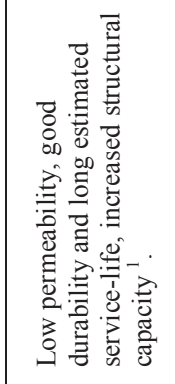 & 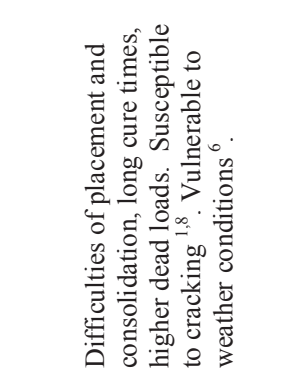 \\
\hline 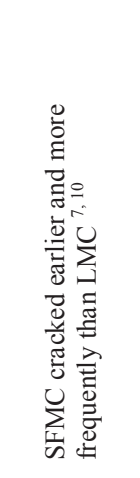 & 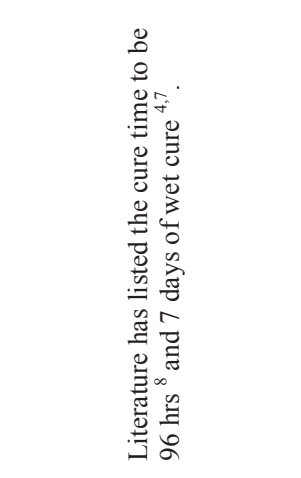 & 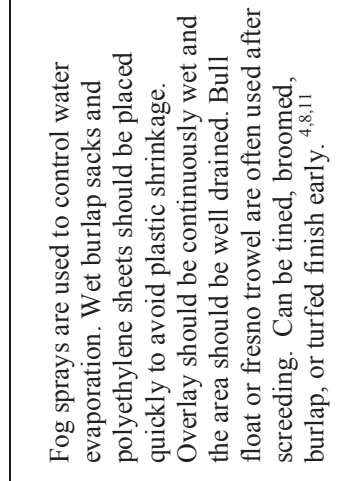 & 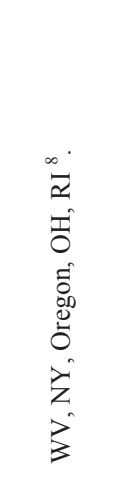 & 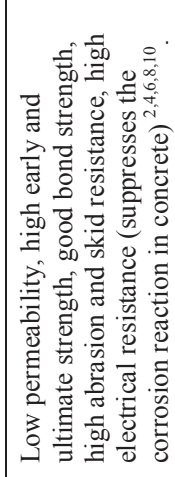 & 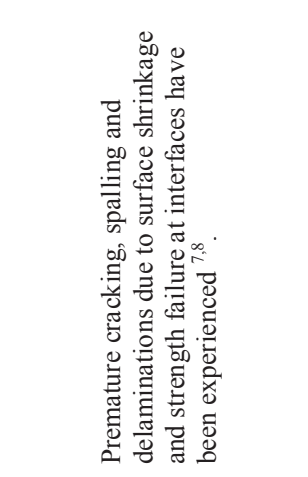 \\
\hline 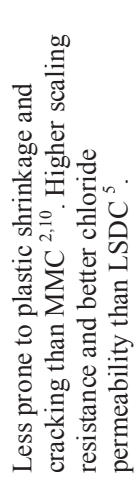 & 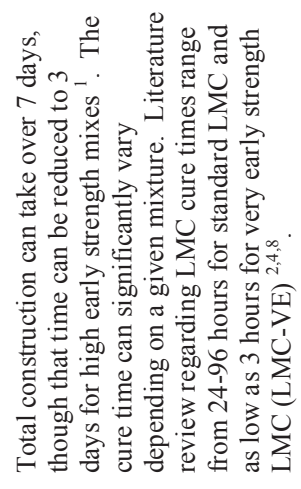 & 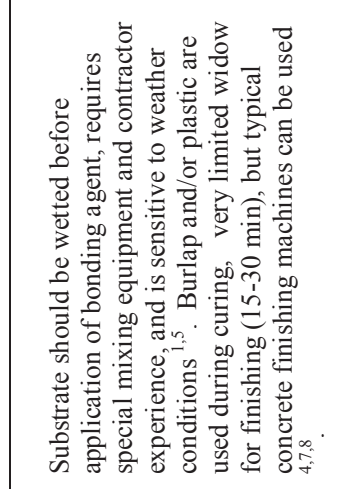 & 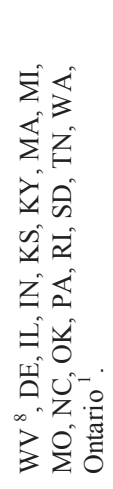 & 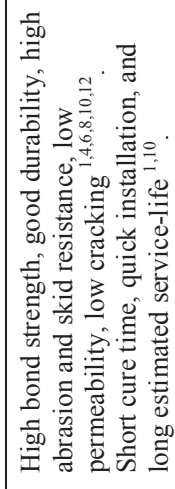 & 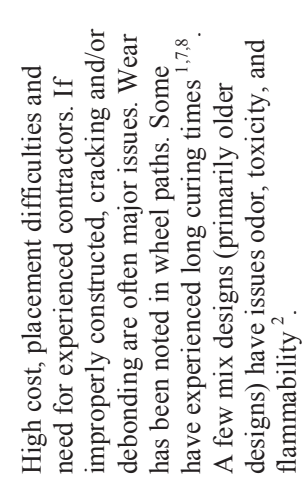 \\
\hline 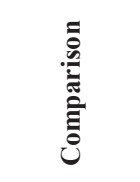 & 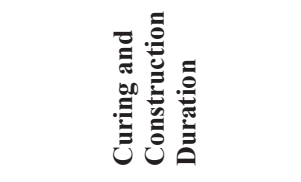 & 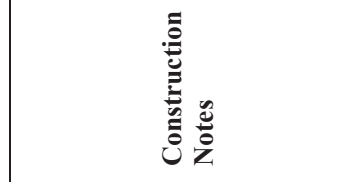 & 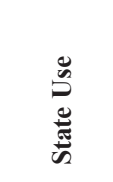 & 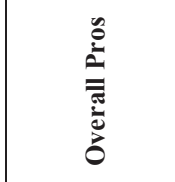 & 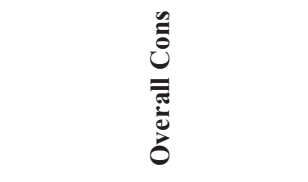 \\
\hline
\end{tabular}




\begin{tabular}{|c|c|c|c|c|c|c|c|c|c|c|}
\hline 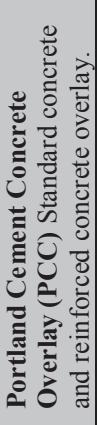 & 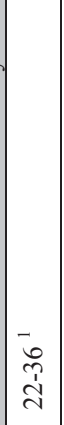 & 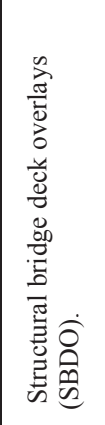 & $\begin{array}{l}\bar{\equiv} \\
\dot{\infty} \\
\dot{m} \\
\dot{m}\end{array}$ & 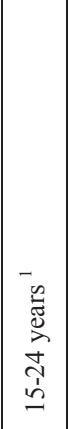 & 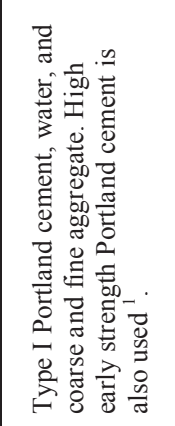 & 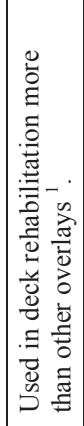 & 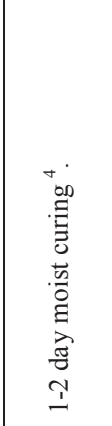 & 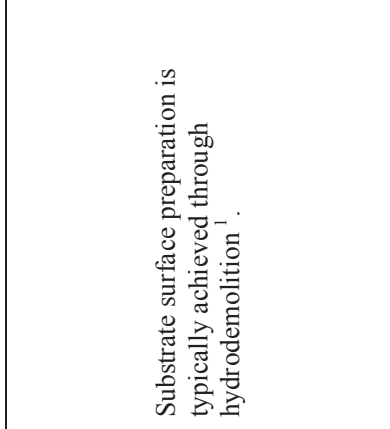 & 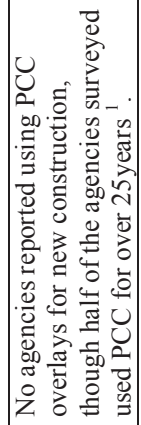 & 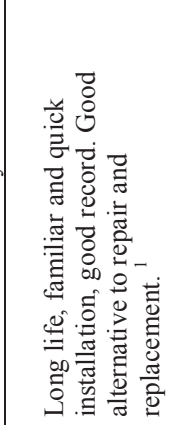 \\
\hline 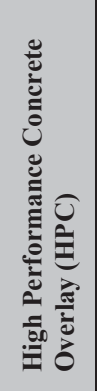 & 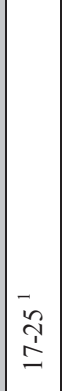 & & $\begin{array}{l}\bar{\vdots} \\
\text { in } \\
\text { bे } \\
\text { - }\end{array}$ & $\begin{array}{l}n \\
\text { n. } \\
\text { ते } \\
\text { bे }\end{array}$ & & & 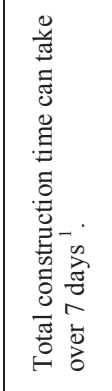 & 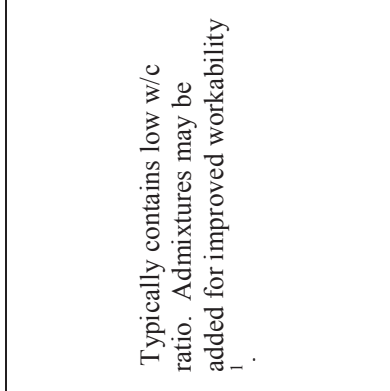 & 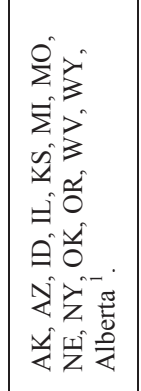 & 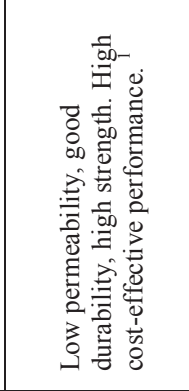 \\
\hline 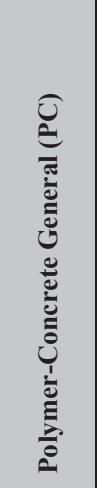 & $\frac{\vec{c}}{\mathrm{~d}}$ & & 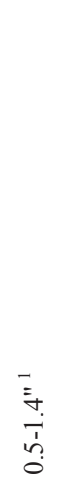 & $\begin{array}{l}-\infty \\
5 \\
5 \\
\frac{\infty}{\infty} \\
\bar{\alpha}\end{array}$ & 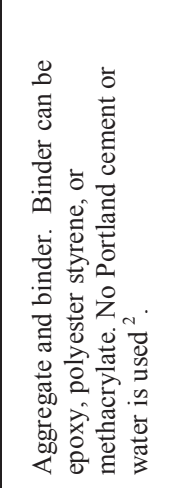 & 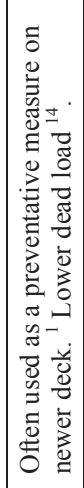 & 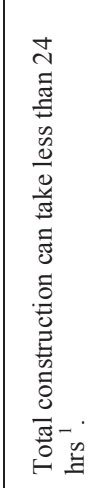 & 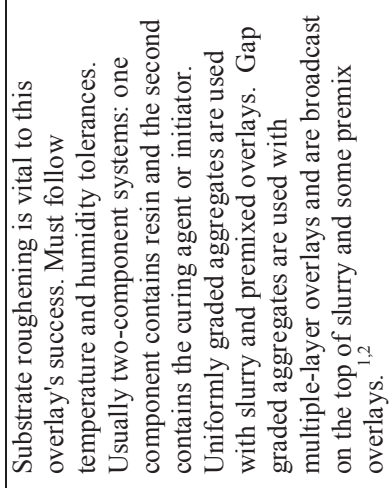 & 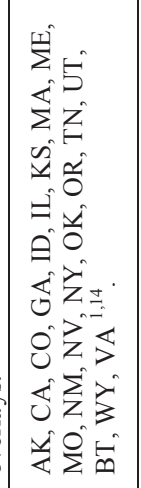 & 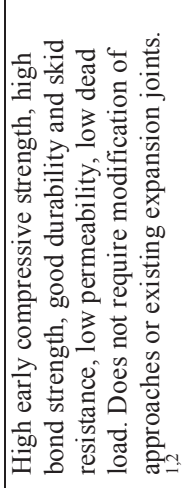 \\
\hline 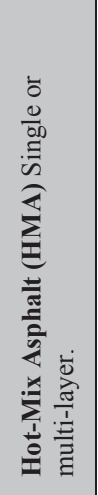 & $\begin{array}{l}\vec{j} \\
\stackrel{0}{1} \\
\dot{i} \\
\dot{m}\end{array}$ & 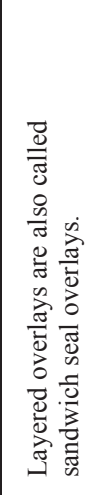 & 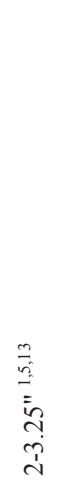 & 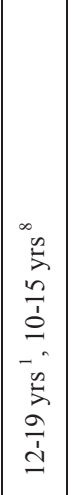 & 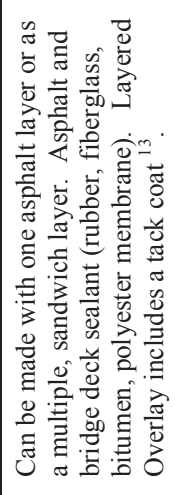 & & 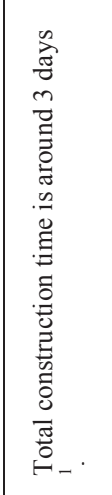 & 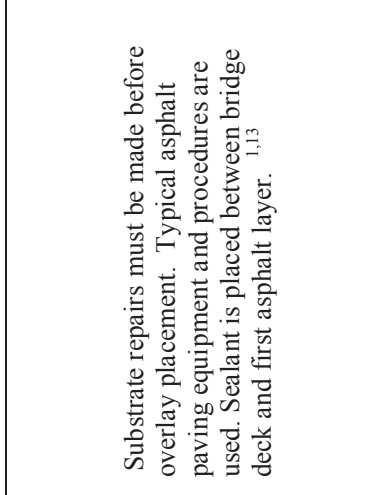 & 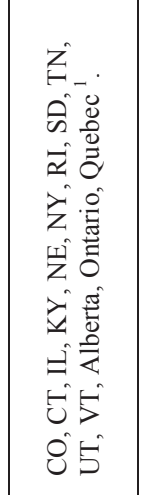 & 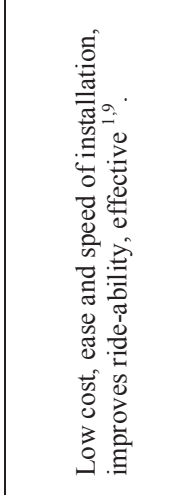 \\
\hline 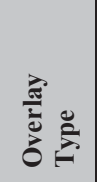 & 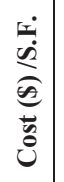 & 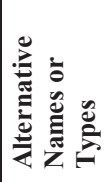 & 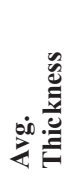 & 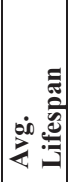 & 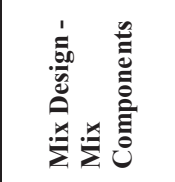 & 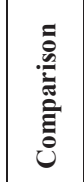 & 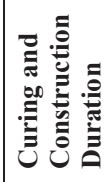 & 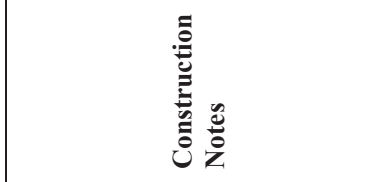 & 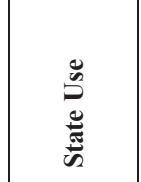 & 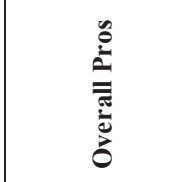 \\
\hline
\end{tabular}




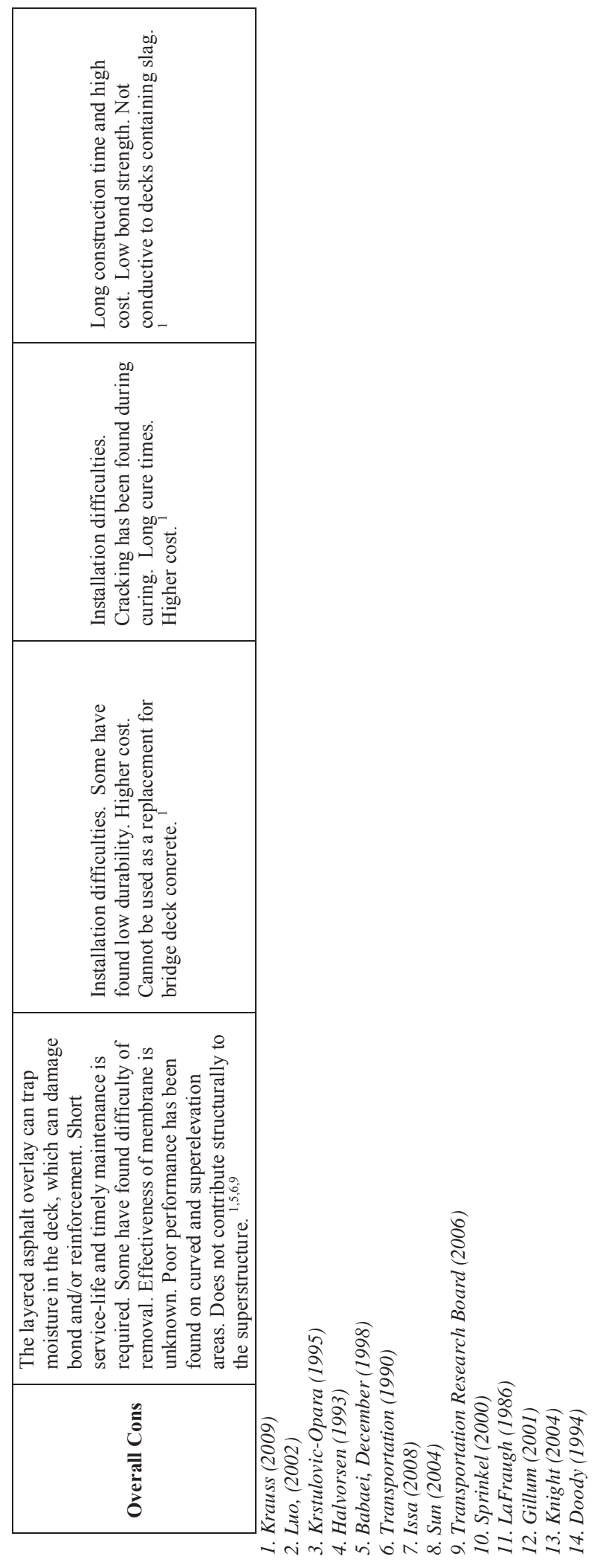


In the document "Guidelines for selection of Bridge Deck Overlays, Sealers, and Treatments" (Krauss et al. 2009), asphalt concrete overlays with waterproofing membrane had the highest number of agencies that used this overlay type in their current practices. LSDC overlays had the most respondents who used the overlay in the past, but was not current practice. LMC has been utilized in the U.S. beginning around 1956 (Sun 2004), where SFMC, LSDC, and FRC began being used as overlays around the 1960s (Krstulovic-Opara et al. 1995; Sun 2004). The initial years during research, adoption, and installation of these overlays agencies had significant challenges unifying and perfecting installation and maintenance techniques (LaFraugh and Zinserling 1986). However, progression of these overlays advanced in time and more agencies began adopting these practices. Similar progression and adoption is expected with UHPC as a thin-bonded overlay as experience with the material improves.

NCHRP Synthesis 423 includes summaries or standard overlays and typical practices for various states with a focus on polymer concrete overlays (Fowler and Whitney 2011). It also included design charts displaying shear and normal stresses in overlays for various thickness and modulus ratios. However, this chart only includes overlays that have modulus of elasticity less than that of the substrate, in which case UHPC does not apply.

In regards to poor quality of construction highlighted in Section 2.3, it is important to note that only one type of overlay (LMC) has industry construction and material specifications (ACI 1998). Other overlays, which are commonly used by state and local DOTs have vastly different construction and inspection specifications. Even the intervention criteria which determines when and what type of overlay should be placed significantly differ between agencies (Krauss et al. 2009).

There are a few overlay alternatives being currently researched which were not included in the comparison of traditional overlays. Most of these newer overlays are of the polymer concrete (PC) type, including SafeLane ${ }^{\circledR}$ HDX developed by Cargill, Flexogrid ${ }^{\circledR}$ produced by Poly-Carb, Inc., Flexdeck or Flexolith ${ }^{\circledR}$ produced by Tamms Industries, and Kwik Bond PPC MLS by Kwik Bond Polymers to name a few. These PC overlays are fully discussed in (Nelsen 2005; Sprinkel et al. 2009; Soltesz 2010). Also, concretes containing various supplementary cementing materials (SCM) and proportions of these materials are being investigated by others to find optimum mix designs for overlay applications.

Each overlay type presented here has advantages in certain applications and are poor in others, and literature suggests that no one overlay is a perfect fit for every scenario. Overlay selection must be evaluated for each individual project. Transportation agencies however tend to have preferences based on experience, past performance, and environment, which is not always quantifiable from literature. 


\subsection{Modeling of Overlay Systems}

One main objective of this research was to investigate the compatibility of a thin-bonded UHPC overlay on a concrete bridge deck for various parameters, such as deck and overlay thickness, material strengths, bridge geometry, and live load. To examine the effects of these various parameters on the state of stress in the composite system, finite element models were constructed. Presented in this section is relevant literature regarding the finite element modeling of overlay systems, including how the system was modeled, what parameters were considered in analysis, and what the general findings were from the various research conducted.

Research conducted by Issa aimed to correlate the live load and shrinkage induced stresses between a polymer concrete overlay and bridge deck substrate with the direct tensile bond strength of the overlay (Issa et al. 2008; Issa and Alrousan. 2009). Finite element models using ANSYS 12.0 were used to determine the normal and shear bond stresses at critical locations considering the effects of overlay thickness, deck thickness, relative elastic modulus, and slab strength. The finite element model was validated from experimental testing previously completed by this author. Trends found in this analysis include increased shrinkage-induced interface shear stress with increased overlay-to-slab Young's modulus, increased thickness ratios, and increased compressive slab strength. In addition, shrinkage-induced normal bond stresses increased with overlay-to-slab thickness ratio up to approximately 2.5 in., where the trend decreased for stiffness ratios greater than 0.75 , and moderately increased for stiffness ratios near 0.50 . It was also found that normal and shear bond stresses decreased when the polymer overlay thickness was increased from 0.25 in. to 2.0 in. from applied live loads. Overall, overlay thicknesses of 1.5 in. -2.5 in. were recommended to avoid debonding due to high shrinkage and live load induced stresses, while maintaining the quality of the bond.

Tang conducted a numerical analysis of a 3 in. PCC overlay on concrete segmental boxgirders (2005). A parametric stress analysis was performed to evaluate the effects of concrete age, shrinkage, and temperature gradients when no cracks existed in the substrate to model perfect bonding, when minor cracks existed at the top of the overlay to investigate crack propagation through the overlay material, and when one major crack was present at the centerline of the bridge to determine the effect of existing cracks. The goal of the study was to determine the major parameters causing overlay defects and the behavior of a PCC overlay when stress concentrations exist in the bridge substrate and overlay itself. The author found that temperature stresses were high directly after placement and overlay delamination was primarily caused by shrinkage and the daily thermal gradient. It was suggested that fiber-reinforced concrete be considered in the upper section of a PCC overlay (Tang 2005).

Several authors numerically investigated the crack propagation of concrete overlay systems using fracture mechanics. These authors included the effect of friction on the interfacial bond strength and investigated the stress at the crack and debonding tip, 
typically using a node-by-node approach. These numerical models are simulated using gap, contact, or nonlinear interface elements. By considering fracture mechanics in an overlay-deck FEM, the progression of failure after the point of first failure can be investigated. Research conducted by Kim et al. (2010) looked into fracture mechanics of asphalt overlay pavements under the loading configuration and tire pressure of Boeing 777s to accurately determine how existing cracks progress in the system (Kim 2010). Walter et al. (2007) examined fatigue damage in orthotropic steel bridge decks of steel box girder bridges. The authors used a fictitious cracking model and Kelvin chains to model traffic loading, shrinkage, and temperature gradients (Walter et al. 2007). Nossoni and Harichandran investigated the behavior of a FRP overlay under a corrosion load (Nossoni and Harichandran 2008). Tran et al. (2006) modeled the shrinkage effect of overlay-substrate systems on the system mechanical behavior using moisture diffusion and hydration models. Using fracture mechanics in these analyses's provided better estimates of the performance and life of the selected overlays under various thermal, chemical, and vehicle loading. The development of failures after an initial crack or delamination can be used to develop critical maintenance and repair plans, in addition to understanding the total service life of a given system (Tran et al. 2006). Granju et al. analyzed the post-crack tensile stress with crack-opening (Mode I fracture) and the postcrack shear stress with relative slip (Mode II fracture), along with the combined effects in regards to an overlay bonded to an existing concrete bridge deck (Granju et al. 2004). It was found that interlocking forces are vital in modeling debonding propagation. By including interlocking forces, more accurate investigations can be conducted regarding the life of a system after first failure has occurred before repair of the system must be conducted. A study conducted by Xu et.al. considered the classic Coulomb friction model to determine the interface stresses between a polyacrylamide polymer (PAM) modified concrete overlay on bridges (Xu et al. 2009). It was found that the flexural strength and bond strength were the most influential parameters for the overlay success. Also, the maximum tensile principal stress occurred at the beam joints and the maximum shear stress occurred at the interface below the tire contact area. Again, by considering the effects of friction on the bond capacity after slip or failure has occurred a better prediction to the overall behavior and performance of the overlay system in question is provided.

Although the study of overlay performance after the point of first failure is critical to understanding the complete in-service behavior of a system, the scope of the current study was limited to the initial cracking or debonding failure. This was because the advanced mechanical and durability properties of UHPC indicate extended service lives may be possible with only minimal required maintenance. Therefore, the primary interest of the current research was to model only mechanical performance of the UHPC system before any maintenance had to be conducted. 


\subsection{Ultra-High Performance Concrete (UHPC)}

Ultra-High Performance Concrete (UHPC) is a class of concretes that exhibits extremely high durability and strength properties. It belongs to the family of engineered cementitious composites (ECC) (Habel et al. 2006a) and is defined as a cement-based concrete with compressive strength equal to or greater than $22 \mathrm{ksi}(150 \mathrm{MPa})$ (Naaman and Wille 2012; Resplendino 2012). Additionally, UHPC is characterized as a concrete which has an extremely low water-to-cement ratio, high binder content, optimum packing density to eliminate capillary pores and provide an extremely dense matrix, and direct tensile mortar strength higher than $1 \mathrm{ksi}(7 \mathrm{MPa}$ ) (Naaman and Wille 2012; Resplendino 2012). UHPC is also referred to as UHP-FRC when fibers are added for improved mechanical properties.

\subsubsection{Brief History of UHPC}

French researchers were the first to write technical recommendations focusing on the design of UHPC in 2002 (SETRA 2002). This report is called the Interim Recommendations for Ultra-High Performance Fiber Reinforced Concrete. In 2003, Germany developed a state-of-the-art report that includes material and design aspects of UHPC, called DAfStB (DAfStB 2003). Similar standards have been developed in Japan (JSCE 2008) and Australia (SAI 1994).

In North America, several UHPC formulations have been developed in research environments (Astarlioglu et al. 2010), but few are commercially available. Pierre Rossi and the French Public Works Research Laboratory (LCPC) developed CEMTEC ${ }^{\circledR}$ and CEMTEC-multi-scale ${ }^{\circledR}$ in France in 2000, which is being used by government agencies and universities in North America (Rossi 2002; Astarlioglu et al. 2010). However, the primary commercially available product is Ductal ${ }^{\circledR}$, manufactured by Lafarge North America. The results presented herein are applicable to the Ductal ${ }^{\mathbb{R}}$ brand BS1000 product of ultra-high performance concrete.

\subsubsection{General Composition of UHPC}

A general outline for the composition of UHPC is shown in Table 2.3 provided by Graybeal (2006a). Ground basalt and other variations of these materials have been used in UHPC mix designs (Schmidt et al. 2008; Burkart and Müller 2009). It can be seen that the constituents used in UHPC are similar to that used in conventional concrete, though the percentages of material differ greatly and there is no coarse aggregate. The brass covered, steel fibers of Ductal have a nominal diameter of $0.008 \mathrm{in}$. and are $0.5 \mathrm{in}$. long (Graybeal 2006a). BS1000 Ductal ${ }^{\circledR}$ is premixed and delivered in $50 \mathrm{lb}$ bags. It should be noted that accelerator is not required for the BS1000 mixture. 
Table 2.3

General UHPC composition (Graybeal 2006a)

\begin{tabular}{lcc}
\hline Material & Amount $\left(\mathrm{lb} / \mathrm{yd}^{3}\right)$ & $\begin{array}{c}\text { Percent by } \\
\text { Weight }\end{array}$ \\
\hline Portland Cement & 1,200 & 28.5 \\
Fine Sand & 1,720 & 40.8 \\
Silica Fume & 390 & 9.3 \\
Ground Quartz & 355 & 8.4 \\
Superplasticizer & 51.8 & 1.2 \\
Accelerator & 50.5 & 1.2 \\
Steel Fibers & 263 & 6.2 \\
Water & 184 & 4.4 \\
\hline
\end{tabular}

\subsubsection{Material Properties of UHPC}

UHPC is similar to HPC, but with advanced mechanical and durability properties. Table 2.4 compiled by Misson (2008) compares properties of normal strength concrete (NSC), HPC, and UHPC. UHPC has significantly superior strength, chloride resistance, and stiffness when compared to traditional concrete materials.

Ultra-high performance concrete (UHPC) has several specific properties, which make it a viable material for thin-bonded concrete bridge deck overlays. These properties include high compressive strength, post-cracking tensile capacity, high resistance to environmental and chemical attack, negligible permeability, high early strength gain, and its ability to self-consolidate. Due to the dense particle packing of UHPC, not all cement particles react during curing. Advanced steam treatments are required to obtain the maximum material characteristics. The type of curing regime has a significant effect on UHPC properties, as can be seen in Table 2.5 adapted from Graybeal (Graybeal 2006a; 2006b). However, this high thermal treatment is not always feasible for every application of the material. For instance, with an overlay application under in-service conditions, ambient curing is most probable, where as the capabilities of a precast plant are most similar to the tempered cure. 
Table 2.4

Concrete comparison (Misson 2008)

\begin{tabular}{llll}
\hline Mechanical Properties & NSC & HPC & UHPC \\
\hline Compressive Strength (ksi) & $3.0-6.0$ & $6.0-14.0$ & $25.0-33.0$ \\
Split Cylinder Cracking Strength (ksi) & $0.36-0.45$ & & $1.0-3.5$ \\
Creep Coefficient, $\mathrm{C}_{\mathrm{u}}$ & 2.35 & $1.6-1.9$ & $0.2-0.8$ \\
$\begin{array}{l}\text { Porosity (\%) } \\
\text { Modulus of Elasticity (ksi) }\end{array}$ & $20-25$ & $10-15$ & $2-6$ \\
\hline Durability Characteristics & $2000-6000$ & $4500-8000$ & $8000-9000$ \\
\hline Freeze-Thaw Resistance & $10 \%$ & & \\
$\begin{array}{l}\text { Chloride Ion Penetrability (coulombs) } \\
\begin{array}{l}\text { Scaling Resistance (lb/ft^2 mass } \\
\text { removal) }\end{array}\end{array}$ & $>2000$ & $50 \%$ & $100 \%$ \\
\hline
\end{tabular}

Table 2.5

Selected material characteristics of UHPC (Graybeal 2006a; 2006b)

\begin{tabular}{lccc}
\hline & $\begin{array}{c}\text { Steam } \\
90^{\circ} \mathrm{C}, 95 \% \\
\mathrm{RH}, 48 \mathrm{hrs}\end{array}$ & $\begin{array}{c}\text { Tempered } \\
60^{\circ} \mathrm{C}, 95 \% \\
\mathrm{RH}, 48 \mathrm{hrs}\end{array}$ & $\begin{array}{c}\text { Ambient } \\
23^{\circ} \mathrm{C}, \\
50 \% \mathrm{RH}\end{array}$ \\
\hline 28-day compressive strength (ksi) & 28.0 & 24.8 & 18.3 \\
Modulus of Elasticity (ksi) & 7600 & 7397 & 6193 \\
Direct tension cracking strength (ksi) & $1.4-1.6$ & $1.1-1.3$ & $0.8-1.0$ \\
28-day indirect tension cracking strength & $1.6-1.7$ & $1.6-1.7$ & 1.3 \\
(ksi) & 1.3 & 1.5 & 1.3 \\
Prism flexural cracking strength (ksi) & No scaling & No scaling & No scaling \\
Scaling resistance & 0.006 & 0.007 & 0.028 \\
Abrasion resistance (oz lost) & $96 \%$ & $100 \%$ & $112 \%$ \\
Freeze-thaw resistance (RDM) & $<0.004$ & $<0.004$ & $<0.04$ \\
Chloride ion permeability (lb/ft ${ }^{3}$ ) & 18 & 39 & 360 \\
Chloride ion permeability (coulombs) & & & \\
\hline
\end{tabular}




\subsubsection{Time-Dependent Characteristics of UHPC}

As with traditional concrete, some of UHPC's material and mechanical properties change over time and due to hardening of the concrete. These time-dependent properties include volume changes (shrinkage and creep relaxation) and compressive strength and modulus.

\subsubsection{Volume Change}

UHPC exhibits substantial autogenous shrinkage, especially when a full thermal cure is not applied. The consideration of these shrinkage strains within an overlay is important to measuring the compatibility of the overlay-deck system. Presented in this section are relevant literature of free and restrained shrinkage tests performed on UHPC.

Drying shrinkage is very low in UHPC due to the low water-to-cement ratio (Nassif et al. 2007; Garas et al. 2009a; Kosmatka and Wilson 2011). This is also true with Ductal ${ }^{\circledR}$ brand UHPC. Lafarge North America, claims a free endogenous shrinkage of Ductal ${ }^{\circledR}$ is 300-400 microstrain when no thermal treatment is applied and no residual endogenous shrinkage after the full thermal cure regime of $195^{\circ} \mathrm{F}\left(90^{\circ} \mathrm{C}\right), 95 \%$ relative humidity for $48 \mathrm{hrs}$ is applied (Lafarge North America).

Research conducted by Graybeal investigated the long-term free-shrinkage (ASTM C157) of Ductal ${ }^{\circledR}$ brand UHPC (Graybeal 2005; 2006a). The initial shrinkage recording occurred 30 minutes after demolding, which happened 22 hours after casting. However, Graybeal found that this initial reading missed some of the early age shrinkage of UHPC and showed that the requirement of ASTM C157 specification that concrete must set before measurements can begin was not valid for UHPC. Shrinkage measurements were recorded over a duration of 1 year. Graybeal found that $95 \%$ of Ductal's ${ }^{\circledR}$ ultimate freeshrinkage was obtained by two months. To fully investigate the unrestrained shrinkage at early ages, Graybeal tested ambient and fully cured specimens by beginning measurements at the time of demolding using an embedded vibrating wire strain gage. The steam cured specimens reached a plateau of 850 microstrain at approximately 4 days, while the ambient cured specimens continued to shrink beyond 790 microstrain at 40 days of casting.

Soliman and Nehdi studied the effects of drying (curing) conditions, shrinkage-reducing admixture, and a superabsorbent polymer on the early-age free autogenous shrinkage of UHPC (Soliman and Nehdi 2011). Two UHPC mixtures were considered, one with 0.22 water-to-binder ratio $(\mathrm{w} / \mathrm{b})$ and one with $0.25 \mathrm{w} / \mathrm{b}$ ratio. After casting, prismatic specimens were covered with polyethylene sheets and cured at ambient temperatures $\left(74^{\circ} \mathrm{F}, 50 \% \mathrm{RH}\right)$ until demolding (final setting was achieved between 5-7 hours after casting). The specimens where then cured at temperatures of $50^{\circ} \mathrm{F}, 68^{\circ} \mathrm{F}$, and $104^{\circ} \mathrm{F}$ and relative humidity's of $40 \%, 60 \%$, and $80 \%$, respectively, to simulate field-like conditions. The researchers found that increased temperature of cure increases the autogenous strain rate in the first 24 hours. For example, the $104^{\circ} \mathrm{F}$ regime reached $550 \mu \varepsilon$ in 7 days, while 
the $68^{\circ} \mathrm{F}$ cure reached $400 \mu \varepsilon$ and $50^{\circ} \mathrm{F}$ cure reached $200 \mu \varepsilon$ in the same amount of time. When the $104^{\circ} \mathrm{F}$ regime was combined with a relative humidity of $40 \%, 1100 \mu \varepsilon$ of autogenous shrinkage was obtained after seven days; the highest obtained in the study. It was also found that drying and autogenous strains were depended on each other and should not be superimposed to avoid overestimations. It was stated that ample curing is required for reduced shrinkage. For example, only 52\% of the target compressive strength was reached when UHPC is cured at $50^{\circ} \mathrm{F}$. This was especially true for thin sections, as drying reduced the role autogenous shrinkage in the total deformation.

Habel et al. (Habel and Denarié 2005; Habel et al. 2006a) also studied the effect of autogenous shrinkage on $\mathrm{CEMTEC}_{\text {multiscale }}{ }^{\circledR}$ UHPC, which has steel fibers and a w/b ratio of 0.14 . Both free and restrained shrinkage tests were completed. The restrained shrinkage test used a linear device which had a fixed stealhead at one end and a moving stealhead at the other that would reapply fixity to the system as the specimen displaced. The free shrinkage test had the same fixed stealhead at one end and a free end at the other. LVDTs measured the deformations in each tests 54 hours after of casting prism specimens (24 hours after setting). The main finding was that the majority of free autogenous shrinkage occurs within the first few hours after setting (150 $\mu \varepsilon$ at 48 hours and $325 \mu \varepsilon$ at 7 days) and reaches a constant value around 90 days. The drying shrinkage contribution to the total shrinkage of free specimens was minimal, with only $40 \mu \varepsilon$ after 20 days and less than $100 \mu \varepsilon$ after 400 days. Restrained shrinkage of $300 \mu \varepsilon$ after 7 days was found, though the total deformation with creep included amounted to only $150 \mu \varepsilon$. The creep found in restrained tests accounted for $60 \%$ of the free shrinkage deformations, indicating that UHPC relaxation significantly influences the total deformation at early ages.

Garas et al. (2009a) investigated the effects of fiber reinforcement and thermal treatment on the short-term tensile creep and free shrinkage of Ductal ${ }^{\circledR}$ UHPC. After 14 days of drying, the free shrinkage of an ambient air cured UHPC mixture with $2 \%$ fibers by volume was about six times higher than a UHPC mix which was thermally treated at $190^{\circ} \mathrm{F}$ for 48 hours. It was also found that thermally cured mixtures with $2 \%$ fibers by volume reached an asymptotic free-shrinkage strain value around 6 days, while the mixtures which cured under ambient air continued to have measurable free shrinkage over time. The authors also found that thermal treatment had a significant effect on the tensile creep of UHPC. At seven days, the thermally treated mixtures had a 73\% lower creep coefficient and $77 \%$ reduction in specific creep than the ambient cured specimens. In another study published by the same author (Garas et al. 2009b), autogenous shrinkage of thermally cured UHPC comprised $93 \%$ of the total shrinkage after 20 days, furthering the general finding that drying shrinkage is minimal in UHPC.

The free shrinkage of UHPC was also investigated by Burkart and Müller (2009). It was found that cylindrical specimens ranging from 3 in. - 6 in. (maintaining a height:diameter ratio $=3$ ) had very little difference in total shrinkage, with $300 \mu \varepsilon$ occurring after 250 days. It was also determined that UHPC did not appear to have any drying shrinkage. 
AASTHO PP34-99 (AASHTO PP-34-99) "ring tests" were conducted by Piérard et. al to determine the restrained shrinkage and cracking tendency of UHPC (Piérard et al. 2009). The UHPC mixture used in this study was developed by the Belgian Building Research Institute and the Vrije Universiteit Brussel and has a $\mathrm{w} / \mathrm{b}$ ratio of 0.23 . Drying was only permitted from the outer circumferential surface. The first visible crack appeared between 24-25 days after casting in UHPC that did not contain fibers. However, UHPC that contained a $2 \%$ by volume of steel micro- and macro-fibers had not cracked by 70 days, which was the end of the test duration.

Research conducted by Kim et al. investigated the effects of expansive admixtures (EA) and shrinkage reducing agent (SRA) on the free and restrained shrinkage of UHPC (S Kim et al. 2012). The UHPC mix considered had a w/b ratio of 0.2 and $2 \%$ of steel fibers by volume. The total shrinkage values for non-restrained tests were found to be similar to other research presented here ( $600 \mu \varepsilon$ at 28 days), though the test itself was unique to Japanese Concrete Institute. In this test, the specimen top surface of a rectangular specimen is exposed to air, while all other sides are placed in a Teflon covered mold for reduced friction. The free autogenous and drying shrinkage is then measured by an embedded strain gage at the center specimen. To quantify the restrained shrinkage of UHPC, the AASHTO PP34-99 test was conducted with drying allowed in the circumferential direction. The steel strain measured during this test was around $125 \mu \varepsilon$ at 28 days for the non-modified UHPC mixture. Cracking did not occur during the test duration.

The behavior and magnitude of restrained shrinkage is critical to the study of thin-bonded overlay systems, because the stresses that develop at the composite interface may exceed the bond strength of the system. This would lead to cracking or debonding failures at the interface. From this literature it has been determined that the shrinkage of UHPC may be very high, especially at early ages. The risk of cracking due to early-age stresses, as the material strength which resists these stresses are not fully developed. Investigation into the restrained shrinkage of Ductal ${ }^{\circledR}$ UHPC is therefore essential in determining the compatibility of a thin-bonded UHPC overlay on concrete bridge decks.

\subsubsection{Compressive Strength}

Other time-dependent properties of UHPC are its compressive strength gain. In addition to being dependent on age, the compressive strength and strength gain of UHPC is also significantly influenced by cure regime. Strength gain of this material becomes important in overlay applications when looking at optimizing time to traffic opening or bed turnover time. Therefore, proper analysis is vital to the long-term performance of the structures.

Several steam treatments used in recent literature are listed in Table 2.6. The tempered and pre-steam cure regimes have been adjusted from the standard steam treatment specified by Ductal ${ }^{\circledR}$ to a cure regime that is easily obtainable in a precast facility, where the applications of UHPC are ideally suited. Graybeal used a "tempered steam cure" 
which is similar to the standard treatment but with a reduced temperature (Graybeal 2005; 2006a). Nyland and Flietstra reduced the temperature of the standard treatment, as well as the cure duration to one that obtained $14 \mathrm{ksi}$ and reduced demolding time, naming it the "pre-steam" cure regime (Nyland 2009; Flietstra 2010). Although the tempered and pre-steam cure regimes are slightly different, they provide good comparison of the early age strength gain of UHPC under steam curing regimes that are obtainable by precast plants.

Table 2.6

UHPC steam cure regimes

\begin{tabular}{lcccc}
\hline & $\begin{array}{c}\text { Standard } \\
\text { Steam Cure }\end{array}$ & $\begin{array}{c}\text { Tempered } \\
\text { Steam Cure }\end{array}$ & $\begin{array}{c}\text { Pre-steam } \\
\text { Cure }\end{array}$ & $\begin{array}{c}\text { Ambient } \\
\text { Cure }\end{array}$ \\
\hline Temp $\left({ }^{\circ}\right.$ F) & 195 & 140 & 140 & 74 \\
RH (\%) & 95 & 95 & 95 & 50 \\
Duration & 48 & 48 & $14-18$ & - \\
(hrs) & & & & \\
Demolding & - & 24 & 14 & 24 \\
\hline
\end{tabular}

Figures 2.2-2.4 are compiled data of Ductal ${ }^{\circledR}$ UHPC compressive strengths at various ages and cure regimes (Graybeal 2006a; Misson 2008; Nyland 2009; Flietstra 2010; Ahlborn et al. 2011). Some variation can be seen between researchers, which is primarily thought to be caused by changes in filler material and mix designs between research publications (Flietstra 2010). Cure duration and procedure for the varying regimes are also slightly different. For example, while Graybeal's data prior to $28 \mathrm{hrs}$ of age is labeled "steam" and "tempered" thermal treatments, it is important to note that they had not yet begun the thermal treatment at the time of testing. Contrary to the other publications listed here, Graybeal demolded at final set ( $28 \mathrm{hrs})$ and then began thermal treatment (Graybeal 2006a). Furthermore, the Graybeal (2006a) steam treatment included $44 \mathrm{hrs}$ at the specified temperature and RH with $2 \mathrm{hrs}$ of ramp up and down time for a total of $48 \mathrm{hrs}$, while Ahlborn et al. (2011) steam treated specimens for $48 \mathrm{hrs}$ excluding the $6 \mathrm{hr}$ ramp up and down periods. Figure 2.2 displays the strength gain of this material within 48 hours after casting, which are quite consistent at early-ages when differences in cure regime are considered. Similarly, Figure 2.3 highlights the strength gain within the first 7 days after casting. The compressive strength gain for UHPC under ambient cure is quite similar, though there is discrepancy between Graybeal's tempered and Flietstra and Nyland's pre-steam cure regimes results and Graybeal's and Ahlborn's ambient tests. In both of these cases, Graybeal's results are lower than was found in other literature. Finally, Figure 2.4 shows the strength of Ductal ${ }^{\circledR}$ up to 30 days of age. Again, the difference between research results is noticeable in the long-term. As a type of mortar/concrete, UHPC is a diverse material that does not have exact mix designs or mix procedures, so some variation is expected. 


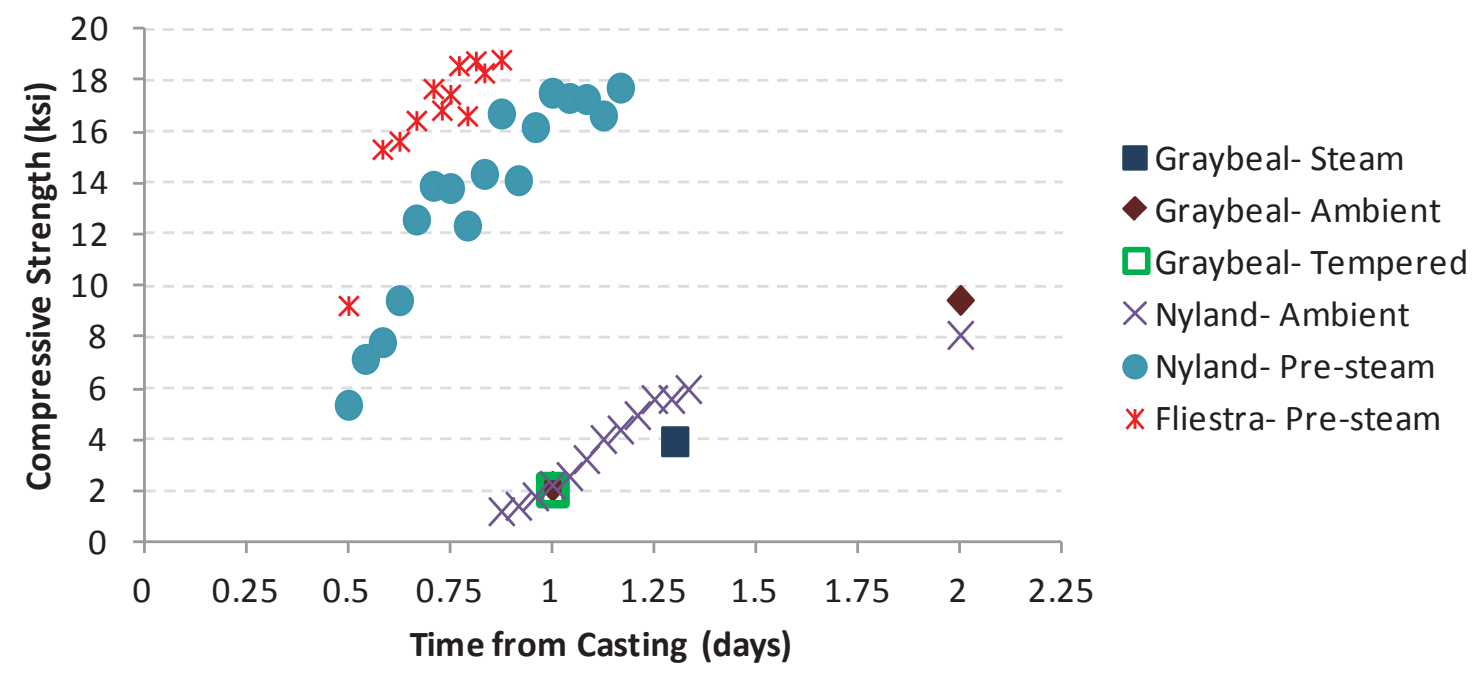

Figure 2.2: Early age compressive strength gain of Ductal ${ }^{\circledR}$ within 2 days

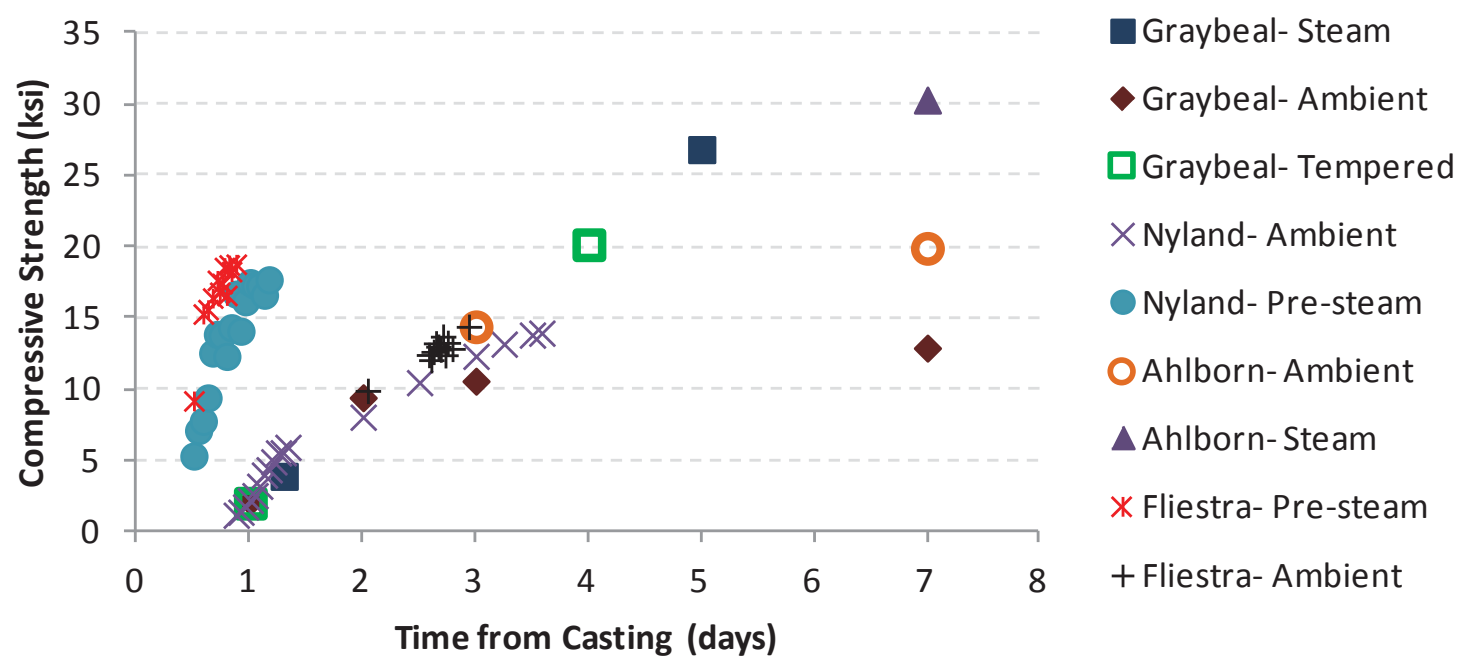

Figure 2.3: Compressive strength gain of Ductal ${ }^{\circledR}$ within 7 days 


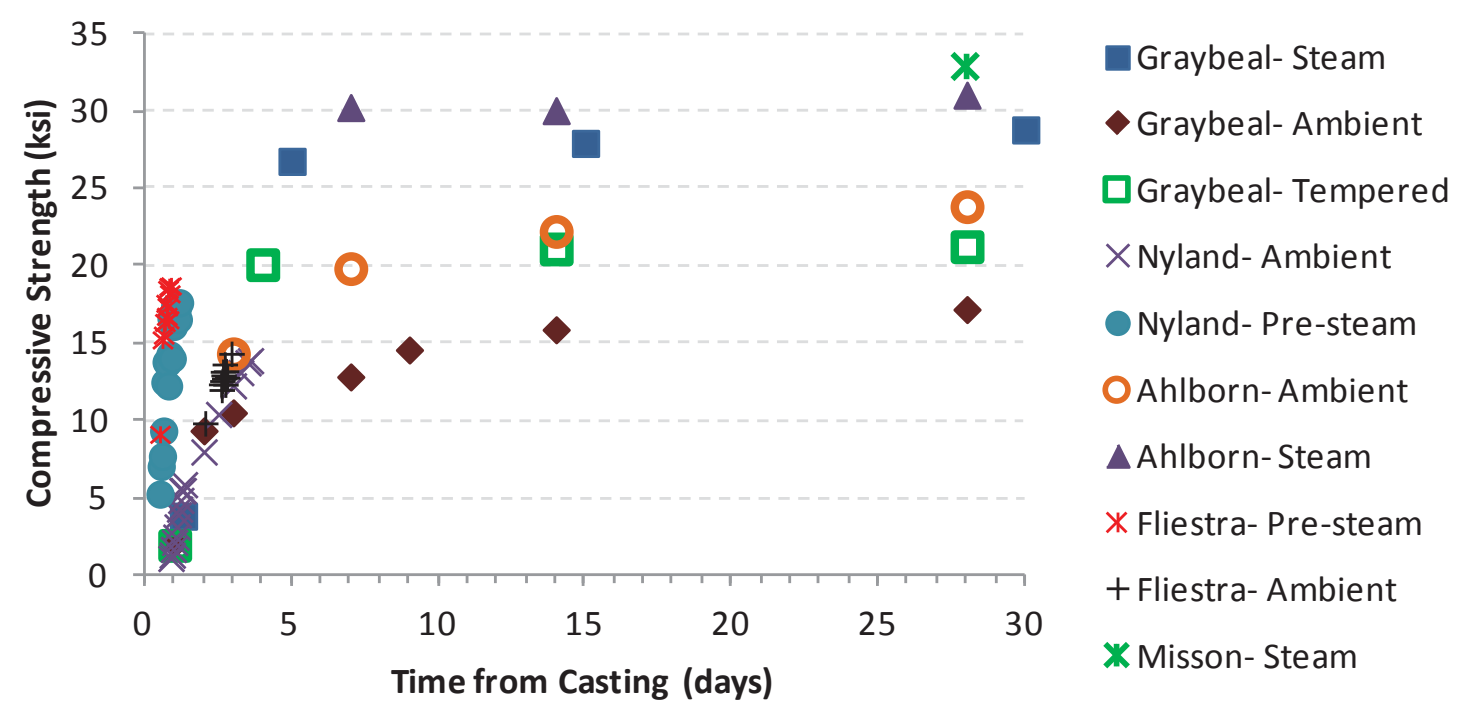

Figure 2.4: Compressive strength gain of Ductal ${ }^{\circledR}$ within 30 days

\subsubsection{Elastic Modulus}

The elastic modulus of UHPC is also time-dependent, even under thermal and steam treatment, but especially when ambient conditions are considered. Graybeal (2006a) and Ahlborn et al. (2011) conducted modulus tests, based on compressive strength tests, at various ages and cure regimes. Flietstra also conducted modulus test on UHPC, but his results are not considered here at they were determined from creep testing, not compressive strength testing (Flietstra 2010). As with the compressive tests, there is discrepancy between results, particularly when ambient curing was applied. This can be seen in Table 2.7. For instance, Graybeal's results at 3 days of age under ambient cure treatment are 24\% less than Ahlborn's, where 28-30 day results under standard steam cure are only $8 \%$ less. As the compressive strength has a major effect on the moduli results, the discrepancies within compressive results the steam cured specimens would also be reflected in these results. Again, this may be caused by changes in Ductal ${ }^{\mathbb{R}}$ mix design between publications, facility mixing procedures and equipment, variations in cure regimes, testing procedures and as a concrete material some variation is expected.

In his research, Graybeal found that UHPC follows nearly linear elastic behavior until right before failure for all specimens where some steam and thermal treatment has been applied. Ambient specimens were found to have region of near linear-elastic behavior after final set had occurred, but some non-linear behavior at early ages. He also discussed several numerical equations relating $f^{\prime}{ }_{c}$ and $E$ and proposed one that best fit his experimental data shown in Equation 1 (Graybeal 2006a). However, these large differences in elastic modulus, especially at specific ages, must be accounted for in design and analysis. 
Table 2.7

Variation of elastic modulus of UHPC

\begin{tabular}{ccccc}
\hline & \multicolumn{2}{c}{ Graybeal } & \multicolumn{2}{c}{ Ahlborn } \\
\hline Age at Testing (days) & E (ksi) & Std. Dev. & E (ksi) & COV (\%) \\
\hline Ambient Cure & & & & \\
\hline $\mathbf{3}$ & 5220 & 43 & 6910 & 0.6 \\
$\mathbf{7}$ & 5660 & 111 & 7520 & 1.9 \\
$\mathbf{1 4}$ & 5970 & 172 & 7865 & 0.8 \\
$\mathbf{2 8}$ & 6076 & 164 & 7863 & 1.8 \\
\hline Standard Steam Cure & & & & \\
\hline $\mathbf{5}$ & 7600 & 109 & - & - \\
$\mathbf{7}$ & - & - & 8056 & 1.6 \\
$\mathbf{1 4}$ & - & - & 8215 & 1.3 \\
$\mathbf{1 5}$ & 7620 & 162 & - & - \\
$\mathbf{2 8}$ & - & - & 8114 & 0.7 \\
$\mathbf{3 0}$ & 7460 & 167 & - & - \\
\hline
\end{tabular}

$$
E_{c}=46,200 *{\sqrt{f^{\prime}}}^{\prime} \text { in psi } \quad \text { Equation } 1
$$

As a material's strength is represented by stiffness in the finite element models later discussed, accurate modulus values for a given age are vital to determining the system state of stress and overall compatibility.

\subsubsection{Summary of the Effect of Time Dependent Properties on Material Compatibility}

The mechanical and material time depended properties of UHPC are of special interest in determining the compatibility of the proposed composite system at early-age and inservice loading. If UHPC strength or modulus has not adequately developed at the time live loads are applied to the system, failures such as cracking or debonding may occur. Additionally, if drying shrinkage or autogenous shrinkage within the UHPC overlay develop at a faster rate than the material strength required to resist them, the resulting internal stresses will cause cracking in the overlay-deck system. To determine when these failures would occur, analytical models are conducted as part of this research to investigate the state of stress at various ages due to applied design truck loads.

\subsection{UHPC as an Overlay}

There are several material, mechanical and durability properties of UHPC, which make it a desirable material for use as a thin-bonded overlay on concrete bridge decks; many of which were highlighted in Section 2.6.3. UHPC has low porosity, chloride ion permeability, high freeze thaw resistance, and high scaling resistance, which indicate 
overall high ductility and long material service lives. The high compression and tension strength of UHPC suggests that increased load capacity of an entire bridge structure may be possible, in addition to reduced risk of cracking under applied loads. Further benefits include reduced traffic closures and increased precast bed turnover rates due to the high strength gain of UHPC.

Although the general properties of UHPC indicate good compatibility in overlay applications, specific investigation must be conducted to determine the total compatibility of the system when bonded to concrete bridge decks. The bond integrity of UHPC to normal strength concrete (NSC) deck systems have to be evaluated to quantify the strength of the composite system. Lastly, the thickness of a UHPC overlay must be optimized to reduce the dead load added to the structure while maintaining integrity of the bond interface.

\subsubsection{Bond Strength}

Combinations of optimized overlay thickness and elastic modulus, derived from compression testing, were evaluated to ensure that the interfacial stresses between the UHPC overlay and normal strength concrete (NSC) substrate were less than the bond strength determined from past and current research. This section outlines past and concurrent research being conducted to characterize the bond of UHPC to NSC and other similar materials.

Research conducted by Harris et al. (2011) investigated the bond strength of UHPC to mortar by conducting slant shear tests (ASTM C882-99) and splitting tensile test (modified ASTM C496). This study was continued by Carbonell et al. (2012) to investigate the bond strength of UHPC to NSC under the modified ASTM C469. These studies were used as the bounds on bond capacity. Table 2.8 presents the bond strength results and coefficient of variation (COV) of UHPC to NSC and mortar for different surface preparations. These combined shear-compression and indirect tension tests are not exact characterizations of the bond strength between the two materials; however, they provide a base representation for comparison in this research. 
Table 2.8

UHPC bond test results (Harris et al. 2011; Carbonell et al. 2012)

\begin{tabular}{lcccc}
\hline Bond Surface Preparation & \multicolumn{2}{c}{ Slant Shear Test } & \multicolumn{2}{c}{ Splitting Prism Test } \\
& psi & COV $(\%)$ & psi & COV (\%) \\
\hline Bonded to Mortar & & & & \\
\hline Grooved & 2060 & 11.7 & 479 & 34.0 \\
Smooth & 1606 & 11.3 & 754 & 16.5 \\
\hline Bonded to Normal Strength Concrete & & & \\
\hline Grooved & - & - & 696 & 18.0 \\
Sandblasted & - & - & 450 & 45.8 \\
Brushed & - & - & 595 & 8.3 \\
Smooth & - & - & 522 & 16.9 \\
\hline
\end{tabular}

\subsubsection{Summary of UHPC Applications as Bridge Deck Overlays}

There have been a few instances where UHPC has been applied as an overlay on bridge decks. Many of these studies have included reinforcing layers into the overlay or investigated the feasibility of UHPC as an overlay on steel decks. In all cases the overlay system has not been optimized to minimize thickness or optimize constructability issues such as cure time.

Schmidt et al. used UHPC as a white topping to repair and increase the bearing and fatigue capacity of a concrete and bituminous bridge deck (Schmidt et al. 2008). The UHPC topping was between $2.4-3.2$ in. $(6-8 \mathrm{~cm})$ thick, had $2.5 \%$ fiber content by volume, and $8 \mathrm{~mm}$. bars (similar to No. 3 bars). No existing material was removed before its placement and deck joints did not contain any dowel reinforcement. The amounts of superplasticizer, silica fume, and fibers were reduced to create a stiffer mix. The authors assumed that the overlay topping and substrate were fully bonded. Experimental tests were conducted to determine the fatigue behavior of a 2.4 in. UHPC white-topping on a 10 in. NSC slab. After 500,000 fatigue cycles, deformations remained in the elastic zone and the fatigue stresses did not exceed the design strength of $50 \%$ of the static load strength. Further tests were planned to monitor the long-term performance of the UHPC white-topping on a parking deck and highway lane.

A Research and Technology Development (RTD) and Demonstration research project called SAMARIS (Sustainable and Advanced Materials for Road InfraStructure) along with several independent authors investigated the composite action of UHPC and NSC on 15 full-size beams that were approximately $18 \mathrm{ft}$ long (Denarié and Brühwiler 2005; Habel and Denarié 2005; Charron et al. 2006; Habel et al. 2006a). The beams were cast in ambient conditions and demolded after seven days, at which point the sides of the beams were then covered with an epoxy resin to prevent drying. The UHPC thicknesses considered were $1.18,2$, and 4 in. $(3,5$, and $10 \mathrm{~cm})$ and reinforcing layers equaling 0 and 
$2 \%$ by volume were included. The researchers tested the beams in statically determinant and indeterminate boundary conditions. Larger UHPC layers increased mid-span deformations. Fracture and fatigue tests were conducted on these specimens. Increased reinforcement reduced beam deflections, especially in the 4 in. UHPC layer; however, the increased reinforcement also provided a higher degree of restraint and therefore higher stresses. It was found that no shear reinforcement between the UHPC layer and substrate was needed to achieve composite behavior at ultimate loading. A few surface cracks were found through visual inspection due to drying of the skin layer of UHPC. Two bending cracks did occur in the UHPC 1.18 in layer in the statically indeterminate beam, which was the beam with the highest degree of restraint. In all beams, no significant interface cracks or debonding was found except when beams underwent fracture testing. The researchers found that a majority of the total beam deflection was attributed to deformations caused by autogenous shrinkage and thermal changes in the UHPC. The authors recommended adding reinforcing to the UHPC layer to strengthen the system in cases of high bending or moderate fatigue loading. Another study conducted by this research group included a 1.18 in $(3 \mathrm{~cm})$ thick UHPC overlay cast on a bridge deck over the river la Marge near Sion, Wallis, France. UHPC was also used in bridge widening and rehabilitation of sections of this bridge. A 1.58 in $(4 \mathrm{~cm})$ thick layer of bituminous concrete was cast on top of the UHPC overlay to create a cross slope on the bridge deck. A traditional waterproof membrane was not needed in the bituminous concrete due to the UHPC's impermeable characteristics. The UHPC overlay underwent eight days of moist curing and traffic was opened one month after the start of construction. Timber formwork was found to minimize the corrosion of exposed fibers when compared to metal formwork. The authors found that the total cost of the project, project duration, and traffic closures were less than the local traditional methods.

UHPC has also been considered as a topping layer on orthotropic steel bridge decks. Research conducted by Marchand et al. studied the feasibility of using a 0.40-0.55 in (10$14 \mathrm{~mm}$ ) layer of UHPC with shear studs and wire mesh to reduce fatigue stresses and cracking between deck troughs and the top plate (Marchand et al. 2012). Perfect bonding was not obtained in this system, which caused slippage and some cracking at the interface under extremely high loading. Experimental and numerical modeling found that a 30$60 \%$ reduction in fatigue stress could be achieved by using UHPC as a topping layer. Yuguang et al. investigated the bending behavior and strengthening of a deteriorating orthotropic steel bridge deck with a 1.18 in $(3 \mathrm{~cm}), 1.57$ in $(4 \mathrm{~cm})$, and 2 in $(5 \mathrm{~cm})$ UHPC (Yuguang et al. 2008). A multilayer model, validated with four-point bending tests, was used to determine the bending behavior of the overlay-deck system using a simplified equivalent stress-strain relationship. It was assumed that the UHPC overlay and steel deck were perfectly bonded prior to cracking. An epoxy coating was placed between the overlay and deck to improve the interface ductility. In addition to the steel fibers within the UHPC matrix, layers of rebar mesh reinforced the overlay system. The authors found that the overlay without mesh was adequate for the maximum expected traffic load. They also found that adding one layer of mesh significantly increased the bending capacity, but adding two layers was not as effective due to their location within the cross section. 
Finally, it was found that the 2.20 in. overlay was an overly conservative thickness. Further testing was needed to have full confidence in an optimized overlay thickness. 


\section{Methodology}

This section explains the methodology employed to conduct experimental testing and develop the analytical finite element models, for assessing the compatibility of a thinbonded UHPC overlay on concrete bridge decks. Section 3.1 outlines the experimental testing conducted in this research and includes the materials and equipment used to mix, cast, and cure UHPC. This section also gives brief summaries each test conducted and addresses any modifications to the standard tests. Section 3.2 covers the theory, elements, loading, and assumptions made within the analytical finite element models. Also included are the geometric and material properties assessed in the parametric analysis and the model validation.

\subsection{Experimental Testing}

To meet the goals of this research in assessing the compatibility of a UHPC-overlay system, optimizing overlay thickness, and minimizing construction time experimental tests needed to be conducted in addition to previously discussed literature (see Section 2.6.4). Therefore, a small number compressive strength tests (ASTM C39 2012) were conducted to fully characterize the strength gain of UHPC using the current Ductal ${ }^{\circledR}$ premix design at ages not considered in past research. As discussed in previous sections, restrained shrinkage stresses can vastly affect the debonding and cracking potential of an overlay-deck system. Although some research has been conducted on the restrained shrinkage of UHPC, none has been conducted specifically for Ductal ${ }^{\mathbb{B}}$. As every mix design has slightly different constituents and material properties, it was important to determine the restrained shrinkage stresses through the use of Practice for Estimating the Crack Tendency of Concrete to accurately assess the compatibility of the proposed system (AASHTO PP-34-99).

\subsubsection{UHPC Batching and Mixing Procedure}

The proportions of material constitutes for each batch of UHPC are listed in Table 3.1. All tests described in this paper were from one shipment of premixed $50 \mathrm{lb} \mathrm{Ductal}{ }^{\mathbb{B}}$ bags from Lafarge North America. The BS1000 Ductal ${ }^{\circledR}$ mix requires the addition of superplasticizer, water, and $2 \%$ of fibers by volume. The superplasticizer used in all batches was Chryso ${ }^{\circledR}$ Fluid Premia 150. Copper plated steel fibers were supplied by Lafarge N.A. These $1 / 2$ in. long fibers have are 0.008 in. in diameter and are not deformed or hooked. Steel fibers were used to enable comparison with companion research (Graybeal 2006a; Peuse 2008; Nyland 2009; Flietstra 2010); however, for applications as thin-bonded overlays, poly-vinyl alcohol (PVA) fibers may be desired. The use of PVA fibers over steel would increase public safety, though the tensile strength would be slightly reduced due to differences in tensile strain-hardening and strain-softening behaviors (Lafarge North America). 
Table 3.1

UHPC batch proportions

\begin{tabular}{lc}
\hline Constituent & Proportion by Weight (lbs) \\
\hline Ductal $^{\circledR}$ BS1000 Premix & 87.05 \\
Steel Fibers & 6.19 \\
Water & 5.11 \\
Superplasticizer & 1.19 \\
\hline
\end{tabular}

Each batch yielded 18.0 liters $\left(0.63 \mathrm{ft}^{3}\right)$ of UHPC, weighing $101.9 \mathrm{lbs}$. A $300 \mathrm{lb}$ capacity scale with a precision of $0.05 \mathrm{lbs}$ was used to measure the Ductal ${ }^{\circledR}$ premix, all other constituents where measured on a $33 \mathrm{lb}$ capacity scale with a precision of $0.01 \mathrm{lbs}$.

A $2.0 \mathrm{ft}^{3}$ Doyon planetary mixer (Figure 3.1) was utilized for its high shear mixing capabilities. The mix procedure practiced for all batches can be found in Appendix A, which was originally developed by Kollmorgen (Kollmorgen 2004). Though the mixing process has been slightly modified over time for different batch sizes and to shorten turn over times, it has generally been consistent as shown in (Misson 2008; Peuse 2008; Nyland 2009; Flietstra 2010). First, the Ductal ${ }^{\circledR}$ premix is blended to break down any clumps that may have formed during storage. The water and half of the superplasticizer were added after two minutes. The speed of the mixture is gradually increased according to the procedure listed in Appendix A until the turning point has been reached, at which time the remaining superplasticizer is added. The turning point (also called the flux point) is when the mixture begins clumping and falls from the edge of the bowl, which typically correlates to 12-15 Amps output from the Doyon mixer. Once the amperage of the mixture reduces and stabilizes (around 6-8 Amps) the fibers are slowly added and blended to ensure even distribution.

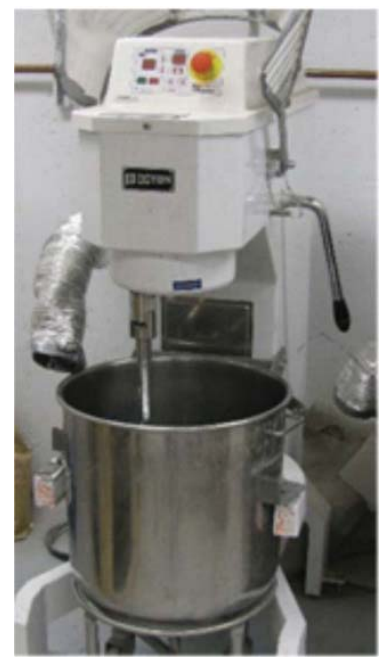

Figure 3.1: Doyon planetary mixer 


\subsubsection{Quality Control}

After the mixing process has been completed, an ASTM C1437-07 standard for measuring the flow of hydraulic cement was completed to measure the rheology of the UHPC, as instructed by the Ductal ${ }^{\circledR}$ reference T 006 (Lafarge North America 2003a). For this test, a small brass cone mold was slightly dampened, filled with material, stricken off, and lifted straight up to allow the material to flow out. Material remaining in the cone was removed and added to the center of the UHPC on the flow table. After the cone is removed and an equilibrium spread has been obtained, the spread diameter is measured in four directions. The flow table was then mechanically dropped 20 times from a height of 0.5 in and the flow is measured again (ASTM C1437 2007). Figure 3.2 shows the initial flow test setup and the measurement of UHPC spread across the flow table. The stiffness of the mix was then determined according to Table 3.2.
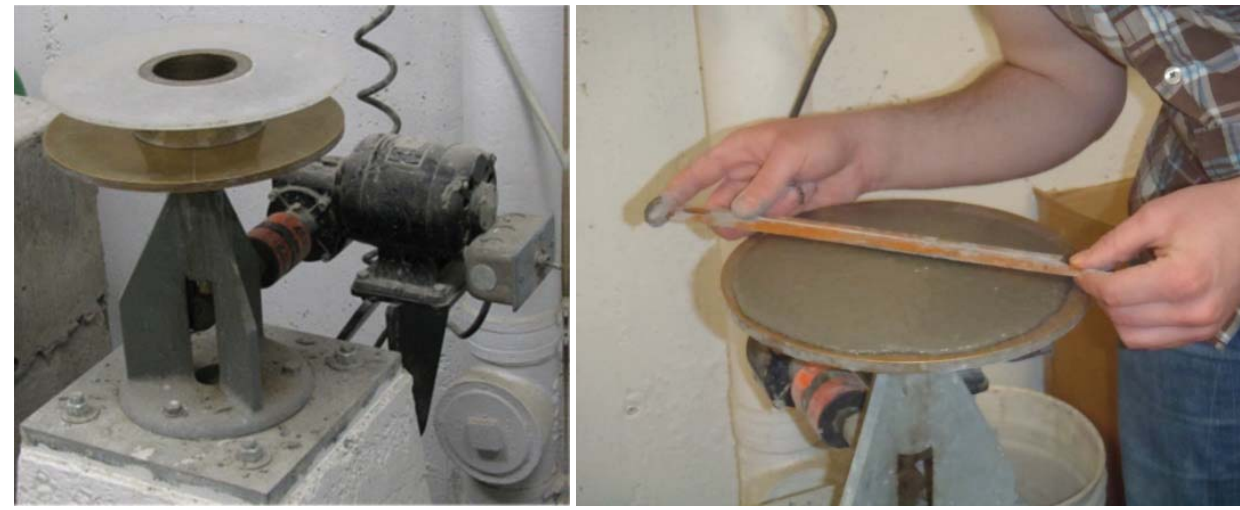

Figure 3.2: Flow test setup and spread measurement

Table 3.2

Rheology measurement

\begin{tabular}{cc}
\hline $\begin{array}{c}\text { Spread Diameter after } \\
\text { 20 Drops }(\mathrm{mm})\end{array}$ & Mix Rheology \\
\hline$<200$ & Stiff \\
$200-250$ & Fluid \\
$>250$ & Highly Fluid \\
\hline
\end{tabular}

\subsubsection{Curing Regimes and Demold Time}

The type of cure treatment has significant implications for the mechanical and durability properties of a UHPC overlay including strength at the time of opening, stiffness differential between overlay and substrate, and long-term compatibility of the composite deck section. Because the full extent of UHPC's mechanical properties are believed to 
not be necessary in overlay applications where improved load capacity is not required, the cure regimes are considered in this research which are less intensive than the standard steam cure recommended by Lafarge N.A $\left(195^{\circ} \mathrm{F}\right.$ at $95 \% \mathrm{RH}$ for $\left.24 \mathrm{hrs}\right)$. To accurately represent field and precast applications of UHPC, two cure regimes were selected. The cast-in-place regime was ambient curing at $74^{\circ} \mathrm{F}\left(23^{\circ} \mathrm{C}\right)$ and $50 \% \mathrm{RH}$. A modified steam cure (MSC) was chosen to mimic the thermal and moisture capabilities of a precast plant, while reducing the duration of cure. This modified treatment consisted of $140^{\circ} \mathrm{F}\left(60^{\circ} \mathrm{C}\right)$ at $95 \% \mathrm{RH}$ for $12 \mathrm{hrs}$ followed by an ambient cure. Due to the limitations of test facilities, this cure duration included $1 / 2-1 \mathrm{hr}$ ramp up time from a starting temperature of $120^{\circ} \mathrm{F}$.

Ambient cure specimens were demolded at $48 \mathrm{hrs}$. This duration was based on initial live load results by Shann et al., which indicated a cast-in-place overlay could be opened to traffic 48 hrs after casting (Shann et al. 2012). Furthermore, ambient specimens reach their final set prior to $48 \mathrm{hrs}$ and delaying demolding reduces moisture loss resulting higher strength gain (Graybeal 2006a). Therefore, to better represent field conditions and prevent drying as long as reasonably possible, demolding occurred 48 hours after casting.

Modified steam cure specimens were demolded at 12 hours to reduce bed turnover time in a precast application of this overlay system. Research conducted by Shann et al. (2012) indicated that from a mechanical standpoint, strength obtained at $14 \mathrm{hrs}$ did not induce high stresses in the overlay system, indicating that earlier turnover times may be appropriate. Therefore, $12 \mathrm{hr}$ demolding time was selected to represent the drying conditions that would be encountered after slabs were moved off of the bed and stored until shipping.

\subsubsection{Early Compression Strength}

Compression tests (ASTM C39 2012) were conducted on cylinders to better understand the early age strength gain of UHPC and fill in compressive strength data at ages that were not determined in past literature. Additional tests were conducted at 28 days for ambient cured specimens and at 7 days for cylinders under modified steam treatment. All cylinders had a nominal diameter of 3 in and a length of 6 in. Horizontal steel molds shown in Figure 3.3 were used for most compression tests to improve the speed and ease of testing, as UHPC's high early strength gain created the need to frequently and precisely test specimens. The steel molds provided flat and perpendicular ends, so cutting and grinding cylinder ends before tests was not required. There is a 1 inch gap in the steel molds to allow specimen casting, which is then sealed with a form fitting steel piece. Only a limited number of steel molds are available, so plastic molds were used for some of the 28-day compression specimens, where low material strengths were not an issue. These specimens were cut and ground to a planar surface as per ASTM C192 and ASTM C39. 

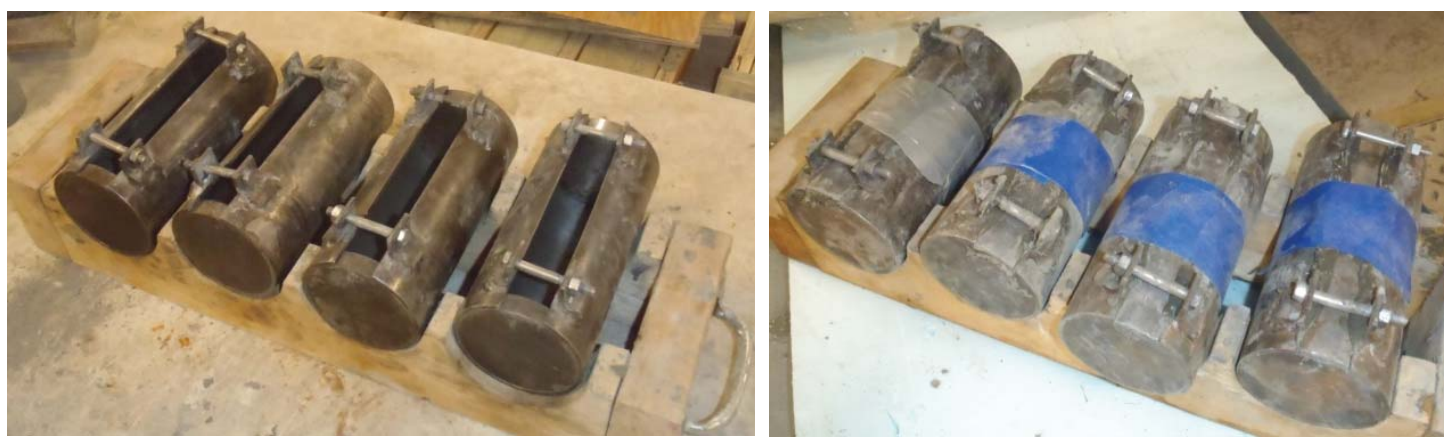

\section{Figure 3.3: Steel cylinder molds}

Only one lift was applied in accordance with the standard for horizontal molds, while two lifts were used for the plastic molds (ASTM C192 2007). If the flow from the modified ASTM C1437 (Section 3.1.2) was found to be satisfactory, the molds were vibrated after being filled (8-10 seconds) to release air bubbles. The appropriate cure regimes began immediately after casting and the specimens were demolded as stated in Section 3.1.3.

The planeness of cylinder ends was verified with the limits of ASTM C617 (ASTM C617 2011) and the diameter, length, and mass were recorded prior to testing and can be found in Appendix B.

A Baldwin CT 300 hydraulic load frame compression testing machine was used to measure the compressive strength of UHPC. A modified loading rate of $150 \mathrm{psi} / \mathrm{sec}$ was used in place of the standard $35 \mathrm{psi} / \mathrm{sec}$ as recommended in the Ductal ${ }^{\circledR} \mathrm{T} 001$ reference (Lafarge North America 2003b) document to keep within the 3 minute time frame recommended by the ASTM C39 (Peuse 2008). Steel bearing plates, 5 in. in diameter, were placed above and below the UHPC specimens to evenly distribute the load.

\subsubsection{Restrained Shrinkage and Creep}

As mentioned in Section 2.3, shrinkage stresses are a primary component of interfacial bond failures and the restraint provided by a deck will create higher shrinkage stresses in a UHPC overlay than if it was allowed to move freely, while tensile creep of the material relieves a portion of this interfacial stress. To determine the total, or net, interfacial stresses caused by shrinkage and creep of UHPC in field conditions, the AASHTO PP3499 "Practice for Estimating the Crack Tendency of Concrete" was performed (AASHTO PP-34-99). The drying boundary conditions were modified in this test, as discussed later in this section, and the cure regime was modified to analyze the effect of modified steam treatment on the total system behavior.

The AASHTO PP34 "Practice for Estimating the Crack Tendency of Concrete" and ASTM C1581 "Standard Test Method for Determining Age at Cracking and Induced Tensile Stress Characteristics of Mortar and Concrete under Restrained Shrinkage,” 
commonly known as the restrained ring test, are typically used to compare relative restrained shrinkage cracking likelihood of different concrete materials (AASHTO PP34-99 ; ASTM C1581 2009). In both of these standards, a concrete annulus is cast around a steel ring, which provides restraint of the concrete ring. As the concrete shrinks, compressive stresses develop in the concrete ring and tensile stresses develop in the steel ring. Measurement of these circumferential stresses is completed through linear strain gages and the time of cracking is recorded, which is when the tensile concrete stresses due to shrinkage are greater than its strength. The tests were initially developed to represent an infinitely long, partially restrained pavement or deck (Weiss and Shah 2002). These standards are written for comparative analysis between concrete mixtures, due to the fact that the potential for cracking in-service is dependent on the type of structure, degree of restraint, modulus of elasticity, construction methods, curing methods, and environmental conditions (AASHTO PP-34-99). However, numerous researchers have used an analytical stress method to use the results from these tests to determine the maximum residual tensile stress at the concrete-steel interface (Weiss and Shah 2002; Pease 2005; Moon et al. 2006; Hossain et al. 2009; Nguyen et al. 2010; Briffault et al. 2011). There are several advantages to using a restrained ring tests over other restrained experiments, such as the flat panel tests or linear restrained shrinkage test, including its low cost, simplicity, and its ability to account for all material factors that affect shrinkage cracking) development of stress, geometric and volume changes, and creep) from the time of casting, so no assumptions or difficult derivations are needed (Nassif et al. 2007). Most important is that the stress results from this test closely simulate those developed by real structures (Nassif et al. 2007).

The two standards differ slightly in regards to specimen geometry, testing duration, and ring surface roughness requirements (see Table 3.3). The reduced concrete geometry and slightly increased steel geometry of the ASTM standard was intended to shorten the time to cracking and increase the restraint conditions (Nassif et al. 2007). One main adverse affect of ASTM geometry, is that it limits the maximum course aggregate size. The AASHTO test is considered complete when cracking occurs, which can last from 56-90 days (Delatte et al. 2007), where the ASTM test duration is 28 days regardless of cracking (Nassif et al. 2007). 
Table 3.3

Differences between ASTM and AASHTO ring test standards

\begin{tabular}{|c|c|c|}
\hline & ASTM C1581-05 & AASHTO PP34-99 \\
\hline $\begin{array}{l}\text { Concrete Annulus } \\
\text { Thickness }\end{array}$ & $\begin{array}{l}3 \text { in } \\
(76 \mathrm{~mm})\end{array}$ & $\begin{array}{l}1.5 \mathrm{in} \\
(38 \mathrm{~mm})\end{array}$ \\
\hline Steel Ring Thickness & $\begin{array}{l}1 / 2 \text { in } \pm 1 / 64 \text { in } \\
(12.7 \mathrm{~mm} \pm 0.4 \mathrm{~mm})\end{array}$ & $\begin{array}{l}0.5 \pm 0.05 \text { in } \\
(13 \pm 0.12 \mathrm{~mm})\end{array}$ \\
\hline Steel Outer Diameter & $\begin{array}{l}12 \text { in } \\
(305 \mathrm{~mm})\end{array}$ & $\begin{array}{l}13 \pm 0.12 \text { in } \\
(330 \pm 3.3 \mathrm{~mm})\end{array}$ \\
\hline $\begin{array}{l}\text { Concrete Outer } \\
\text { Diameter }\end{array}$ & $\begin{array}{l}18 \text { in } \\
(457 \mathrm{~mm})\end{array}$ & $\begin{array}{l}16 \text { in } \pm 0.12 \text { in } \\
(406 \pm 3 \mathrm{~mm})\end{array}$ \\
\hline Time to Demolding & $24 \pm 1 \mathrm{hr}$ & 24 \\
\hline $\begin{array}{l}\text { Surface } \\
\text { Requirements of } \\
\text { Ring }\end{array}$ & $\begin{array}{l}\text { Smooth, round and true, } \\
\text { polished }\end{array}$ & $\begin{array}{l}\text { Ring must be machined to a } \\
\text { smooth surface with a } \\
\text { texture of } 63 \text { micro inches } \\
\text { ( } 1.6 \text { micrometers) }\end{array}$ \\
\hline
\end{tabular}

The AASHTO PP34-99 test was selected over the ASTM C1581 for its relaxed steel ring surface requirements and its availability to the Michigan Tech facilities. The test dimensions and setup is shown in Figure 3.4.

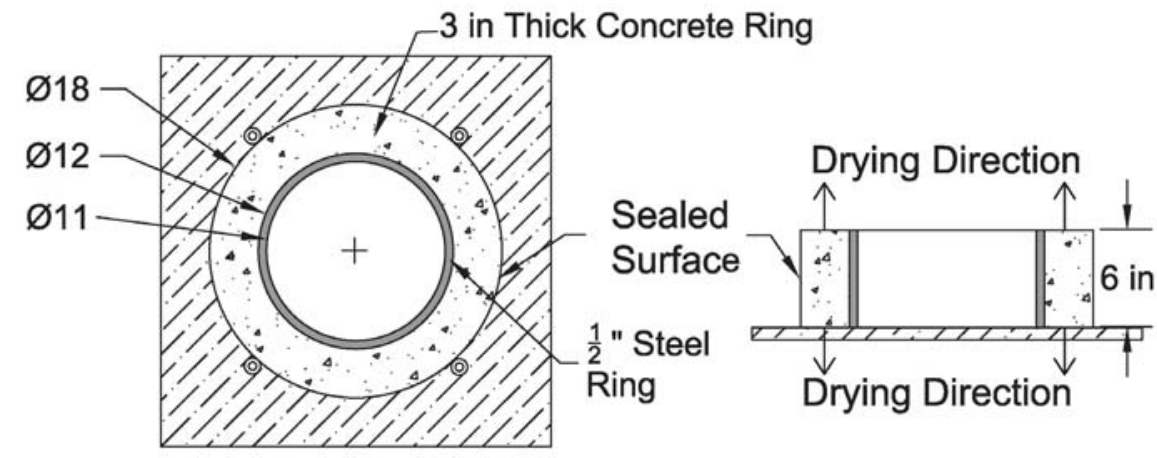

TOP VIEW

CROSS-SECTION

Figure 3.4: AASHTO PP 34-99 test details

The AASHTO PP 34-99 test was not intended for UHPC or its cure requirements. Therefore, the test was modified for the modified steam cure. The restrained shrinkage strain of the steel was monitored for both rings at the time of casting. Two ring specimens were cast for each cure regime. For specimens under the ambient cure regime, no changes were made to the standard AASHTO spec. To investigate the effects of the 
modified steam cure regime, specimens were placed in cure chamber immediately after casting at a temperature of $140^{\circ} \mathrm{F}\left(60^{\circ} \mathrm{C}\right)$ and $95 \%$ relative humidity for 12 hours.

Following this steamed cure, specimens are moved to an ambient air environment at $73^{\circ} \mathrm{F}\left(23^{\circ} \mathrm{C}\right)$ and $50 \%$ relative humidity, as specified in this ASTM.

The steel cylinder was instrumented with four strain gages halfway up the cylinder to measure the circumferential steel strain (see Figure 3.5). Each gage was wired in a quarter-bridge configuration.

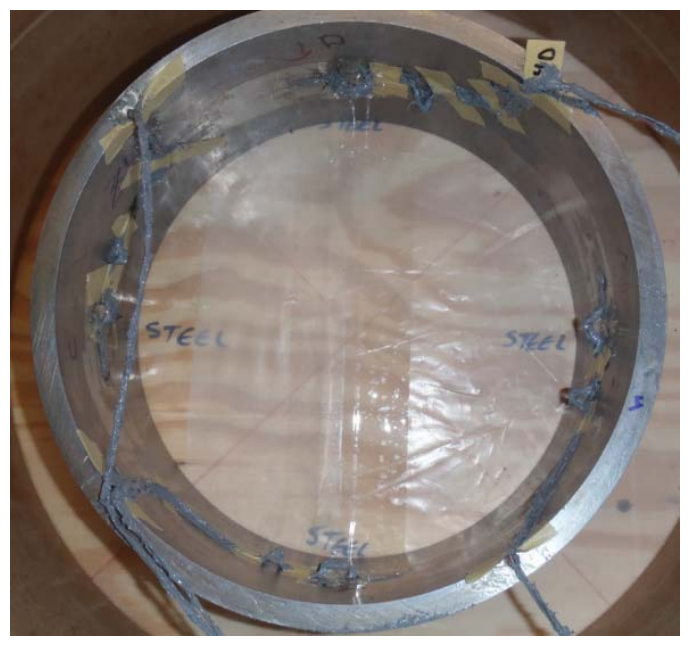

Figure 3.5: Complete strain gage installation

Due to the large thermal range of the modified steam cure regime, Vishay L2A-06250LW-350 encapsulated contstantan gages were chosen for the large operating temperature range from $-100^{\circ} \mathrm{F}$ to $250^{\circ} \mathrm{F}$. M-Bond AE- 15 adhesive was also selected for it high operating range (up to $250^{\circ} \mathrm{F}$ long term). The strain gages were installed per the manufacturer instructions. The resistance of each gage was verified with a digital multimeter after strain gage installation and after soldiering of wires. To protect against the high humidity of the modified steam cure regime a protective coating, Vishay 3145 RTV was used for its high elongation capabilities, lack of runoff, large temperature range of $65^{\circ} \mathrm{F}$ to $500^{\circ} \mathrm{F}$ in the long term, and moisture resistance. The RTV coating was only applied on the strain gages of the rings which were exposed to the modified steam treatment; the gages on the ambient cure rings were left bare. Fifteen feet of Vishay 326DFV wire was used for all gages plus or minus $1 / 4$ in. This is a stranded tinned-copper flat wire with three conductors and vinyl insulation, which has a temperature range up to $180^{\circ} \mathrm{F}$. It was a concern that the wire insulation would not provide adequate protection when exposed to the $95 \% \mathrm{RH}$ of the modified steam treatment. To ensure measurement accuracy, approximately five feet of wire leading from the specimen, which would be closed within the cure chamber, was also covered in the 3145 RTV coating. The installation of the ambient and modified steam cure gages are displayed in Figure 3.6. 

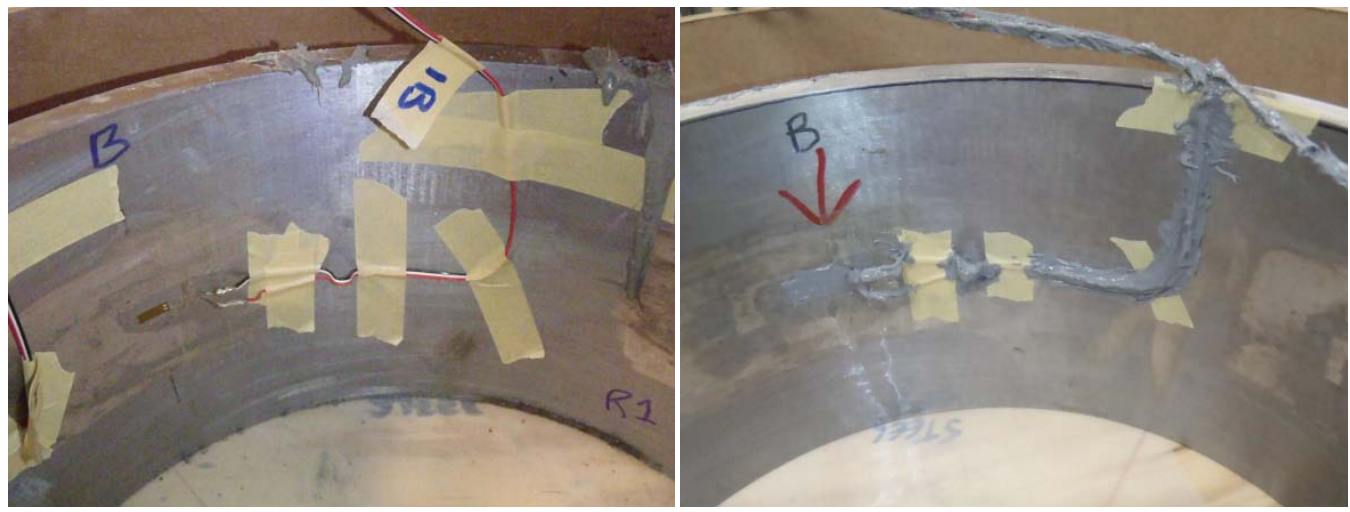

Figure 3.6: Strain gage installation

A Campbell Scientific CR9000X data acquisition system was used to record strain at 15 minute intervals for 28 days. Prior to the start of tests, the recording of the data acquisition system was verified through the use of a strain indicator calibrator where various strains were applied to each sensor. Measurements began recording $30 \mathrm{~min}$. before the first specimens was cast so gages could be zeroed and stabilize. Figure 3.7 shows the Campbell Scientific system and wiring setup of the 16 gages.

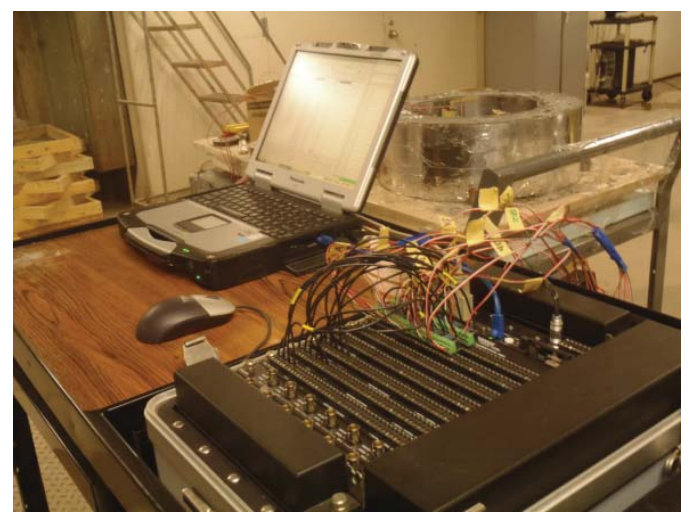

Figure 3.7: Data acquisition system

Outer forms for the ring test were made from non-absorptive and non-reactive cardboard tube, which had an inner diameter of 18 in. and were cut to 6 in. lengths (see Figure 3.8). The plywood based was covered in plastic to prevent moisture absorption and allow free movement of the specimen during shrinkage.

Specimens were not vibrated on a vibrating table in an effort to avoid fiber consolidation and strain gage damage, as gage readings were already being collected by the data acquisition systm. Instead, the rings were rodded after the placement of three approximately equal layers with a small metal tool approximately $1 / 8$ in. in diameter. A 
traditional rodding tool could not be used due to fibrous reinforcement. Figure 3.8 shows a newly cast ambient cured ring specimen.

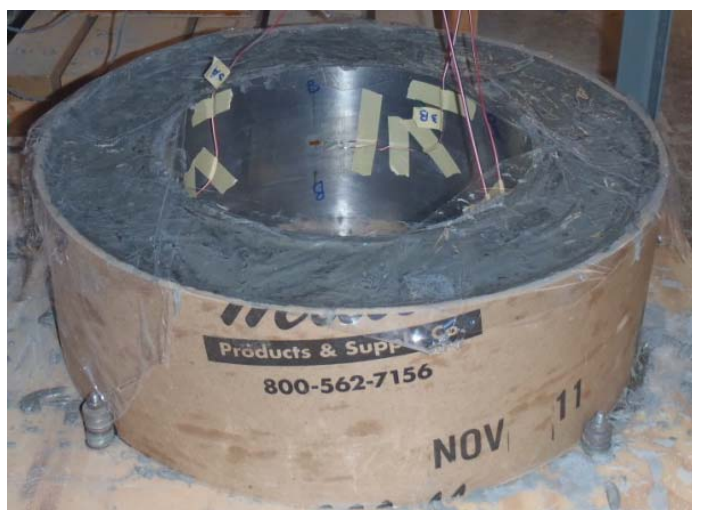

\section{Figure 3.8: AASHTO PP34-99 cast specimen}

After the corresponding cure regime were completed, demolding of specimens occurred as described in Section 3.1.3 and the circumference of the rings were sealed with adhesive aluminum-foil tape, as shown in Figure 3.9. The specimens were also lifted off their base at this time to prevent restrained conditions and allow drying to occur through the bottom cylinder surface, as recommended in the AASHTO specification and Weiss and Shah study (Weiss and Shah 2002).

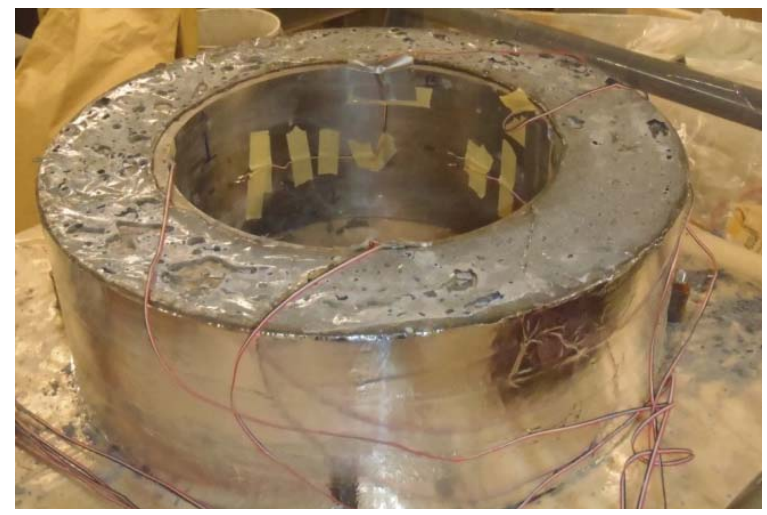

\section{Figure 3.9: Sealed ring}

This study used an analytical stress method developed used Hossain and Weiss to determine the actual restrained tensile stresses of the AASHTO ring tests at the concretesteel interface at time ' $t$ ' (Hossain and Weiss 2004). This solution separates the ring specimen into a concrete ring with a uniform pressure at its inner surface and a steel ring with an equal and opposite pressure at its outer surface, as shown in Figure 3.10. The actual interface pressure can be calculated as the pressure required to produce a strain 
equal to that measured by the strain gages attached to the interior steel ring surface (Hossain and Weiss 2004).

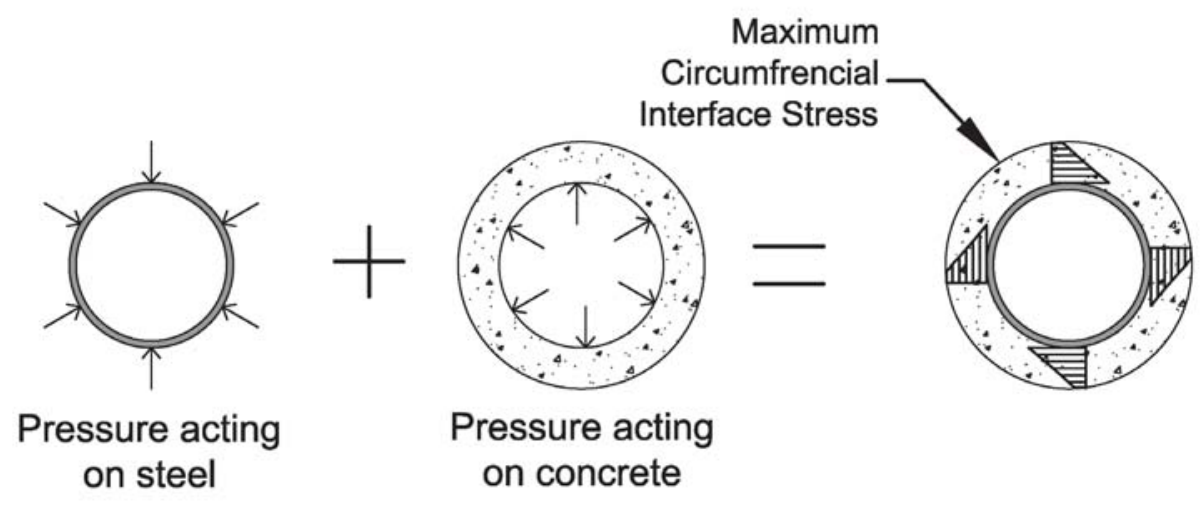

Figure 3.10: Pressure idealization for determine the residual concrete stress

Analytical equations have been developed to determine the interfacial tensile stress when drying occurs as is recommended in the standard specification, which is drying from the outer circumference (Moon and Weiss 2006). This method uses superposition to account for the stress fields caused by the steel ring restraint and the stress field caused by nonuniform drying. Figure 3.11 adapted from (Moon and Weiss 2006) illustrates the nonlinear stress distribution through the concrete annulus depth due to the non-uniform drying and ring restraint.

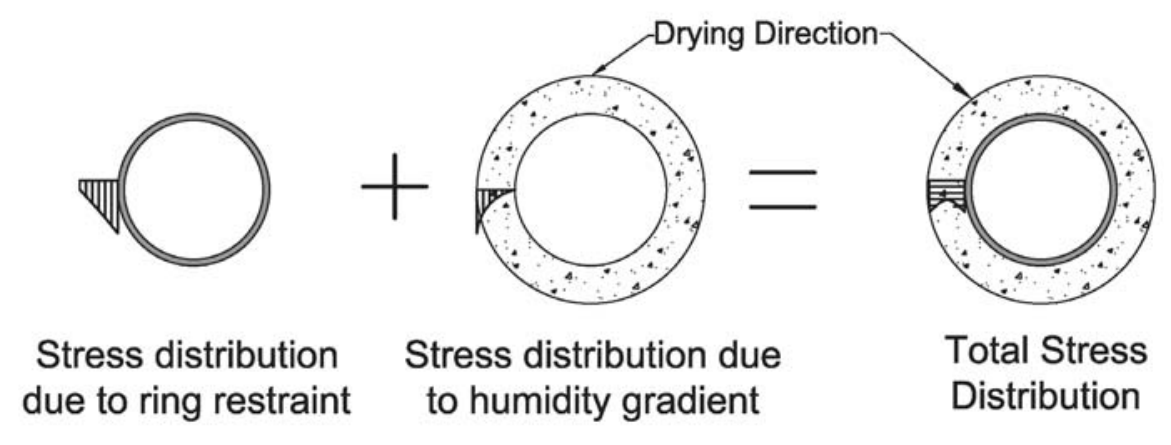

Figure 3.11: Stress distribution when drying occurs from outer circumference

However, due to the negligible drying shrinkage exhibited by UHPC as discussed in Section 2.6.4.1, the stress gradient from the non-uniform circumferential drying will be minimal compared to the total tensile stress at the interface (Habel et al. 2006a). Therefore, a simplified approach was chosen, where the boundary conditions are oriented such that drying will occur uniformly along the radius of the concrete ring specimen (see 2.6.4.1). This eliminates the analytical component caused by the non-uniform moisture gradient. Uniform drying through the depth of an overlay for UHPC is a valid scenario 
for measuring the tensile interface stresses of UHPC in a restrained condition due low percentage of the total shrinkage which is caused by drying (most of the shrinkage in UHPC is caused by autogenous shrinkage, which is not dependent on volume:surface ratio) and due to thinness of a UHPC overlay. Some researchers have used a 3 in. ring height to increase the shrinkage rate of the rings and enable a direct comparison between free shrinkage ASTM C157 test, but a 6 in. tall ring is also valid for this drying boundary condition (Hossain and Weiss 2004). It is important to note that the degree of restraint provided by the steel ring is much greater than the restraint provided by a normal strength concrete bridge deck, causing overestimation of the interfacial tensile stresses in an actual bridge system.

Using this drying method, the mechanics of the test behave as a thick-walled cylinder with a uniform pressure at its inner surface and a steel ring with an equal and opposite pressure at its outer surface due to the internal concrete shrinkage. Figure 3.12 adapted from (Boresi and Schmidt 2003) shows the stresses of a thick walled cylinder due to an internal $\left(\mathrm{p}_{1}\right)$ and externally $\left(\mathrm{p}_{2}\right)$ applied pressure and no applied axial force; where the theoretical stresses of this system are calculated with Equation 2, Equation 3, and Equation 4. In this figure, "a" is the radial distance to the inner surface and " $b$ " is the radial distance to the outer surface.

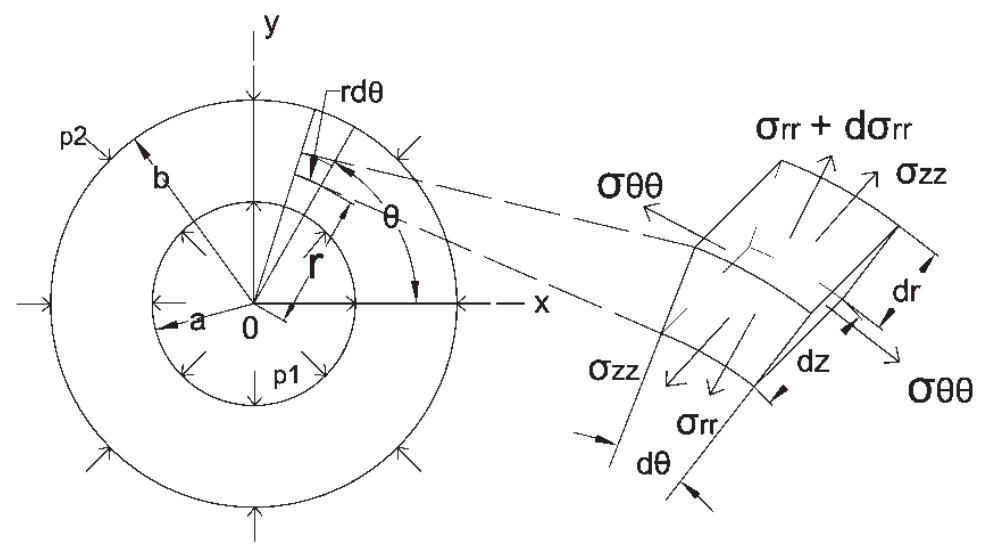

Figure 3.12: Free body diagram of pressurized cylinder

$$
\begin{gathered}
\sigma_{r r}=\frac{p_{1} a^{2}-p_{2} b^{2}}{b^{2}-a^{2}}-\frac{a^{2} b^{2}}{r^{2}\left(b^{2}-a^{2}\right)}\left(p_{1}-p_{2}\right) \\
\sigma_{\theta \theta}=\frac{p_{1} a^{2}-p_{2} b^{2}}{b^{2}-a^{2}}+\frac{a^{2} b^{2}}{r^{2}\left(b^{2}-a^{2}\right)}\left(p_{1}-p_{2}\right)
\end{gathered}
$$




$$
\sigma_{z z}=0
$$

Equation 4

When the UHPC shrinks, the steel is in compression along the $\theta$-direction, while the concrete is in tension. For both materials, radial stresses are compressive and would not contribute to debonding of the materials. Therefore, the stress distribution at the interface due to radial shrinkage was not considered in this study. More information on the fracture mechanics of this test can be found in (Ouyang et al. 1996). The stress in the zdirection is zero for open cylinders with no applied axial load and there are no differences in temperature between the inner and outer surfaces of the cylinder (Boresi and Schmidt 2003). Furthermore, only an internal pressure is present on the concrete annulus in this study, so the $\mathrm{p}_{2}$ terms $=0$, reducing the Equation 1 to:

$$
\sigma_{\theta \theta}(r)=p_{1} \frac{a^{2}\left(r^{2}+b^{2}\right)}{r^{2}\left(b^{2}-a^{2}\right)}
$$

Equation 5

The circumferential tensile stress in the concrete-steel interface can then be calculated by setting $r=a$, as shown in Equation 6. The terminology of Equation 6 has been changed to match those used in studies performed by Hossain and Weiss specifically for the AASHTO PP34-99 ring test; where $\mathrm{P}_{\text {int }}$ is the interface pressure at an age $t$, and $\mathrm{R}_{\mathrm{OS}}$ and $\mathrm{R}_{\mathrm{OC}}$ are the outer radii of the steel and concrete ring, respectively (Hossain and Weiss 2004). Perfect bond between the steel and concrete rings is assumed, which causes continuous circumferential stresses and strains.

$$
\sigma_{\theta \theta_{-} \text {interface }}(t)=P_{\text {int }}(t) * \frac{R_{O S}^{2}+R_{O C}^{2}}{R_{O C}^{2}-R_{O S}^{2}}
$$

Equation 6

The residual interface pressure $\left(\mathrm{P}_{\text {int }}\right)$ at an age $\mathrm{t}$ is found as shown in Equation 7 where $\varepsilon_{\text {steel }}(t)$ is the measured steel strain at time $t$, and $E_{s}$ is the modulus of elasticity of the steel ring equal to $29000 \mathrm{ksi}$ (Hossain and Weiss 2004). Note that $\mathrm{R}_{\mathrm{OS}}=\mathrm{R}_{\mathrm{IC}}$ through displacement due to shrinkage until cracking occurs.

$$
P_{\text {int }}(t)=-\varepsilon_{\text {steel }}(t) * E_{S} * \frac{R_{O S}^{2}-R_{I S}^{2}}{2 * R_{O S}^{2}}
$$

Equation 7

Equation 5 re-written in the terminology set forth by Hossain and Weiss, the circumferential stress in the concrete ring as a function of the depth through the ring is: 


$$
\sigma_{\theta \theta}(r)=-\varepsilon_{\text {steel }}(t) * E_{S} * \frac{R_{O S}^{2}-R_{I S}^{2}}{2 *\left(R_{O C}^{2}-R_{O S}^{2}\right)} *\left(1+\frac{R_{O C}^{2}}{r^{2}}\right) \quad \text { Equation } 8
$$

For further information regarding the mechanics of this test, see Hossain and Weiss's article published in 2004 where a full discussion is included for the derivation of the theoretical elastic stress (Hossain and Weiss 2004).

Using this method, the circumferential normal tensile stress through the depth of the ring can be determined. Due to the axi-symmetric geometry of the test, there is no shear stress in the ring. As previously stated, this test was created to represent an infinitely long slab or pavement. Therefore, when a small increment $\mathrm{d} \theta$ of the ring test is straightened to a represent a level slab, the normal stresses through the depth cause equal and opposite shear stresses at the composite steel-concrete interface as shown in Figure 3.13.
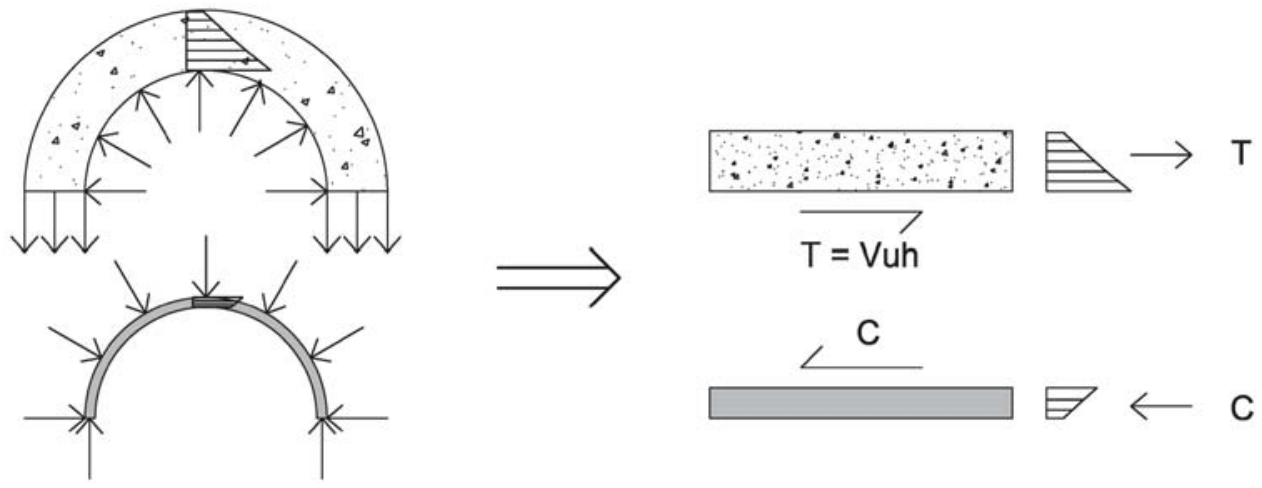

Figure 3.13: Horizontal interface shear stress diagram

ACI 318-08 Chapter 17 addresses the industry design specifications for composite concrete flexural members pertaining to horizontal shear strength and analysis (ACI 31808 2008). Industry standard outlined in Section 17.5 .1 of the ACI 318-08 is to consider the full transfer of horizontal force at the contact surface, which is the force in the top composite material that is "pushing" the top composite material (overlay) off the substrate (deck slab). Using this standard, the normal stresses through the depth of the concrete annulus were calculated for each of the considered ages and the resultant force (T) was determined that is equal and opposite to the shear force $\left(\mathrm{V}_{\mathrm{uh}}\right)$ at the composite interface. Equation 9 shows how the $\mathrm{T}$ and $\mathrm{V}_{\mathrm{uh}}$ forces were determined, where 6 inches is the height, or surface width, of the steel ring. The shear stress at the interface was determined using Equation 10. This shear stress is later added to the shear stress found in the analytical model due to live load to determine the total shear stress at the interface. This total shear stress was then compared to the slant-shear strength of UHPC-NSC composite materials determined in past literature to determine the compatibility of the overlay-substrate system. The maximum residual circumferential tensile stress, which 
occurs at the steel-UHPC interface, was also calculated and compared to UHPC splitting tensile strength from past literature in order to determine if the UHPC would crack under the restrained shrinkage loads.

$$
\begin{gathered}
T=V_{u h}=\text { Areaunder } \sigma_{\theta \theta}(r) \text { curve } * 6 \text { in } \\
v_{u h}=\frac{V_{u h}}{\text { Interface Surface Area }}
\end{gathered}
$$

Equation 9

Equation 10

The procedure described in the previous paragraph determined the tensile and shear stress at the composite interface due to the restrained shrinkage of a 3 in. thick UHPC annulus. The overlay thicknesses that are being considered in this research range from $1 / 4$ " to 2 " and would therefore have slightly different responses than the 3 in. thick annulus. However, alternative UHPC thicknesses were not considered in this restrained shrinkage test, because the majority of UHPC shrinkage is caused by autogenous shrinkage, which is not a function of the surface-to-volume ratio. Additionally, researchers have found that concrete annulus thickness did not have an immense effect on the maximum interface pressure or maximum interface stress at cracking, though thicker concrete rings produced slightly higher interface pressures and stresses (Hossain and Weiss 2006; Nguyen et al. 2010). In other words, at any given age thicker concrete specimens had higher stresses at the interface than thinner specimens. Also, it was found that the rate of increase or general trend of interface pressure and stress over time were not significantly influenced by the concrete thickness; however, the age of cracking occurred earlier with thinner concrete rings (Hossain and Weiss 2006; Nguyen et al. 2010). The earlier age to cracking was attributed to the fact that thinner specimens are more sensitive to small initial cracking than thicker specimens, causing them to crack at lower stress levels (Hossain and Weiss 2006). Only concrete annulus thicknesses of 1.5, 3, 4.5, and 6 in. were included in these analyses, so the influence of concrete thicknesses below $1.5 \mathrm{in}$. is not directly known. Because the maximum interface pressure and stress and the rate of increased interface stress over time were not significantly influenced by concrete thickness, the shrinkage stresses of the 3 in. thick rings was used for all overlay thicknesses. Also, the rate of shrinkage stress through the concrete depth remained constant for all overlay thickness.

\subsection{Analytical Models}

The finite element method was used as the primary basis for optimizing the UHPC overlay thickness. Two model scenarios were used to evaluate the state of stress at the interface between a UHPC overlay and a concrete bridge deck. The first model scenario evaluated a basic plate with variable boundary constraints intended to represent the deck 
region between girders in a slab-girder bridge system, while the second scenario evaluated the system response of a full bridge structure. This staged approach proved to be more computationally cost-effective due to the complexity of modeling a complete bridge. For both model scenarios, the objective was to assess the state of stress parametrically as the geometric and material characteristics varied. Specifically the interlaminar shear stress between the UHPC overlay and NSC bridge deck were of interest, as was the maximum tensile principal stress perpendicular to the bond interface, which would cause debonding of the materials. Additionally, the tensile stress in the UHPC overlay which would cause cracking was investigated.
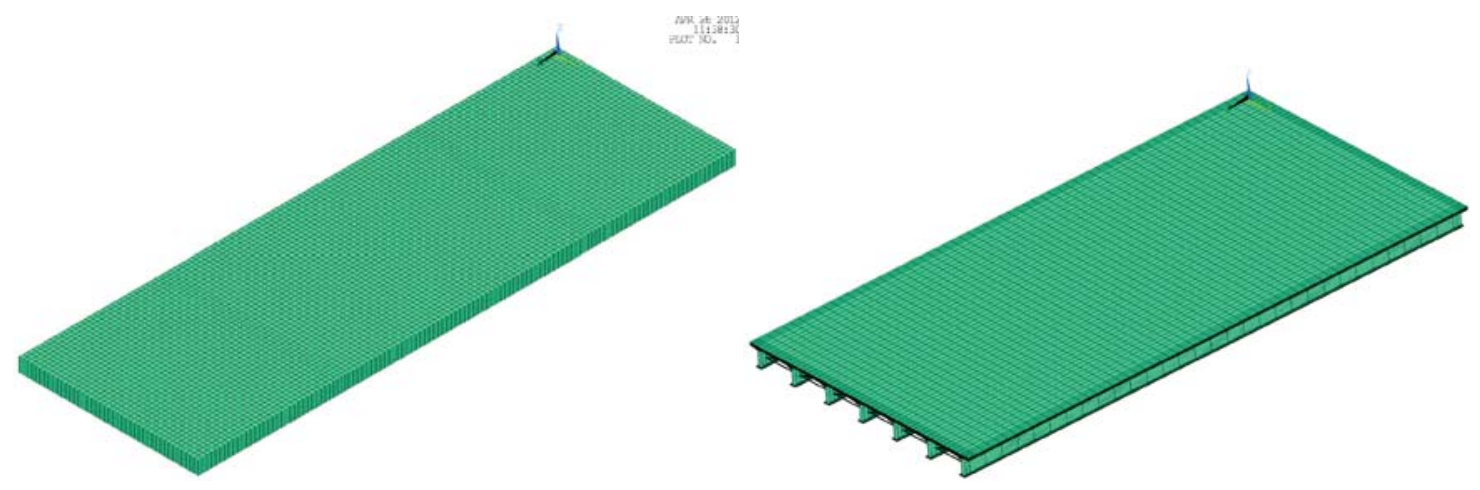

Figure 3.14: Plate and S11 Bridge FEM

All models were created using ANSYS 12.0 (2011) with the following assumptions:

- Perfect bond between the normal strength concrete deck and UHPC overlay

- Perfect bond between fibers and matrix

- Linear-elastic materials

- No cracking occurred in substrate

\subsubsection{Scenario 1 - Plate Model}

A plate model representing the interior region between girders was created to evaluate the variation of the interfacial stress under a variety of loading scenarios based on the HL-93 design truck configuration (2010).

\subsubsection{Element Selection}

Several elements were considered for the bridge deck and overlay, including the SHELL63, SHELL181, SHELL281, SOLSH190, SOLID65, and SOLID168. The main considerations in element selection were the elements intended purpose, ability to represent layers, boundary conditions, and computational cost. The number of integration points through the depth of shell elements is important for accurate stress analysis, as the stress at a shell layer surface is determined from the outermost integration 
points, not necessarily on the layer surface indicated by the "top" and "bottom" output labels in the ANSYS postprocessor (ANSYS 2011). They are also important in calculating bending moments and in-plane forces. A minimum of two integration points are recommended for linear elastic materials, because extrapolation can be used to calculate the surface stresses (ANSYS 2011). ANSYS suggests using four to five integration points for non linear materials in order to reduce calculation errors between the outermost integration point and the shell surface. When three integration points are included in a linear elastic material layer, the top and bottom integration points are located on the top and bottom surfaces. Therefore, three integration points were used in each shell layer.

Table 3.4 summarizes these elements. Solid elements were not considered due to their high computational cost, owning to more elements required through the thickness and more complex numerical equations behind the element theory, which results in longer computational durations (Szilard 2004; ANSYS 2011). The SOLSH190 element was considered for its ability to simulate shell structures with a wide range of thicknesses and its ease to be connected to both shell and solid elements. However, the accuracy of the SOLSH190 element was the same as the SHELL elements at a higher computational cost.

Because the UHPC layer was expected to be thin, it was important to consider the ratio of the bridge deck and overlay height (h) to its characteristic length (L) in order to determine if its behavior represented thin, moderately thick, or thick plates. The actual plate behavior is modeled by appropriate plate or shell theories, which differ in how transverse shear are considered and the validity of element assumptions.

If the deck thickness is less than 1/15 (.067) - 1/30 (.033) of the characteristic length, the deck will behave as a thin plate and classical plate theory is suitable (Szilard 2004). Classical plate theory is based on the assumption that plane sections remain plane before and after loading, resulting in a linear strain distribution through the depth of the section. However, the deck is referred to as moderately thick when $\mathrm{h} / \mathrm{L}>1 / 10(0.1)-1 / 5(0.2)$ (Szilard 2004). In this case, Mindlin-Reissner shell theory, also called first order shear deformation theory, is appropriate (ANSYS 2011). Mindlin-Reissner theory assumes that any straight line that is normal to the mid-surface prior to deformation is assumed to remain straight, but does not remain perpendicular after deformation. If this $\mathrm{h} / \mathrm{L}$ ratio $>>$ $1 / 5$, the plate is referred to as a thick plate, where the behavior requires that all threedimensional elasticity equations are applied to determine the proper three-dimensional distribution of stresses in the plate (Szilard 2004).

The thicknesses of UHPC overlay considered in this study have thickness to length ratios of 0.08-0.15. Therefore, Mindlin-Reissner was found to be appropriate and all traditional shell elements based on classical plate theory discarded. The SOLSH190 element is primarily used in applications where a shell element shares nodes with a solid element, as it provides the same DOF as a solid element while accurately modeling shell and plate behavior. It is also a relatively new element compared to the others considered for this analysis. Due to the lack of modeler experience with this element, the SOLSH190 
element was excluded. Higher degree elements provide higher element accuracy due to the added mid-side nodes (Szilard 2004); therefore, the final decision was made to use the SHELL281 element over the SHELL181.

The number of integration points through the depth of shell elements is important for accurate stress analysis, as the stress at a shell layer surface is determined from the outermost integration points, not necessarily on the layer surface indicated by the "top" and "bottom" output labels in the ANSYS postprocessor (ANSYS 2011). They are also important in calculating bending moments and in-plane forces. A minimum of two integration points are recommended for linear elastic materials, because extrapolation can be used to calculate the surface stresses (ANSYS 2011). ANSYS suggests using four to five integration points for non linear materials in order to reduce calculation errors between the outermost integration point and the shell surface. When three integration points are included in a linear elastic material layer, the top and bottom integration points are located on the top and bottom surfaces. Therefore, three integration points were used in each shell layer.

Table 3.4

Summary of considered deck elements

\begin{tabular}{lcccccc}
\hline Element & SHELL63 & SHELL181 & SHELL281 & SOLSH190 & SOLID45 & SOLID186 \\
\hline $\begin{array}{l}\text { Plate } \\
\text { Type }\end{array}$ & Thin & $\begin{array}{c}\text { Thin to } \\
\text { mod. Thick }\end{array}$ & $\begin{array}{c}\text { Thin to } \\
\text { mod. Thick }\end{array}$ & $\begin{array}{c}\text { Thin to } \\
\text { mod. Thick }\end{array}$ & Thick & Thick \\
$\begin{array}{l}\text { Nodes } \\
\text { Mid- } \\
\text { side }\end{array}$ & 4 & 4 & 8 & 8 & 8 & 20 \\
$\begin{array}{l}\text { Nodes } \\
\text { Layered } \\
\text { Element }\end{array}$ & No & No & Yes & No & No & Yes \\
$\begin{array}{l}\text { Plate } \\
\text { Theory }\end{array}$ & Classical & $\begin{array}{l}\text { Mindlin- } \\
\text { Reisnner }\end{array}$ & $\begin{array}{c}\text { Mindlin- } \\
\text { Reisnner }\end{array}$ & $\begin{array}{c}\text { Mindlin- } \\
\text { Reisnner }\end{array}$ & N/A & N/A \\
DOF & 6 & 6 & 6 & 3 & Yes & Yes \\
\hline
\end{tabular}

A sensitivity analysis for the plate model, outlined in Section 3.2.1.4, was conducted to select the appropriate mesh size and density.

\subsubsection{Boundary Conditions}

For all of the plate models, the end restraints were assigned simple support conditions, similar to what would be observed in a simple span bridge (see Figure 3.18 - Figure 3.22), whereas the edges labeled "girder supports" were evaluated under both simple and fully restrained conditions in order to bound the global system response. To prevent the longitudinal boundary conditions from influencing the transverse behavior, an aspect ratio of 1:3 (width:span) was used in all plate models (Timoshenko and Woinowksy- 
Krieger 1959). The models with simple girder supports serve as a lower bound on the interfacial stresses, as this configuration will be the most flexible. The fully restrained girder supports model the upper bound of the true response by assuming that the in-plane and rotational restraint provided by the deck continuity and supports respectively, are infinite. Of course, in reality the true degree of restraint is somewhere between these two scenarios.

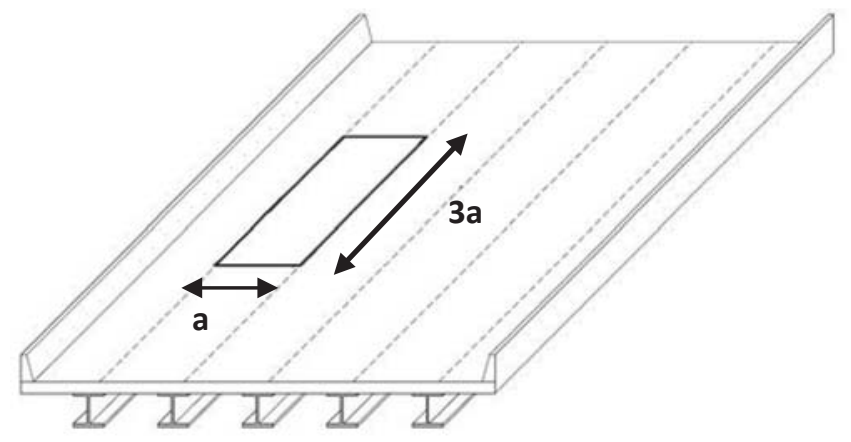

Figure 3.15: Simplified Plate Model Boundary Conditions

\subsubsection{Design Truck Load}

In addition to the restraint conditions, loading configurations were varied to determine the design loads and wheel pattern position that caused peak stress conditions. To assess the representative behavior and compatibility of the composite system, notional truck and tandem loads were applied to the FEM. The HS-20 design truck and design tandem from the HL-93 design loads were chosen to represent these notional loads. Design lane load was not included in the FEM, in addition to multiple presence of vehicle, no load factors were applied, and no impact factors were considered. The loading on this FEM is not intended for design, but for analysis of system behavior under a typical truck load.

Figure 3.16 displays the loading and spacing of the HS-20 notional load, while Figure 3.17 illustrates that of the notional design tandem. Both the HS-20 and design tandem have $6 \mathrm{ft}$ wheel spacing. To increase the loads on both the simplified plate model and the full bridge model, the rear axles were spaced at the closer $14 \mathrm{ft}$ distance. The wheel load(s) of the HS-20 design truck and design tandem were applied to the plate as a uniform pressure distributed over a patch area of 10 in x 20 in (AASHTO 2010). The various wheel patterns analyzed in the simplified plate model are shown in Figure 3.18 Figure 3.22 and are referred to as loading configurations Case A-E in later analysis. 


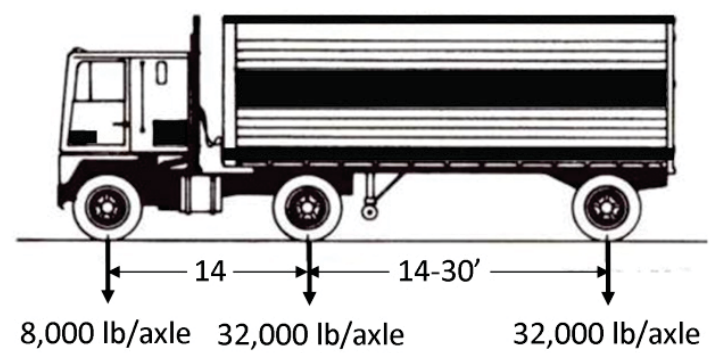

Figure 3.16: HS-20 design truck

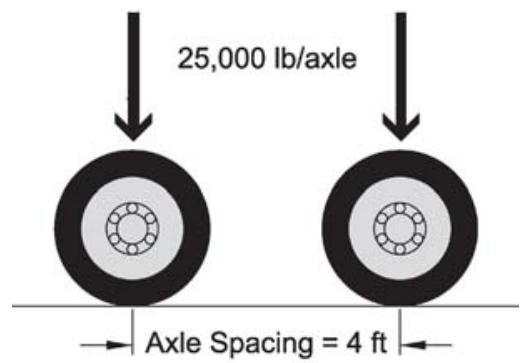

Figure 3.17: Tandem notional design loading

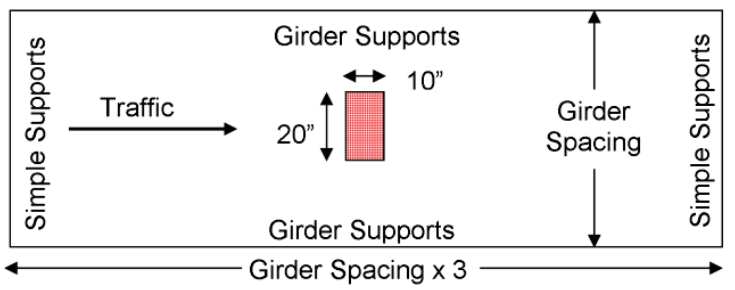

Figure 3.18: Case A - single tire of HS-20

Girder Supports

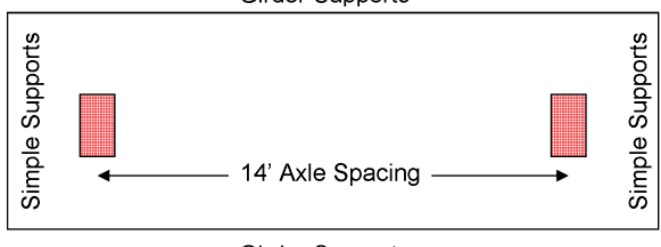

Girder Supports

Figure 3.19: Case B - wheels from one side of HS-20 


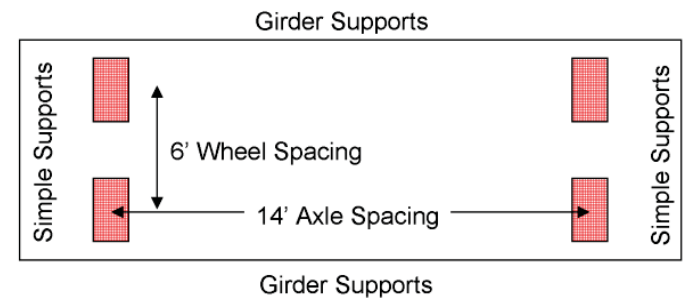

Figure 3.20: Case C - middle and rear axles of HS-20

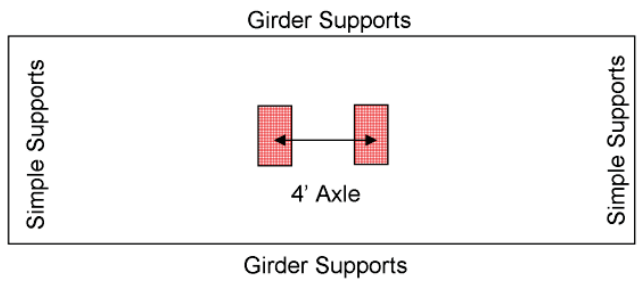

Figure 3.21: Case D - half of design tandem

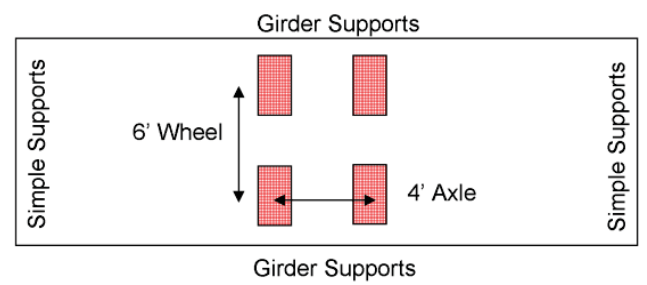

Figure 3.22: Case E - design tandem

\subsubsection{Validation of Plate Model}

Several methods were used for validation of the plate model. The maximum deflection and stress results for square plate models of varying boundary conditions were compared to known values of Mindlin-Reissner moderately thick plates. Example problems for this validation were chosen from various texts (Timoshenko and Woinowksy-Krieger 1959; Ugural 1981; Cook et al. 2001; Szilard 2004). It was found that multiple layers were needed through the shell thickness to obtain satisfactory results, in addition to multiple integration points through each shell layer (ANSYS 2011). Once the square plate models were validated, multiple shell layers with constant material properties were introduced and the solutions were checked again.

The accuracy of the SHELL281 element and post processing were further validated through the execution of ANSYS Verification Manual problems, which had similar loading or geometric configurations as the models considered in this analysis. ANSYS Verification Manual (VM) Problem 78 uses a SHELL281 element to find the transverse 
shear stresses in a layered cantilever beam with an applied load at its free end. The SHELL281 element resulted in a 1.000 accuracy ratio between the FEM result and the known solution. VM Problem 144 compares stress and deflection results of the SHELL281, 8-node SOLID185, 20-node SOLID186, and SOLSH190 elements. In this example, a composite cantilevered beam had an applied bending moment and was exposed to a significant thermal change. The SHELL185 element was found to be most accurate with a 1.000 accuracy ratio, while all other elements had a 1.00 accuracy ratio. VM Problem 82 determines the maximum deflection of a simply supported, thin, laminated plate model. The results of various elements were compared, including the SOLSH190, SOLID185, SOLID186, SHELL181, and SHELL281. The SOLID185 was found to be most accurate with a 1.000 accuracy ratio, while the SOLID186 was least accurate at 0.991. The SOLSH190 element produced an accuracy ratio of 0.996. The shell elements scored slightly better than the SOLSH element with 0.997 and 1.003 for the SHELL181 and SHELL281, respectively. It should be noted that the mesh used in this VM was relatively large. These verification manuals built confidence in the element, layering, meshing, multiple point integration through layer thicknesses, and post processing of data.

The plate model was then modified to represent a rectangular deck section between bridge girders with appropriate UHPC and NSC material properties. To ensure the accuracy of this final model, the element mesh size was analyzed to determine the point at which deflection and stress values converged. This mesh analysis is shown in Figure 3.23 for a plate with simple supports to represent bridge deck girders, slab thickness of 8 in., overlay thickness of 1 in., UHPC $\mathrm{f}^{\prime}{ }_{\mathrm{c}}$ of $17 \mathrm{ksi}, 3 \mathrm{ksi} \mathrm{f}^{\prime}{ }_{\mathrm{c}}$ of $\mathrm{NSC}\left(\mathrm{E}_{\mathrm{o}} / \mathrm{E}_{\mathrm{d}}=2.3\right)$, and load case $\mathrm{C}$. It can be seen that the maximum deflection (not the deflection at a given coordinate) converges to $0.01835 \mathrm{in}$. at a quadrilateral-shaped mesh size of 6 in. $\mathrm{x} 6$ in. Due to slight variation of the results when mesh size was further reduced, a final mesh size of 3 in. $x 3$ in. was used for all models. The waved variation in the maximum deflection with change in mesh size is due to the load case applied and how the nodal mesh aligned with the point of maximum deflection. As load case $\mathrm{C}$ was one of the heavier and more advanced configurations, it was important to determine the point of convergence for this case over the lighter, less complex cases. Normal stresses in the $\mathrm{x}-$ and y-direction and principal stresses were also monitored during this mesh validation and analysis was also conducted on simply supported plates, but only the deflection results for one load case is presented here. Additionally, it is important to note that the total deflection variation shown this figure is only 0.00029 inches. It was found that 1 in. thick layers produced converging results at this mesh size. 


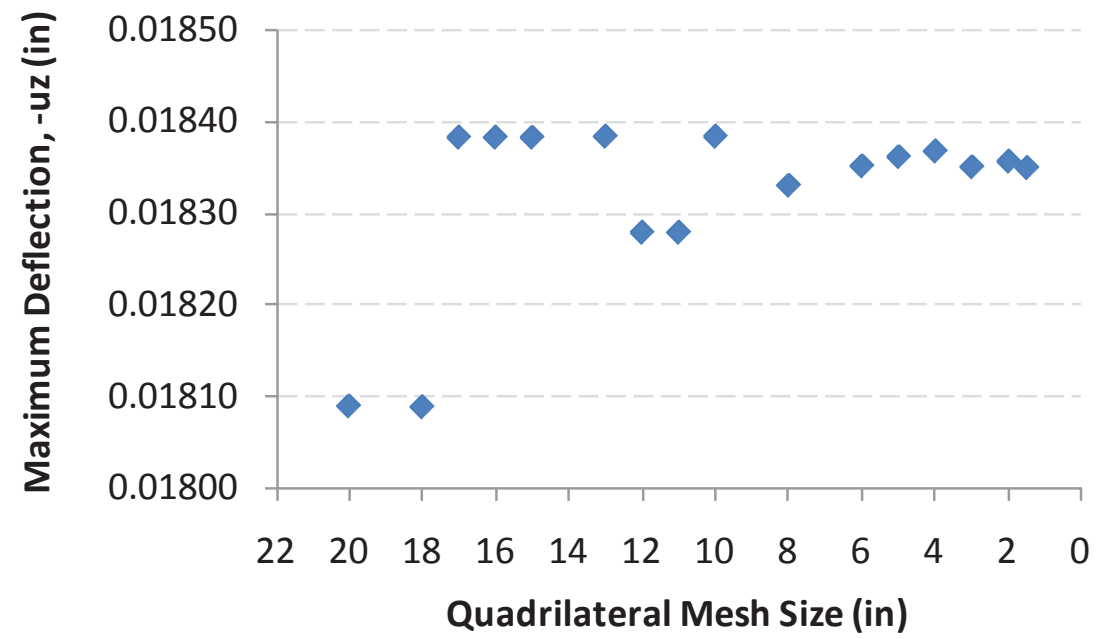

Figure 3.23: Mesh validation

\subsubsection{Tested Parameters}

The main purpose of these finite element models was to look at discrete ages representative of early and in service behavior and determine the overall compatibility of the system at that age. The other main purpose was to optimize the overlay thickness to reduce dead load and material cost.

The plate response was evaluated parametrically by changing features of the design, including overlay and slab thickness, material stiffness, girder spacing, and restraint conditions. A summary of the parameters considered are presented in Table 3.5 and material properties used in this analysis are shown in Table 3.6 with the justification for parameter selection highlighted below.

Overlay thicknesses $\left(t_{0}\right)$ ranging from $1 / 4$ in. to 2 in. were selected to determine the optimum thicknesses of UHPC for this application that maintained the compatibility of the overlay-deck system while reducing material quantity, dead load, and initial cost. It is understood that challenges may arise regarding the constructability of extremely thin UHPC toppings, but the intent was to consider the application of UHPC as a thin bonded overlay from a mechanical aspect. Possible constructability issues are discussed briefly in the Section 6.1 of Chapter 6 - Future Work.

Bridge deck thicknesses ( $\mathrm{t}_{\mathrm{d}}$ ) of 6, 8, and $10 \mathrm{in}$. and 6, 8, and $10 \mathrm{ft}$ spacing between girders $\left(\mathrm{s}_{\mathrm{g}}\right)$ were considered in this parametric study based on common transportation department use. The effect of slab strength of $3 \mathrm{ksi}$ and $5 \mathrm{ksi}$ was also considered in this parametric model. These strengths are represented in the model by 3122 and 4030 ksi elastic moduli, respectively. 
Table 3.5

Optimized parameters

\begin{tabular}{lcccccccc}
\hline $\mathrm{t}_{\mathrm{o}}$ (in) & 0.25 & 0.50 & 0.75 & 1.00 & 2.00 & & & \\
$\mathrm{t}_{\mathrm{d}}(\mathrm{in})$ & 6.0 & 8.0 & 10.0 & & & & & \\
$\mathrm{~s}_{\mathrm{g}}(\mathrm{ft})$ & 6 & 8 & 10 & & & & & \\
Girder & Simple & Fixed & & & & & & \\
Support & 1.1 & 1.2 & 1.5 & 1.6 & 1.7 & 1.8 & 2.2 & 2.3 \\
$\mathrm{E}_{\mathrm{o}} / \mathrm{E}_{\mathrm{d}}$ & 1.1 & & & & & & \\
\hline
\end{tabular}

Table 3.6

Material properties

\begin{tabular}{lccc}
\hline & & UHPC & NSC \\
\hline Modulus of Elasticity (E) & ksi & $4.4-7.2$ & $3.1-4.0$ \\
Poisson Ratio (v) & - & 0.21 & $0.15-0.20$ \\
\hline
\end{tabular}

The edge supports where the deck would be supported by longitudinal girders were modeled as simple supports and as fixed supports. Again, these support conditions were selected to represent the upper and lower limit of the global behavior. Further information regarding these support conditions can be found in Section 3.2.1.2.

Due to UHPC's time-dependent material properties, specifically shrinkage, strength gain, and elastic modulus, it was important to determine the compatibility of the UHPC overlay-NSC deck system at early ages when the overlay material is weak and shrinkage stresses are high, as well as at long-term ages when the full properties of UHPC have been developed. Accurate material modulus and Poisson ratio are vital components in obtaining an overall accurate finite element model, as they represent the building blocks of material behavior, such as a material's strength, stiffness, and ductility during analysis.

Poisson ratio of 0.15 and 0.20 were used for NSC were chosen for 3 and $5 \mathrm{ksi}$ compressive strength concrete, respectively (Kosmatka and Wilson 2011). Ahlborn et al. (2011) found a constant Poisson ratio of 0.21 for UHPC regardless of cure regime and age.

Time- and cure- dependent compressive strength and moduli were determined from available literature discussed in Section 2.6.4. A compressive strength $9.0 \mathrm{ksi}$ was used to represented the optimized cure duration and cure capabilities of a precast plant for UHPC between 12-14 hours of age. Averaged values between 36-60 hrs were considered in the $48 \mathrm{hr}$ ( 2 day) compressive strength for ambient cured UHPC, resulting in a $8.2 \mathrm{ksi}$ strength. This time range was considered in attempt to determine the earliest an owner could open traffic after a cast-in-place UHPC overlay was placed, while maintaining the integrity of the bonded system. A 28-day UHPC compressive strength of $21.3 \mathrm{ksi}$ was selected to represent the in-service strength of UHPC after undergoing a modified steam cure in a precast plant. The average ambient cured UHPC strength was approximately 
$20.6 \mathrm{ksi}$ a 28 -days of age, representing the in-service strength of a cast-in-place application of this composite system.

Relative moduli were then interpolated from the available experimental test results (Graybeal 2006a; Peuse 2008) and numerical relationships (see Equation 1), taking into account the variations between researchers and publications. Ratios were then determined which best represented the difference in stiffness between the composite materials at various ages of strength development. The interpolation of modulus values from past research is reasonable, because UHPC as a whole is not a standardized material and variation will occur between mixes. The objective of this FEM is to obtain a representative understanding of how cure regime and age effects the state of stress at the bond interface and determine whether the compatibility of the system is maintained.

It was initially intended to determine the early age strength gain of UHPC under the proposed modified steam cure in order to optimize the bed-turnover time in a precast facility. However, poor experimental results were found from compressive tests which underwent this cure regime, causing the test results to be neglected in this FEM analysis even though the findings were inconclusive (see Section 4.1.1).

\subsubsection{Scenario 2 - Bridge Model}

To further evaluate the behavior of UHPC as a thin bonded overlay, the findings from the plate model were incorportated into a model of a complete bridge system under HS-20 design truck loading. To eliminate the need for a full design, an existing $131 \mathrm{ft}$ bridge was used as the template for the analysis (Nowak and Eom 2001). The chosen bridge is MDOT owned and was built in 1972. The S11-25032 Bridge on Stantley Road spans over I-75 and is located in Flint, Michigan. Modeling a complete bridge model also allowed in the investigation of the compatvility of the proposed system under gloval behavior and the entire design truck loading. Lastly, the bridge model provided validation and comparision of global behavior to the simplified plate models used in Scenario 1.

Figure 3.24 shows the bridge cross section at the end of the bridge and at a typical bracing point. The cross-sectional view at the end of the bridge shows the lateral bracing and diaphragm as is presented on the left side of the figure, while the right side of the figure displays the cross-section at brace points. The S11 Bridge is a two lane bridge with $11 \mathrm{ft}$ shoulders on each side and a slight cross slope. Within the finite element model, the bridge cross slope was neglected, reducing the shoulder to $10 \mathrm{ft}-3 \mathrm{in}$. Girders are spaced at $7.24 \mathrm{ft}$ ( $87 \mathrm{in})$, the deck is 8 in thick, and there is a 27 in overhang. The bridge has three spans, but only the $131 \mathrm{ft}$. center span is included in this model, as multiple span structures were beyond the scope of this research. The bridge has no skew, has composite deck-slab system, and was constructed as a simply supported structure. Table 3.7 lists the actual dimensions and shapes of the girder, cross-bracing, and diaphragm members. Although the bridge barriers are shown in the figure below, they were not considered in analysis. 


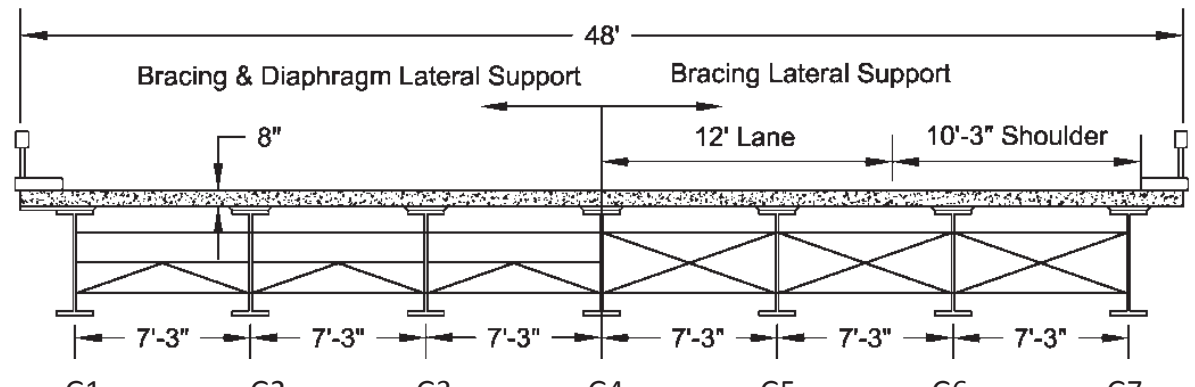

Figure 3.24: MDOT S11 Bridge over Stanley Rd.

Table 3.7

Bridge member details

\begin{tabular}{lll}
\hline Girder & Top Flange & PL 18" x 1-7/8" \\
& Web & PL 48" x $1 / 2 "$ \\
& Bottom Flange & PL $18 " \times 2-3 / 8 "$ \\
Cross-Bracing & & L $3-1 / 2 " \times 3-1 / 2 " \times$ x 3/8" \\
Diaphragm & & C $1.2 " \times 1.46 "$ \\
\hline
\end{tabular}

\subsubsection{Element Selection}

Similar to the plate model, the full bridge model used layered shell elements (SHELL281) to represent the concrete bridge deck and overlay. The girders and bracing members were modeled using 3-D, 2-node Timoshenko beam elements (BEAM188). The element has 6 DOFs per node, which include translations and rotations in the $\mathrm{x}, \mathrm{y}$, and $\mathrm{z}$ directions. The effects of shear deformation are also included in this element (ANSYS 2011).

Although the SHELL281 and BEAM188 have the same 6 DOF, ANSYS advises that beams should not be directly connected in the normal direction of shells. If this is done, the torsional moment of the torsional moment of the beam will be transferred to a very small torsional stiffness of the shell. Numerical difficulties will arise in the form of small pivots and the accuracy of results has decreased (ANSYS 2011). Therefore, composite action introduced with the multi-point constraint element MPC184 between the deck and girders.

\subsubsection{Validation of the Base Global Bridge Model}

To eliminate the need for a complete bridge design, the existing MDOT S11 - Bridge over Stanley Road was used the basis of the global bridge finite element model. This particular bridge was chosen due to the field load testing conducted in August 2000. Full details of the bridge and on-site tests are described in PROJECT 2000-0341 DIR report conducted by University of Michigan for submission to the Michigan DOT (Nowak and 
Eom 2001). This experimental data allowed validation of the bridge model through the comparison of girder strains at the bottom girder flanges at midspan.

Two 11-axle trucks were used in the field study, one with a gross weight of 148,374 lbs labeled "Truck A" and the other with a gross weight of 147,699 lbs referred to as Truck B. The configurations of these trucks are shown in Figure 3.25 and Figure 3.26. Two of the field static load cases were used for this model validation. One load case positioned Truck $A$ in the center of one lane at the bridge midspan (see Figure 3.24). This load case caused Girder 2 and 3 to carry most of the load. The second load case positioned both Truck A and Truck B on the bridge, each in the center of opposing lanes. The S11 bridge does contain a cross-slope for drainage, as well as curbs and parapets which would contribute some structural stiffness to the bridge. These features were not included in the FEM, as there was no information provided concerning their composite behavior, so their structural contribution was unknown. Depending on the connection details and construction methods, some structural contribution could be provided by these components and absence of their inclusion would induce inaccuracy between the field and FEM results. The span ends were modeled as simple and fixed supports in an effort to bound the global response of the actual bridge.

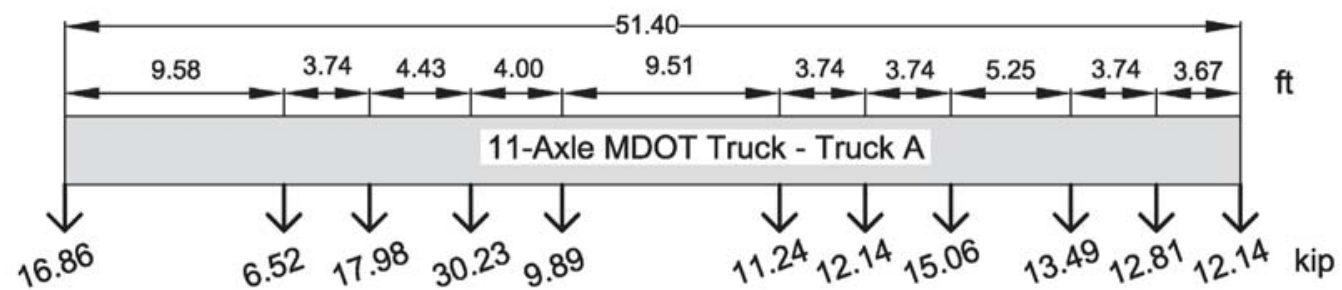

Figure 3.25: Truck A used in MDOT loading of S11 Bridge

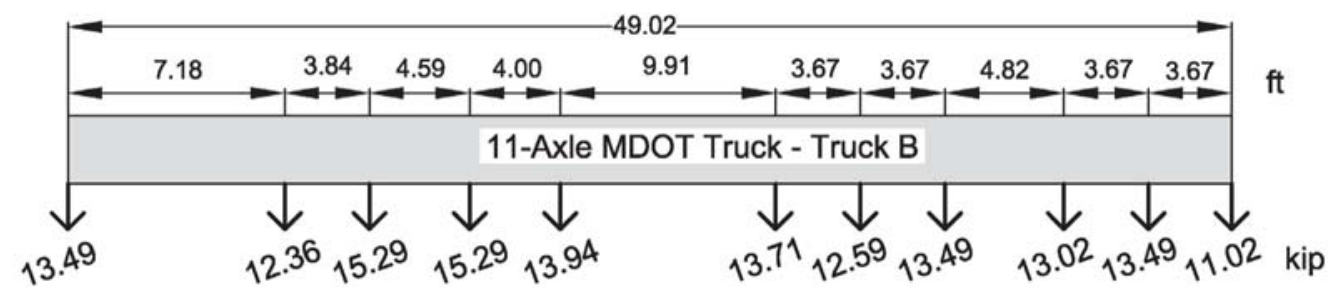

Figure 3.26: Truck B used in MDOT loading of S11 Bridge

The following figures (Figure 3.27-Figure 3.28) compare the MDOT strain measurements from field tests with FEM strains of the bottom flanges at midspan for both end support bounds. The general distribution of girder strain from FEMs showed good agreement with those measured in the field tests. It can be seen that the pin-pin and pin-roller FEM supports of the S11 Bridge adequately bound the actual bridge response. No attempt was made to refine restraint conditions, as the original research did, to match test results. For 
these reasons, the FEM of the S11 Bridge was found to be satisfactory and were deemed acceptable for the parametric investigation of UHPC as an overlay.

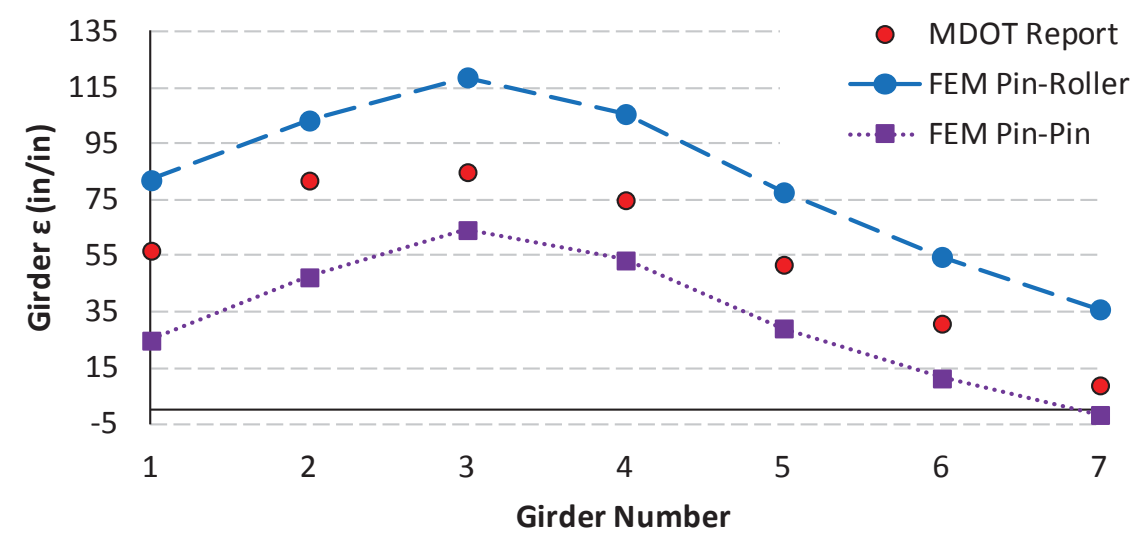

Figure 3.27: Girder strain - one truck in one lane

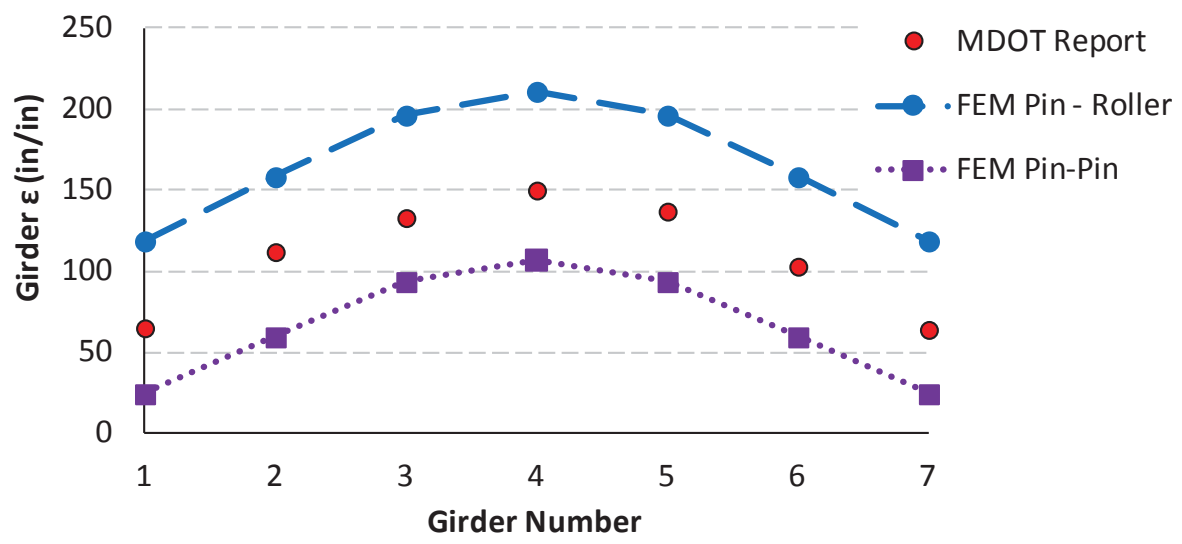

Figure 3.28: Girder strain - both trucks on bridge

\subsubsection{Boundary Conditions}

Variations in the design, including overlay thickness and strength (Table 3.5), were evaluated parametrically to assess the interfacial stresses; however, no variations in the base bridge design were considered. Specifically, the girder spacing was not modified from the original model. A summary of the material properties used in the model are presented in Table 3.6.

The boundary conditions for each model were assumed to be simple supports located at the bottom of the girders. Rigid links (MPC184 elements) connected the BEAM188 elements to dummy nodes located at the bottom of the girders. This configuration was 
drawn from (Chung and Sotelino 2006)'s eccentric beam idealizations, which have been used by several other researchers (Chan and Chan 1999; Barr et al. 2001; Harris 2007).

\subsubsection{Design Truck Loading}

HL-93 design truck (HS-20) and design tandem were applied to the full bridge model to analyze the global system behavior under notional design loading. Images of these notional loads can be found in Section 3.2.1.3. Both vehicle loads were placed in the center of one lane and directly in the center of the bridge. The state of stress at the bond interface when the truck load was placed on the shoulder of the bridge deck was not considered.

\subsubsection{Overlay Parameters}

Overlay thickness and UHPC stiffness (see Table 3.8) were evaluated parametrically to assess the interfacial stresses. No variations in the base bridge design were considered, as this would cause a need for a bridge re-design. The S11 Bridge has $3 \mathrm{ksi}$ deck concrete. As in the plate models, various overlay thicknesses were analyzed to minimize the dead load applied to the structure while ensuring the integrity of the bond interface and compatibility of the composite system. Numerous stiffness ratios were considered in order to mimic early-age and in-service UHPC under AMC and MSC regimes. Additional information regarding the selection of these parameters can be found in Section 3.2.1.5.

Table 3.8

Tested parameters for bridge model

\begin{tabular}{lccccc}
\hline $\mathbf{t}_{\mathbf{0}}$ (in) & 0.25 & 0.5 & 0.75 & 1 & 2 \\
$\mathbf{E}_{\mathbf{0}} / \mathbf{E}_{\mathbf{d}}$ & 1.5 & 1.6 & 2.2 & 2.3 & \\
\hline
\end{tabular}

\subsection{Summary of Methodology}

The experimental and numerical models discussed in this section were selected to analyze the state of stress of a thin-bonded UHPC overlay to a concrete bridge deck. The restrained shrinkage tests provide information regarding the tensile and shear stresses that develop in a restrained system due to combined shrinkage and creep relaxation effects. The numerical FEMs investigated the same stresses, in addition to debonding stresses, of the UHPC overlay-NSC system due to notional design truck loads. The stresses present from both of these factors can then be superimposed and compared the bond and tensile strengths determined from available literature. This comparison is then used to establish the compatibility of the system at various UHPC ages, UHPC thicknesses, and deck thicknesses. 


\section{Results}

Presented in this section are the results from the early-age compression tests, restrained shrinkage, and parametric finite element models. The results from the restrained shrinkage tests were then superimposed onto the finite element results to determine the full compatibility of the UHPC overlay-NSC deck system under restrained shrinkage and notional truck loading for various overlay thicknesses and cure durations.

\subsection{Experimental Results}

The following sections contain the results from ASTM C39-12 compression tests and AASHTO PP34-99 restrained shrinkage tests.

\subsubsection{Early Age Compression Strength}

The results from early-age compressive strength test results for specimens under ambient cure treatment are presented in Table 4.1 and Figure 4.1. Compressive strengths for the specimens that underwent the modified steam cure (MSC) are listed in Table 4.2. Additional details regarding these compression tests can be found in Appendix B.

Table 4.1

Ambient cure compression test results

\begin{tabular}{cccc}
\hline Specimen & Age (days) & Age (hrs) & f' $_{\mathbf{c}}(\mathbf{k s i})$ \\
\hline AMC_1_A & 1.38 & 33 & 0.67 \\
AMC_1_B & 1.46 & 35 & 0.71 \\
AMC_1_C & 1.75 & 42 & 5.58 \\
AMC_1_D & 1.88 & 45 & 6.18 \\
AMC_2_A & 2.00 & 48 & 3.13 \\
AMC_2_B & 2.00 & 48 & 3.46 \\
AMC_2_C & 2.22 & 53.25 & 8.36 \\
AMC_2_D & 2.29 & 55 & 8.59 \\
AMC_2_E & 2.42 & 58 & 9.64 \\
AMC_1_E & 28 & - & 19.02 \\
AMC_1_F & 28 & - & 21.73 \\
AMC_2_F & 28 & - & 21.45 \\
AMC_2_G & 28 & - & 19.85 \\
\hline
\end{tabular}




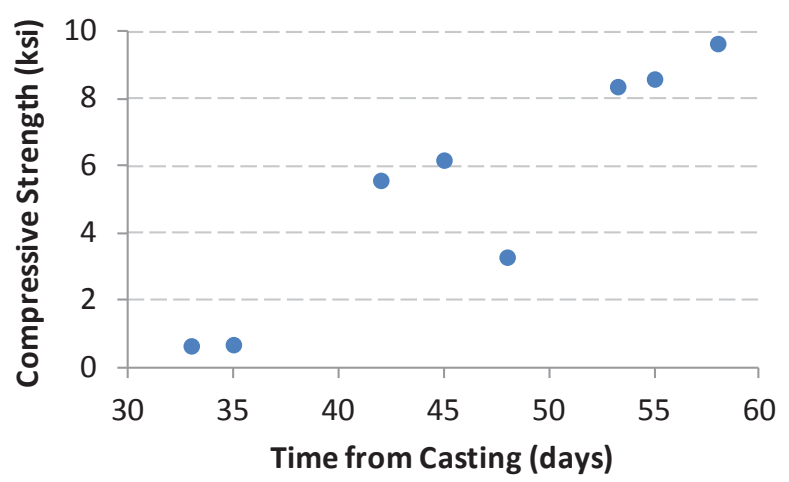

Figure 4.1: Ambient cure compressive strength test results

Table 4.2

Modified steam cure compression test results

\begin{tabular}{ccc}
\hline Specimen & Age (days) & f $_{\mathbf{c}}$ (ksi) \\
\hline MSC_3_A & 7 & 9.37 \\
MSC_3_B & 7 & 10.46 \\
MSC_3_C & 7 & 10.81 \\
MSC_5_A & 7 & 6.78 \\
MSC_5_B & 7 & 8.49 \\
MSC_5_C & 7 & 6.75 \\
\hline
\end{tabular}

From the ambient test specimens (AMC), it can be seen that UHPC is still green before 36 hours. By 42 hours of age, the strength of test specimens had drastically increased, though the results are lower than what was found in other literature (Graybeal 2006a; Nyland 2009; Flietstra 2010). After 28 days, compressive strengths are more in-line with literature (Graybeal 2007; Peuse 2008), showing good quality control between lab facilities, researchers, and time between research studies. The low early-age results could be attributed to late batching or inadequate mixing, but most likely it is due to differences cure conditions and/or mold preparation. Samples were difficult to remove from their molds, indicating inadequate greasing during mold preparation. In addition, the relative humidity at room temperature in the lab facilities was difficult to maintain during the week the first two batches were cast (see Appendix A). Laboratory relative humidity in this week ranged from $18 \%$ to $78 \%$. Actions were taken after the first two batches to stabilize the relative humidity $(\mathrm{RH})$ in the lab facilities, which averaged at $52 \%$ for the remaining test duration. 
The results of the MSC quality control specimens were much lower than expected. Physically, specimens were a much darker grey than all other UHPC specimens cast. The exterior layer of mortar was very brittle and flaked off when touched. Mortar beneath this outer crusted layer was not hydrated and fibers were not bonded. Additionally, the samples were very porous near mold slot opening, so inadequate vibration may be the cause of the poor results. Furthermore, demolding was found to be difficult, which is attributed to poor quality of greasing molds. This insufficient mold preparation could be the cause of these drastically low test results. Although batch quality could be another cause for concern, this is thought to be unlikely due to the fact that ambient cure batches were mixed on the same day and near the same time. Also, the same researchers conducted all six batches included in this study, as well as numerous batches for other researchers in the same university. Lastly, the coloring of the ring specimens from the same batches and cure regimes were the lighter grey found in all other UHPC specimens. Another possible cause for these poor test results could be that a lower limit has been reached for which steam treatment is beneficial. Twelve hours of steam treatment may not be enough to properly hydrate the UHPC material and the detrimental effects could be due to early removal. However, this also seems unlikely, as tests conducted by Flietstra involved removing specimens at 12 hours of the same cure temperature and RH (Flietstra 2010). In these tests, the dark coloring was not mentioned and low compressive strengths were not found. No further research was conducted to support any of these possibilities, so the actual cause is unknown.

Due to the inconclusiveness of these test results, further early-age compression tests under the MSC were not conducted. As material compressive strength in finite element analysis is represented as the compressive modulus of elasticity, previous research of early-age compressive strength gain using a pre-steam cure $\left(140^{\circ} \mathrm{F}, 95 \% \mathrm{RH}, 14 \mathrm{hrs}\right)$ was substituted for the MSC in the finite element models (see Section 3.2.1.5).

\subsubsection{Restrained Shrinkage}

Presented in this section are the results from the AASHTO PP34-99 "Standard Practice for Estimating the Cracking Tendency of Concrete" (AASHTO PP-34-99). The purpose of this test was to determine the approximate state of stress at the bond interface and compare it to the material and bond strength. This stress is due to combined autogenous and drying shrinkage and tensile creep relaxation.

Two ring specimens were cast for each cure regime, as shown in Table 4.3. Each specimen had four strain gages attached at quarter points (one per quadrant) on the interior steel ring midway up the height (see Figure 3.5 and Figure 3.6). 
Table 4.3

\begin{tabular}{ccc} 
Ring specimen mix and steam details \\
\hline Ring & Mix & $\begin{array}{c}\text { Cure } \\
\text { Regime }\end{array}$ \\
\hline $\mathbf{1}$ & 4 & AMC \\
$\mathbf{2}$ & 3 & MSC \\
$\mathbf{3}$ & 6 & AMC \\
$\mathbf{4}$ & 5 & MSC \\
\hline
\end{tabular}

During the gage installation process Gage D on Ring 2 failed and was not replaced. The AASHTO PP 34 specification states that all four strain gages per ring should be averaged together. Since the one gage was not collecting data, it was decided to average opposing strain gages first and then average the two opposing sets of data to obtain the total ring strain. For Ring 2, the working opposing gages were averaged and then averaged with the single working gage.

The data acquisition system was zeroed a temperature of $65^{\circ} \mathrm{F}, 30$ minutes prior to the casting of the first ring. All specimen readings were corrected for changes in laboratory temperature per gage manufacturer instructions. Figure 4.2 illustrates the steel ring strain for the duration of the test. Rings 3 and 4 were cast a week after Ring 1 and 2, so the duration of test varies between specimens with the minimum time being 28 days.

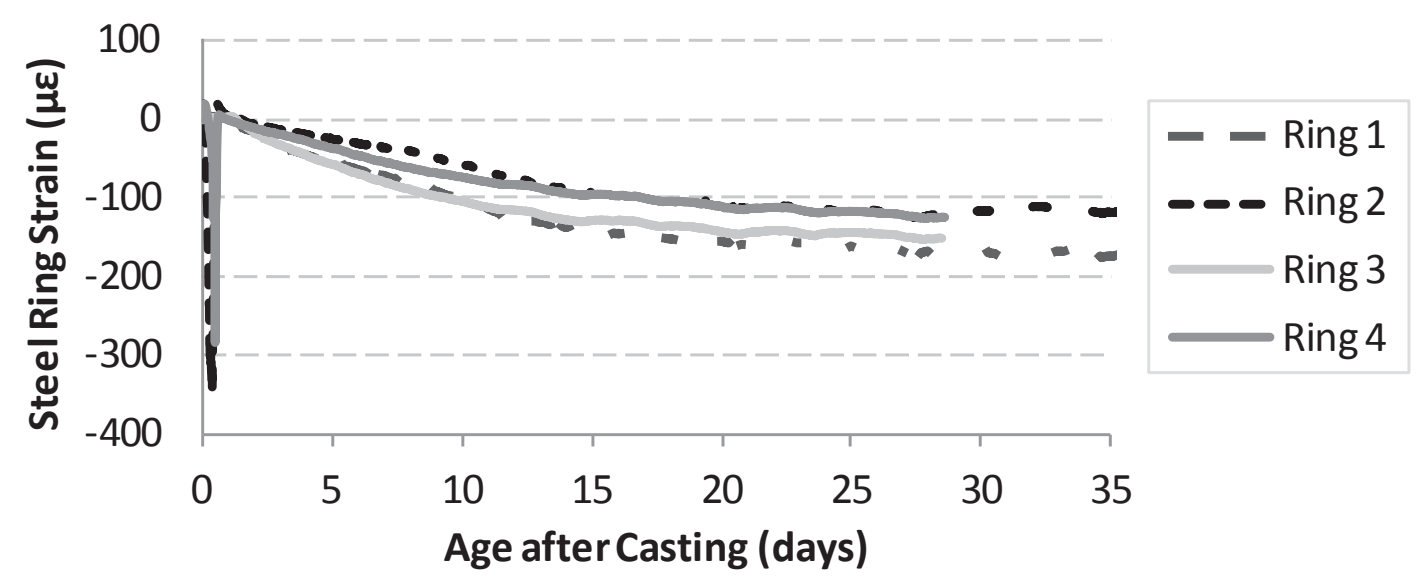

Figure 4.2: Measured strain in steel ring

From Figure 4.3 it can be seen that MSC specimens (Ring 2 and 4) experienced significant movement during cure. This is thought to be caused by thermal gradients in the steel ring due to the insulation provided by the green UHPC. When cylindrical metal objects have thermal gradients through the thickness, compression occurs at the higher temperature surface and tension on the cooler surface (Young and Budynas 2002).

Further investigation into this spike in measured strains was not conducted, as the general behavior corresponds to the theoretical heat transfer and thermal behavior of a metal cylinder when thermal gradients are present. 


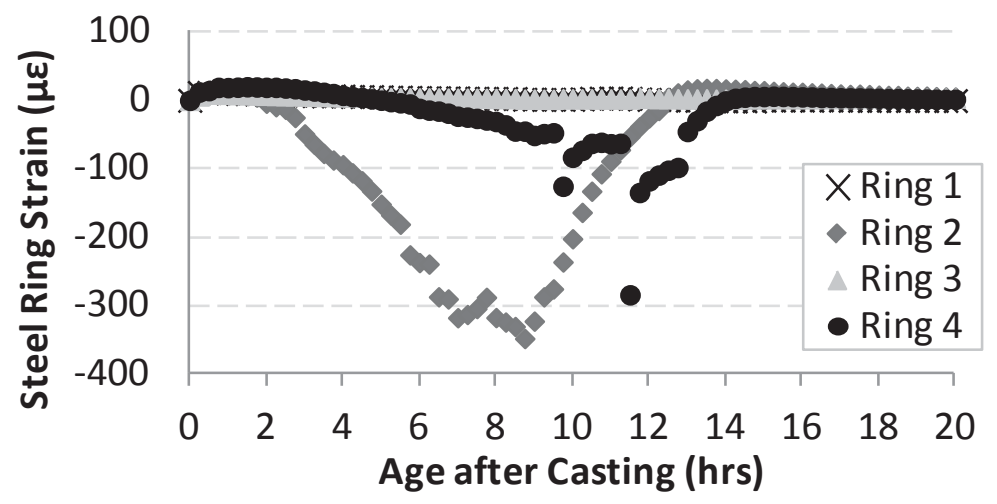

Figure 4.3: Steel ring strain resulting from MSC

The difference between the time and severity of the measured Ring 2 and 4 steel strain is attributed to differences in the ramp up time of the MSC. Prior to the start of a cure regime, the cure chamber was brought to $140^{\circ} \mathrm{F}$ and $95 \% \mathrm{RH}$. However, some heat and RH was lost when the door was opened to place specimens in the chamber. During the MSC for Ring 2, the cure chamber took 30 minutes to ramp up to the correct levels, while this took $1 \mathrm{hr}$ during the Ring $4 \mathrm{MSC}$. Although the exact cause has not been thoroughly investigated, peaks occur exactly $1 \mathrm{hr}$ and 45 minutes apart for both rings, indicating similarities in the steel behavior regardless of the point of occurrence. The measured strain returned to zero approximately $2 \mathrm{hrs}$ after the MSC was completed.

It is understood that at some point during this cure regime, the UHPC reached final set and the differences in the material coefficients of thermal expansion (CTE) would have some affect on the measured strain. Additionally, the final strain caused by shrinkage of the UHPC may be slightly higher than measured, due self desiccation during hydration that may have occurred in this time. However, the magnitudes of these effects are expected to be minimal compared to the negative strain caused by thermal gradients in the steel ring; therefore, this region is not considered in the following analysis and is excluded from Figure 4.4 for clarity.

Figure 4.4 shows the measured steel strain over time due to the net effects of UHPC shrinkage and restrained creep under restrained conditions. Note that the measured strain is the steel's response to the UHPC behavior and not directly the shrinkage strain in the UHPC material itself. It can be seen that shrinkage of the AMC specimens (Ring 1 and 2) did not begin until after demolding (1 day). These AMC specimens reached an average of $160 \mu \varepsilon$ after 28 days and $175 \mu \varepsilon$ after 35 days. MSC UHPC rings caused less steel strain than the ambient specimens throughout the test duration, reaching an average microstrain of $125 \mu \varepsilon$ at 28 days and $122 \mu \varepsilon$ at 35 days after casting. The general trend of shrinkage over time is similar for both cure regimes. Although the MSC specimens were exposed to steam and thermal curing, the duration was short and mild; therefore similar MSC and AMC specimen behavior was expected. 


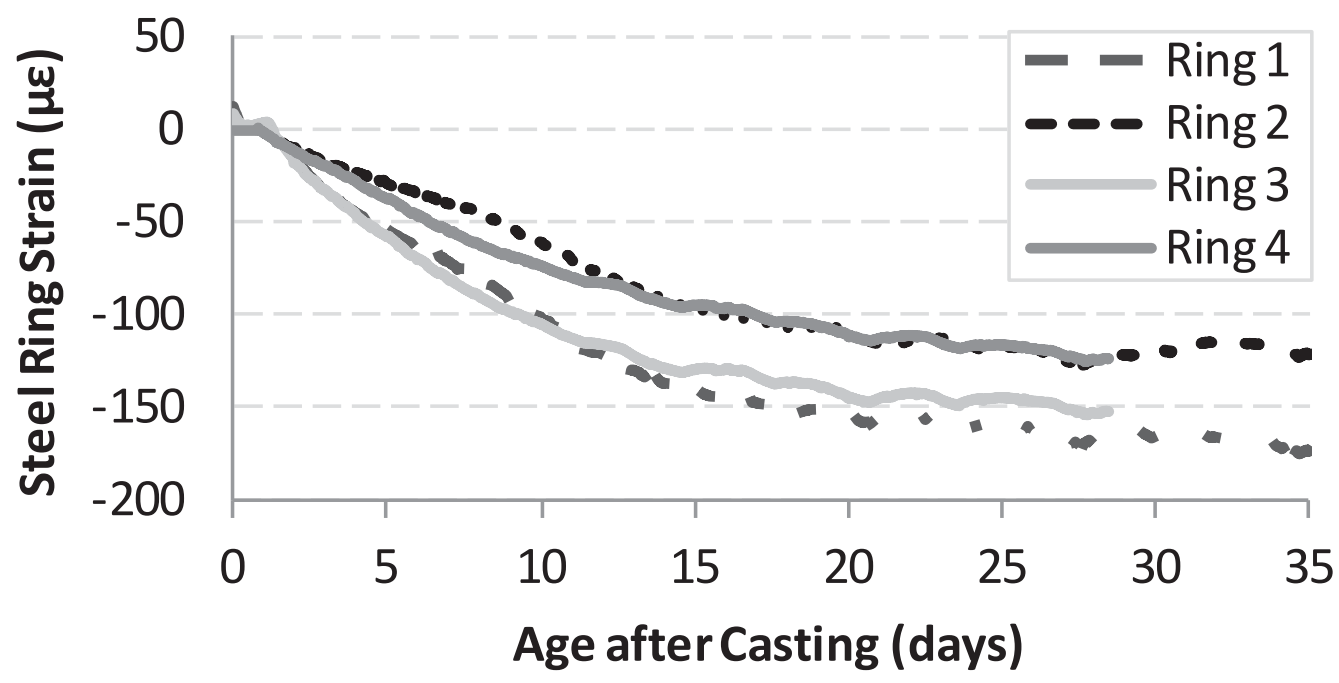

\section{Figure 4.4: Adjusted steel ring strain}

Figure 4.5 shows the average steel strain for each cure regime, as well as logarithmic functions that best fit the strain increase over time. It can be seen that the specimens from both cure regimes are expected to experience continued shrinkage beyond the test duration. Using this curve-fit, shrinkage of the MSC specimens is expected to increase at a lower rate than the AMC specimens. After 1 year, MSC rings should experience approximately $-206 \mu \varepsilon$ and AMC specimens are expected to reach $-279 \mu \varepsilon$. These logarithmic functions assist in understanding the general shrinkage trend over time; however, they are only provided as estimates to the actual behavior.

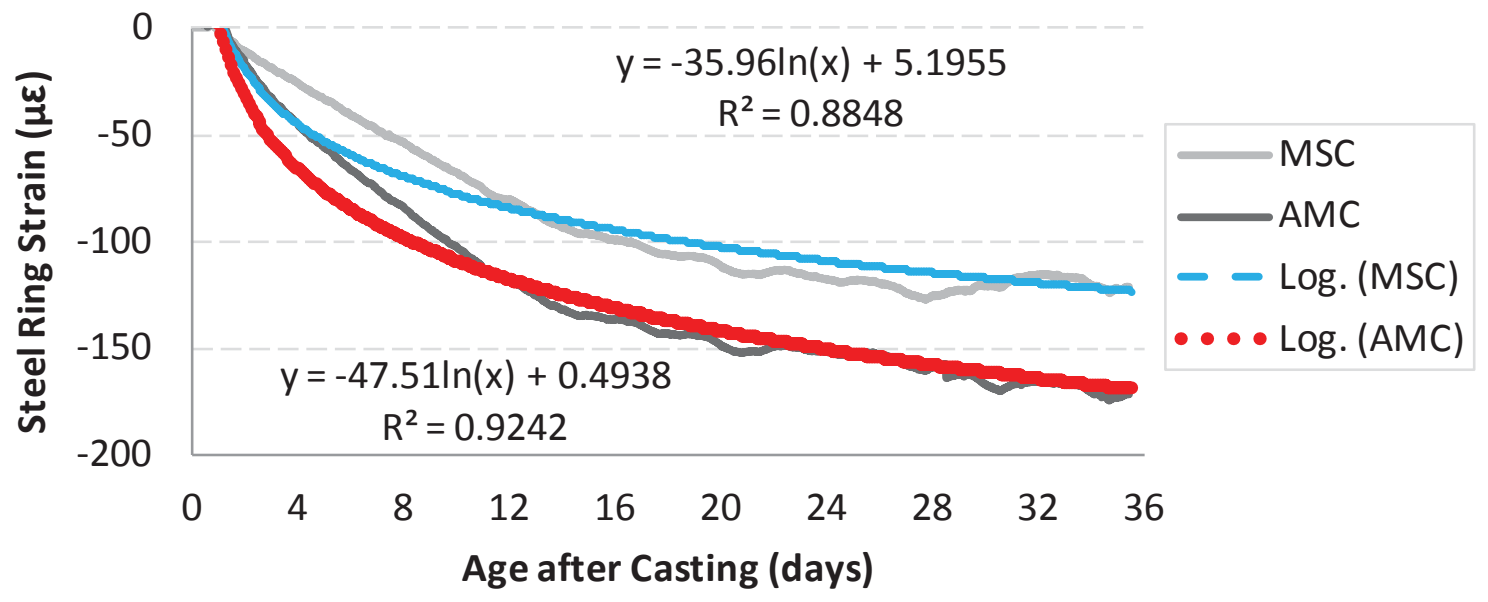

Figure 4.5: Average steel strain and projected trend line

The net response of UHPC under restrained conditions varies somewhat than that found in previous research. For example, when initial measurements began $23 \mathrm{hrs}$ after casting, 
Graybeal (2005) found $555 \mu \varepsilon$ of free shrinkage in ambient cured UHPC and $620 \mu \varepsilon$ for tempered steam cured specimens after 250 days. Tests conducted by Flietstra (2010) resulted in less free-shrinkage than Graybeal, but still higher than was found in this study, as he found $300 \mu \varepsilon$ of free-shrinkage for pre-steam cured specimens and $375 \mu \varepsilon$ for ambient cured specimens after 28 days. Soliman and Nehdi (2011) studied a UHPC design other than Ductal ${ }^{\circledR}$ and found autogenous shrinkage strains of approximately 400 $\mu \varepsilon$ after 7 days at near ambient conditions and $600 \mu \varepsilon$ after 7 days at $104^{\circ} \mathrm{F}$. It was also found that increased relative humidity during cure resulted in lower total strain, because the increased RH reduces drying shrinkage. However, research conducted by Kim et al. (2012) does correlate with the findings in this study. Using the restrained ring AASHTO PP34-99, Kim et al. observed $125 \mu \varepsilon$ occurred after 28 days with specimens that were allowed to dry in the circumferential direction.

Although some of the literature stated here has found higher shrinkage strains in UHPC than in the current study, differences can be party attributed to variation in the test conducted, specimen geometry, cure conditions, and test duration. However, the major cause of this variation is thought to be due to the creep relaxation that occurs in the UHPC material under restrained conditions. Habel and Denarié (2005) found that creep relaxation significantly affected the total strain and deformation of $\mathrm{CEMTEC}_{\text {multiscale }}{ }^{\circledR}$ UHPC, with $60 \%$ of the free shrinkage was offset by creep relaxation. In these mechanically restrained tests, the total effect including restrained shrinkage and creep relaxation resulted in $150 \mu \varepsilon$ after 7 days. Although Graybeal (2006) found that thermally treated UHPC exhibited higher shrinkage than ambient cured samples, Garas et al. (2009) found results that agree with the current study, where $247 \mu \varepsilon$ of free shrinkage occurred in ambient cured specimens and $44 \mu \varepsilon$ occurred in thermally cured samples.

Overall, UHPC ring specimens had not cracked by the end of testing signifying that the tensile strength of UHPC can withstand the net behavior of restrained shrinkage and creep relaxation (Hossain and Weiss 2004). This result indicates that UHPC of this geometric configuration and restraint should perform well as a restrained composite material.

The maximum tensile stress in the UHPC due to restrained shrinkage which occurs at the concrete-steel interface as discussed in Section 3.1.5, was also investigated in this study. Figure 4.6 displays the increase in tensile stress over time for each ring specimen. The general trend of rings with equivalent curing regimes is fairly consistent. The variation in tension stress over time is attributed to fluctuations in laboratory ambient conditions. Figure 4.7 illustrates the average stress for each cure regime. Ambient cured specimens resulted in higher tensile stress at the UHPC-steel interface with an average 960 psi at 28 days and 1040 at 35 days. Relatively linear tensile stress was found in the first 10 days after casting for MSC rings, which developed a total of 753 psi after 28 days and 735 psi after 35 days. 


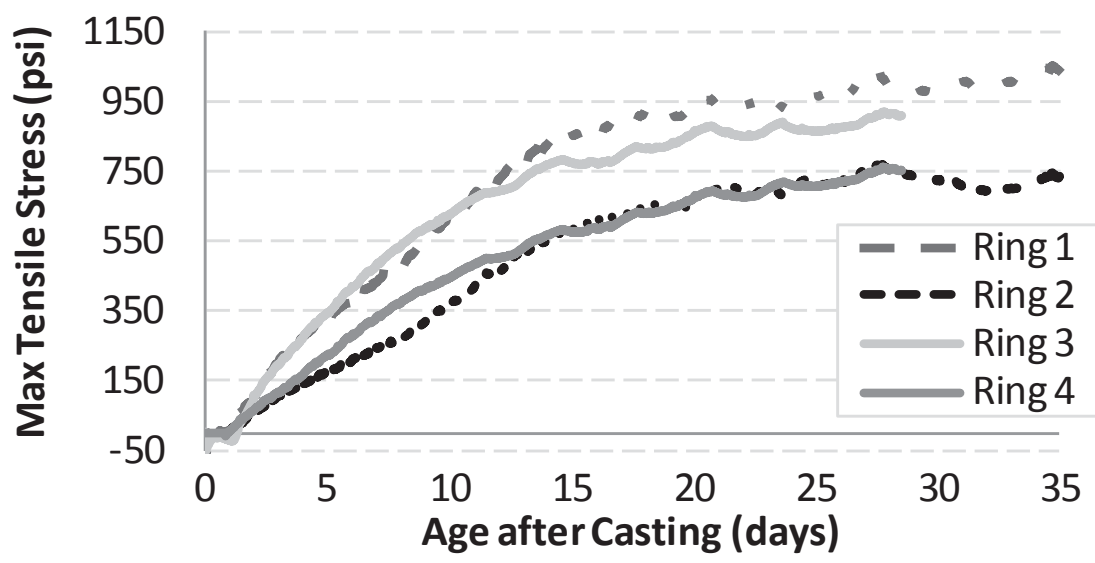

Figure 4.6: Max tensile stress in UHPC

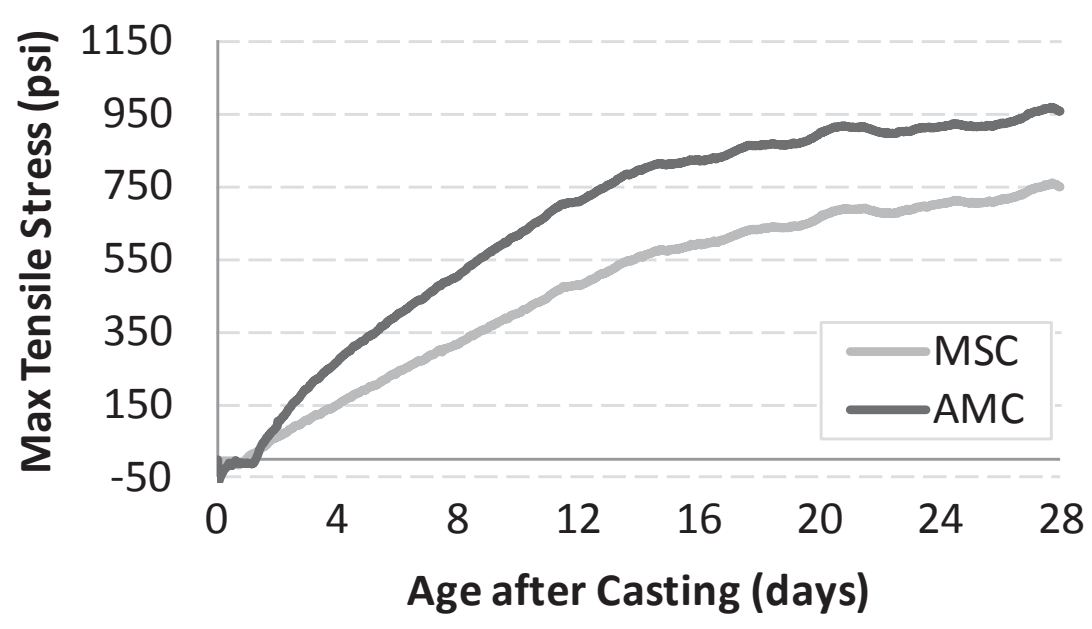

Figure 4.7: Max tensile stress in UHPC per cure regime

Research conducted by Graybeal found the splitting tensile strength of UHPC under various cure regimes (Graybeal 2006b). For untreated, or ambient, specimens, the 5, 15, and 28 day indirect tensile strength was 958, 1257, and 1335 psi, respectively. Graybeal also conducted direct tensile strength tests on untreated UHPC at 28-days and found the strength to be between 800-1000 psi (Graybeal 2006a). The stresses found in the ambient cure $(A M C)$ restrained shrinkage tests were lower than these strengths for all considered ages. For UHPC that underwent tempered steam, Graybeal found a 28 day indirect tensile strength of 1658 psi (Graybeal 2006b) and a direct tensile strength between 1100 and 1300 psi (Graybeal 2006a). Although the tempered steam treatment is different than the MSC, it can be seen that tensile stress due to restrained shrinkage is slightly less than the approximate strength, indicating adequate tensile strength of the UHPC material under high restraint conditions. 
Lastly, the circumferential stresses through the depth of the AASHTO PP34 ring test was used to quantify the shear force and stresses acting on the interface if the "infinitely long slab" representation was straightened to an equivalent flat slab (see Section 3.1.5 for details). Figure 4.8 and Figure 4.9 illustrate the circumferential stresses that occur through the depth of the concrete annulus for UHPC under different curing regimes, in addition to highlighting the range of UHPC overlay thicknesses (to) considered in this research. The resultant force $(\mathrm{T})$ was calculated from the stress acting through the ring depth and equated to the shear force (Vuh) shown in Table 4.4 and Table 4.5 for various UHPC overlay thickness and cure regimes (see Section 3.1.5 for details). These tables also include the calculated shear stress (vuh) acting on the interface of the composite system for various UHPC overlay thicknesses. This interface shear values are for the UHPC-steel composite system of the AASHTO ring test, not a UHPC-NSC system. However, as the stiffness and restraint provided by the steel is greater than the restraint which would be provided in a NSC bridge deck, these values are being used as an upper bound on the actual behavior.

For all overlay thicknesses (to) and cure regimes, the shear stresses in the composite UHPC-steel surface induced by the net effect of restrained shrinkage and creep relaxation is significantly less than the 1600 and 2060 psi slant shear strength for smooth and grooved UHPC-mortar surfaces found in past literature (Harris et al. 2011). Although the bond strengths determined from experimental testing do not provide a direct comparison to the shear stress, they are used here for a baseline comparison. These findings further validate satisfactory bond strength of ambient cured and modified steam cured UHPC overlays to NSC. In later sections the bond strength of this overlay-deck system is again analyzed for cases of combined truck loading and restraint conditions.

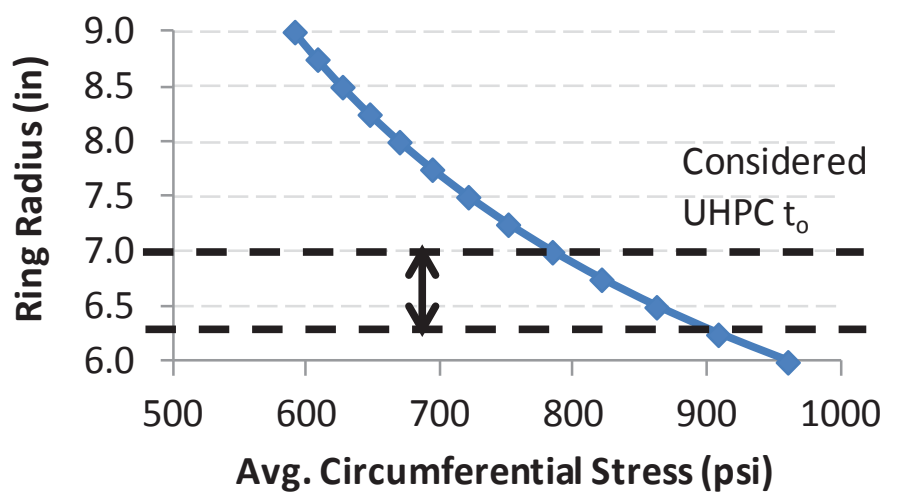

Figure 4.8: Avg. hoop stress through ring depth - AMC cure 


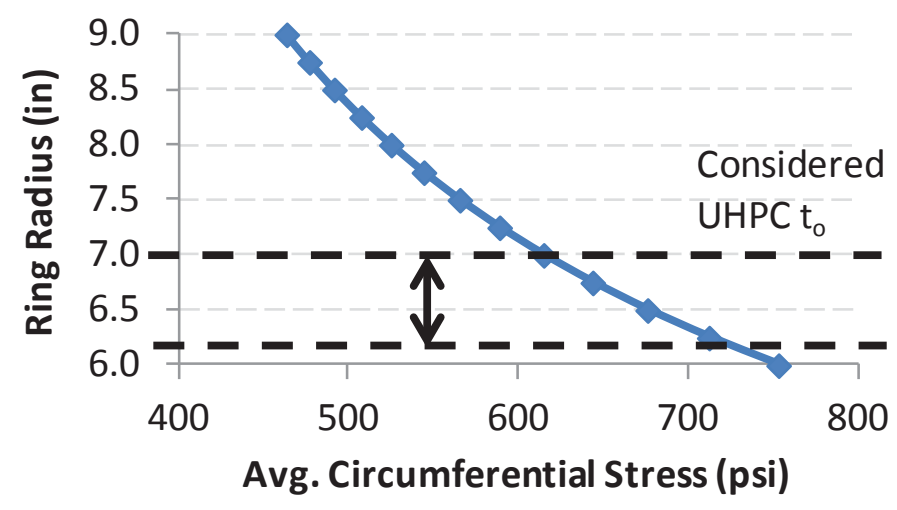

Figure 4.9: Avg. hoop stress through ring depth - MSC cure

Table 4.4

Shrinkage induced interface shear force and stress - AMC cure

\begin{tabular}{ccc}
\hline $\mathbf{t}_{\mathbf{0}}$ (in) & $\mathbf{V}_{\text {uh }}$ (kip) & $\mathbf{V}_{\text {uh }}$ (psi) \\
\hline $\mathbf{1 / 4} "$ & 1.40 & 6.19 \\
$\mathbf{1} / 2$ & 2.73 & 12.06 \\
$3 / 4$ & 3.99 & 17.64 \\
$\mathbf{1}$ & 5.19 & 22.96 \\
$\mathbf{1 . 5}$ & 7.45 & 32.93 \\
$\mathbf{2}$ & 9.53 & 42.14 \\
\hline
\end{tabular}

Table 4.5

Shrinkage induced interface shear force and stress - MSC cure

\begin{tabular}{ccc}
\hline $\mathbf{t}_{\mathbf{0}}$ (in) & $\mathbf{V}_{\text {uh }}$ (kip) & $\mathbf{v}_{\text {uh }}$ (psi) \\
\hline $\mathbf{1 / 4} "$ & 1.10 & 4.86 \\
$\mathbf{1} / \mathbf{2}$ & 2.14 & 9.46 \\
$\mathbf{3} / \mathbf{4}$ & 3.13 & 13.84 \\
$\mathbf{1}$ & 4.07 & 18.01 \\
$\mathbf{1 . 5}$ & 5.84 & 25.82 \\
$\mathbf{2}$ & 7.48 & 33.05 \\
\hline
\end{tabular}

While these test results give a general idea of UHPC performance under restrained conditions, it does not measure the exact performance one would see under field conditions. Environmental conditions vary greatly in the field and therefore the ambient conditions considered here only provide a baseline of performance. Also, induced stresses due to the steel ring restraint are higher than would be found in a UHPC on a NSC deck as a result of the greater degree of restraint that the steel provides. The actual 
degree of restraint under field conditions would depend on the deck roughness, strength and extent of deck failures. Furthermore, in this analysis it was assumed that the shrinkage strain and the stress relationship through the overlay depth were constant for all UHPC ring thicknesses. Literature exists to support this assumption for concrete thicknesses of 1.5-6 in., but indicates that interface stresses may be higher for some of the thinner overlay thicknesses considered in this analysis. Future analysis must be conducted to quantify the actual interface tension and shear stresses present in thin sections of a composite UHPC-NSC system in order to fully understand the compatibility of this overlay application, as the results presented here are only a baseline of the actual material and mechanical behavior.

\subsection{Finite Element Analysis Results}

A parametric finite element analysis was conducted in addition to the previously described experimental tests to correlate various loading scenarios, geometric properties, and material properties to bond and cracking stresses within a UHPC overlay and NSC deck system. Two finite element model (FEM) scenarios were considered in this analysis. The first model scenario was a simple plate representing a section of bridge slab between supporting girders. This scenario was included to allow for a computationally efficient parametric analysis without the need for a full bridge design. The second FEM scenario was an entire bridge that allowed for analysis of the global system behavior and validation of the simplified model. Only varied overlay thicknesses and material properties were included in the second scenario to allow for observation of the system response in a validated structure without redesigning the bridge.

Interfacial debonding and shear stresses were analyzed in these models to evaluate the compatibility overlay-deck system, by comparing the state of stress with measured bond test results found in literature. It was also necessary to investigate the truck load induced stresses that can cause cracking in the UHPC surface.

The shear stress at the UHPC-NSC interface was determined using the interlaminar shear stress ILSXZ and ILSYZ outputs available in ANSYS software. In both the plate and full bridge models, the x-axis refers to the longitudinal direction and the y-axis refers to the transverse direction across the plate or bridge width. The maximum element interlaminar shear stress of the two directions is presented in this section. Maximum debonding stresses were determined using the nodal tensile principal stress present in the xz- and yz- plane of the composite interface (Equation 11). An illustration of the tensile stresses for the three principal planes is shown in Figure 4.10 on Mohr's circle. Since these principal stresses were not oriented perpendicular to the interface, the angle $\left(\theta_{\mathrm{p}}\right)$ of the principal plane was determined (Equation 12). The $\sigma_{\mathrm{z}}$ ' and $\sigma_{\mathrm{x}}$ ' or $\sigma_{\mathrm{y}}$ ' equations were then calculated to determine which axis resulted in the maximum stress and which axis was the minimum stress for the given plane. From this information, the net z-component of the max and min principal stresses was then calculated, as shown in Figure 4.11. The zX-plane calculation is shown in the equations below, but the same equations were used 
for the zy-plane by substituting the $\mathrm{x}$ values for $\mathrm{y}$. The compressive bearing stress at the interface which may cause crushing was not investigated due to the scope of this research. The maximum tensile principal stress in the xy-plane was calculated at the UHPC surface using Equation 9 to determine the tensile stress to cause cracking.

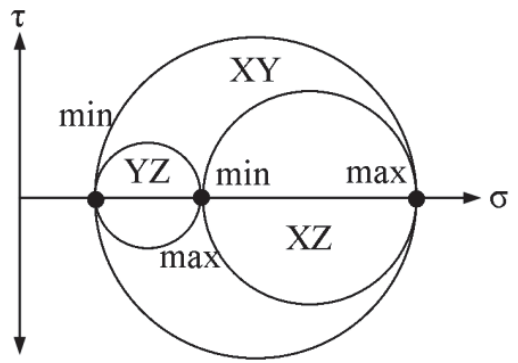

Figure 4.10: Mohr's circle - max and min stress of 3 planes

$$
\begin{aligned}
& \sigma_{\max }=\frac{\sigma_{x}+\sigma_{z}}{2}+\sqrt{\left(\frac{\sigma_{x}-\sigma_{z}}{2}\right)^{2}+\tau_{z x}^{2}} \\
& \theta_{p}=\frac{1}{2} * \arctan \left(\frac{2 * \tau_{z x}}{\sigma_{x}-\sigma_{z}}\right) \\
& \sigma_{z}^{\prime}=\frac{\sigma_{x}+\sigma_{z}}{2}-\frac{\sigma_{x}-\sigma_{z}}{2} * \cos \left(2 * \theta_{p}\right)-\tau_{z x} * \sin \left(2 * \theta_{p}\right) \\
& \sigma_{x}^{\prime}=\frac{\sigma_{x}+\sigma_{z}}{2}+\frac{\sigma_{x}-\sigma_{z}}{2} * \cos \left(2 * \theta_{p}\right)+\tau_{z x} * \sin \left(2 * \theta_{p}\right) \\
& \sigma_{Z_{-} \text {net }}=\sigma_{z}{ }^{\prime} \cos \left(\theta_{p}\right)+\sigma_{x}{ }^{\prime} * \sin \left(\theta_{p}\right)
\end{aligned}
$$
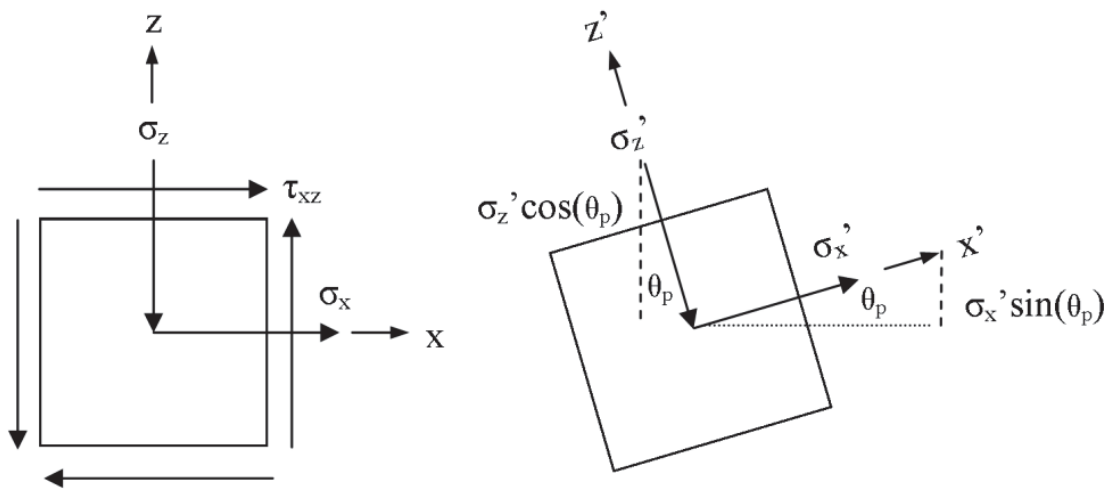

Figure 4.11: Debonding stress determination 


\subsubsection{Scenario 1 - Plate Model}

A parametric analysis was first conducted on the plate models in an effort to reduce the computational time of using the complete bridge model. Several loading scenarios were considered in this analysis, in addition to the geometric and material investigations, which was discussed in Section 3.2.1. The goal of this parametric analysis was to determine the effect of each parameter on the state of stress in the system, to optimize the overlay thickness, and to provide reference data for bridge owners to use UHPC overlay installations in the future. The model is deemed representative of the results obtained for the different parameters investigated.

An example of the general plate model behavior is presented in Figure 4.12, which shows the deflected shape of plate model with girders modeled as fixed and simple supports. This particular model has a $10 \mathrm{ft}$ girder spacing, $8 \mathrm{in}$. deck, 1 in. overlay and is under loading configuration Case $\mathrm{C}$. The highest modulus ratio of 2.3 was included for this model, which represents a 3 ksi deck and 21 ksi UHPC deck. As expected, fixed girder supports yield lower deflections, but also cause larger slopes within the deflected shape, which in turn causes higher tensile stress in the UHPC surface. The general stress distribution under load Case $\mathrm{C}$ is shown in Figure 4.13 and Figure 4.14. For all stress illustrations, blue colors indicate maximum negative (compressive) stress and red indicates maximum positive (tension) stress. It can be seen that tensile stresses occur near the support face adjacent to wheel loads when fixity occurs in girder supports. Slight tension stresses in the UHPC surface also occurs in plate corners and between wheel loads in $\sigma_{\mathrm{x}}$ direction, though this is not shown in the contoured colors of the figures below. Examples of interlaminar shear stress distribution within the plate are included in Figure 4.15 and Figure 4.16. Locations of maximum of interface shear in the zx-direction occur adjacent to the wheel loads in the longitudinal direction, whereas the shear in the zy-direction was found to occur adjacent to the wheel loads in the transverse direction. High shear stresses also occur at plate edges. Locations of maximum debonding stress were found to occur at plate edges and in the center of applied wheel loads, but are not shown graphically herin.

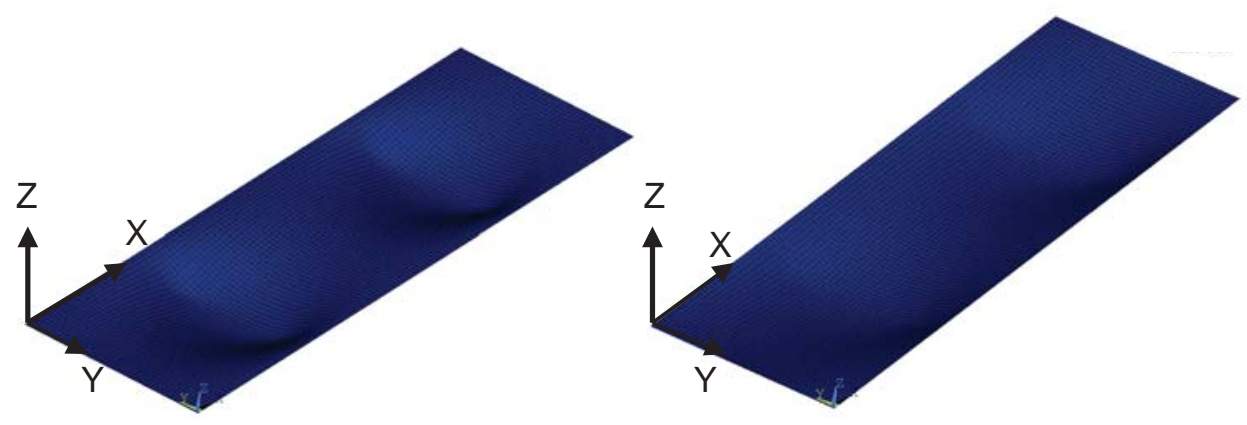

Figure 4.12: Deflected shape for fixed (left) and simple (right) girder supports 


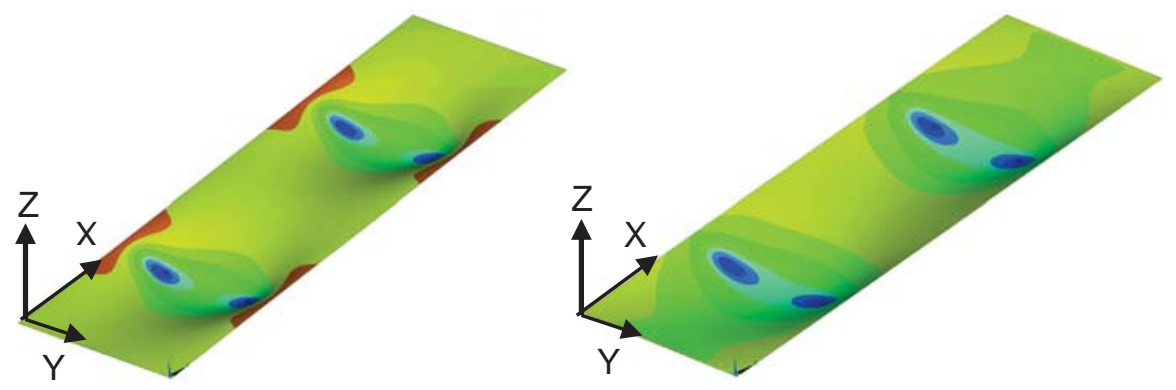

Figure 4.13: Longitudinal normal stress $\left(\sigma_{x}\right)$ distribution for fixed (left) and simple (right) girder supports

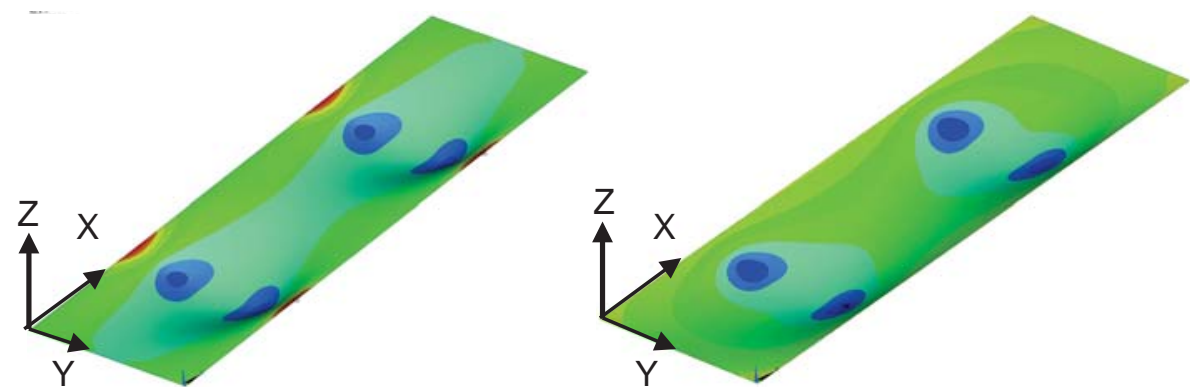

Figure 4.14: Transverse normal stress $\left(\sigma_{y}\right)$ distribution for fixed (left) and simple (right) girder supports
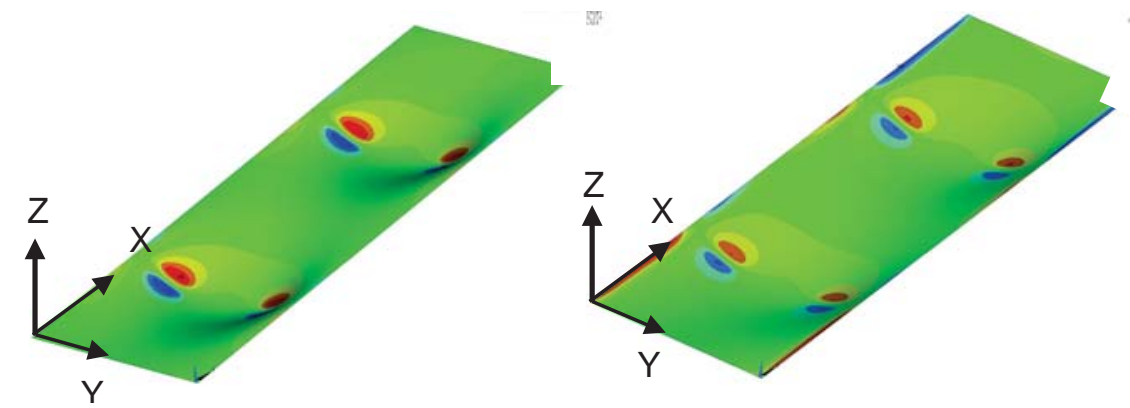

Figure 4.15: Interlaminar longitudinal shear stress (ILSXZ) distribution for fixed (left) and simple (right) girder supports 

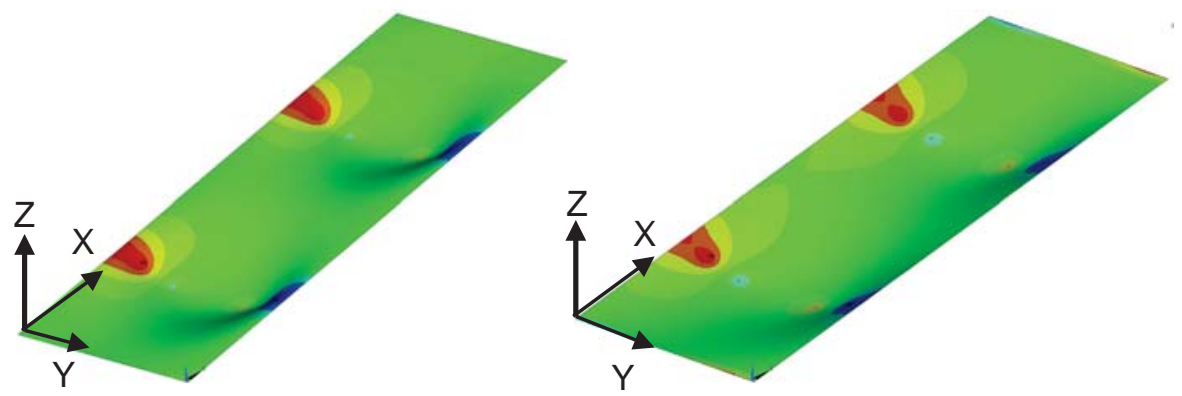

Figure 4.16: Interlaminar transverse shear stress (ILSYZ) distribution for fixed (left) and simple (right) girder supports

The effects of boundary conditions, girder spacing, and loading configurations that created the highest state of stress in the overlay-deck system were first analyzed using this plate model. To analyze only these parameters, the deck and overlay thicknesses was held constant in all models at 8 in. and $3 / 4$ in., respectively. These values were chosen because they were not at the extreme ends of the parameter ranges and they provided representative stress distributions that were thought to control the design based on preliminary analysis. The highest modulus ratio of 2.3 was included for this model, which represents a 3 ksi deck and 21 ksi UHPC deck. All load five load cases (LCs) discussed in Section 3.2.1.3 were included in this analysis and are referred to as LC-A, LC-B, LC-C, LC-D, and LC-E for load case A, B, C, D, and E, respectively. Each load case was applied to a plate model that was supported with fixed girder supports and simple girder supports, in an effort to bound the system response. These support conditions are referred as $\mathrm{S}$ or $\mathrm{F}$ in the following figures, for simple and fixed girder supports, respectively.

The results from this analysis are summarized in Figure 4.17. More detailed figures are included in Appendix C. Note that load Case C and E were not applied to the $6 \mathrm{ft}$. girder spacing, as the narrow plate did not accommodate the full $6 \mathrm{ft}$. center-to-center wheel spacing. 


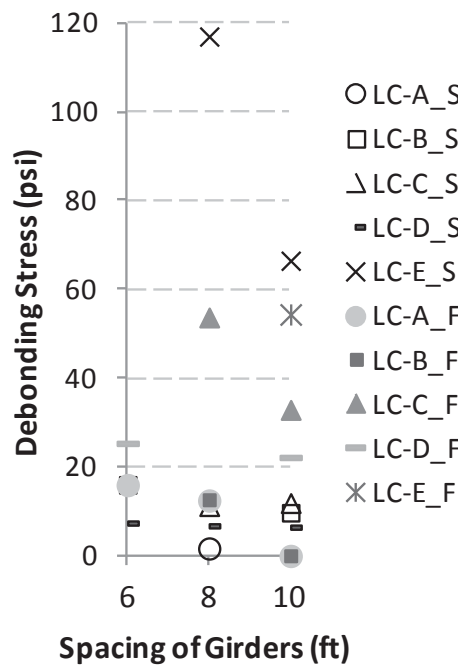

(a) Debonding stress

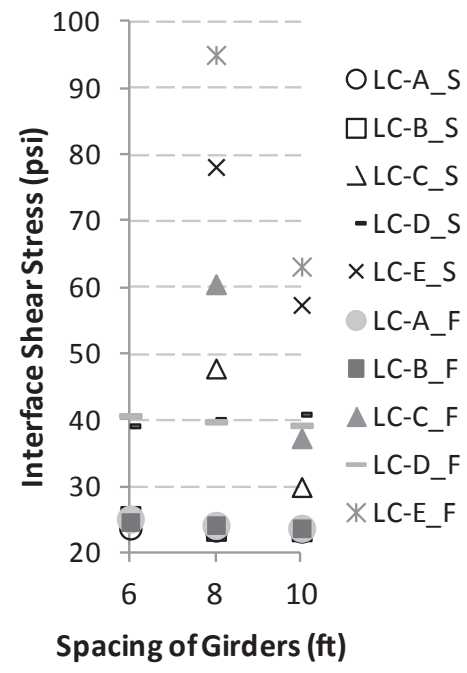

(b) Interface shear stress

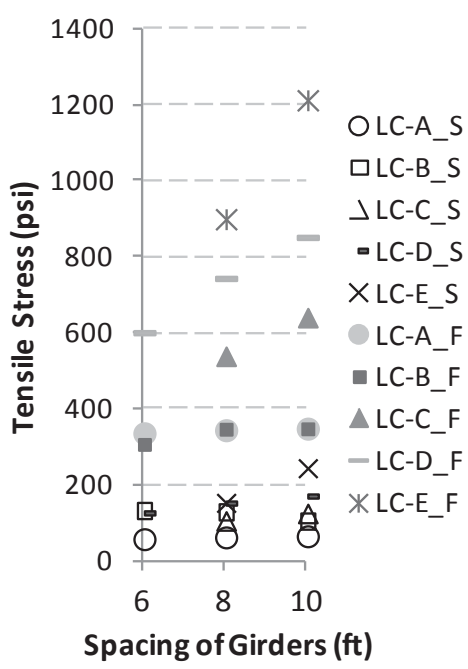

(c) Tensile stress

Figure 4.17: Influence of girder spacing, load configuration, and girder support on state of stress in overlay-UHPC system

From these figures, it can be seen that the degree of fixity provided by girders affect the maximum interface shear stress, debonding stress, and tension stress. This is most easily seen for heavier load configurations (Case E and C). For all load configurations, fixed girder supports induce the highest interlaminar shear stress and surface tensile stress than the corresponding simply supported plates, though the difference is substantially lower at lighter truck configurations. The governing support condition is more complex when interfacial debonding stresses are considered. This is due to the fact that compression is caused in certain loading and geometric conditions regardless of edge supports. Generally, higher loading is found to cause higher debonding stresses. The state of stress in the composite system is also affected by the spacing of supports. The highest debonding stress occurs with increased load, though the effects of girder spacing and boundary condition are less conclusive, as some configurations do not induce tension into the overlay section and do not experience debonding. The largest interfacial shear stresses occur when girders are placed $8 \mathrm{ft}$ on center. The next highest shear bond stresses appear to be created by $10 \mathrm{ft}$ girder spacing; however, due to load case $\mathrm{C}$ and $\mathrm{E}$ being absent from the $6 \mathrm{ft}$ girder spacing, the influence of this parameter relative to lower girder spacings is unknown. It can be seen that the effect of girder spacing is less influential at lower loading (Case A, B, and D). In regards to the tensile stress on the overlay surface which would case cracking and fracture, the general trend is fairly linear for all cases. For tandem loading (Case $\mathrm{C}$ and $\mathrm{E}$ ), the increase of tensile stress with girder spacing is substantial, but these parameters are less influential when truck loads are applied, which is attributed to the magnitude of wheel loads and axle spacing. Though this analysis provides good insight into the influence of the spacing and support of girders and various design loadings, further investigation is required to fully understand the influence of girder spacing on the bond stresses of a UHPC overlay-NSC bridge deck. 
Possible further investigation could include additional girder spacing distances and increased loads.

Geometric and material properties were also included in this analysis and the findings of which are presented in Figure 4.18 through Figure 4.29. The variables considered include overlay thickness $\left(\mathrm{t}_{\mathrm{o}}\right)$, deck thickness $\left(\mathrm{t}_{\mathrm{d}}\right)$, ratio of the overlay-deck material stiffness $\left(E_{o} / E_{d}\right)$, and fixed and simple girder support $(G S)$ conditions. Although the magnitude of stress results are affected by the spacing of girders and applied load, the overall trend and influence of overlay-deck thickness ratios and stiffness ratios do not change for these parameters, as shown in the preliminary findings of Shann et al. (2012). Therefore, the girder spacing and load configuration were held constant in order to analyze only the individual effects these parameters. Load case E with girders spaced 10 $\mathrm{ft}$ on center were used in this case. Load case $\mathrm{E}$ was the worst case loading for $8 \mathrm{ft}$. and $10 \mathrm{ft}$. girder spacing (recall that it was not placed on the $6 \mathrm{ft}$ girder spacing model due to geometric constraints). Spacing girders $10 \mathrm{ft}$. apart induced the highest tensile stress, and relatively high debonding and shear stresses. Although girders spaced $8 \mathrm{ft}$. on center was the worst case placement for interface shear stresses in every case, the interest of this model set was to make direct comparisons of the effect $t_{0}, t_{d}, E_{o} / E_{d}$, and boundary conditions had on the stresses. Furthermore, $8 \mathrm{ft}$. girder spacing caused the worst case debonding stress for some boundary conditions, but caused only compression stresses in others, while a $10 \mathrm{ft}$. girder spacing induced tensile debonding in all load cases. Figure 4.18 through Figure 4.23 illustrate the effects of stiffness ratio and overlay thickness for fixed and simple girder supports and with a constant 8 in. deck thickness. An 8 in. deck thickness was chosen as it is the middle parameter considered in this analysis and because trial investigations by the author indicated that this would be the maximum deck thickness where a UHPC overlay would be compatible, which as described later in this section. Figure 4.24 through Figure 4.29 show the effects of stiffness ratio and deck thickness for a constant arbitrary $1 / 2$ in UHPC overlay thickness under both support conditions. This method of results presentation (separating the effect of overlay and deck thickness as opposed to using a ratio relationship) was chosen to help readers and bridge owners understand the parameters affecting their specific bridge. Note that the results presented here are not meant to be the maximum stresses that could be achieved for each thickness or stiffness, but are included to show the general effect thickness and stiffness has on the state of stress in the system. 


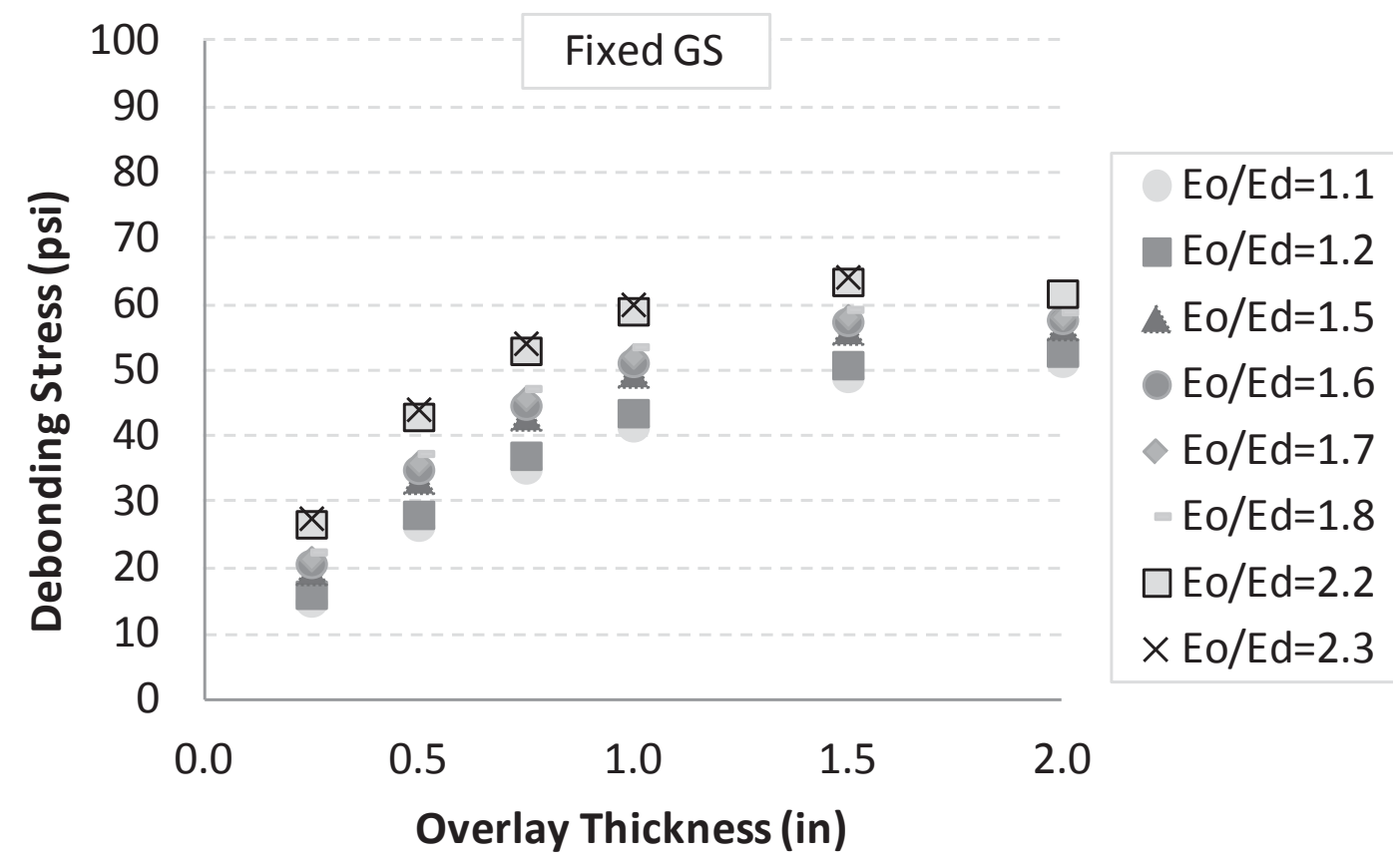

Figure 4.18: Effect of $t_{0}$ and $E_{0} / E_{d}$ ratio on debonding stress with fixed girder supports ( $t_{d}$ constant)

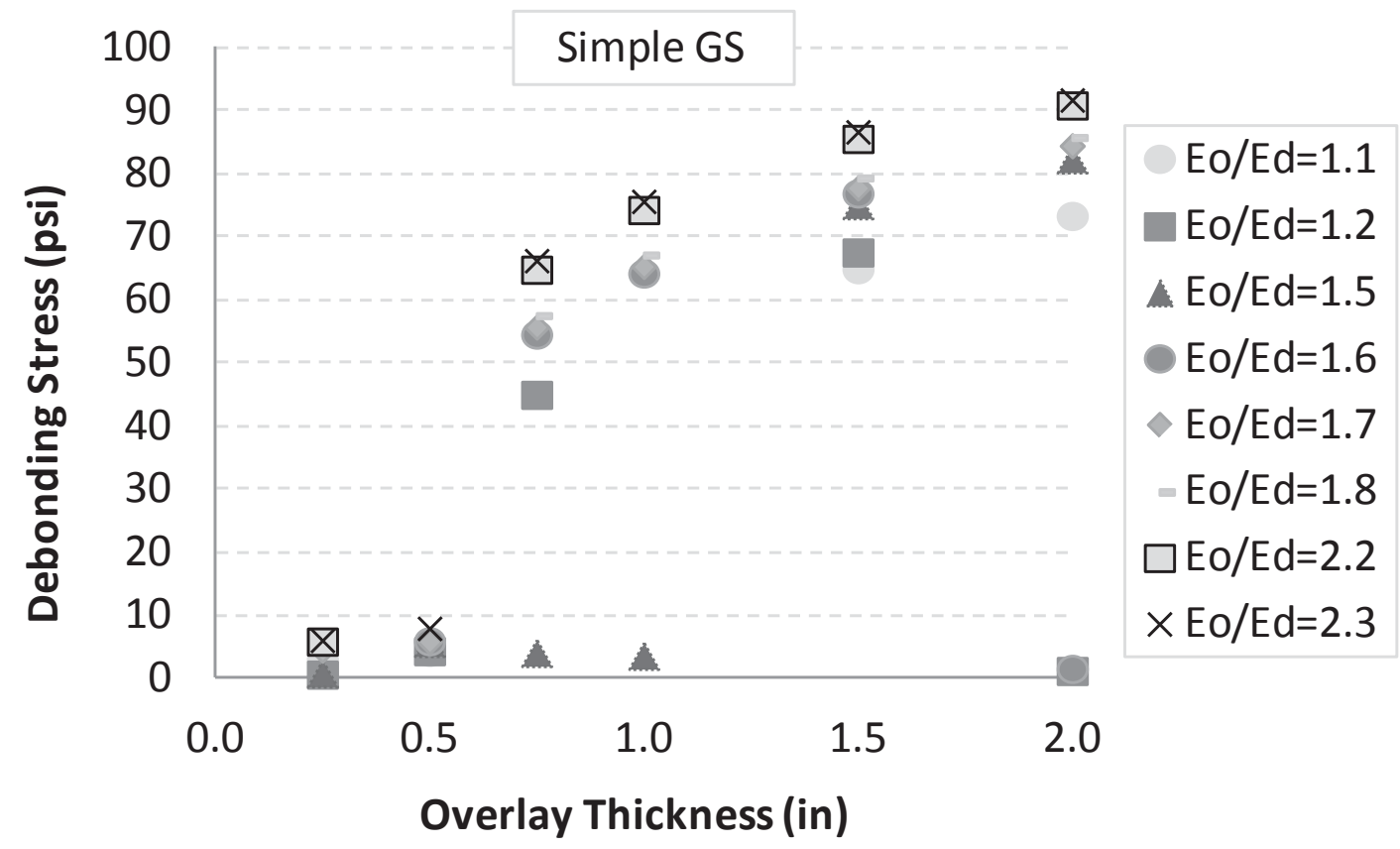

Figure 4.19: Effect of $t_{0}$ and $E_{0} / E_{d}$ ratio on debonding stress with simple girder supports ( $t_{d}$ constant) 


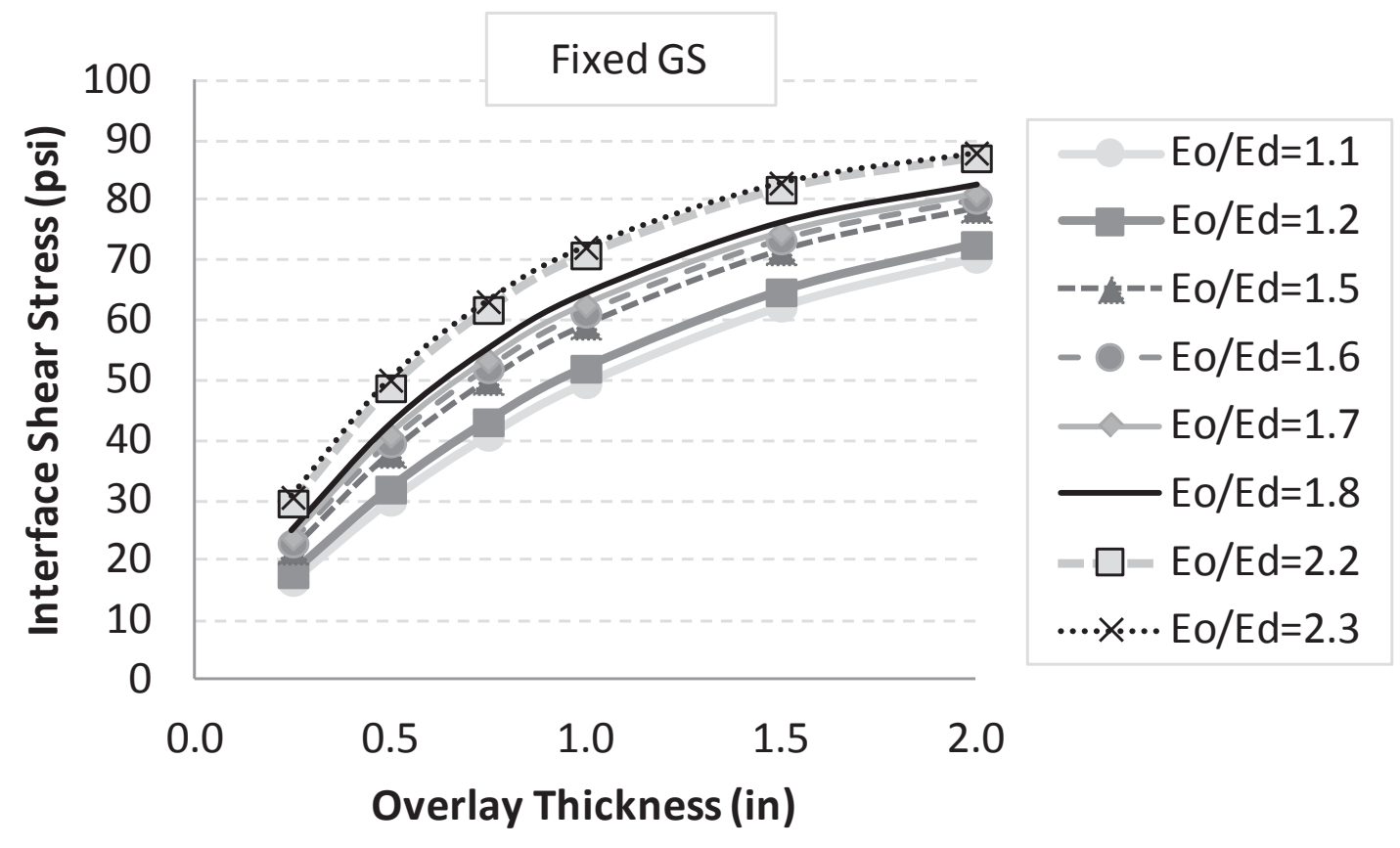

Figure 4.20: Effect of $t_{0}$ and $E_{0} / E_{d}$ ratio on interface shear stress with fixed girder supports ( $t_{d}$ constant)

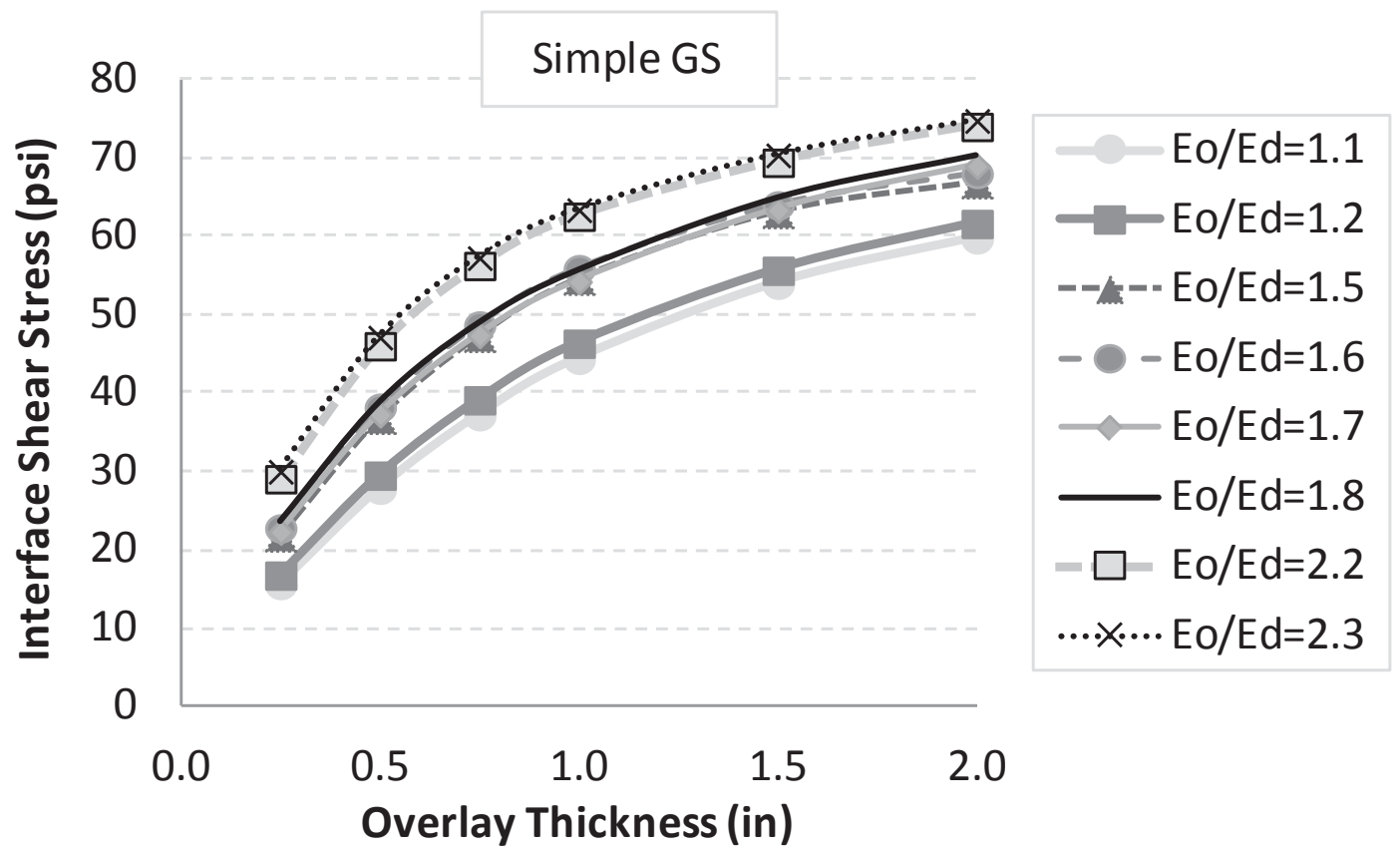

Figure 4.21: Effect of $t_{0}$ and $E_{0} / E_{d}$ ratio on interface shear stress with simple girder supports ( $t_{d}$ constant) 


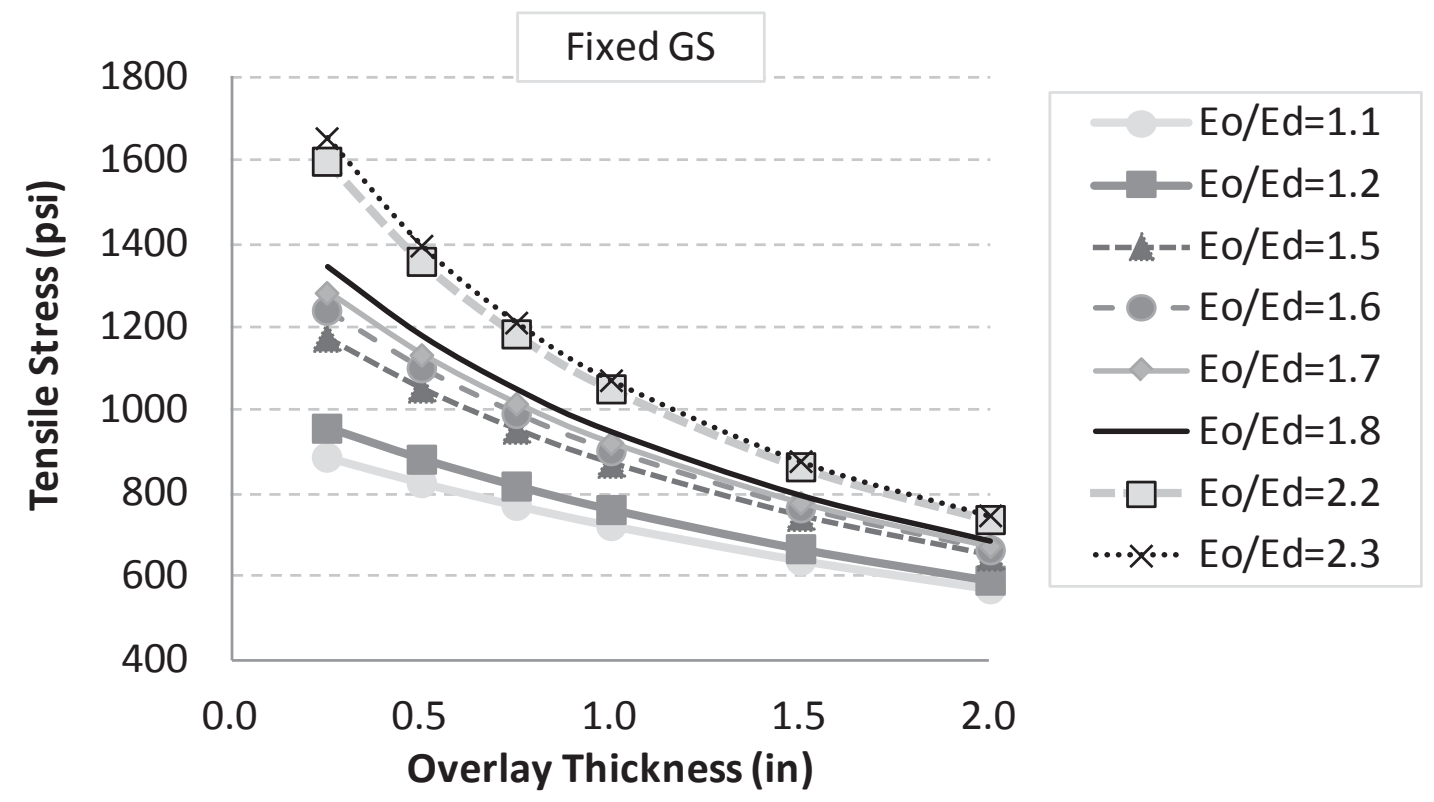

Figure 4.22: Effect of $t_{0}$ and $E_{0} / E_{d}$ ratio on tensile stress with fixed girder supports $\left(t_{d}\right.$ constant)

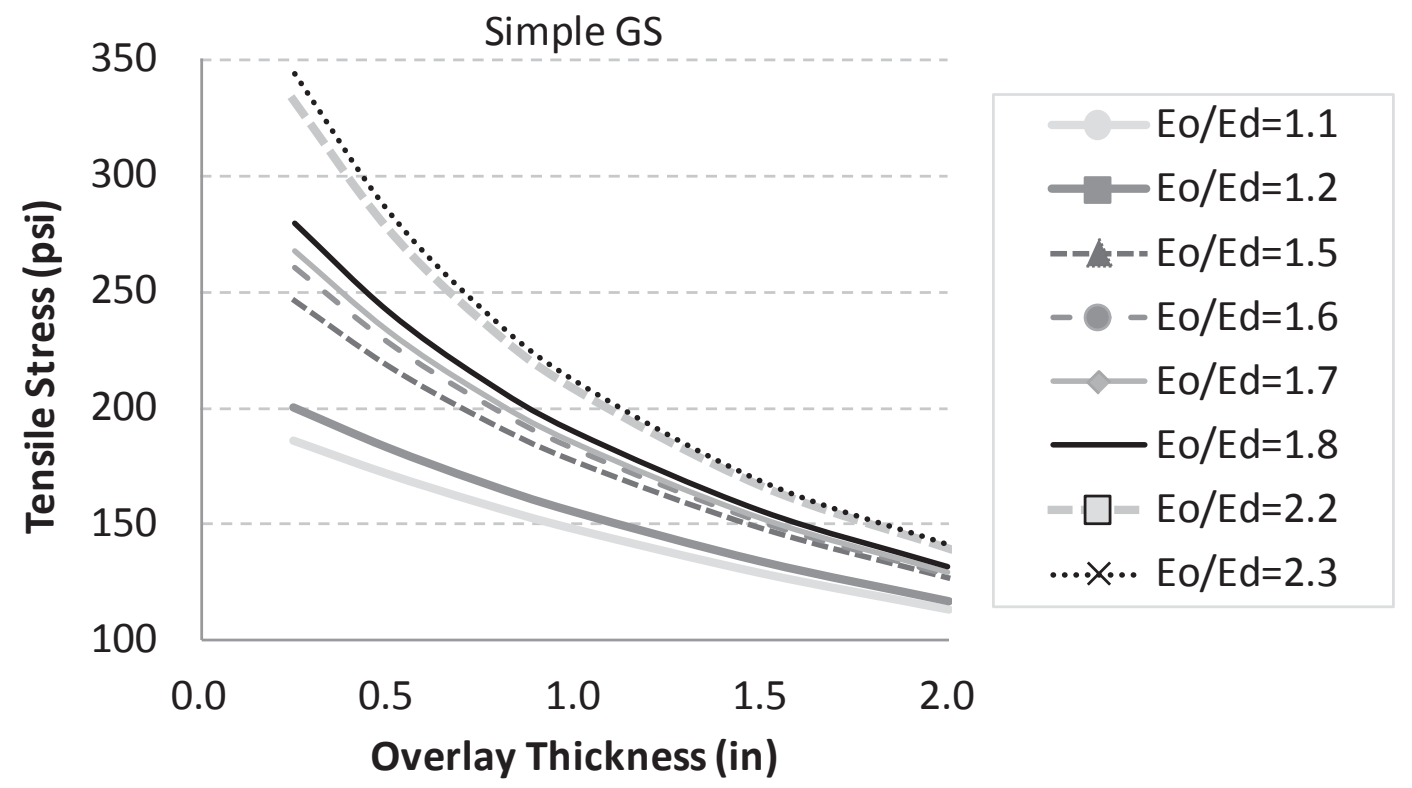

Figure 4.23: Effect of $t_{0}$ and $E_{0} / E_{d}$ ratio on tensile stress with simple girder supports $\left(t_{d}\right.$ constant) 


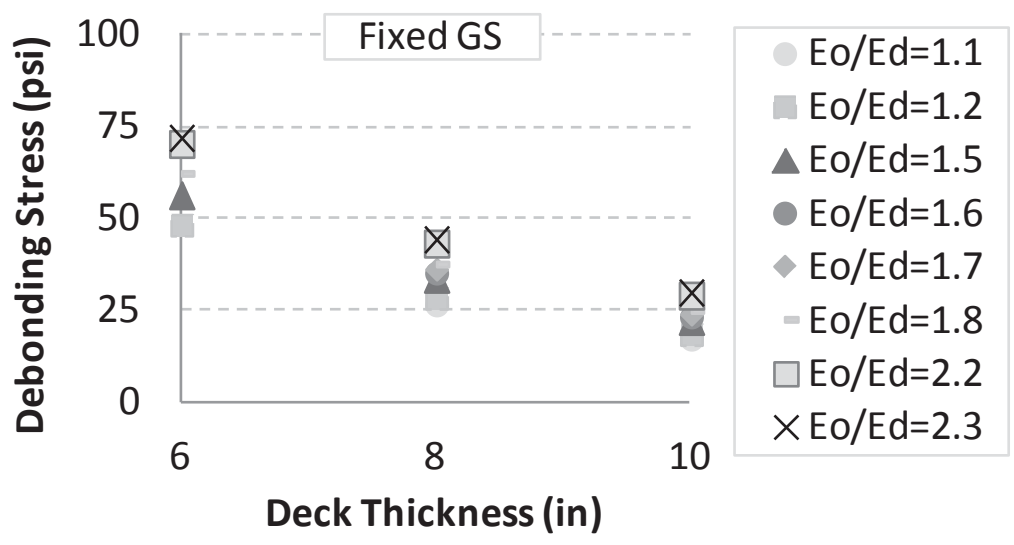

Figure 4.24: Effects of $t_{d}$ and $E_{0} / E_{d}$ ratio on debonding stress with fixed girder supports ( $t_{0}$ constant)

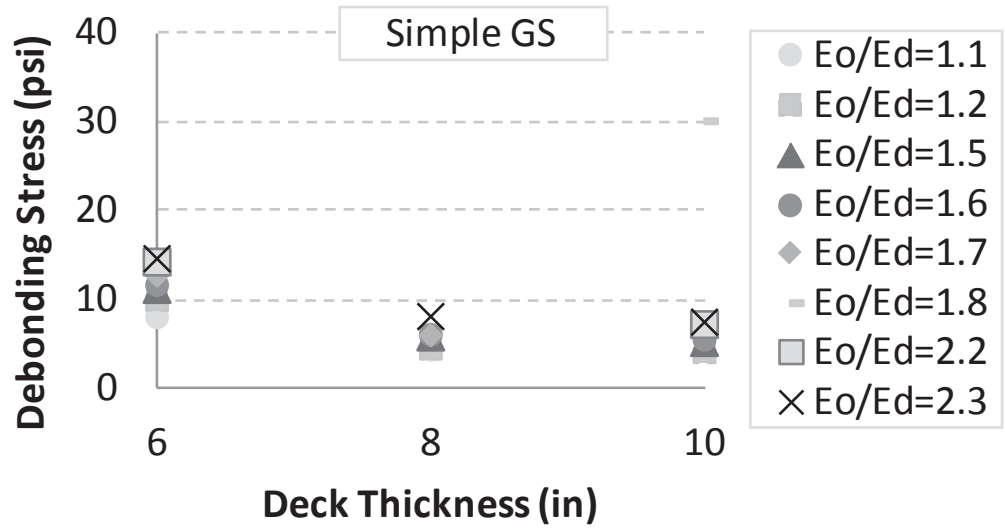

Figure 4.25: Effects of $t_{d}$ and $E_{0} / E_{d}$ ratio on debonding stress with simple girder supports ( $t_{0}$ constant)

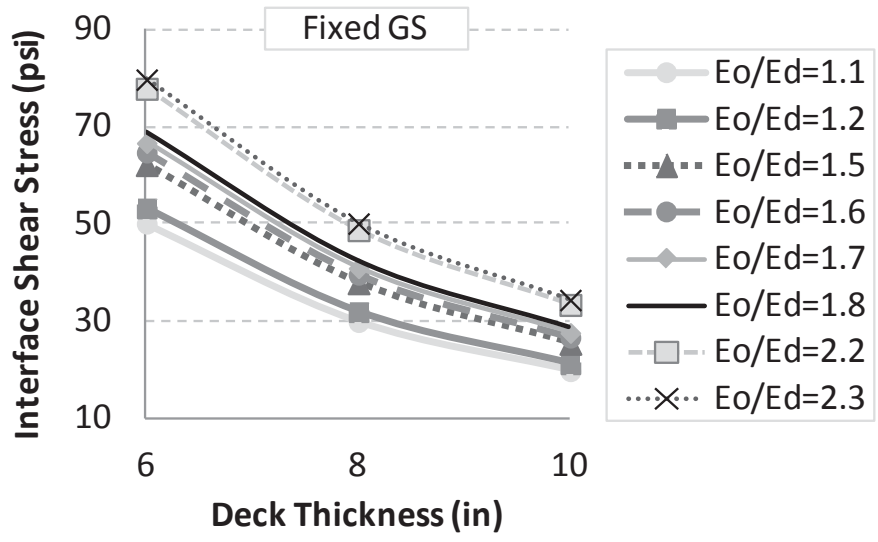

Figure 4.26: Effects of $t_{d}$ and $E_{0} / E_{d}$ ratio on interface shear stress with fixed girder supports ( $\mathbf{t}_{\mathbf{0}}$ constant) 


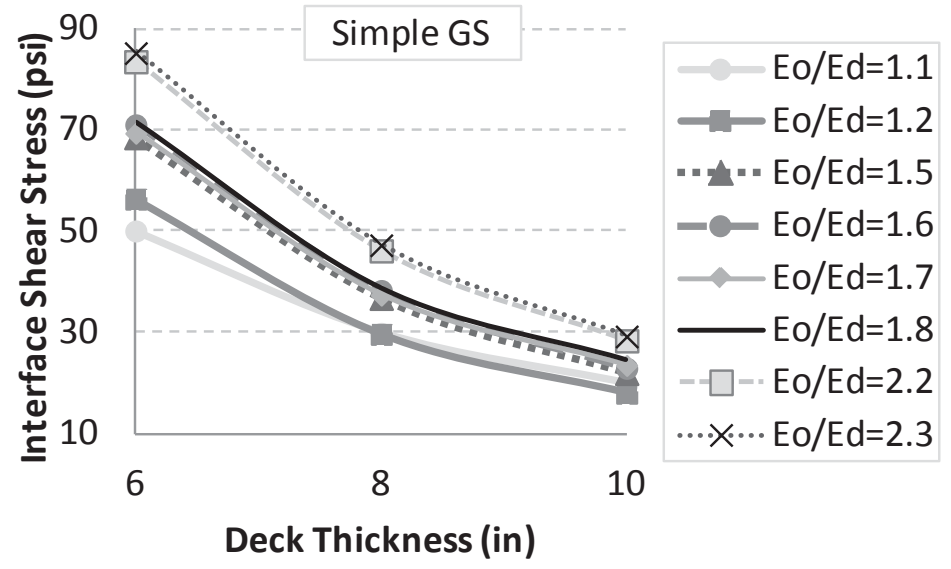

Figure 4.27: Effects of $t_{d}$ and $E_{0} / E_{d}$ ratio on interface shear stress with simple girder supports ( $t_{0}$ constant)

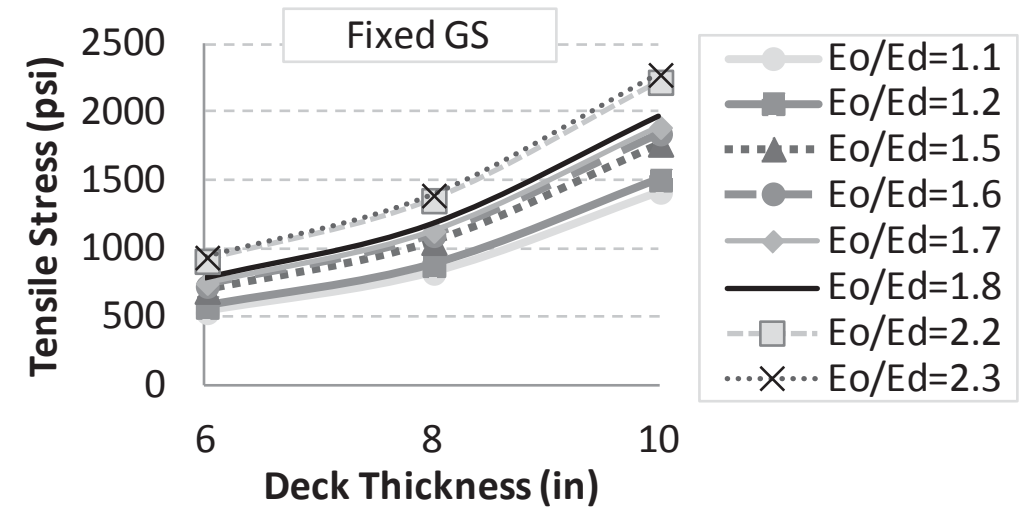

Figure 4.28: Effects of $t_{d}$ and $E_{0} / E_{d}$ ratio on tensile stress with fixed girder supports ( $t_{0}$ constant)

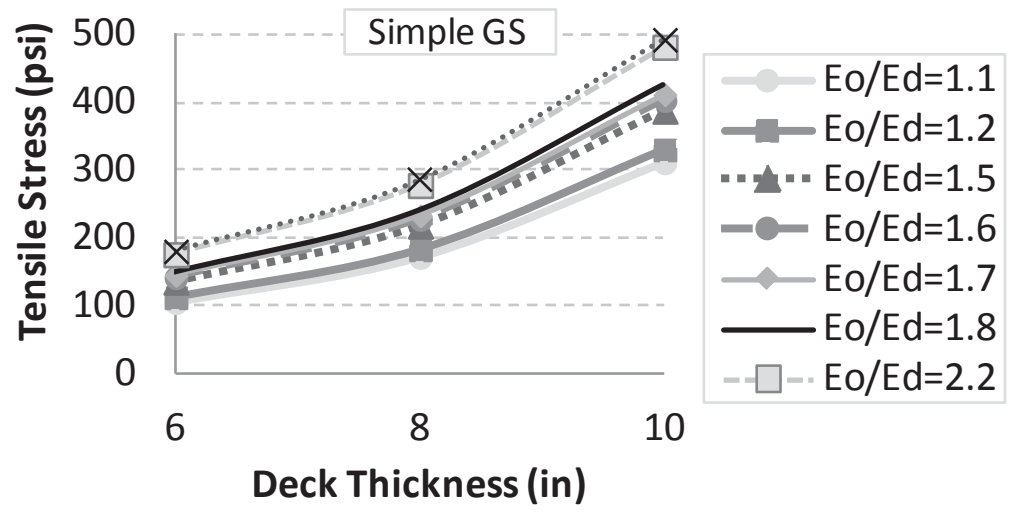

Figure 4.29: Effects of $t_{d}$ and $E_{0} / E_{d}$ Ratio on tensile stress with simple girder supports ( $t_{0}$ constant) 
Considering the effects of stiffness ratio and overlay thickness, two distinct trends can be found: an increase in interfacial shear stress and a decrease in tensile stress with an increased in overlay thickness regardless of boundary conditions. In general it was also found that increased overlay thickness caused higher debonding stresses; however some variations occurred due to the fact that some parametric configurations do not induce tension into the UHPC overlay. This was found to occur more often in cases with less rigid girder supports (see Figure 4.18). Analysis on the influence of bridge deck thickness found that interfacial shear and debonding stresses decreased and tensile stresses increased with increased deck thickness. These trends can be attributed to a shift in the location of the neutral axis. Increased levels of restraint provided by the girders generally resulted in higher states of stress in the composite system, especially in regards to tensile cracking stress. Increasing fixity of girder supports restricts plate movement, which is the reason for the higher tensile stresses.

In all cases, large differences in stiffness between the composite overlay and deck were found to increase the state of stress in the system. This finding indicates that the risk of failure is highest when the UHPC overlay is steam cured, is placed on a low-strength concrete bridge deck, and is loaded after full material strength has been obtained (near 28 days). Under these conditions, the UHPC is much stronger and rigid than the bridge deck and thereby attracts a greater contribution of the applied load than when the UHPC is not thermally treated or has lower strengths. This is an interesting finding, as early-age conditions were initially thought to be the controlling factor in a UHPC overlay design.

The effect of overlay thickness on the tensile cracking stress agree well with the research conducted by Issa and Alrousan (2009) on polymer concrete, which is described in the literature review portion of this thesis. In the research conducted by Issa and Alrousan, live-load induced tensile stresses increased with increased overlay thickness, as was found in this thesis. Increased overlay-to-slab elastic modulus similarly caused the highest stresses in the system. However, the effect of interface shear stresses was opposite from their findings, where they found increased shear stress with increased overlay-to-deck thickness ratios. This difference in results is attributed to difference in materials used in analysis, in addition to the fact that they were investigating the average summation of shear stress at the interface and the results presented here are the maximum nodal interfacial shear stress.

These initial parametric analysis results were then used to determine the ultimate states of stress that would be anticipated in a UHPC overlay cast on a NSC bridge deck from the parameters considered in this analysis. The configurations which resulted in the maximum stresses for both fixed and simple girder supports can be found in Table 4.6 and Table 4.7. The stresses found in these models were then compared to bond and tensile cracking strengths found in previous research to determine the overall compatibility of the proposed system. 
Table 4.6

Critical debonding stress

\begin{tabular}{ccccccc}
\hline $\begin{array}{c}\text { Girder } \\
\text { Supports }\end{array}$ & $\begin{array}{c}\text { Load } \\
\text { Case }\end{array}$ & $\mathbf{s}_{\mathbf{g}}(\mathbf{f t})$ & $\mathbf{t}_{\mathbf{0}}(\mathbf{i n})$ & $\mathbf{t}_{\mathbf{d}}(\mathbf{i n})$ & $\mathbf{E}_{\mathbf{0}} / \mathbf{E}_{\mathbf{d}}$ & $\begin{array}{c}\text { Max Debonding } \\
\text { Stress (psi) }\end{array}$ \\
\hline Simple & $\mathrm{E}$ & 8 & 2.0 & 6.0 & 2.3 & 80 \\
Fixed & $\mathrm{E}$ & 10 & 1.5 & 6.0 & 2.3 & 129 \\
\hline
\end{tabular}

Table 4.7

Critical interface shear stress

\begin{tabular}{ccccccc}
\hline $\begin{array}{c}\text { Girder } \\
\text { Supports }\end{array}$ & $\begin{array}{c}\text { Load } \\
\text { Case }\end{array}$ & $\mathbf{s}_{\mathbf{g}}(\mathbf{f t})$ & $\mathbf{t}_{\mathbf{0}}(\mathbf{i n )}$ & $\mathbf{t}_{\mathbf{d}}(\mathbf{i n )}$ & $\mathbf{E}_{\mathbf{0}} / \mathbf{E}_{\mathbf{d}}$ & $\begin{array}{c}\text { Max Interface } \\
\text { Shear Stress (psi) }\end{array}$ \\
\hline Simple & $\mathrm{E}$ & 8 & 2.0 & 6.0 & 2.3 & 149 \\
Fixed & $\mathrm{E}$ & 8 & 2.0 & 6.0 & 2.3 & 183 \\
\hline
\end{tabular}

Under the worst case loading, geometric, and material configurations, an interface debonding stress of 129 psi is still substantially less than the 450 psi splitting prism strengths of UHPC bonded to sandblasted NSC (Carbonell et al. 2012). The maximum interface shear stress of 183 psi is also much less than the 1606 psi slant shear strength found for smooth mortar-UHPC samples (Harris et al. 2011). This finding suggests that due to the contribution of truck load alone, the likelihood of an interfacial failure is low. It is again noted that the results from the bond testing do not provide a direct comparison to the complex state of 3-D stress at the interface, but do provide a basis for comparing the magnitude interface shear and debonding stress.

Although debonding and shear stresses at the compose interface were found to be satisfactory, there are some configurations where the tensile stress exceeds the strength limits, especially in cases were full fixity of the girder supports is modeled. Figure 4.32 through Figure 4.33 show strength limits (Graybeal 2006a,b) combined with the tensile stresses caused in each FEM configuration considered in the previous models. Both of these scenarios had a $10 \mathrm{ft}$ girder spacing and load Case E, which causes the worst case tension stresses of the girder spacings and loading considered in this analysis.

In Figure 4.32 and Figure 4.31, it can be seen that at early ages, AMC and MSC overlays of any thickness bonded to $5 \mathrm{ksi}$ strength concrete $\left(\mathrm{E}_{\mathrm{o}} / \mathrm{E}_{\mathrm{d}}\right.$ equal to 1.1 and 1.2) are adequate under live loads. Recall that these figures were based off models with 8 in. bridge decks. These figures also show that early-age overlays bonded to $3 \mathrm{ksi}$ strength concrete $\left(\mathrm{E}_{\mathrm{o}} / \mathrm{E}_{\mathrm{d}}\right.$ equal to 1.5 and 1.6), only UHPC overlays $3 / 4$ in. or greater can be applied onto 8 in. bridge deck. As shown in Figure 4.32 and Figure 4.33, decreased deck thickness lowers the tensile cracking stresses in the UHPC overlay; therefore, these conclusions are also valid for 6 in. decks. The assessments for AMC are only estimates to the adequate overlay thicknesses, as they are compared to UHPC strength after 5 days, which has a higher tensile strength that what would exist at younger ages.

Although the findings in the previous paragraph assist in understanding the adequate overlay thicknesses at early-ages of traffic opening and bed turnover times, the 
recommended overlays must also be adequate at full strength (in-service) conditions. In Figure 4.32 , it can be seen that AMC $1 / 4$ in. and $1 / 2$ in. overlays bonded to $3 \mathrm{ksi}$ strength concrete $\left(\mathrm{E}_{\mathrm{o}} / \mathrm{E}_{\mathrm{d}}\right.$ equal to 2.2), 8 in. bridge decks are not adequate under live loads. However, all AMC overlay thicknesses are adequate when bonded to a 5 ksi concrete deck $\left(E_{0} / E_{d}\right.$ equal to 1.7). Based on the findings from Figure 4.32, all AMC overlay thickness are adequate on $6 \mathrm{ft}$. thick bridge decks. Literature provides two main values for comparison in determining the adequacy of MSC overlays: indirect and direct tension strength (Graybeal 2006a,b). The direct tension strength will be used in comparison as it is more conservative. Using this lower bound, Figure 4.31 illustrates that $3 / 4$ in. and larger MSC UHPC overlays are adequate when bonded to an 8 in. thick, $5 \mathrm{ksi}\left(\mathrm{E}_{\mathrm{o}} / \mathrm{E}_{\mathrm{d}}\right.$ equal to 1.8) bridge deck. When bonded to a lower strength concrete deck, such as $3 \mathrm{ksi}$, overlay thicknesses greater than 1 in. are adequate. As shown in Figure 4.33, these assessments are adequate for 6 in. deck thickness.

All assessments regarding MSC UHPC are only meant to provide baselines to the actual behavior, as they were compared to UHPC strength for tempered steam cure. Tempered steam cure specimens would have higher tensile strengths than an MSC cure. Also, since the MSC does not reach its full compressive strength after cure is completed (as tempered steam cure specimens do), the strength at early ages will be lower than that shown here.

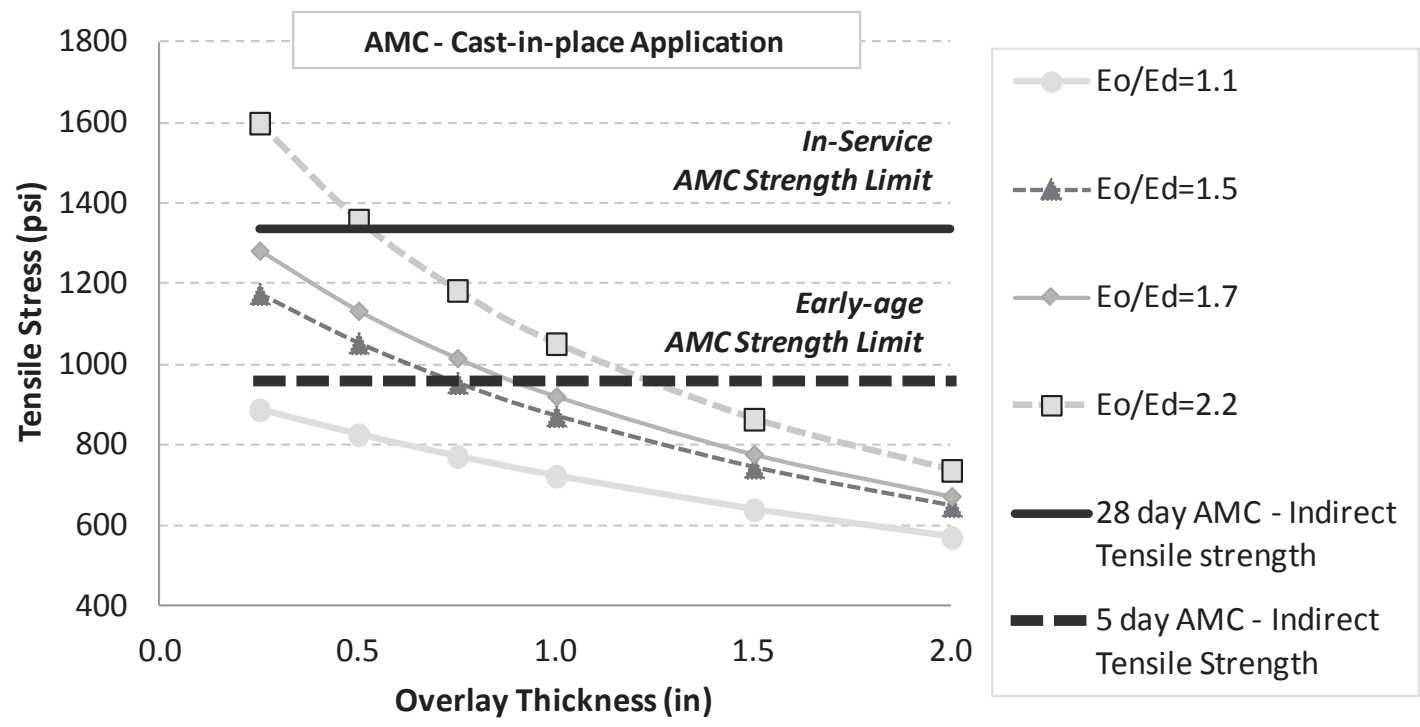

Figure 4.30: Tension stress and strength for AMC UHPC and fixed girder supports $\left(t_{d}=8\right.$ in. $)$ 

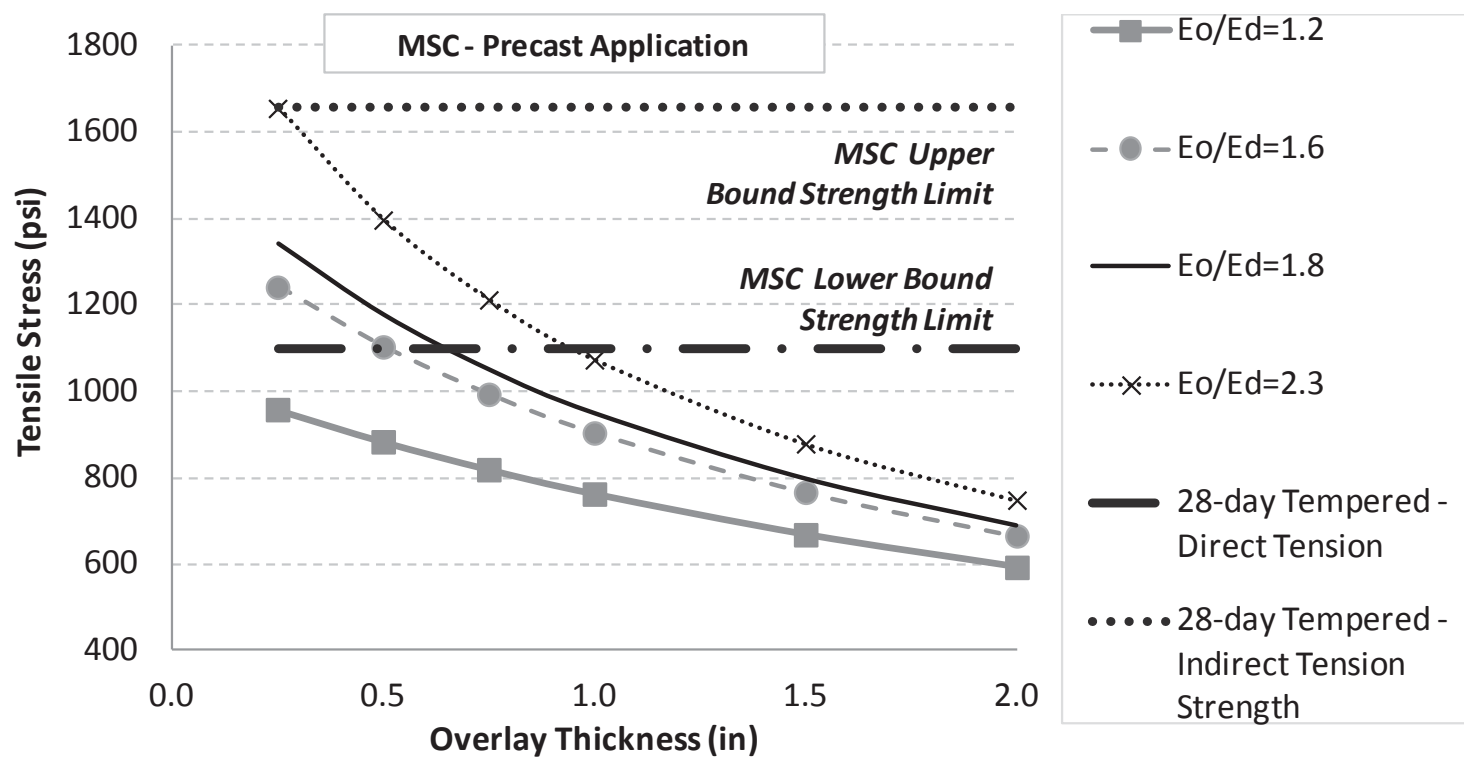

Figure 4.31: Tension stress and strength for MSC UHPC and fixed girder supports $\left(\mathbf{t}_{\mathrm{d}}=8\right.$ in. $)$

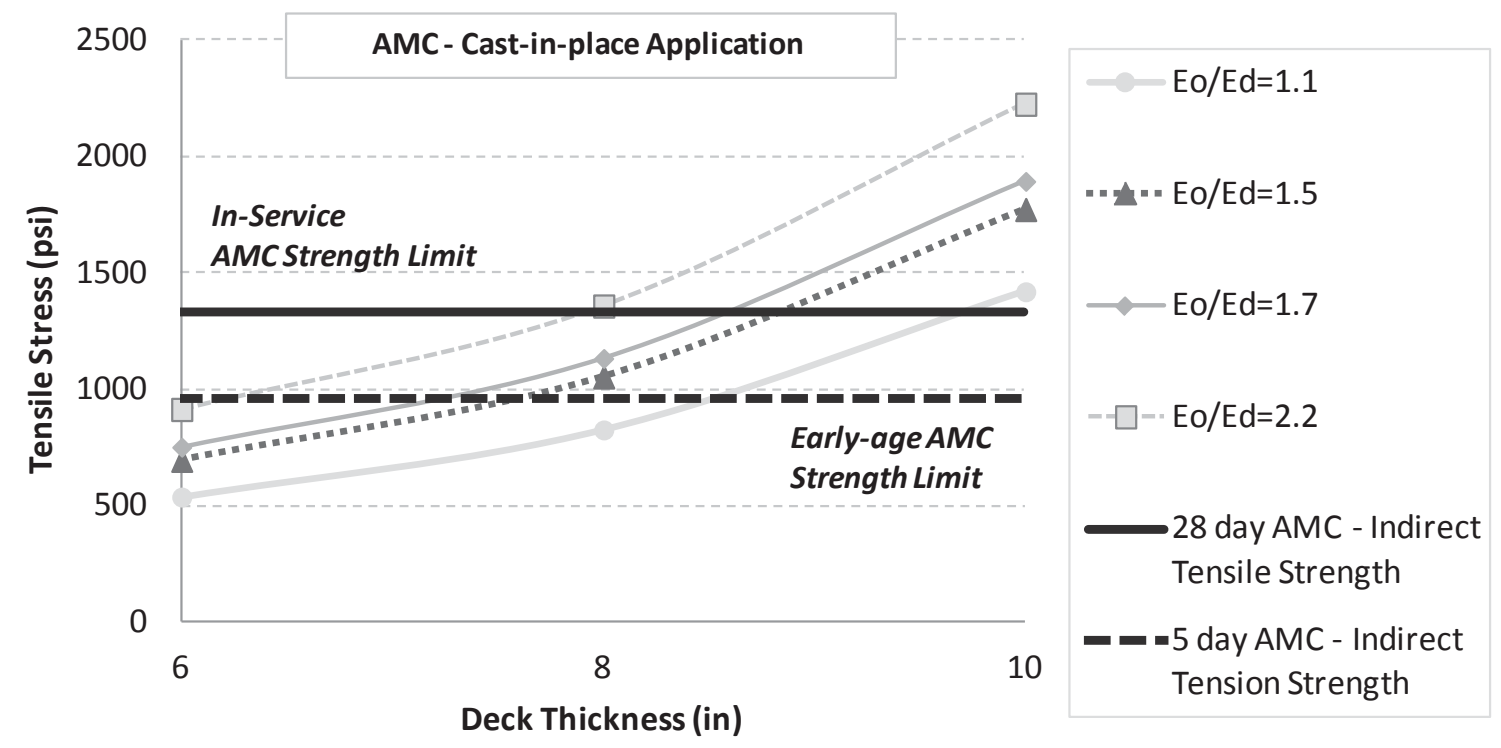

Figure 4.32: Tensile stress and strength for AMC UHPC and fixed girder supports $\left(\mathbf{t}_{\mathbf{0}}=1 / 2\right.$ in $)$ 


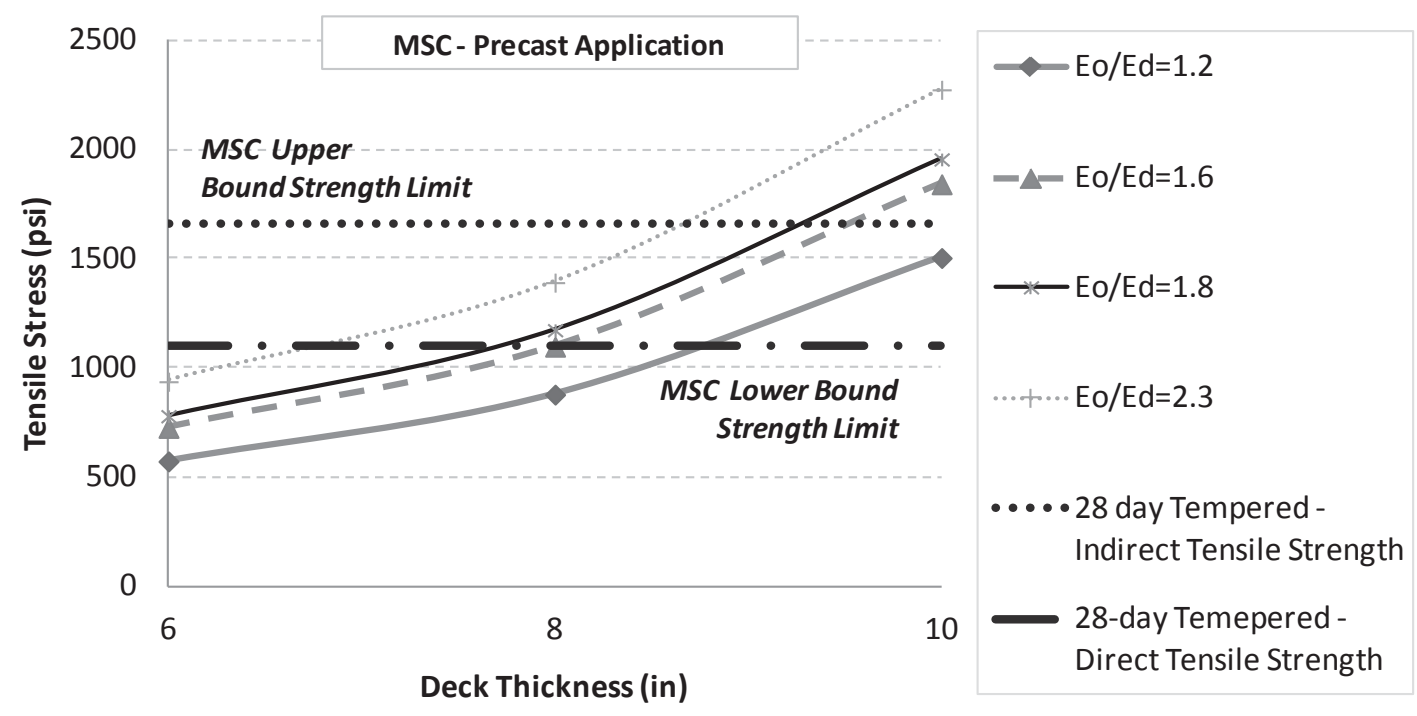

Figure 4.33: Tensile stress and strength for MSC UHPC and fixed girder supports $\left(t_{0}=1 / 2\right.$ in $)$

Overall, this analysis suggests that for a fully restrained bridge deck under the given notional design truck loading, UHPC overlays are not applicable on decks which are 10 in or greater. It was also found that UHPC overlays are most promising on 6 in. bridge decks for the geometry, stiffness, and loading considered. Overlays between 1.0 in. and $2.0 \mathrm{in}$. are recommended for both cure durations and all considered geometric configurations when live load alone is applied and full fixity of the slab occurs.

No bridge system in the field actually provides this high degree of restraint, this fixity considered here is only an upper level bound on the global behavior. In Scenario 2, representative global bridge behavior and degree of restraint is compared to the plate models from this first scenario and the true estimate of tensile cracking stresses is determined. This analysis also does not consider volume changes of UHPC, such as shrinkage, creep, or thermal or environmental changes, but only provides a relative idea as to the mechanical behavior which may be found in a UHPC overlay cast on a concrete bridge deck.

\subsubsection{Scenario 2 - Bridge Model}

In addition to the basic plate models, a full bridge structure was modeled to evaluate the complete system response of UHPC as a thin bonded overlay. The overlay thickness and strength were the only parameters investigated in this model to avoid a re-design of the full bridge model. The deck thickness, concrete strength, and girder spacing of the S11 Bridge remained unchanged at 8 in, $3 \mathrm{ksi}$, and $7 \mathrm{ft}-3$ in., respectively. Notional tandem and truck loads were placed directly in the center of the bridge, as well as in the center of one lane to study the state of stress in the overlay-deck system. 
Figure 4.34 through Figure 4.41 show the variation in interface shear, debonding, and surface cracking stresses as a function of the overlay thickness and overlay strength (stiffness) for this global model. They also illustrate the variation of stresses under different load positions.

Figure 4.34 through Figure 4.37 show the debonding stresses which occur under notional design tandem and truck loading, respectively. As in the plate models, there is some variation in the debonding stress with increased overly thickness and relative material stiffnesses, as some configurations do not induce tension into the slab surface. It can be seen that higher debonding stresses are created when notional loads are placed in the center of one lane than when placed in the center of the bridge. Also, the design tandem controls the maximum debonding stresses at the composite interface, which agrees with the findings of Scenario 1 where load Case E controlled. Relatively similar stresses are found for overlay thickness less than 1.0 in. regardless of the truck loading or positioning applied. Regardless of overlay stiffness, overlay thickness, or the loading applied, the stresses which may cause debonding of the composite deck-overlay system are much lower than the strengths found in past literature (Harris et al. 2011; Carbonell et al. 2012).

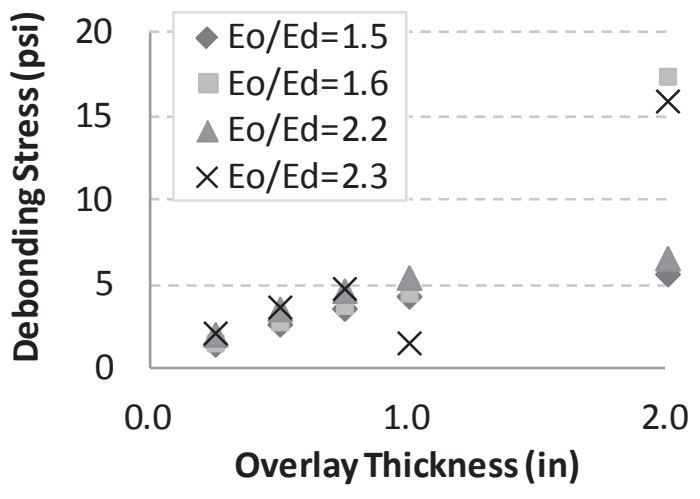

Figure 4.34: Design tandem in bridge center - debonding stress

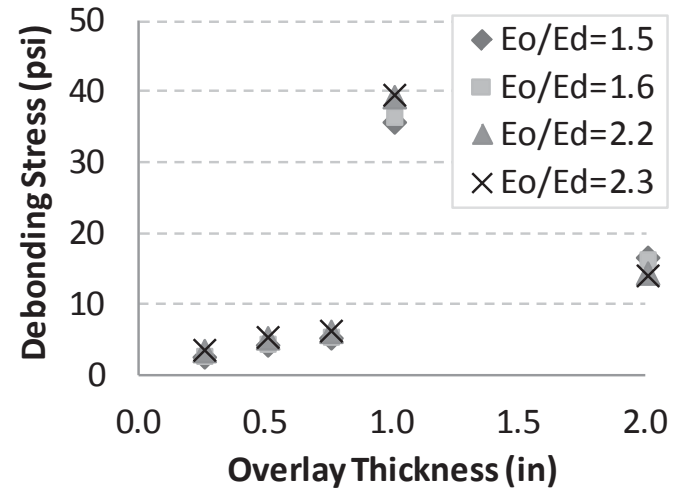

Figure 4.35: Design tandem in bridge lane - debonding stress 


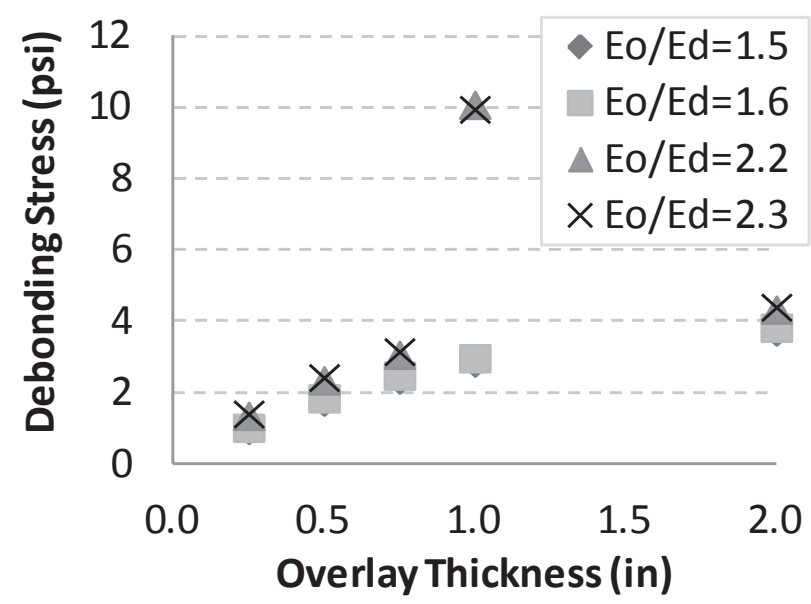

Figure 4.36: HS-20 truck in bridge center - debonding stress

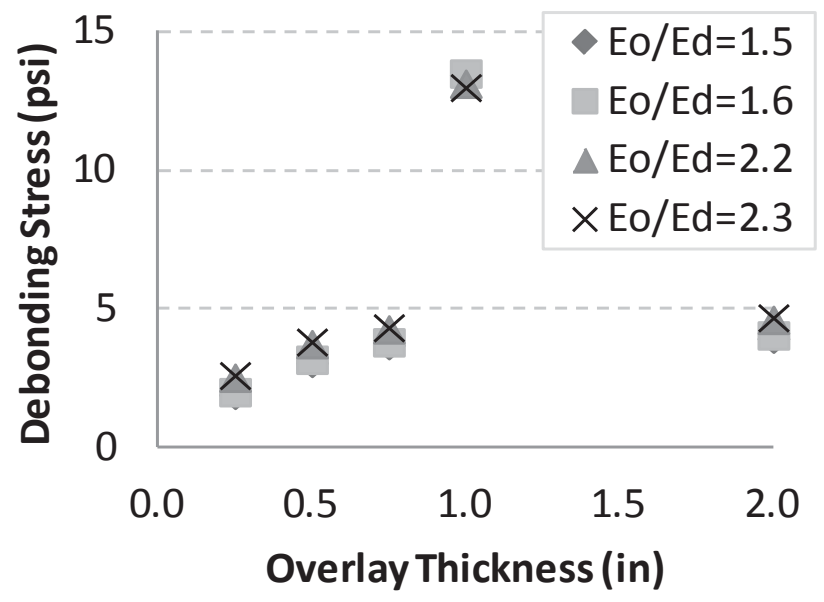

Figure 4.37: HS-20 truck in bridge lane - debonding stress

Interface shear stresses for the various parameters are displayed in Figure 4.38 through Figure 4.41 when notional design tandem and truck loading are applied. The general trend of increased interface shear stress with increased overlay thickness and increased material stiffness ratio is the same as was found in Scenario 1. Similar to the debonding stress distributions, higher interfacial shear stresses are found when notional loads are placed in the center of one lane. Slightly higher stresses are caused when the design tandem is applied, which correlates well with the findings of Scenario 1. All overlay thickness and material stiffness ratios are found to be adequate under various notional loads, as the shear stress found at the composite interface are less than the slant-shear strengths of previous literature (Harris et al. 2011). 


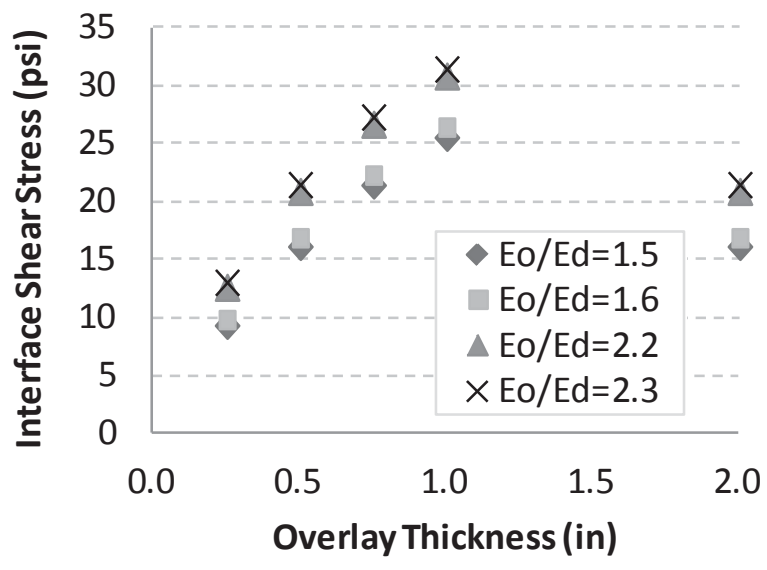

Figure 4.38: Design tandem in bridge center - interface shear stress

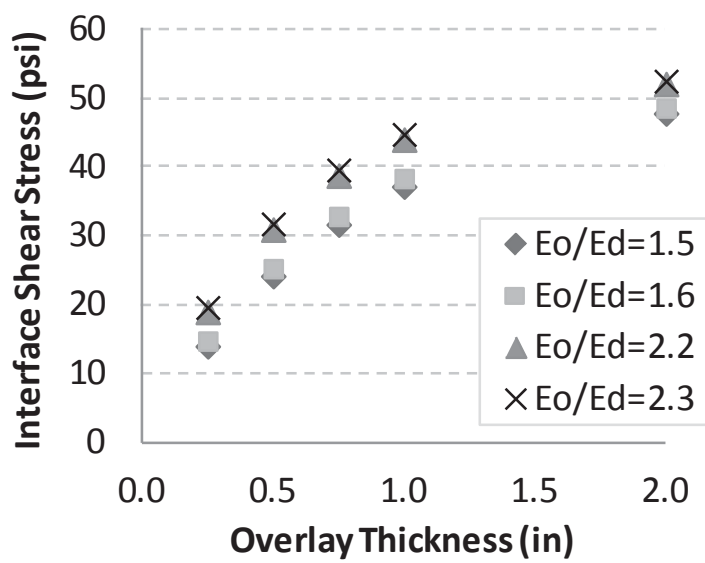

Figure 4.39: Design tandem in bridge lane - interface shear stress

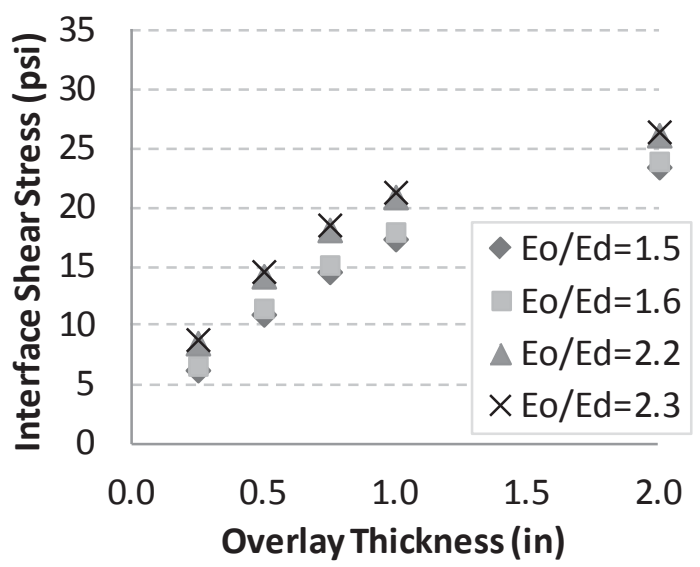

Figure 4.40: HS-20 truck in bridge center - interface shear stress 


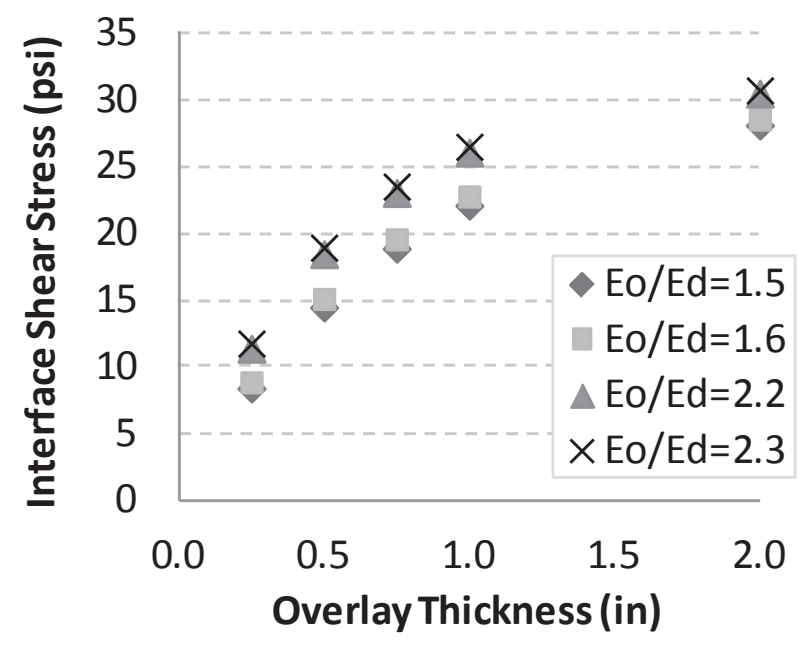

Figure 4.41: HS-20 truck in bridge lane - interface shear stress

The global behavior of tensile stress which would cause cracking in a UHPC overlay system under notional truck load is illustrated in Figure 4.42 and Figure 4.43, while the stress under tandem load is shown in Figure 4.44 and Figure 4.45. The general trend of decreased tensile stress with increased overlay thickness and decreased material stiffness ratio is the same as was found in Scenario 1. Higher tensile cracking stresses are caused when the notional loads are placed in the center of the bridge. Due to the global system behavior of a full bridge with composite girder-deck connections, the magnitude of tensile stresses found for all load configurations are less than the strengths found in previous literature (Graybeal 2006a; 2006b).

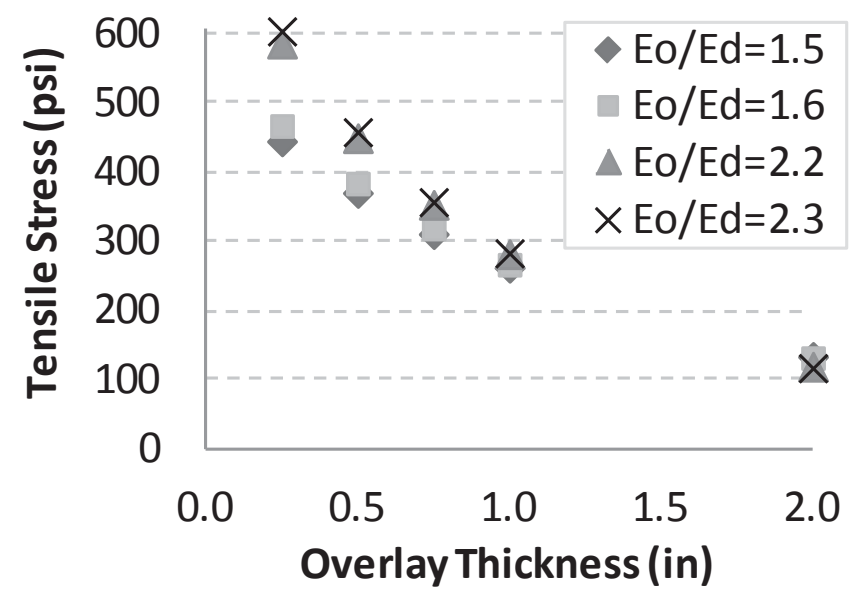

Figure 4.42: Design tandem in bridge center - tensile stress 


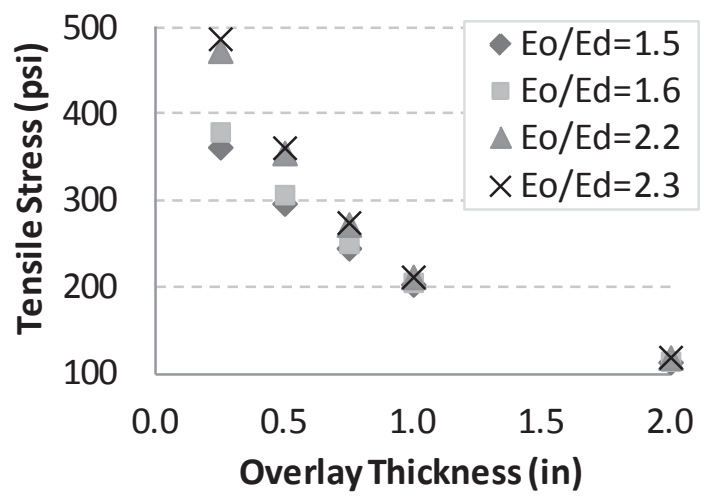

Figure 4.43: Design tandem in bridge lane - tensile stress

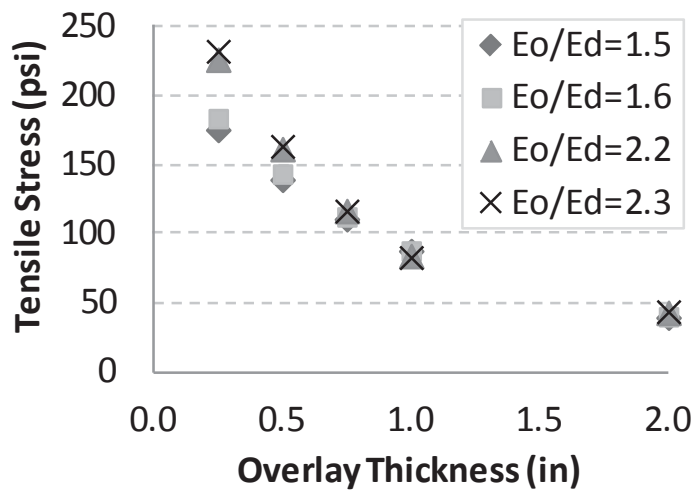

Figure 4.44: HS-20 truck in bridge center - tensile stress

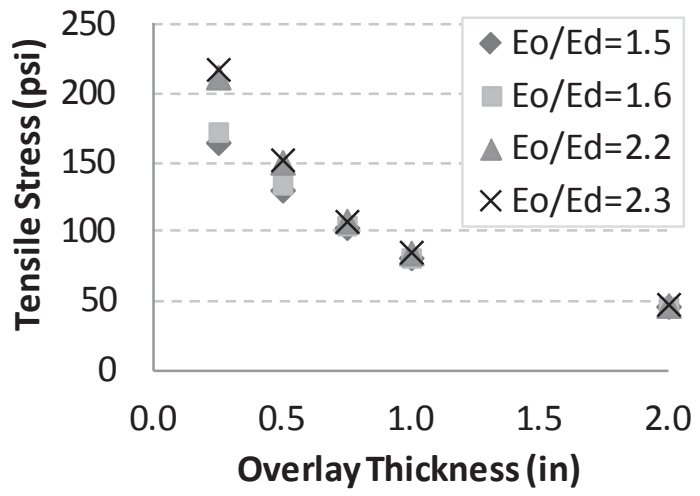

Figure 4.45: HS-20 truck in bridge lane - tensile stress

From the bridge FEA, it is found that all overlay thicknesses and UHPC overlay strengths are adequate. However, this model only considered the girder spacing of $7.25 \mathrm{ft}$ and a deck thickness of 8 in. present on the S11 Bridge. It also only considers loading in two 
locations, which may not be the worst-case positions. For bridge owners who wanted to determine the optimum UHPC overlay thickness for their specific application, constructing a complete bridge FEM is not time or cost effective. A plate model, however, would be much more efficient. In an effort to compare the accuracy of the plate models to the global bridge behavior another plate FEM was constructed which directly mimicked the S11 bridge geometry, material properties, and loads.

\subsubsection{Comparison of Global Bridge and Plate FEM}

The plate models in Scenario 1 were included in this research study to bound the global behavior of a full-scale bridge and to determine the state of stress in a UHPC overlay at these bounds. This provides representative estimates as to the compatibility of the proposed overlay system, but accurate analysis is only found through field tests or by complex FEM. In an effort to simplify the analysis for bridge owners considering a UHPC overlay, while maintaining confidence in model accuracy, comparisons between global FEM and plate FEM consisting of the same geometry, material properties, and loading were conducted here.

Figure 4.46 through Figure 4.57 show the state of stress of the S11 Bridge modeled as a plate. Fixed and simple girder supports were included to determine which constraint more accurately represented the global system behavior. Just as the S11 Bridge, girder supports were spaced $7.25 \mathrm{ft}$. on center, the deck thickness was modeled as $8 \mathrm{in}$., and the deck concrete had 3 ksi compressive strength. In Scenario 2, the notional design tandem and HS-20 were placed in the center of the bridge and the center of one lane. In these configurations, only two wheels (one from each axle) fall between girders. Though the longitudinal wheel positions differ between the design truck and tandem, the transverse distance of wheels to adjacent girders are 36 in. for both positions. For comparison, the bridge FEM results from vehicles located in the center of the bridge are included in these graphs.

The debonding stresses which occur in a $7.25 \mathrm{ft}$. width plate model are shown in Figure 4.46 through Figure 4.49 for the applied design tandem and HS-20 truck. The figures also include the results from the global model FEM for the same loading and configuration. As in the global model, debonding stress generally increased with increased overlay thickness at a similar rate. As in the other FEMs, some loading configurations only induced compression in the overlay layer and therefore are not shown in these figures. Higher differences in modulus of elasticity between composite materials results in higher debonding stresses for both FEM scenarios, though the influence of $\mathrm{E}_{\mathrm{o}} / \mathrm{E}_{\mathrm{d}}$ on the state of stress was greater in the plate models. There were differences in stress magnitudes between models. In all load configurations the plate model produced higher stresses than those found in the global model. For example, the debonding stress caused by a design tandem placed in the center of the bridge with a 2 in. overlay and an $E_{o} / E_{d}$ of 2.3 resulted in 35 psi for the fixed plate, 50 psi for simple plate, and 16 psi for the bridge model. Another example is the HS-20 truck placed in the center of the bride 
with a $3 / 4$ in. overlay and an $E_{0} / E_{d}$ of 1.5 resulted in 15 psi for the fixed plate, 12 psi for simple plate, and 2 psi for the bridge model.

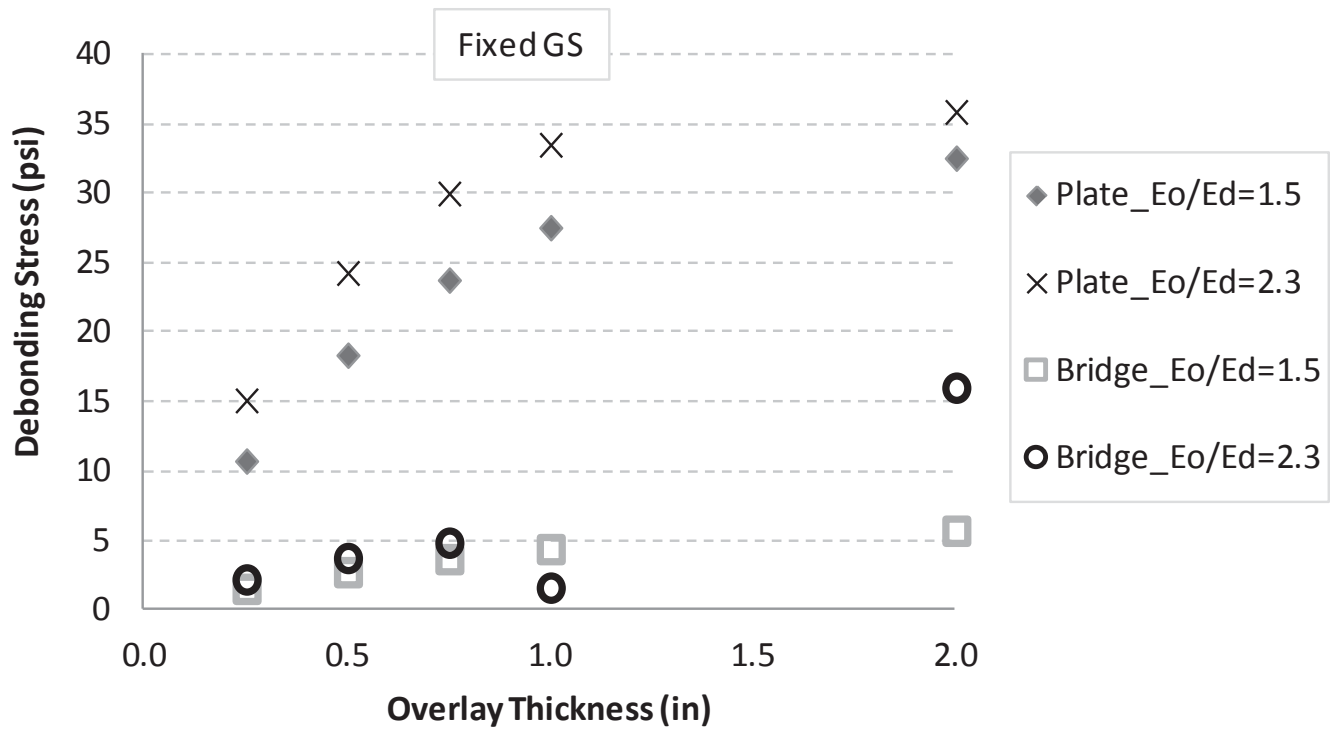

Figure 4.46: Plate and bridge FEM comparison - debonding stress, design tandem, fixed girder supports

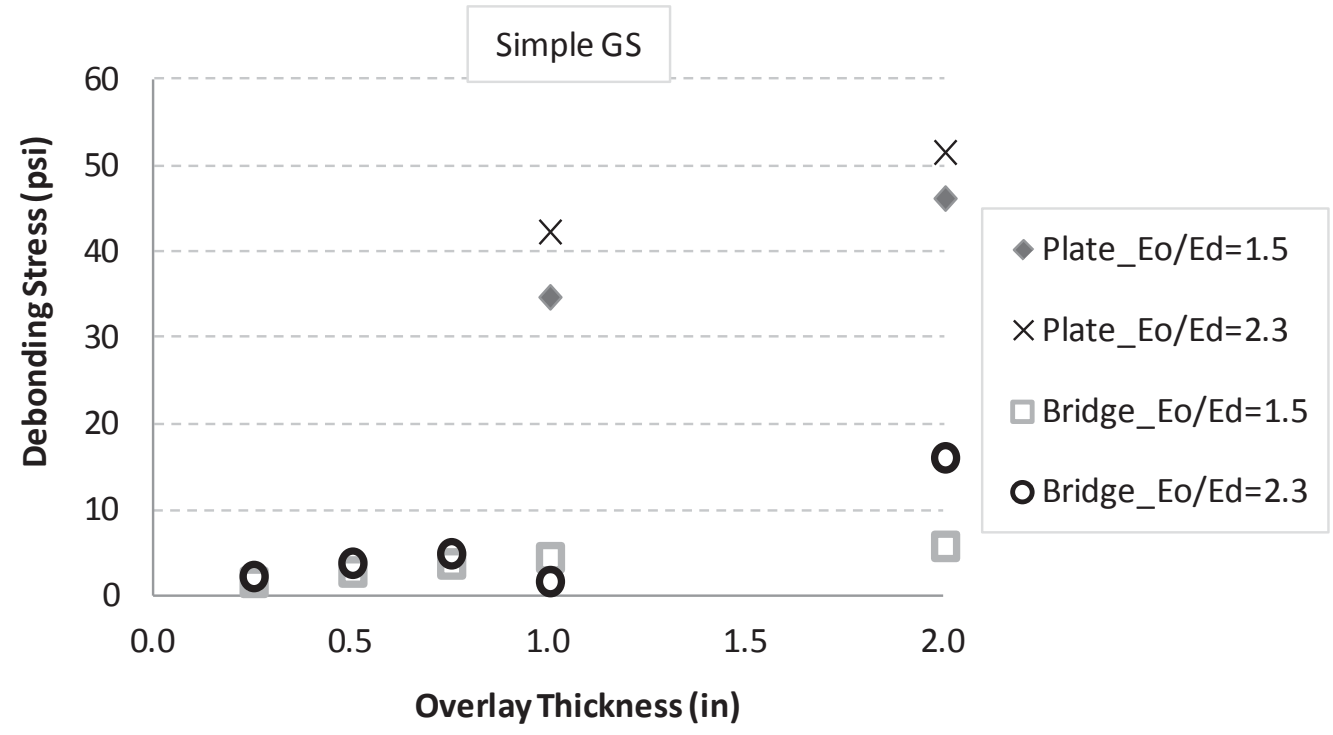

Figure 4.47: Plate and bridge FEM comparison - debonding stress, design tandem, fixed girder supports 


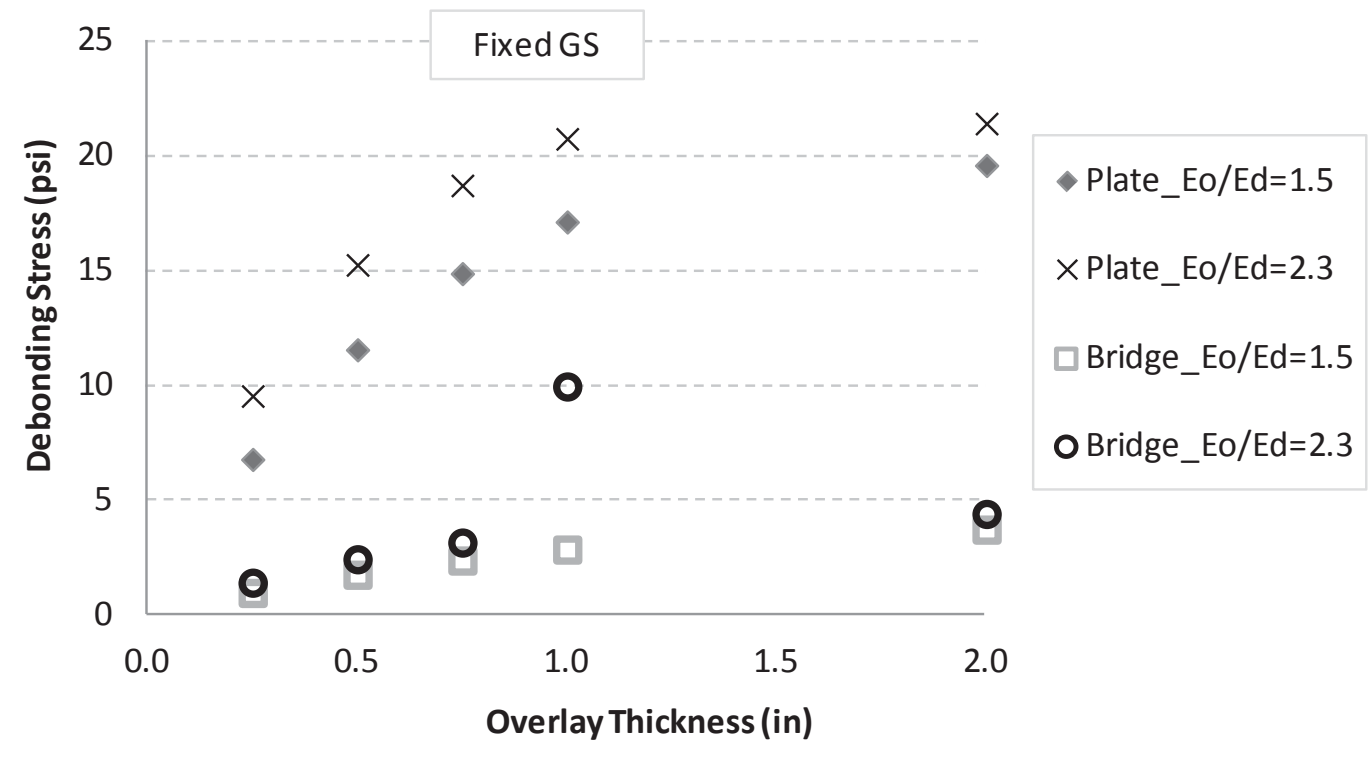

Figure 4.48: Plate and bridge FEM comparison, debonding stress, HS-20 truck, fixed girder supports

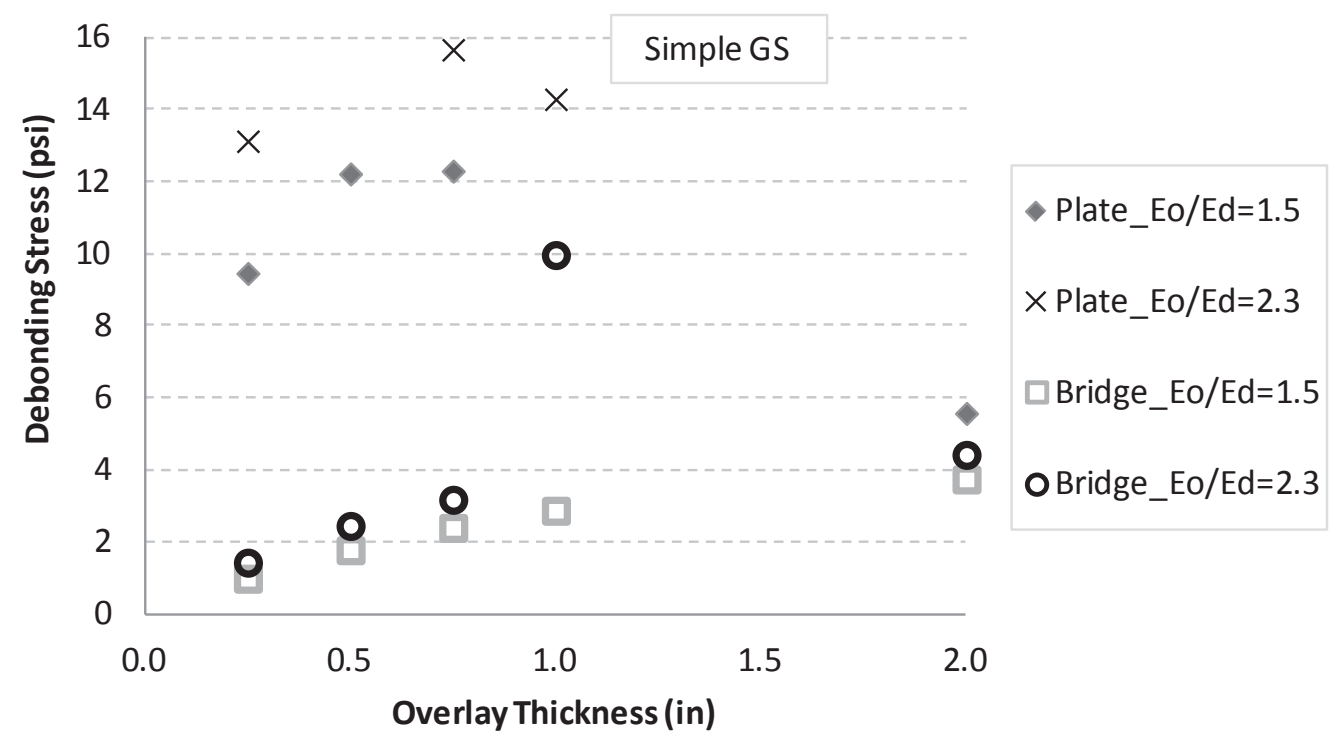

Figure 4.49: Plate and bridge FEM comparison - debonding stress, HS-20 truck, simple girder supports

Figure 4.50 through Figure 4.53 illustrate the interface shear stress of the S11 Bridge plate and bridge model under design tandem and HS-20 truck loading. The general trend of increase shear stress with increased overlay thickness and modulus ratio is very similar to that found in the S11 Bridge global model. The plate model results for simple and 
fixed girder supports are very similar, but it can be seen that the plate model with simple girder supports more accurately models the global system behavior.

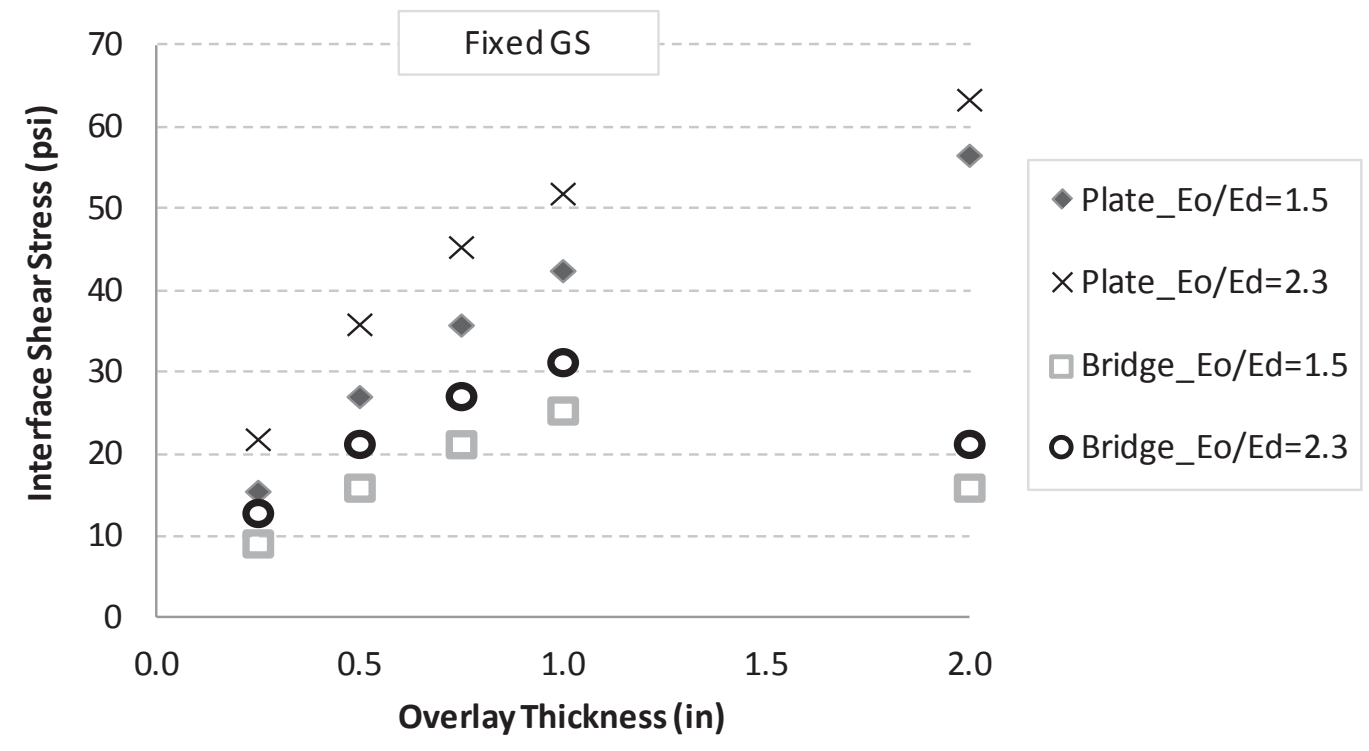

Figure 4.50: Plate and bridge FEM Comparison - interface shear stress, design tandem, fixed girder supports

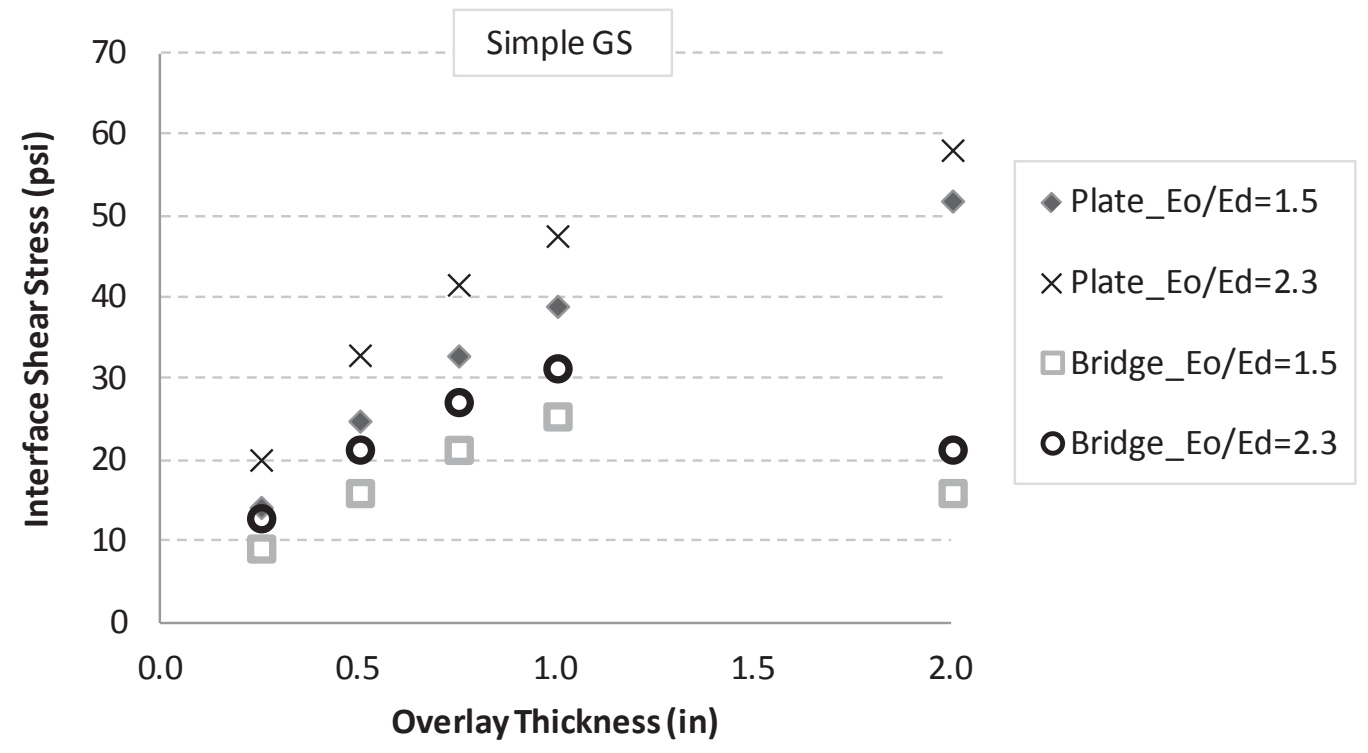

Figure 4.51: Plate and bridge FEM Comparison - interface shear stress, design tandem, simple girder supports 


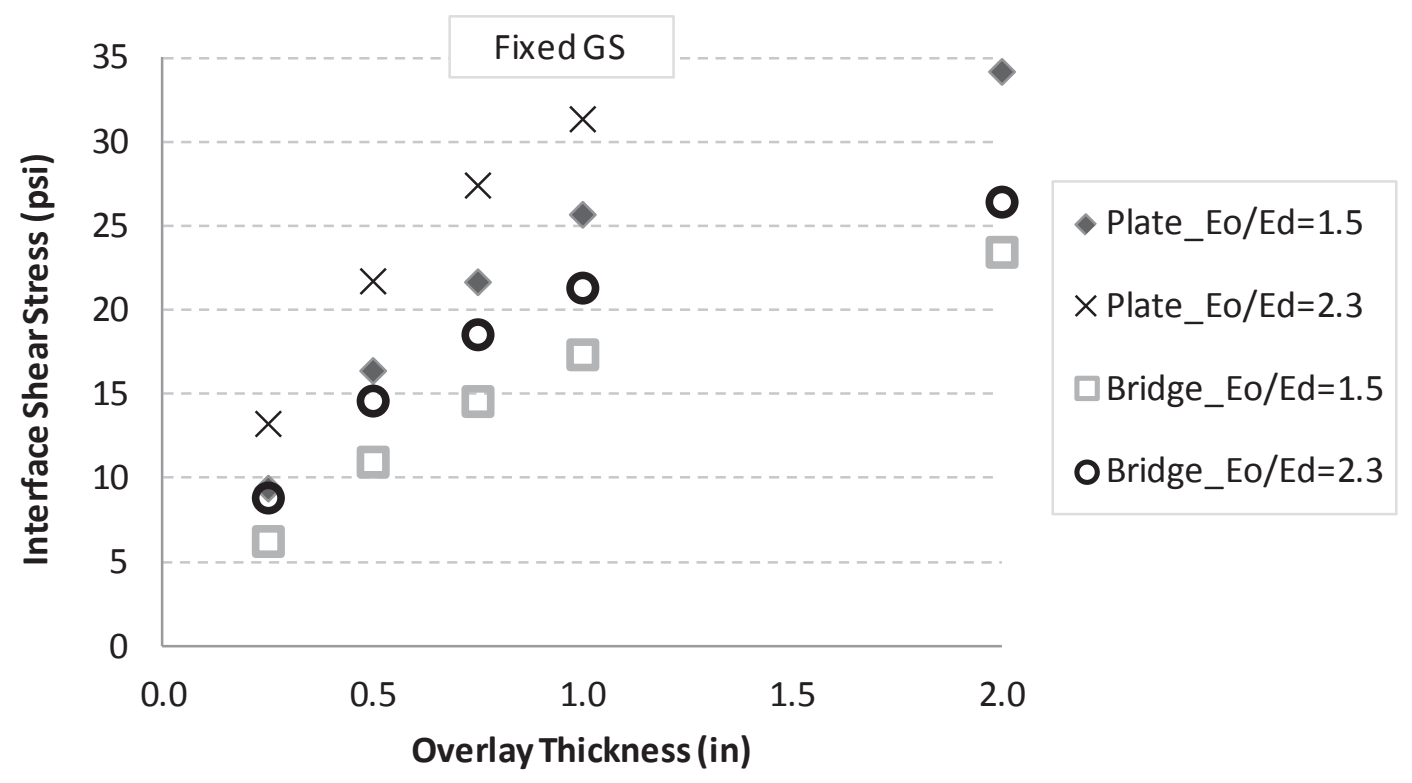

Figure 4.52: Plate and bridge FEM Comparison - interface shear stress, HS-20 truck, fixed girder supports

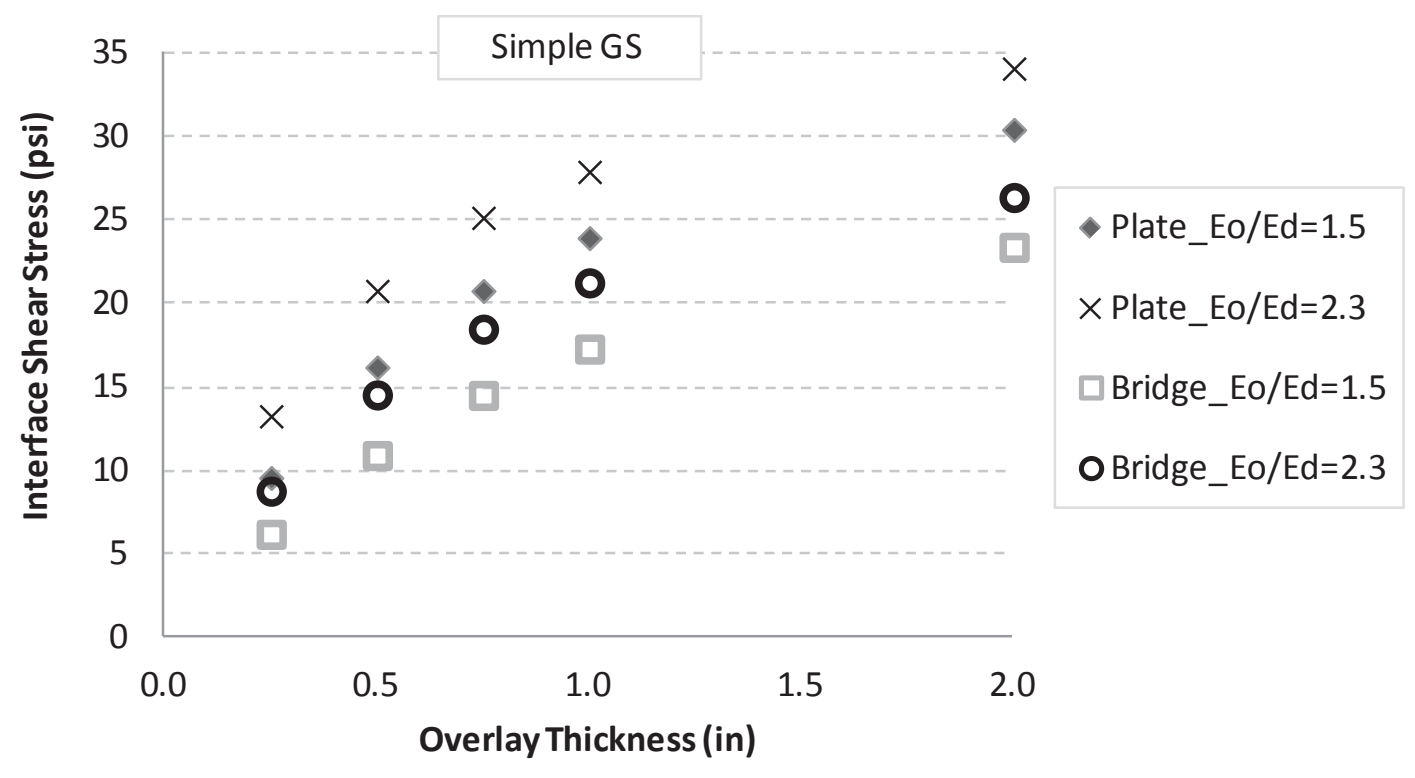

Figure 4.53: Plate and bridge FEM Comparison - interface shear stress, HS-20 truck, simple girder supports

Figure 4.54 through Figure 4.57 illustrate the surface tensile stress of the S11 Bridge plate and bridge model under design tandem and HS-20 truck loading. The general trend of decreased tension stress with increased overlay thickness and decreased material stiffness ratio is very similar to the global bridge FEM. These figures illustrate that the 
fixed girder supports in the plate model provide an upper bound of the global behavior, while simple plate models provide a lower bound. In Figure 4.57, it can be seen that simply supported girders in the plate FEM closely model the global response for this configuration. Additional research by Shann et al. (2012) found that plates with simple girder supports also accurately represented the maximum interfacial principal stresses found from global bridge models.

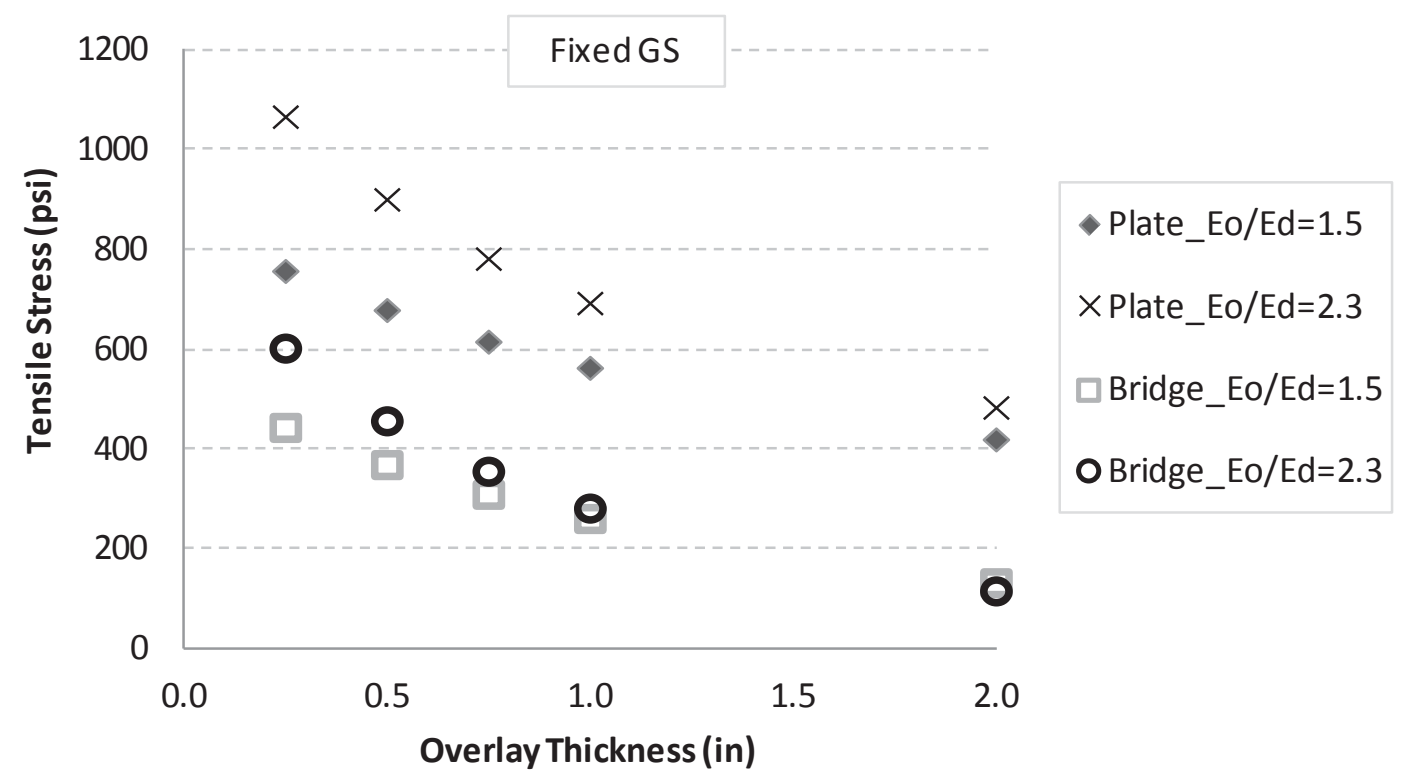

Figure 4.54: Plate and bridge FEM Comparison - tensile stress, design tandem, fixed girder supports 


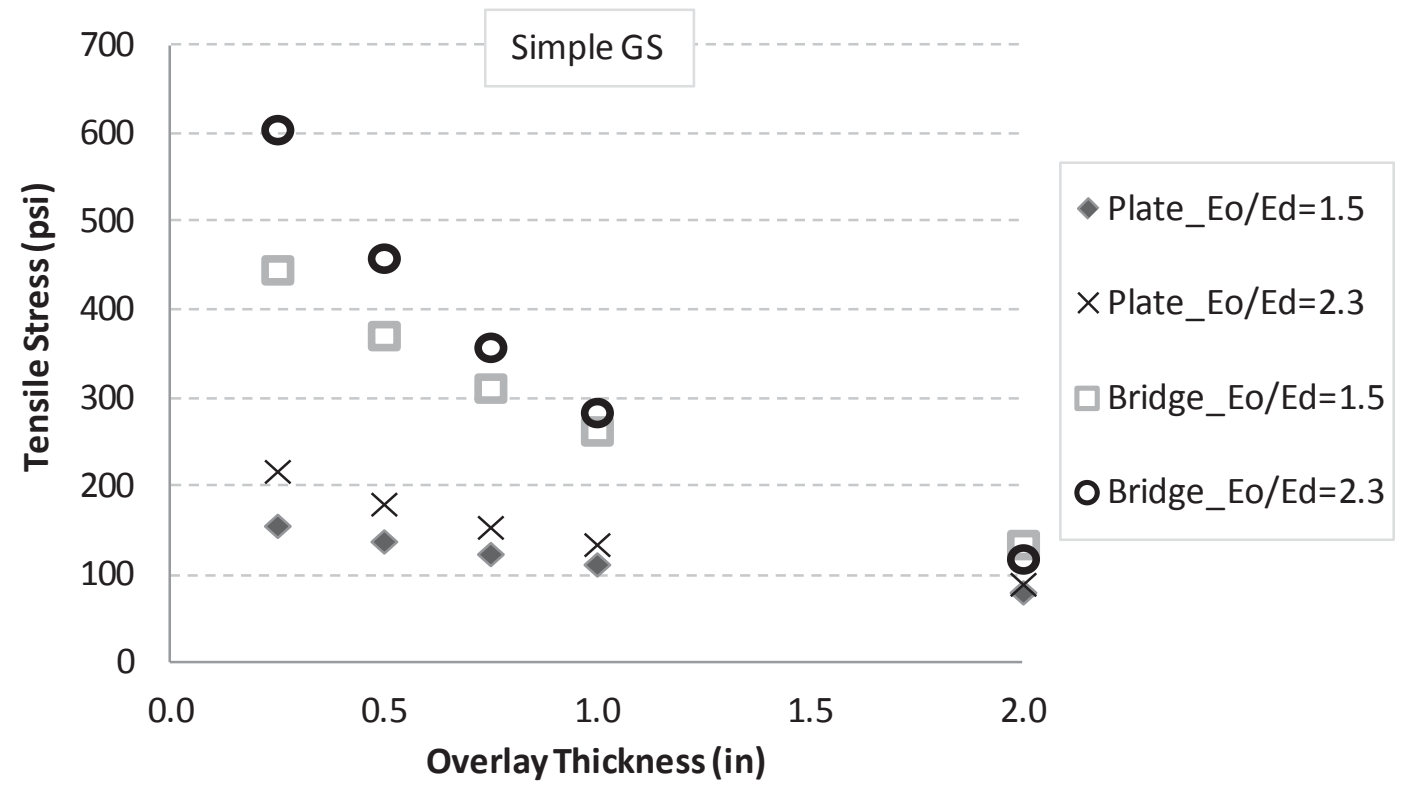

Figure 4.55: Plate and bridge FEM Comparison - tensile stress, design tandem, simple girder supports

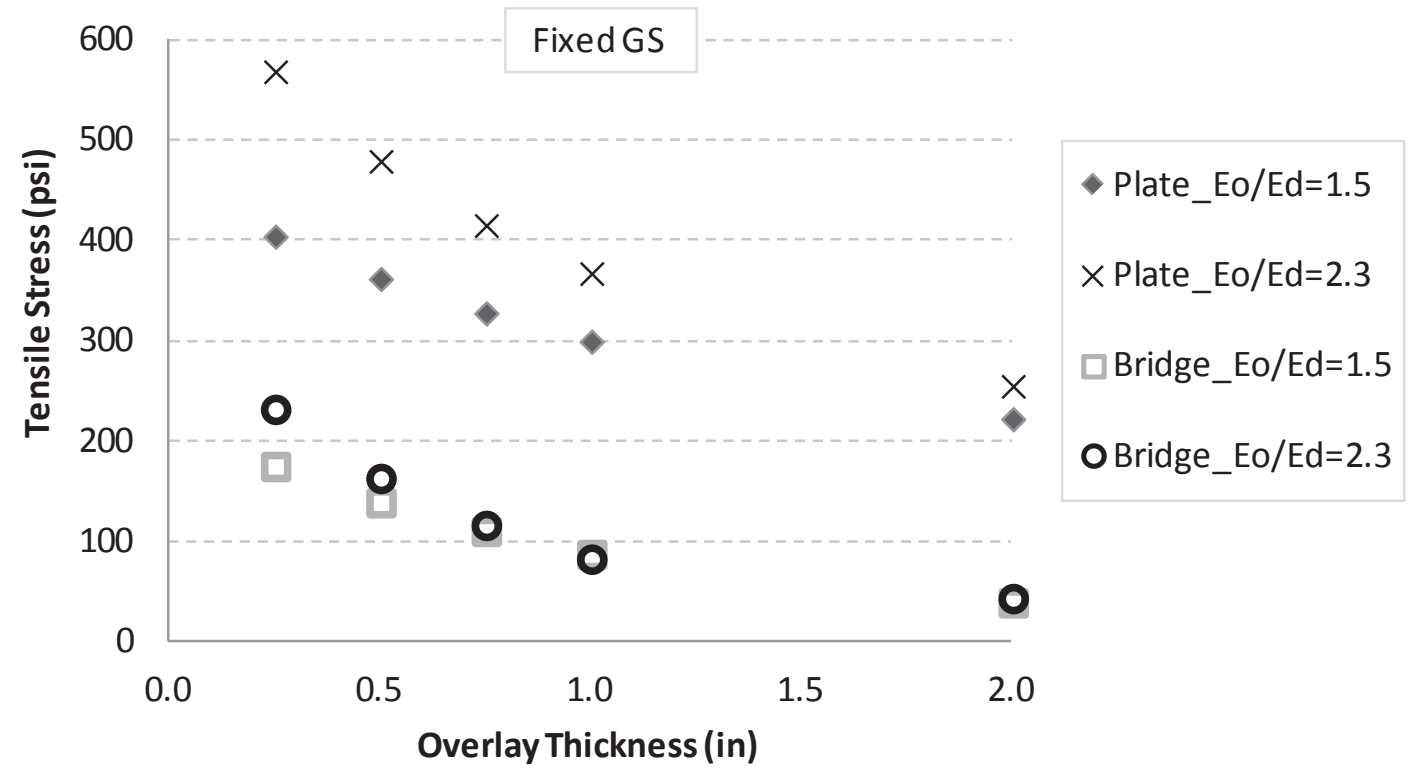

Figure 4.56: Plate and bridge FEM Comparison - tensile stress, HS-20 truck, fixed girder supports 


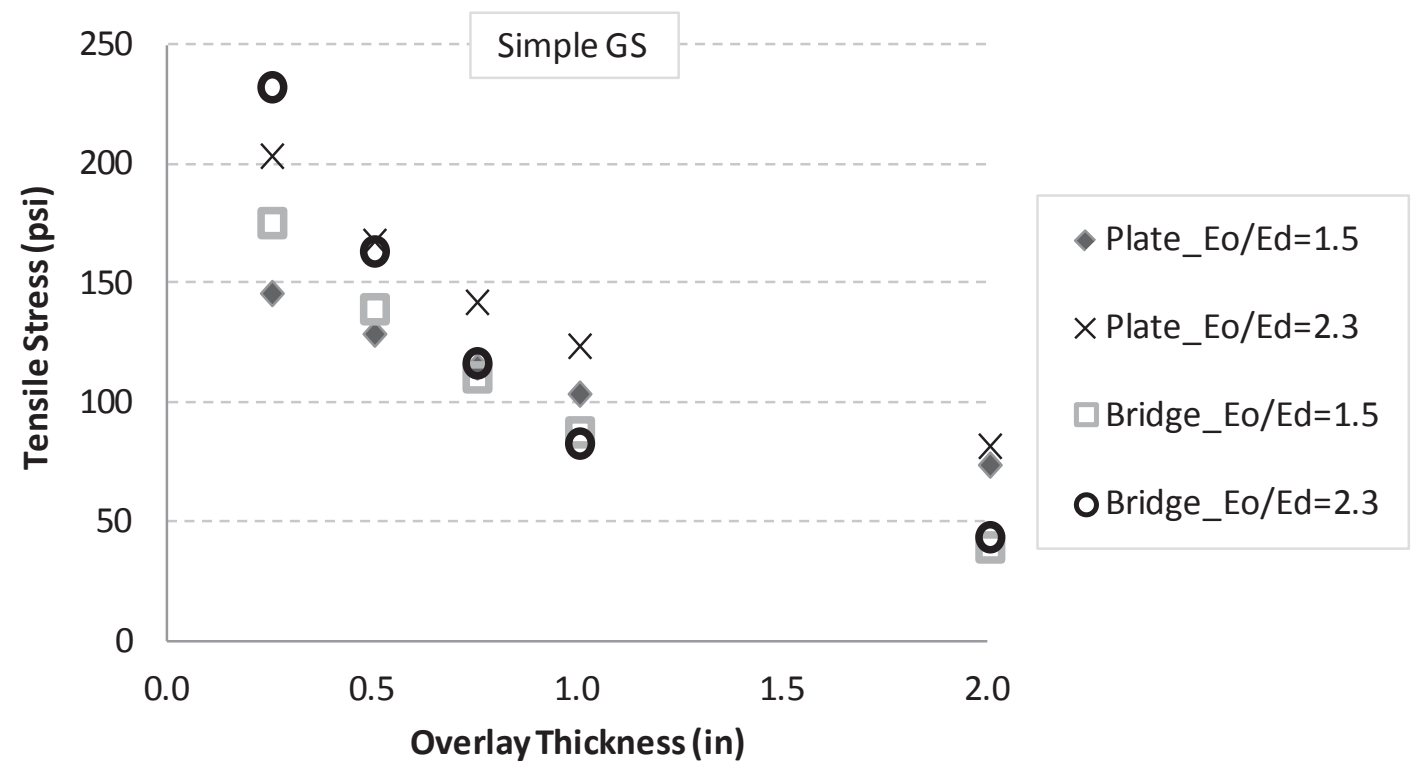

Figure 4.57: Plate and bridge FEM Comparison - tensile stress, HS-20 truck, simple girder supports

From the findings of the current and previous analysis, the actual state of stress in a bridge UHPC overlay-NSC deck system is more closely modeled by simple girder supports; meaning stresses are higher for fixed supports, but more closely match the simply supported plates in the case considered. Plate FEMs can be used by bridge owners to accurately model specific UHPC overlay - NSC deck systems and choose overlay thicknesses that work best for their specific interest, as long as bridge behavior in question is completely understood. It is acknowledged that the construction and connection between a given bridge deck- girder system is different for every bridge and that the results presented here are included to provide the representative state of stress in a UHPC overlay cast on NSC bridge deck. The stresses induced in a particular bridge loading may be more representative of a fixed deck-girder condition rather than simple support findings stated here.

\subsection{Shrinkage and Notional Design Truck Load}

Cracking and interface shear stresses caused by combined restrained shrinkage and notional design truck loading were analyzed to determine the overall compatibility of a thin bonded ultra-high performance concrete overlay cast on a normal strength concrete bridge deck.

The maximum tensile stress caused by restrained shrinkage occurs at the bond interface due to the restraint of the steel ring. The location of maximum tensile stresses caused by flexural loading of the applied truck load occurs at the UHPC surface. The maximum 
tensile stresses from both loads were summed to determine the combined effect and overall compatibility of the system. Using the absolute maximum was more conservative than individually summing the tensile stresses at the top surface and interface. The stresses found from the experimental tests were used for all overlay thicknesses (see Section 3.1.5).

The worst case loading found in both Scenario 1 and Scenario 2 that induces the highest tensile cracking stress is from the design tandem. In Scenario 2, it was found that plates having simple supports more accurately model the global behavior found in a full bridge model than a plate with fixed girder supports. In addition, it was previously determined that complete fixity of the deck slab at all deck thickness induces high states of stress and are not expected to be feasible for the application of UHPC overlays. Therefore, only the design tandem results from simply supported plates are included in this section.

Prior to superposition of shrinkage and truck loads, an investigation was initiated to determine whether any parameters were not compatible for a UHPC overlay system. This was done by comparing the stress results from restrained shrinkage tests to the strengths found in literature and determining the remaining live load capacity available (if any) before failure occurred. Since the tensile stress to produce cracking and tension was the controlling mode of failure in this application, the tensile stress-strength comparison was of primary focus.

The indirect and direct tensile strengths found in literature (Graybeal 2006a,b) yielded different results due to the slightly different modes of failure that occur between test methods. For example, 1335 psi indirect tensile strength was found for 28-day AMC UHPC (Graybeal 2006a), where 800-1000 psi was found in direct tensile strength tests (Graybeal 2006b). In the restrained shrinkage tests, 1040 psi was calculated as the tensile stress at the UHPC-steel interface. This calculated stress is higher than the direct tensile strength found by Graybeal; however, the rings did not crack, so the actual strength of those specific rings are greater than the direct tension strength values. Therefore, the AMC indirect tensile strength will be used for comparison in this section as indication of the system compatibility. Using this indirect tensile strength it can be seen that 300 psi of tensile stress may be added to the AMC overlay system above and beyond what occurs due to restrained shrinkage. In the analysis conducted in Scenario 1 of the FEMs, the tensile stresses induced by live load on a 10 in. thick bridge deck was much greater than 300 psi. This was true for all modulus ratios and boundary conditions indicating that UHPC overlays are not applicable on bridge decks of 10 in. or thicker. Neglecting applications on 10 in decks, the worst case configuration on the tensile stress is a UHPC overlay cast on an $8 \mathrm{in}$. NSC deck with a slab supported every $10 \mathrm{ft}$. on-center by bridge girders. Note that this configuration was used in the earlier models shown in Figure 4.18 through Figure 4.29 under load case E (design tandem).

Due to restrained shrinkage, 750 psi of tensile stress was found in MSC at 28 days (Section 4.1.2). Indirect tension strengths of 1658 psi (Graybeal 2006a) and direct tensile strengths between 1100-1300 psi were found for tempered steam UHPC specimens after 
28 days (Graybeal 2006b), indicating that MSC UHPC overlays only have about 400-900 psi of remaining tensile capacity before cracking would occur.

The tensile stress caused by the combined effect of restrained shrinkage and the notional design tandem is shown in Figure 4.58 for the worst case geometric configurations. Early age UHPC overlays were excluded from this figure, as these modulus ratios did not control overlay design. Furthermore, restrained shrinkage had not yet begun to develop at these early ages. Recall that $\mathrm{E}_{0} / \mathrm{E}_{\mathrm{d}}=1.7$ corresponds to 28-day AMC UHPC overlay cast on a 5 ksi concrete bridge deck, while a $\mathrm{E}_{0} / \mathrm{E}_{\mathrm{d}}=1.8$ represents a 28-day MSC UHPC overlay cast on a $5 \mathrm{ksi}$ bridge deck. $\mathrm{E}_{\mathrm{o}} / \mathrm{E}_{\mathrm{d}}=2.2$ and 2.3 characterize 28-day $\mathrm{AMC}$ and MSC UHPC overlay, respectively, cast on a $3 \mathrm{ksi}$ bridge deck. The lower value for direct tensile strength (Graybeal 2006a) and the indirect tensile strength (Graybeal 2006b) for tempered cured UHPC are included in this figure as upper and lower bounds to the UHPC strength, as well as the indirect tensile strength of AMC UHPC.

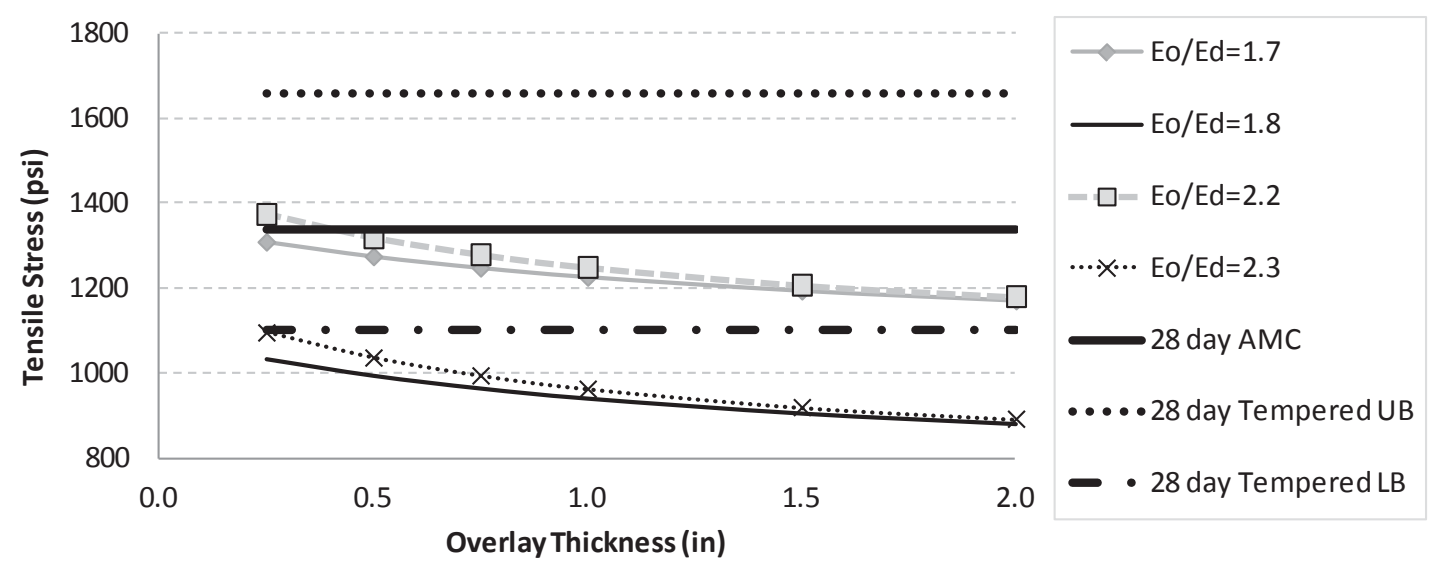

Figure 4.58: Tensile stress under combined restrained shrinkage and design tandem

It can be seen that thin-bonded MSC UHPC overlays of all thicknesses are compatible when bonded to $3 \mathrm{ksi}$ or $5 \mathrm{ksi}$ concrete bridge decks, even when the lower bound tempered strength is considered. When bonded to $5 \mathrm{ksi}$ deck concrete, all AMC UHPC overlay thicknesses are adequate for the combined restrained shrinkage and notional design loading. However, only AMC UHPC overlays greater than $1 / 2$ in. are compatible with $3 \mathrm{ksi}$ deck concrete under the given loads. As the tensile cracking stresses found for 6 in. deck thicknesses were 70-100 psi lower than that found for 8 in. thick decks (see Figure 4.28 and Figure 4.29), it is concluded that all UHPC overlay thickness for both cure regimes and concrete deck strengths are adequate under restrained conditions and notional design loads.

As discussed in Section 4.2.1, the maximum interface shear stress created from all parametric models resulted in an ultimate stress of 183 psi. The $t_{0}$ and $E_{0} / E_{d}$ analysis from this worst case configuration is shown in Figure 4.59 and Figure 4.60. To reiterate, 
the critical interlaminar shear stress is caused when girders are spaced $8 \mathrm{ft}$ apart, deck thickness is 6 in, and load case $\mathrm{E}$ is applied.

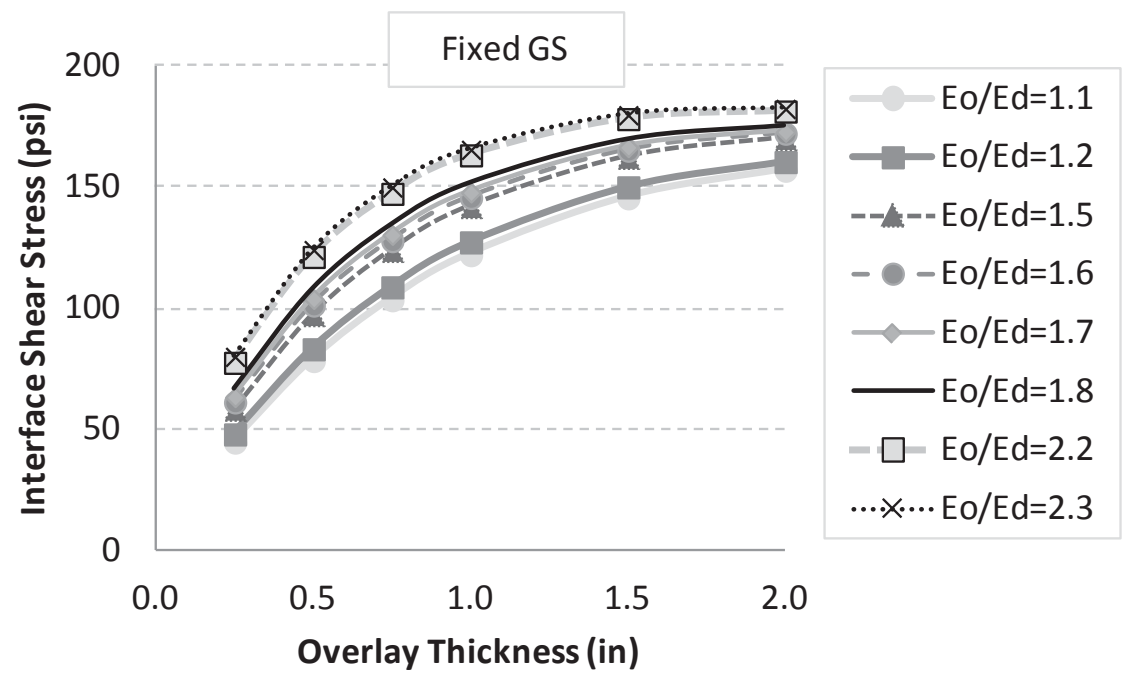

Figure 4.59: Maximum interface shear stress for various $E_{0} / E_{d}$ and $t_{0}$ and fixed girder supports

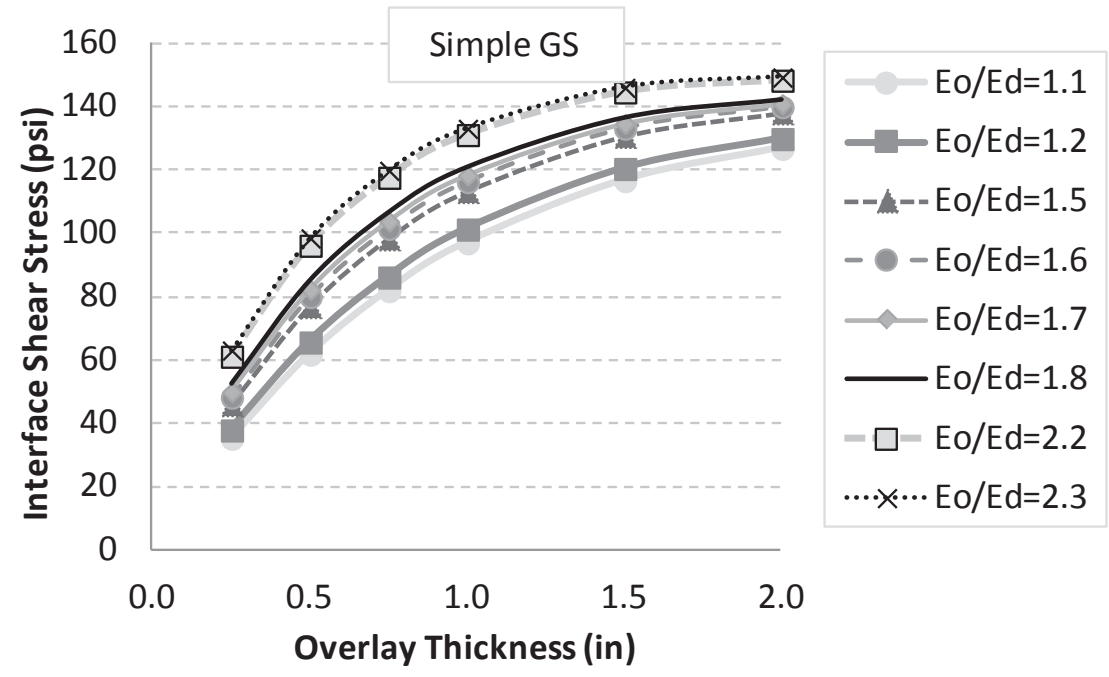

Figure 4.60: Maximum interface shear stress for various $E_{0} / E_{d}$ and $t_{0}$ and simple girder supports

In the comparison of bridge models to plate models, it was found that the interface shear stress results were more accurate when the simple girder supports were used in the plate. Therefore, the interlaminar shear stress results were superimposed with those found shown in Table 4.4 and Table 4.5. Again, early age UHPC overlays were excluded from this figure, as these modulus ratios did not control overlay design and restrained shrinkage had not yet begun to develop at these early ages. 


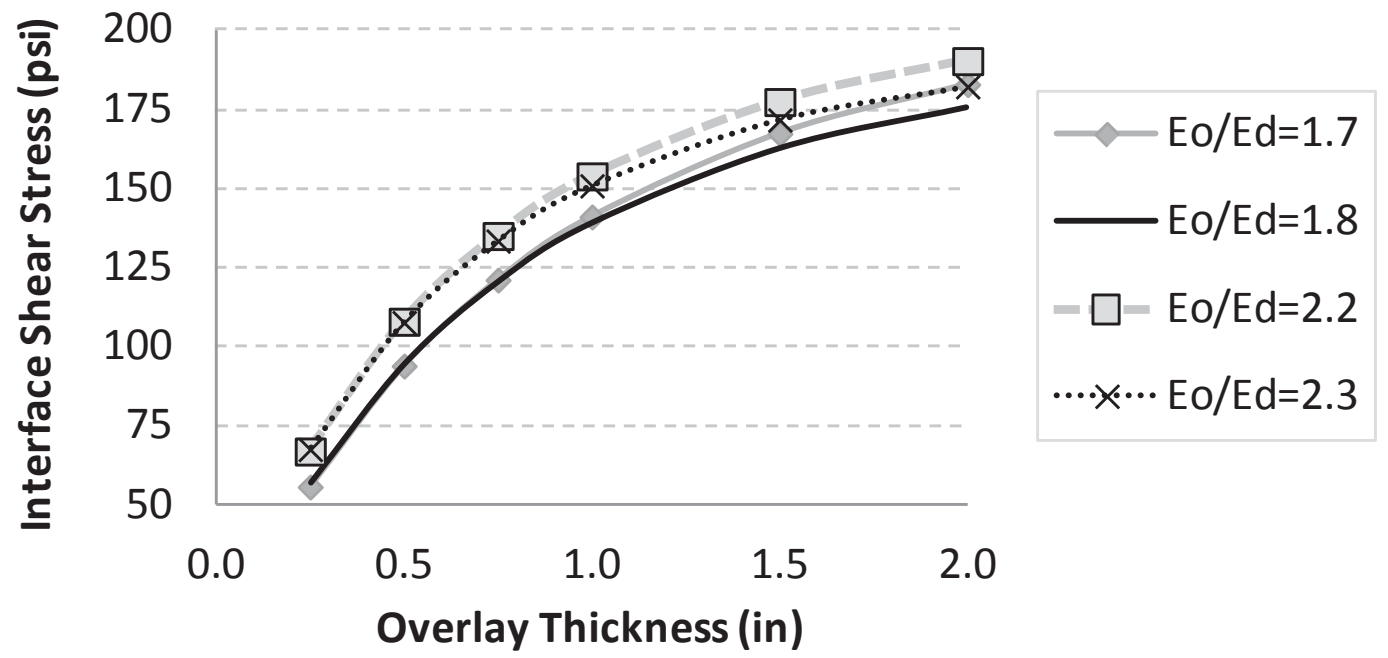

Figure 4.61: Interface shear stress under combined restrained shrinkage and design tandem

Even when restrained shrinkage effects are considered, the shear stresses found at the composite interface are much less than the 1606 psi slant shear strength for smooth UHPC-mortar surfaces found in previous literature (Harris et al. 2011).

From this analysis, it has been found that tensile stresses which produce cracking control the design of UHPC overlays. Based on the findings of this study, thin bonded overlays between $1 / 2$ in. and 2.0 in. are adequate under the considered notional design vehicle loads and restrained volume change, when girders only apply simple supports to 6 in. or 8 in. bridge decks. This parametric analysis suggests that UHPC overlays may not be feasible on deck thicknesses which are 10 in. thick or greater due to the applied loads. For bridge decks that have a high degree of restraint, UHPC overlays of these thicknesses may not be applicable. Furthermore, this analysis does not consider the effects of thermal gradients due to environmental conditions, as it was outside the scope of this project, which would contribute to the total stress in the system and further affect the adequacy of UHPC overlays for a given structure. 


\section{Conclusions}

UHPC represents a recent advancement in the area of concrete materials due to its enhanced mechanical and durability characteristics. These characteristics make UHPC an ideal solution for a number of applications, including bridge deck overlays where the service-life of existing and new structures may be significantly extended. To evaluate the feasibility of using UHPC as a bridge deck overlay, a study was performed to optimize the appropriate thickness required to ensure integrity of the composite deck system. Two cure regimes were considered in this analysis: a modified steam cure (MSC) which represented the capabilities of a precast plant with reduced bed turnover time and an ambient cure which represented cast-in-place applications of this system. The optimization study was performed parametrically using the finite element method, coupled with experimental results of the bond and early-age strength in an effort to minimize the overlay thickness. Though the results from the bond testing do not provide a direct comparison to the complex state of 3-D stress at the interface, they do provide a basis for comparing the magnitude interface shear and debonding stress.

When restrained shrinkage and creep relaxation of UHPC was considered, it was found that increased overlay thickness caused larger horizontal shear stresses at the bond interface. The highest tension stresses due to the restrained shrinkage occurred at the UHPC-steel interface. MSC UHPC appears to exhibit minimal continued shrinkage after 28 days, while the AMC specimens continue to shrink after the 35 day test duration. The stresses induced by restrained shrinkage account for a majority of the available tension capacity of UHPC, which creates limitations when additional loads are considered.

Under notional design truck loads, the locations of maximum of interface shear occurred adjacent to wheel loads and at girder locations. Locations of maximum debonding stress and tensile cracking stress occurred at girder locations and in the center of applied wheel loads. Higher stresses were generally found when girders provided fixed restraint on the bridge deck when compared to simple restraint. The notional design tandem load was found to cause the highest state of stress in the overlay system for all models and load positions. Debonding was not found to occur in all loading, geometric, and material configurations. In some cases only compression occurred in the overlay system, so the interface was never able to separate. Generally speaking, debonding stress and interfacial shear stress increased with increased overlay thickness, while tension stress that would produce cracking or fracture in a UHPC overlay decreased with increased overlay thickness. It was also found that increased deck thickness induced lower debonding and interface shear stresses, but increased the tensile cracking stress. The effect overlay and deck thickness has on the state of stress in the UHPC overlay can be attributed to shifts in the neutral axis location.

An additional finding from this research is that early-age applications of UHPC overlay are not the critical point in the service life. UHPC material strengths are not developed at early ages and therefore have less difference in stiffness between the existing bridge 
deck. This creates better load transfer and overlay compatibility of the composite system. In-service ages are critical in design, as the UHPC has fully developed its mechanical and durability properties and there are large differences in stiffness between the composite materials. By comparing the S11 Bridge results to simple and fixed plates under the same loading, geometric, and material configuration, it was found that bridge deck plates which have girders modeled as simple supports more closely represent the global system behavior. However, every bridge connection and construction is different and the actual girder constraints for a given bridge may provide more fixity.

When the effects of restrained shrinkage and live load were combined, it was determined that the tensile cracking stresses in a UHPC overlay control the design. It was also concluded that UHPC overlays may not compatible on 10 in. or thicker bridge decks, as the increased distance to the neutral axis and high stiffness of the UHPC causes tensile cracking stresses greater than the material strength. Under the worst case loading and geometric configurations, it was found that thin-bonded MSC UHPC overlays of all thicknesses were compatible when bonded to $3 \mathrm{ksi}$ or $5 \mathrm{ksi}$ concrete bridge decks. Additionally, all AMC UHPC overlay thicknesses are adequate when bonded to $5 \mathrm{ksi}$ deck concrete. However, when bonded to 3 ksi deck concrete, only overlays greater than $1 / 2$ in. were compatible for cast-in-place AMC applications and the loading, material, and geometric parameters considered.

Note that these findings consider a bridge decks with no existing damage and does not consider all loads which may cause overlay failure. Residual stresses caused by differences in material coefficient of thermal expansion, for instance, must be considered to fully determine the feasibility of this overlay system. Furthermore, every bridge has different global behavior and boundary conditions due to varied construction methods and connections. In this research it was found that increased fixity caused higher stresses in the composite system to a point where UHPC overlays may not be appropriate. Therefore, if UHPC overlays are being considered, the actual behavior of the bridge in question must be considered, as the research presented here only provides a baseline of actual bridge behavior. 


\section{Future Work}

This investigation included an analytical study on the bond stresses between an ultra-high performance concrete (UHPC) overlay and a normal strength concrete (NSC) bridge deck substrate; in addition to the effects of restrained shrinkage and creep relaxation. Further study is needed in the following areas to completely assess the application of this material as a concrete bridge deck overlay.

- Existing cracks in concrete bridge decks create localized stresses, which may cause cracking, debonding, or spalling in an applied UHPC overlay. The effect of these localized stresses and crack propagation through the depth of the UHPC overlay should be investigated to assess the effectiveness of applying UHPC on damaged, existing structures.

- Large differences in the thermal expansion coefficients (CTE) between composite materials may lead to large residual tensile stresses, which can cause debonding or cracking. Analyses must be completed to understand the severity of UHPC and NSC CTE differences.

- The current research considered the load to first crack and first debonding. However, understanding how a composite UHPC overlay and NSC bridge deck behaves after this point is equally important for maintenance estimates. Therefore, post-cracking propagation and debonding utilizing fracture mechanics should be completed.

- The current study focuses on the state of stress in a simple span bridge. However, higher live load induced stresses may be caused at locations of maximum negative bending in a continuous span bridge. Therefore, multi-span span bridge deck structures must be considered before a UHPC overlay is applied.

- Further investigation is needed to fully understand the influence of girder spacing on the bond stresses of a UHPC overlay-NSC bridge deck greater than $10 \mathrm{ft}$. and less than $6 \mathrm{ft}$., as these were not considered in analysis.

- Restrained shrinkage of UHPC used in this study was determined using a 3 in. concrete annulus in the AASHTO PP34-99 ring test. Although the material properties of UHPC (autogenous shrinkage) and past literature support the methods used in this thesis, the actual net residual stresses of $1 / 4$ in. to 2 in. UHPC due to restrained shrinkage and tensile creep relaxation must be determined.

- Notional design HS-20 truck and design tandem loads were the only live loads considered in this analysis. Though these loads provide representative analysis as to the compatibility of a UHPC overlay - NSC bridge deck, design impact, lane, multiple presence loads should be considered for a full investigation of the system. Furthermore, many state DOTs use higher notional design trucks in their bridge infrastructure. Michigan DOT, for example, considers HS-25 design trucks for highway bridges. These larger notional loads should be considered for DOTs when appropriate.

- The effect of breaking and acceleration on this overlay should also be investigated for full understanding of the compatibility of this application. 


\subsection{Industry Discussion on Applications}

Another major concern regarding the application of thin-bonded UHPC overlays on concrete bridge decks is the constructability aspects of this system. An initial investigation was completed as part of this research. However, full-scale experimental testing needs to be conducted to better understand the constructability of this material in cast-in-place and precast applications.

To gain insight into the challenges from a precast facility perspective, where a UHPC overlay seems most applicable, Spancrete representatives were questioned (Holien et al. June 14, 2011). Spancrete is a precast manufacturer with facilities located in Wisconsin, Illinois, and Florida. They were chosen for their experience with precast deck panels and close proximity to Michigan Tech. Among the discussed topics were casting sequence, curing regime capabilities, demolding times, and possibilities for substrate and riding surface preparations.

Because UHPC is a self-consolidating material, constructability of creating required cross slopes is an issue. Also, due to the high strength of UHPC when steam treatments are applied, scarifying or roughening a cured UHPC overlay to achieve adequate bonding surfaces and skid resistant surfaces may be quite difficult. Other constructability issues such as possible mixers and batching sequences were also discussed.

\subsubsection{Mixing and Casting Sequence Discussion}

Spancrete facilities have both pan mixers and twin shaft mixers. Lafarge North America typically recommends high shear mixers to force more energy into the mix. Therefore, twin shaft mixers are more desirable. Spancrete suggested that a twin shaft mixer would create a more uniform fiber dispersion than a pan mixer could.

Concerning casting sequences and possible constructability challenges, Spancrete suggested three main options for casting a pre-topped UHPC overlay on a concrete deck slab in a precast plant. One option would be to cast the UHPC overlay first, then jack up the portion so that the normal concrete could be filled beneath it. This method would allow the UHPC to be placed in a form that was shaped to allow surface roughness on both sides for skid resistance and bond surface preparation. However, this option is expected to be the most expensive and difficult to obtain required cross slopes. The second option discussed would be to cast the UHPC overlay first, prepare the exposed overlay surface in order to obtain an adequate bonding surface, and then cast the concrete slab on top. This option could also utilize a form that provides an adequate skid resistance shape on the top surface and would easily include desired cross slope. As for the bond surface preparation, Banta recommended the use of jackhammers or hydraulic demolition to create a chipped UHPC surface as it was the fastest considered method and increased bond strength could be obtained from the exposed fibers (Banta 2005). The last option considered would be to cast the concrete slab first, prepare the exposed 
substrate surface, and then cast the UHPC overlay. This option was not preferred, however, due to difficulties related to maintaining a cross-slope and riding surface.

\subsubsection{Curing}

Radiant heat treatment and ambient curing regimes are used at the Spancrete plants. Radiant heat cure is typically around $140^{\circ} \mathrm{F}$, which is consistent with the tempered and pre-steam steam treatment referenced in several works (Graybeal 2006a; Flietstra 2010). Under radiant heat curing, a UHPC overlay could be demolded as soon as curing commenced. Should casting sequence Option 2 be used, the concrete slab can be cast over the UHPC overlay once initial set has been obtained. Graybeal found initial set to occur around $15 \mathrm{hrs}$ for tempered steam curing and final set to occur around $16 \mathrm{hrs}$ depending on the regime (Graybeal 2006a).

\subsubsection{Bonding and Riding Surface Preparations}

As UHPC is an extremely dense material and has no large aggregates, adequate preparation of a riding surface on a UHPC would likely be impossible using water or sand blasting. Depending on the casting sequence, creation of a roughened bond interface on a UHPC overlay is equally difficult. Even using these techniques on a large precast concrete slab would be time consuming and expensive. Therefore, alternative means were investigated when speaking to industry personnel.

Spancrete currently uses several texturing techniques that may prove to be suitable methods for developing a roughened bond and riding surface. Depending on the casting sequence, these techniques could be used for either surface. One suggestion would be to apply acid etching to the concrete. Typically used in architectural applications, acid etching uses chemical retarding agents applied to a form surface which chemically reacts with newly placed concrete. This section is scrubbed and rinsed to produce a surface resembling limestone or sandstone. The acid etching technique appears to be an appropriate method for both bond interface and riding surface texturing. Spancrete often uses an architectural finishing technique that exposes aggregates within the mix through the use of chemical additives that delay hardening of exterior mortar. This mortar is later removed by hydroblasting or sandblasting; however hydroblasted is recommended in this application in order to retain the aggregates angularity. Since UHPC has no course aggregate, aggregate may be added to the substrate mix near the retarding agent to produce a rougher bond interface. Another method to economically and efficiently create a roughened riding surface would be to broadcast sand over a partially cured UHPC overlay. This application could be applied in either a cast-in-place setting or precast setting (depending on the casting sequence chosen). The timing of this applying broadcast sand would need to be explored in addition to investigations on how a riding surface might be restored when the surface becomes dull over time. The use of textured forms is a further suggestion made by Spancrete to roughen either the interface or riding surface. Form liners, such as one that mimics broom strokes could easily be used on the 
concrete deck or UHPC overlay. For cast-in-place applications, tining may also be an option for riding surface preparation, though the timing would have to be investigated in regards to initial and final set.

This preliminarily investigation is included to illustrate the constructability challenges that may be encountered in applying a thin-bonded UHPC overlay on concrete bridge decks. Field and plant testing must be conducted to fully understand and account for all constructability issues that may arise in this application. 


\section{References}

AASHTO. 2010. AASHTO LRFD bridge design specifications, 5th Ed. Washington, DC: American Association of State Highway Transportation Officials.

AASHTO PP-34-99. Standard Practice for Estimating the Cracking Tendency of Concrete. American Association of State Highway Transportation Officials. p. 179-182.

ACI 318-08. 2008. Building Code Requirements for Structural Concrete and Commentary. Farmington Hills, MI: American Concrete Institute.

ACI 345. 2011. Guide for Concrete Highway Bridge Deck Construction. Farmington Hills, MI: American Concrete Institute. No. ACI 345R-11.

ACI. 1998. ACI 548.4-98 "Standard Specification for Latex-Modified Concrete (LMC) Overlays". American Concrete Institute. p. 6.

ACI Concrete Terminology [Internet]. 2010. Farmington Hills, MI: American Concrete Institute. [updated August 31, 2010, cited April 10, 2012]. Available from: http://terminology.concrete.org

Ahlborn TM, Harris DK, Misson DL, Peuse EJ. 2011. Characterization of Strength and Durability of Ultra-High-Performance Concrete Under Variable Curing Conditions. Transportation Research Record 2251:68-75.

ANSYS. 2011. ANSYS Release 12.0 Documentation. 12.0 ed. Cannonsburg, PA: Swanson Analysis System, Inc.

Astarlioglu S, Krauthammer T, Felice C. 2010. State-of-the-art Report on Fiber Reinforced Ultra-high Performance Concrete. University of Florida. No. CIPPSTR-003-2010. 
ASTM C39. 2012. Standard Test Method for Compressive Strength of Cylinderical Concrete Specimens. Annual Book of ASTM Standards,. West Conshohocken, PA: ASTM International.

ASTM C192. 2007. Standard Practice for Making and Curing Concrete Test Specimens in the Laboratory. Annual Book of ASTM Standards. West Conshohocken, PA: ASTM International.

ASTM C617. 2011. Standard Practice for Capping Cylindrical Concrete Specimens. Annual Book of ASTM Standards,. West Conshohocken, PA: ASTM International.

ASTM C1437. 2007. Standard Test Method for Flow of Hydraulic Cement Mortar. Annual Book of ASTM Standards,. West Conshohocken, PA: ASTM International.

ASTM C1581. 2009. Standard Test Method for Determining Age at Cracking and Induced Tensile Stress Characteristics of Mortar and Concrete under Restrained Shrinkage. American Book of ASTM Standards,. West Conshohcken, PA: ASTM International.

Banta TE. 2005. Horizonal Shear Transfer Between Ultra High Performance Concrete and Lightweight Concrete [Thesis]. [Blacksburg, VA]: Virginia Polytechnic Institute and State University.

Barr PJ, Eberhard MO, Stanton JF. 2001. Live-load distribution factors in prestressed concrete girder bridges. Journal of Bridge Engineering 6(5):298-306.

Boresi AP, Schmidt RJ. 2003. Advanced Mechanics of Materials. New York, NY: John Wiley \& Sons, Inc. 
Briffault M, Benboudjema F, Torrenti JM, Nahas G. 2011. A thermal active restrained shrinkage ring test to study the early age concrete behaviour of massive structures. Cement and Concrete Research 41:56-63.

Burkart I, Müller HS. Creep and shrinkage characteristics of Ultra High Strength Concrete (UHPC). Eighth International Conference on Creep, Shrinkage and Durability Mechanics of Concrete and Concrete Structures (CONCREEP8); 2009; Ise-shima, Japan: Taylor \& Francis Group. p. 689-694.

Carbonell MA, Harris DK, Shann SV, Ahlborn TM. 2012. Bond Strength between UHPC and Normal Strength Concrete (NSC) in accordance with Split Prism and FreezeThaw cycling tests. Proceedings of Hipermat 2012 - 3rd International Symposium on UHPC and Nanotechnology for Construction Materials. Kassel, Germany: Kassel University Press.

Chan THT, Chan JHF. 1999. Use of eccentric beam elements in the analysis of slab-ongirder bridges. Structural Engineering \& Mechanics 8(1):85-102.

Charron JP, Herwig A, Wuest J, Birdsal J, Denarie E. 2006. Report on tests of UHPFRC in the laboratory - Part B - Deliverable D18b. Sustainable and Advanced MAterials for Road InfraStructure (SAMARIS).

Chung W, Sotelino ED. 2006. Three-dimensional finite element modeling of composite girder bridges. Engineering Structures 28(1):63-71.

Cook RD, Malkus DS, Plesha ME, Witt RJ. 2001. Concepts and applications of finite element analysis. Wiley, NY.

DAfStB. 2003. Technical Guidelines for Steel Fiber Reinforces Concrete. Berlin: German Association for Reinforced Concrete within DIN and German Institute for Standardization. 
Delatte N, Mack E, Cleary J. 2007. Evaluation of High Absorptive Materials to Improve Internal Curing of Low Permeability Concrete. Cleveland OH: Cleveland State University.

Denarié E, Brühwiler E. 2005. Full scale applications of UHPFRC for the rehabilitation of bridges - from the lab to the field - Deliverable D22. Sustainable and Advanced MAterials for Road InfraStructure (SAMARIS). No. SAM_GE_DE22v03_01.

FHWA. 2006. Bridge Inspector's Reference Manual (BIRM). Washington, DC: Federal Highway Administration,.

National Bridge Inventory [Internet]. 2011. Washington, DC: Federal Highway Administration. [updated December, 2011, cited February 20, 2012]. Available from: http://www.fhwa.dot.gov/bridge/deficient.cfm

Flietstra J. 2010. Creep and Shrinkage Behavior of Ultra High Performance Concrete under Compressive Loading with Various Curing Regimes. [Houghton, MI]: Michigan Technological University.

Fowler DW, Whitney DW. 2011. NCHRP Synthesis 423 - Long-Term Performance of Polymer Concrete for Concrete Bridge Decks. In: National Cooperative Highway Research Program, editor. Washington, DC: Transportation Research Board.

Garas VY, Kahn LF, Kurtis KE. 2009a. Short-term tensile creep and shrinkage of ultrahigh performance concrete. Cement \& Concrete Composites 31:147-152.

Garas VY, Kahn LF, Kurtis KE. Preliminary investigation of the effect of steel fibers on the tensile creep and shrinkage of ultra-high performance concrete. Eighth International Conference on Creep, Shrinkage and Durability Mechanics of Concrete and Concrete Structures (CONCREEP8) 2009b; Ise-shima, Japan: Taylor \& Francis Group. p. 741-751. 
Gillum AJ, Shahrooz BM, Cole JR. 2001. Bond strength between sealed bridge decks and concrete overlays. Aci Structural Journal 98(6):872-879.

Granju J-L, Sabathier V, Turatsinze A, Toumi A. 2004. Interface Between an Old Concrete and a Bonded Overlay: Debonding Mechanism. Interface Science 12:381-388.

Graybeal BA. 2005. Characterization of the Behavior of Ultra-High Performance Concrete [Doctor of Philosophy]. [College Park, MD]: University of Maryland.

Graybeal BA. 2006a. Material Property Characterization of Ultra-high Performance Concrete. McLean, VA: Federal Highway Administration (FHWA). No. FHWAHRT-06-103.

Graybeal BA. 2006b. Practical Means for Determination of the Tensile Behavior of Ultra-High Performance Concrete. Journal of ASTM International 3(8):1-9.

Graybeal BA. 2007. Compressive Behavior of Ultra-High-Performance Fiber-Reinforced Concrete. ACI Materials Journal 104(2):146-152.

Griffin JJ, Issam E. Harik, Choo CC. 2006. Performance Evaluation of Bridges with Structural Bridge Deck Overlays (SBDO). Lexington, KY: University of Kentucky: Kentucky Transportation Centery. No. KTC-06-05 / FRT81-82-97-1F.

Habel K, Denarié E. 2005. Report on tests of UHPFRC in the laboratory - Part A, Deliverable D18 - Part A. Sustainable and Advanced MAterials for Road InfraStructure (SAMARIS).

Habel K, Charron JP, Denarié E, Brühwiler E. 2006a. Autogenous deformations and viscoelasticity of UHPFRC in structures. Part I: experimental results. Magazine of Concrete Research 58(3):135-145.

Halvorsen GT. 1993. Bridge deck overlays. Concrete Construction 38(6):415-419. 
Harris DK. 2007. Lateral Load Distribution and Deck Design Recommendations for the Sandwich Plate System (SPS) in Bridge Applications [Dissertation]. [Blacksburg, VA]: Virginia Polytechnic Institute and State University.

Harris DK, Sarkar J, Ahlborn TM. Interface Bond Characterization of Ultra High Performance Concrete Overlays. Transportation Research Board 90th Annual Meeting; 2011; Washington, D.C.

Holien T, Kaiser J, Reay S. June 14, 2011. Interview with Spancrete. Valders, WI.

Hossain AB, Weiss J. 2004. Assessing residual stress development and stress relaxation in restrained concrete ring specimens. Cement \& Concrete Composites 26:531540.

Hossain AB, Weiss J. 2006. The role of specimen geometry and boundary conditions on stress development and cracking in the restrained ring test. Cement and Concrete Research 36:189-199.

Hossain AB, Foneska A, Bullock H. Restrained shrinkage stress development and stress relaxation in low W/B mortars containing ultrafine fly ash. Eighth International Conference on Creep, Shrinkage and Durability Mechanics of Concrete and Concrete Structures (CONCREEP8); 2009; Ise-shima, Japan: Taylor \& Francis Group. p. 715-721.

Issa MA, Alhassan MA, Shabila H. 2008. High-Performance Plain and Fibrous LatexModified and Microsilica Concrete Overlays. Journal of Materials in Civil Engineering 20(12):742-753.

Issa MA, Alrousan. RZ. 2009. Modeling of Bond Stresses of Overlay-Bridge Deck System. Transportation Research Record(2113):72-82. 
JSCE. 2008. Recomendations for Design and Construction of High Performance Fiber Reinforced Cement Composites with Multiple Fine Cracks (HPFRCC). Japan Society of Civil Engineers.

Kim H. 2010. Mesh-Independent Fracture Modeling for Overlay Pavement System under Heavy Aircraft Gear Loadings. Journal of Transportation Engineering 126(4):370-378.

Knight ML, Wilson GS, Seger WJ, Mahadevan S. 2004. Overlay types used as preventive maintenance on Tennessee bridge decks. Maintenance and Management of Pavement and Structures(1866):79-84.

Kollmorgen GA. 2004. Impact of Age and Size on the Mechanical Behavior of an UltraHigh Performance Concrete. [Houghton, MI]: Michigan Technological Univeristy.

Kosmatka SH, Wilson ML. 2011. Design and Control of Concrete Mixtures, 15th Ed. Stokie, IL: Portland Cement Association.

Krauss P, Lawler J, Steiner K. 2009. Guidelines for Selection of Bridge Deck Overlays, Sealers, and Treatments. Northbrook, IL: Wiss, Janney, Elstner Associates, Inc.

Krstulovic-Opara N, Haghayeghi AR, Haidar M, Krauss PD. 1995. Use of Conventional and High-Performance Steel-Fiber Reinforced Concrete for Bridge Deck Overlays. ACI Materials Journal 92(6):669-677.

Lafarge North America. Mechanical Performances [Internet]. Calgary, Canada. [updated October 20, 2011, cited March 2, 2012]. Available from: http://www.ductallafarge.com/wps/portal/ductal/6 5-Mechanical performances

Lafarge North America. 2003a. Ductal Reference T 006, Operating Procedure Flow Test. Calgary, Canada. 
Lafarge North America. 2003b. Ductal Reference T 001, Operating Procedure Compressive Test. Calgary, Canada.

LaFraugh RW, Zinserling MH. 1986. Concrete Overlays for Bridges. Federal Way, WA: ABAM Engineers Inc. and Washington State Department of Transportation. No. WA-RD-93.1.

Luo S. 2002. Evaluations of Concrete Overlays for Bridge Deck Applications [Thesis]. [Morgantown, WV]: West Virginia University.

Marchand P, Gomes F, Lamine Dieng, Baby F, Renaud J-C, Massotte C, Estivin M, Billo J, Bazin C, Lapeyrere R et al. . Behaviour of an Orthotropic Bridge Deck with a UHPFRC Topping Layer. Proceedings of Hipermat 2012 - 3rd International Symposium on UHPC and Nanotechnology for Construction Materials; 2012; Kassel, Germany: Kassel Unibersity Press.

Misson DL. 2008. Influence of Curing Regime on the Durability of an Ultra-High Performance Concrete Material [Thesis]. [Houghton, MI]: Michigan Technological University.

Moon J-H, Rajabipour F, Pease B, Weiss J. 2006. Quantifying the Influence of Specimen Geometry on the Results of the Restrained Ring Test. Journal of ASTM International 3(8):1-13.

Moon J-H, Weiss J. 2006. Estimating residual stress in the restrained ring test under circumferential drying. Cement \& Concrete Composites 28:486-496.

Naaman AE, Wille K. The Path to Ultra-High Performance Fiber Reinforced Concrete (UHP-FRC): Five Decades of Progress. Proceedings of Hipermat 2012 - 3rd International Symposium on UHPC and Nanotechnology for Construction Materials; 2012; Kassel, Germany: Kassel University Press. p. 3-15. 
Nassif H, Aktas K, Najm H, Suksawang N. 2007. Concrete Shrinkage Analysis of Bridge Deck Concrete. New Jersey: New Jersey DOT Bureau of Research and Federal Highway Administration. No. FHWA NJ-2007-007.

Nelsen T. 2005. Performance of Concrete Bridge Deck Surface Treatments [Thesis]. Brigham Young University.

Nguyen Q-p, Jiang L-h, Zhu Q. 2010. Assessment of early-age cracking of highperformance concrete in restrained ring specimens. Water Science and Engineering 3(1):113-120.

Nossoni G, Harichandran RS. 2008. Improved repair of concrete structures using polymer concrete patch and FRP overlay. Journal of Materials in Civil Engineering 12(4):386-395.

Nowak AS, Eom J. 2001. Verification of Girder Distribution Factors for Steel Girder Bridges. University of Michigan - Dept. of Civil and Environmental Engineering. No. PROJECT 2000-0341 DIR.

Nyland EM. 2009. Early-Age Creep and Shrinkage Behavior of Ultra-High Performance Concrete for Precast/Prestressed Concrete Applications [Thesis]. [Houghton, MI]: Michigan Technological University.

Ouyang C, Yang W, Shah SP. A Fracture Mechanics Model for Shrinkage Cracking Ring. In: Lin YK, Su TC, editors. Engineering Mechanics - Proceedings of the 11th Conference; 1996; Fort Lauderdale, FL: American Society of Civil Engineers. p. 861-864.

Pease B. 2005. The Role of Shrinkage Reduceing Admixtures on Shrinkage, Stress Development, and Cracking [Thesis]. [West Lafeyette, IN]: Purdue University. 
Peuse EJ. 2008. Strength and Durability Characterization of Ultra-High Performance Concrete Under Variable Curing Conditions [Thesis]. [Houghton, MI]: Michigan Technological University.

Piérard J, Cauberg N, Remy O. Evaluation of durability and cracking tendency of Ultra High Performance Concrete. Eighth International Conference on Creep, Shrinkage and Durability Mechanics of Concrete and Concrete Structures (CONCREEP8); 2009; Ise-shima, Japan: Taylor \& Francis Group. p. 695-700.

Resplendino J. State of the art of design and construction of UHPFRC structures in France. Proceedings of Hipermat 2012 - 3rd International Symposium on UHPC and Nanotechnology for Construction Materials; 2012; Kassel, German: Kassel University Press. p. 27-41.

Rossi P. Development of new cement composite material for construction. In: Dhir RK, C.Hewlett P, Csetenyi LJ, editors. International Conference on Innovations and Developments In Concrete Materials And Construction; 2002; University of Dundee Dundee, Scotland. p. 17-29.

S Kim, Park J, Yoo D, Yoon Y. Shrinkage Behavior of Ultra High Performance Concrete at the Manufacturing Stage. Proceedings of Hipermat 2012 - 3rd International Symposium on UHPC and Nanotechnology for Construction Materials; 2012; Kassel, Germany: Kassel University Press. p. 317-324.

SAI. 1994. AS-3600 Australian Standard for Concrete Structures. Sydney, Australia: Standards Australia International,.

Schmidt C, Riedl S, Geisenhansluke C, Schmidt M. Strengthening and Rehabilitation of Pavements Applying Thin Layers of Reinforced Ultra-High-Performance Concrete (UHPC-White topping). Second International Symposium on Ultra High Performance Concrete; 2008; Kassel, Germany. p. 655-662. 
SETRA. 2002. AFGC Ultra High Performance Fiber-Reinforced Concretes. Interim Recommendations. AFGC Groupe de travail BFUP, ed.

Shann SV, Harris DK, Carbonell MA, Ahlborn TM. 2012. Application of Ultra-High Performance Concrete (UHPC) as a Thin-Topped Overlay for Concrete Bridge Decks. Proceedings of Hipermat 2012 - 3rd International Symposium on UHPC and Nanotechnology for Construction Materials. Kassel, Germany: Kassel University Press.

Sohanghpurwala AA. 2006. NCHRP Report 558 - Manual on Service Life of CorrosionDamaged Reinforced Concrete Bridge Superstructure Elements. In: Board TR, editor. Washington, DC: Transportation Research Board.

Soliman AM, Nehdi ML. 2011. Effect of drying conditions on autogenous shrinkage in ultra-high performance concrete at early-age. Materials and Structures 44:879899.

Soltesz S. 2010. Evaluation of Thin Overlays for Bridge Decks. Salem, OR: Oregon Department of Transportation - Research Section. No. FHWA-OR-RD-11-05.

Sprinkel MM, Roosevelt DS, Flintsch GW, Izeppi EdL, Mokarem DW. 2009. Evaluation of the Cargill Safelane ${ }^{\mathrm{TM}}$ Surface Overlay. Charlottesville, VA: Virginia Transportation Research Council. No. VTRC 09-R8.

Sun Z. 2004. Evaluation of Concrete Bridge Deck Overlays [Thesis]. [Morgantown, WV]: West Virginia University.

Szilard R. 2004. Theory and Applications of Plate Analysis: Classical, Numerical and Engineering Methods. Hoboken, NJ: John Wiley and Sons, Inc.

Tang F-F. 2005. Overlay for Concrete Segmental Box-Girder Bridges. Journal of Bridge Engineering 5(4):311-321. 
Timoshenko S, Woinowksy-Krieger S. 1959. Theory of plates and shells. New York, NY: McGraw-Hill.

Tran QT, Toumi A, Granju J-L. 2006. Experimental and numerical investigation of the debonding interface between an old concrete and an overlay. Materials and Structures 39:379-389.

Ugural AC. 1981. Stresses in Plates and Shells. New York, NY: McGraw-Hill.

Walter R, Olesen JF, Stang H, Vejrum T. 2007. Analysis of an Orthotropic Deck Stiffened with a Cement-Based Overlay. Journal of Bridge Engineering 12(3):350-363.

Weiss JW, Shah SP. 2002. Restrained Shrinkage Cracking: The Role of Shrinkage Reducing Admixtures and Specimen Geometry. Materials and Structures 35(246):85-91.

Wight JK, MacGregor JG. 2012. Reinforced Concrete: Mechanics and Design. Boston, Massachusetts: Prentice Hall.

Xu Q, Sun Z, Wang H, Shen A. 2009. Laboratory Testing Material Property and FE Modeling Structural Response of PAM-Modified Concrete Overlay on Bridges Journal of Bridge Engineering 14(1):26-35.

Young WC, Budynas RG. 2002. Roark's Formulas for Stress and Strain. 7th ed. New York, NY: McGraw-Hill.

Yuguang Y, Walraven J, Uijl Jd. Study on bending behavior of an UHPC overlay on a steel orthotropic deck. Second International Symposium on Ultra High Performance Concrete; March 05-06 2008; Kassel, Germany. p. 639-646. 


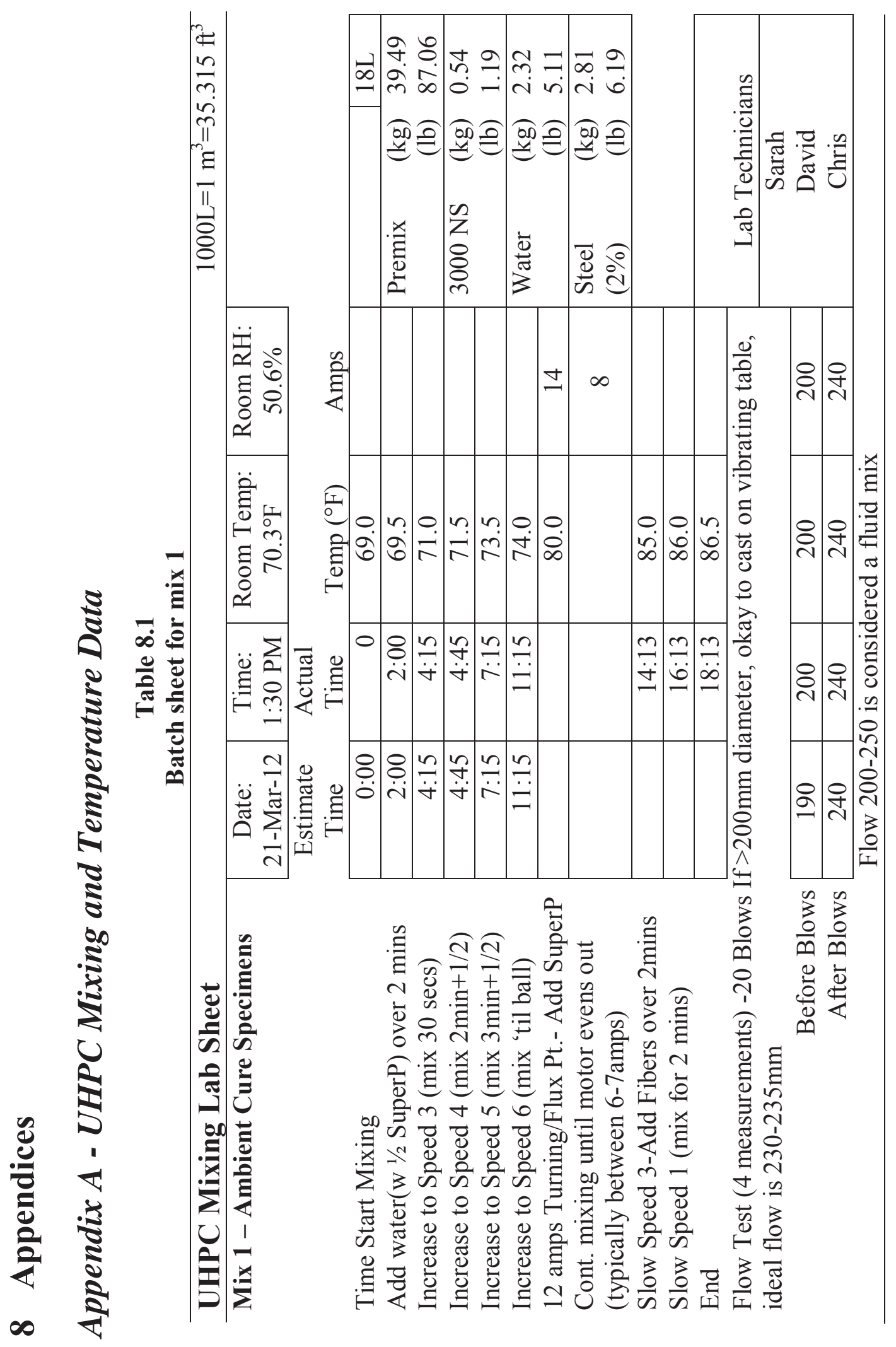




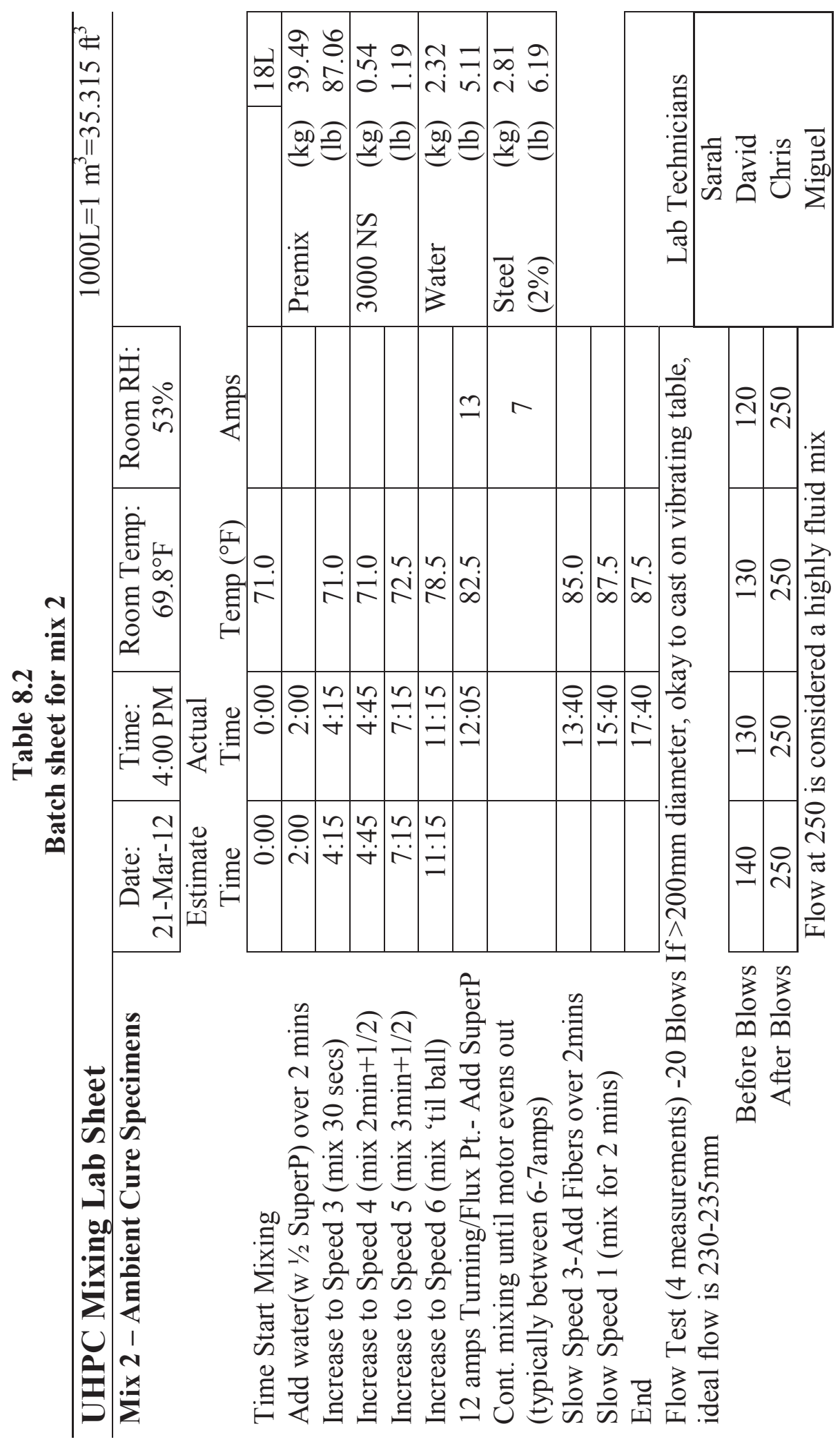




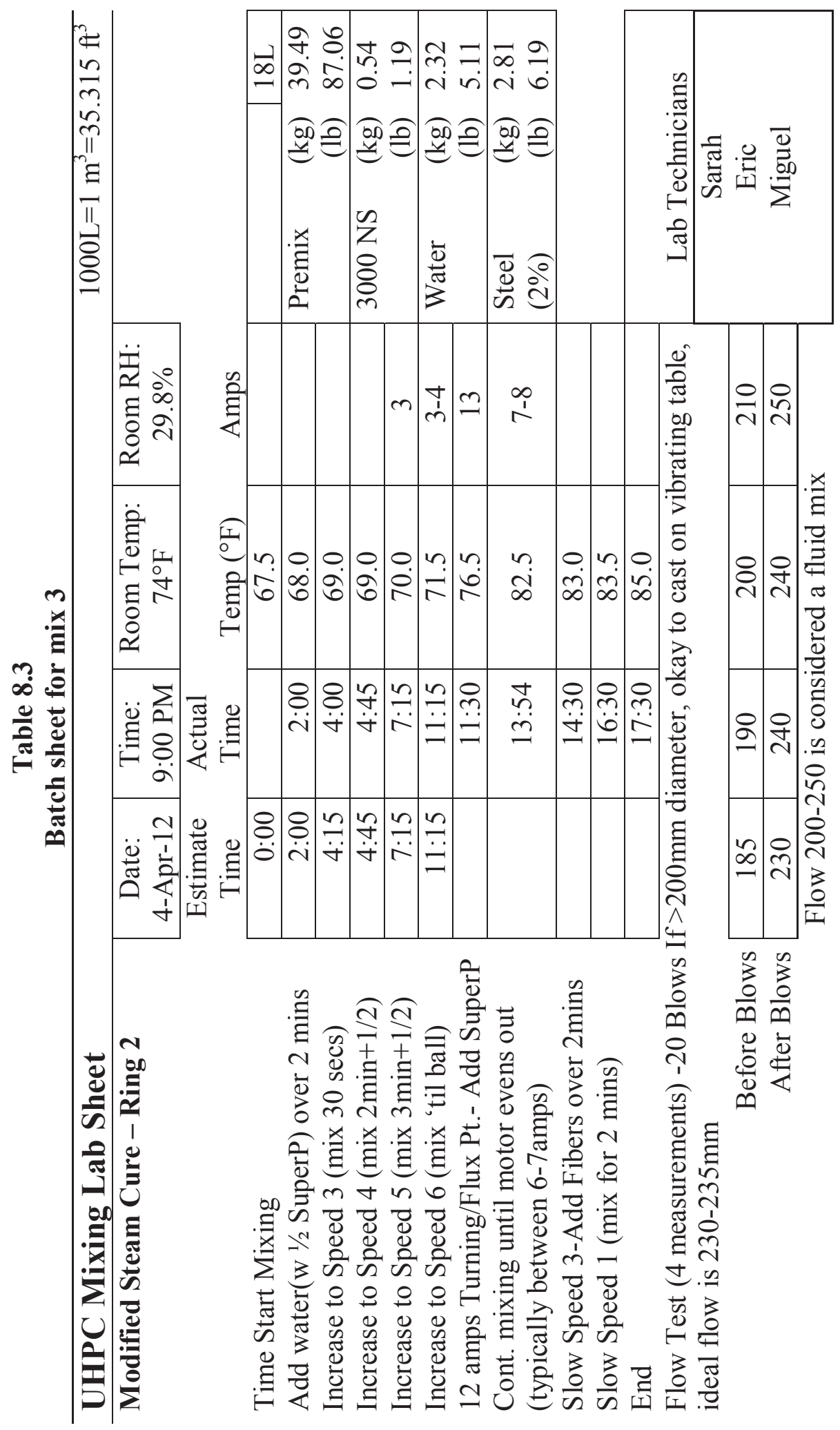




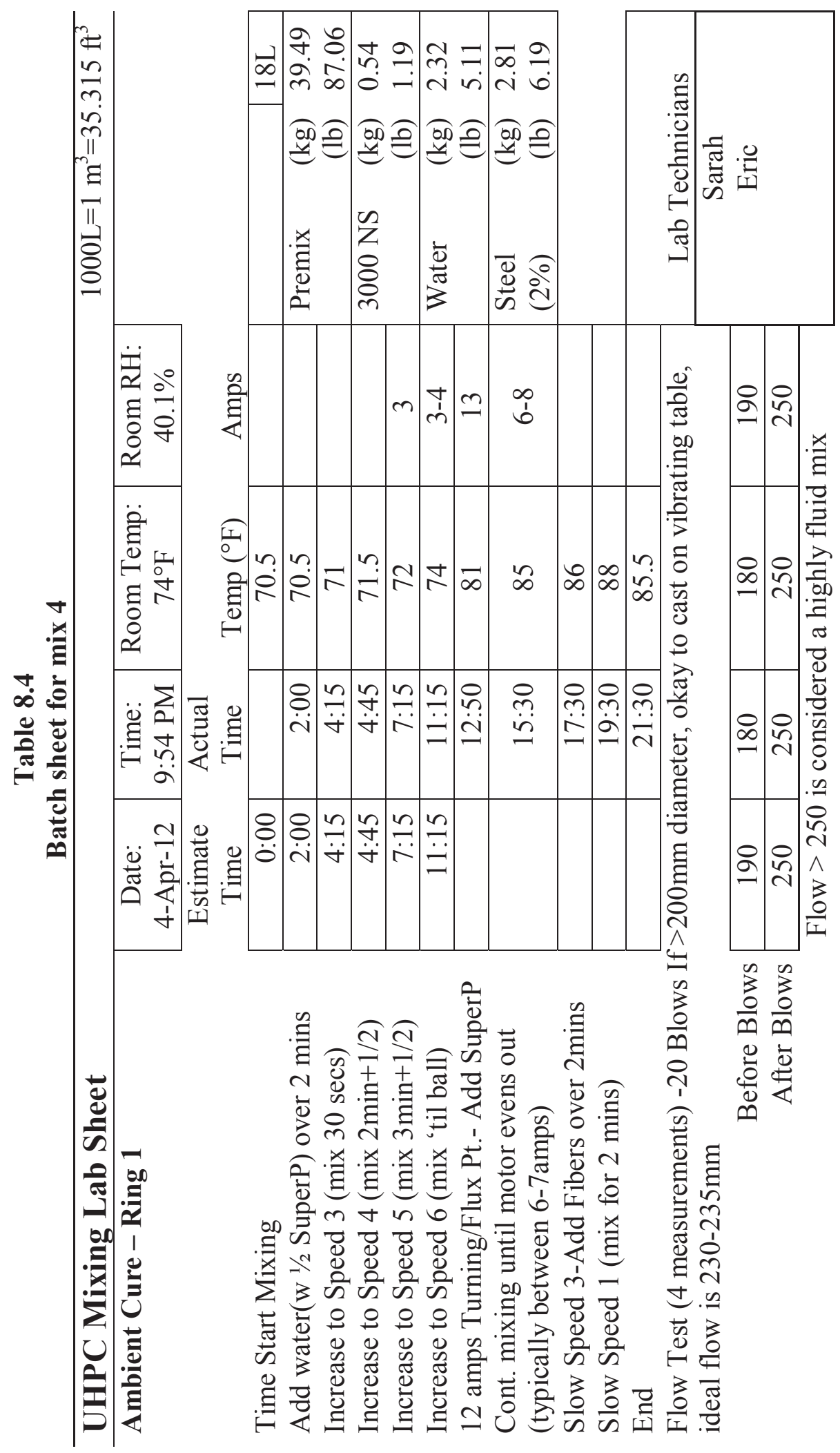




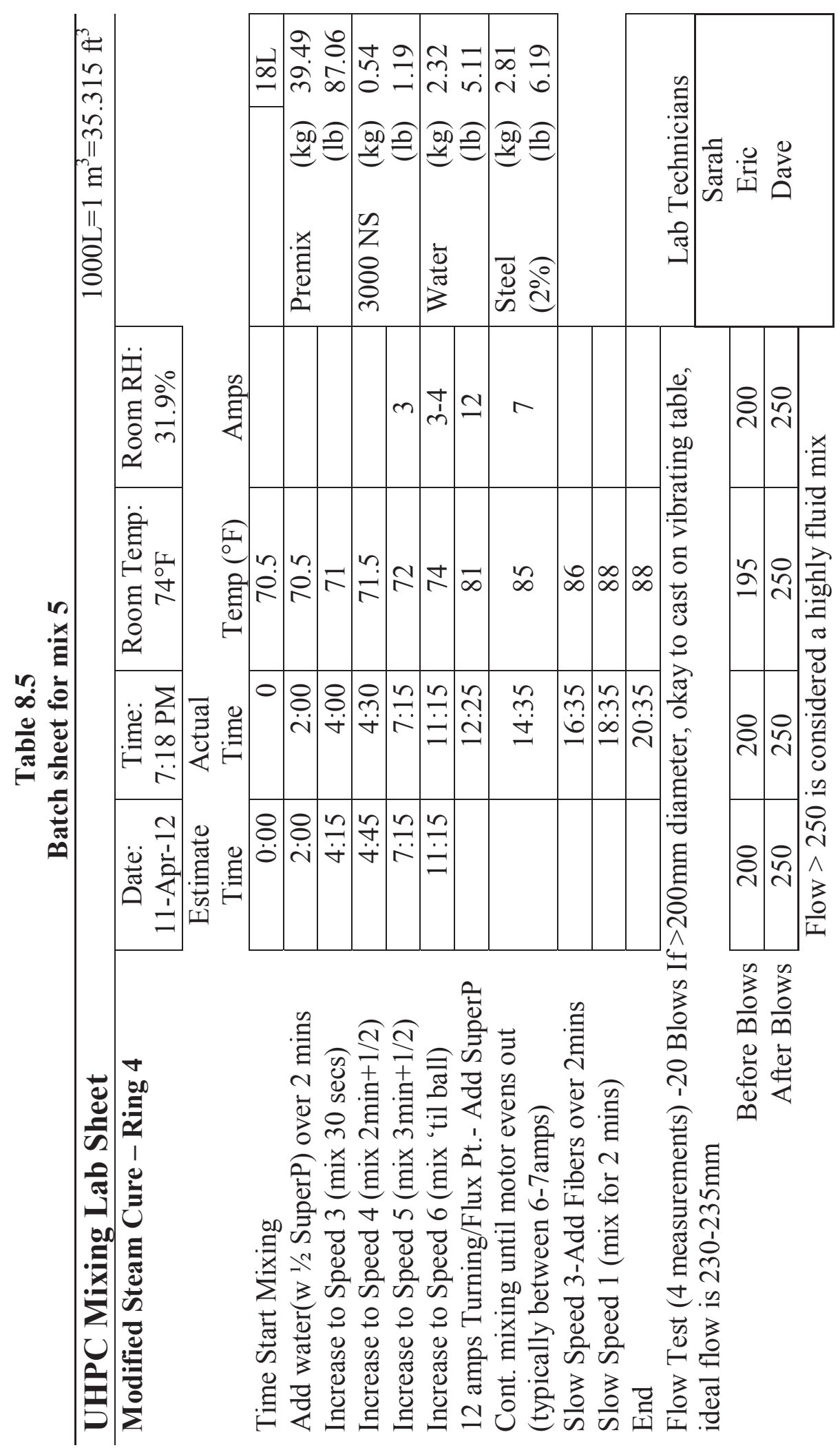




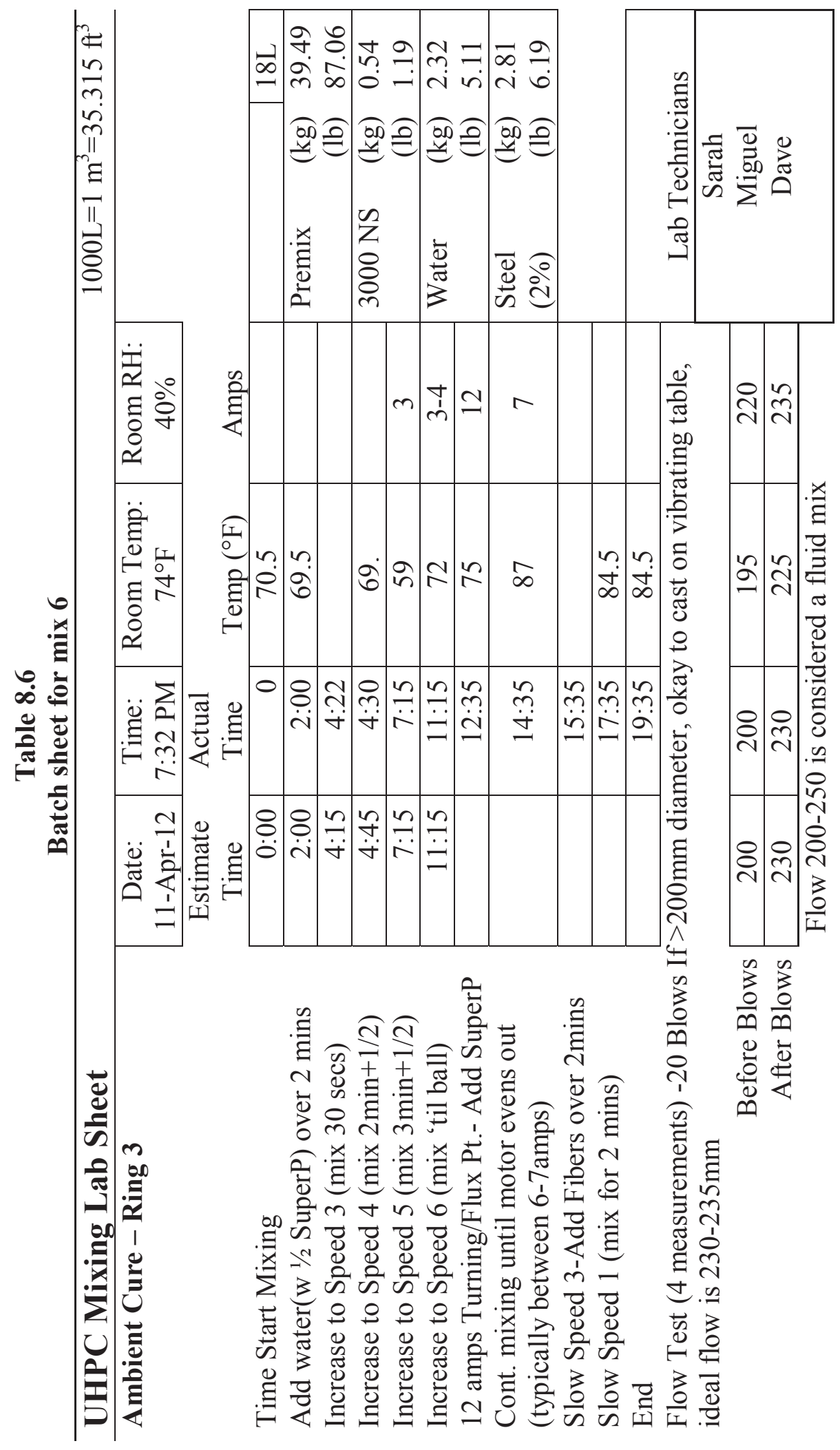



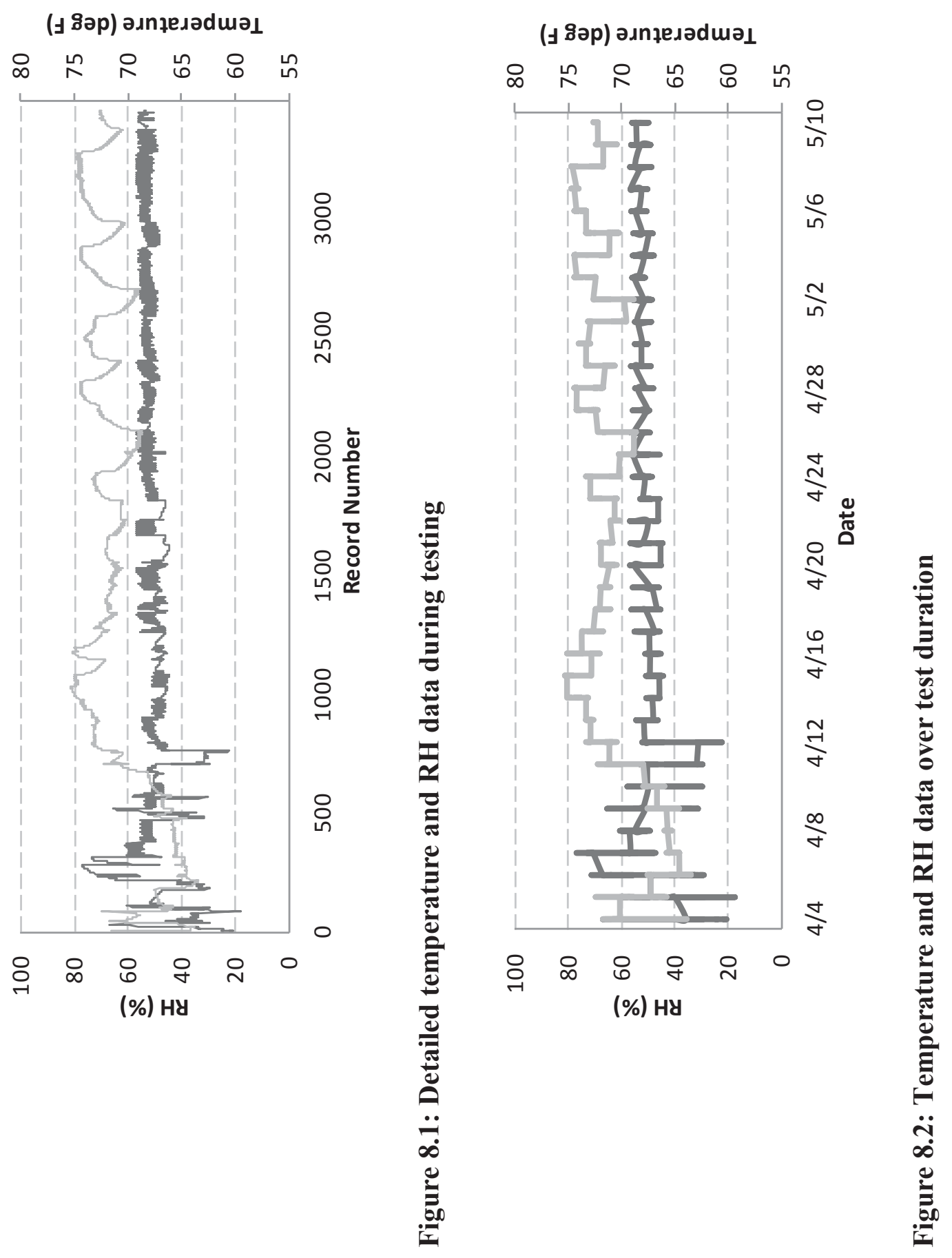


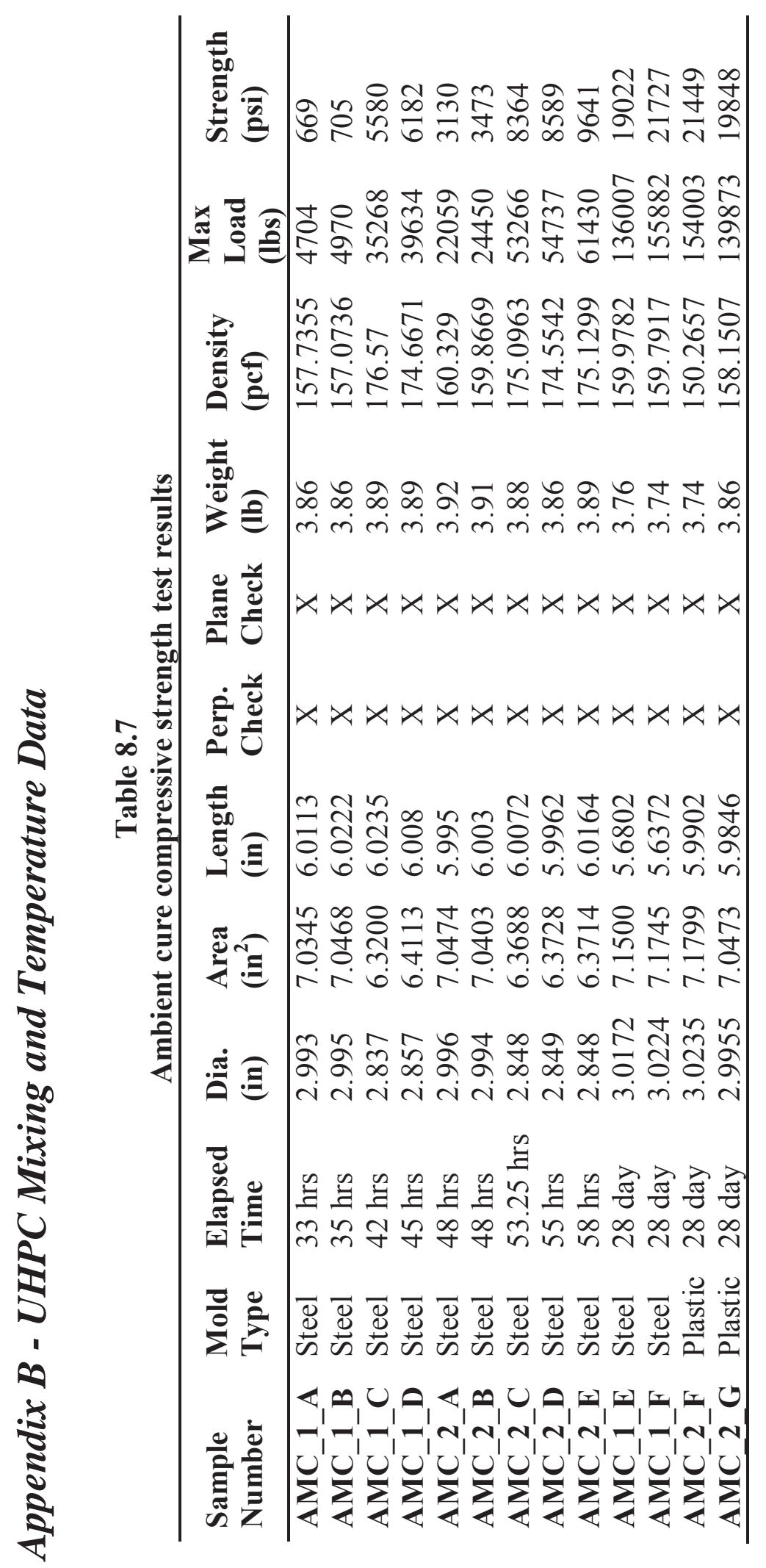




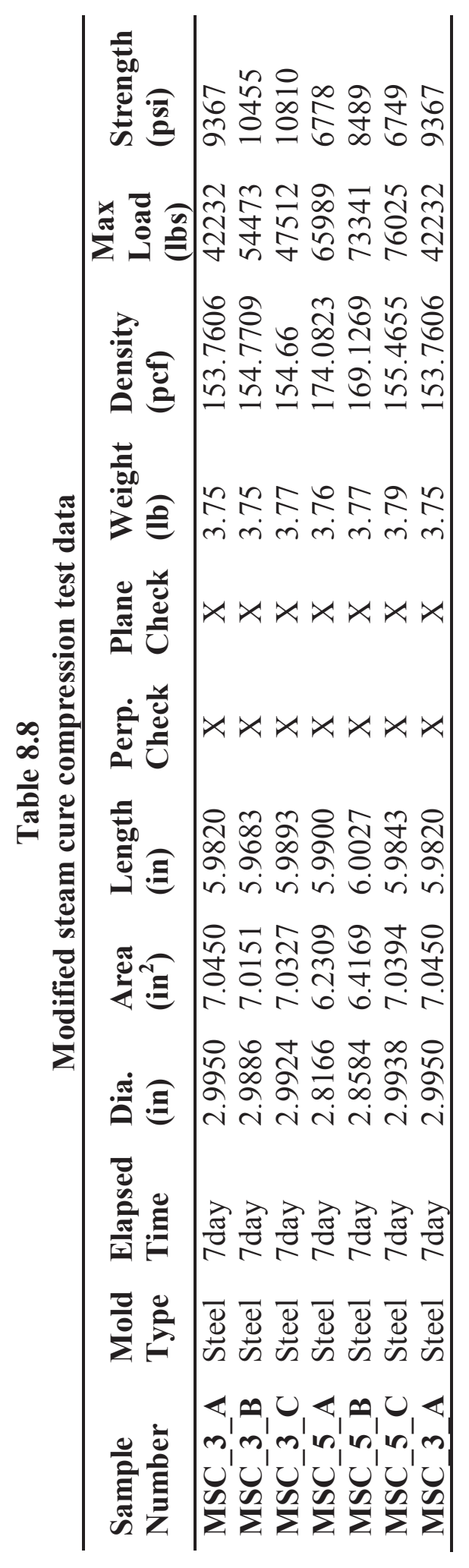




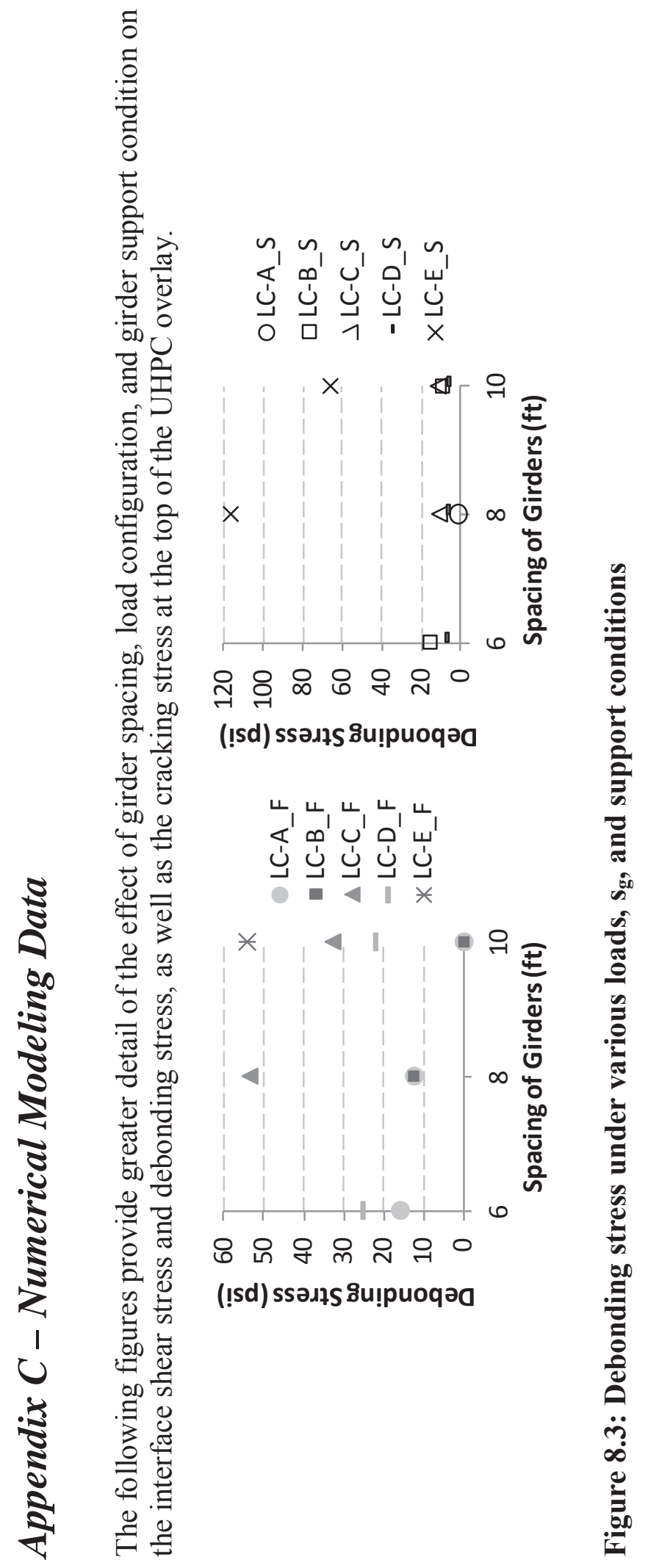




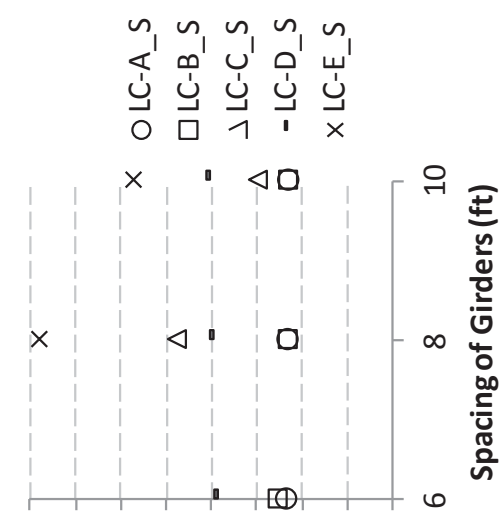

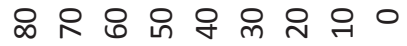
(!sd) ssәдұs деәчs әэендәұи।

나, 나, ㄴ, ㄴ, 나

षण

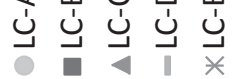

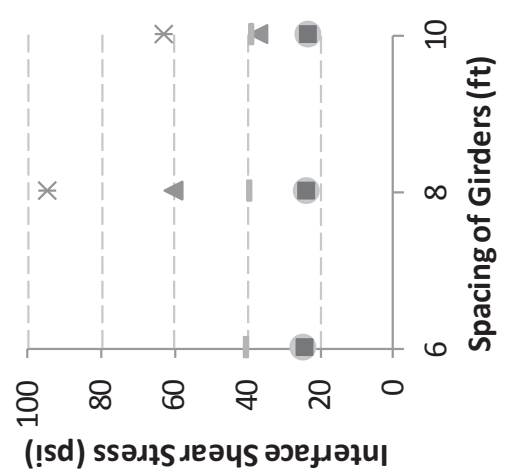

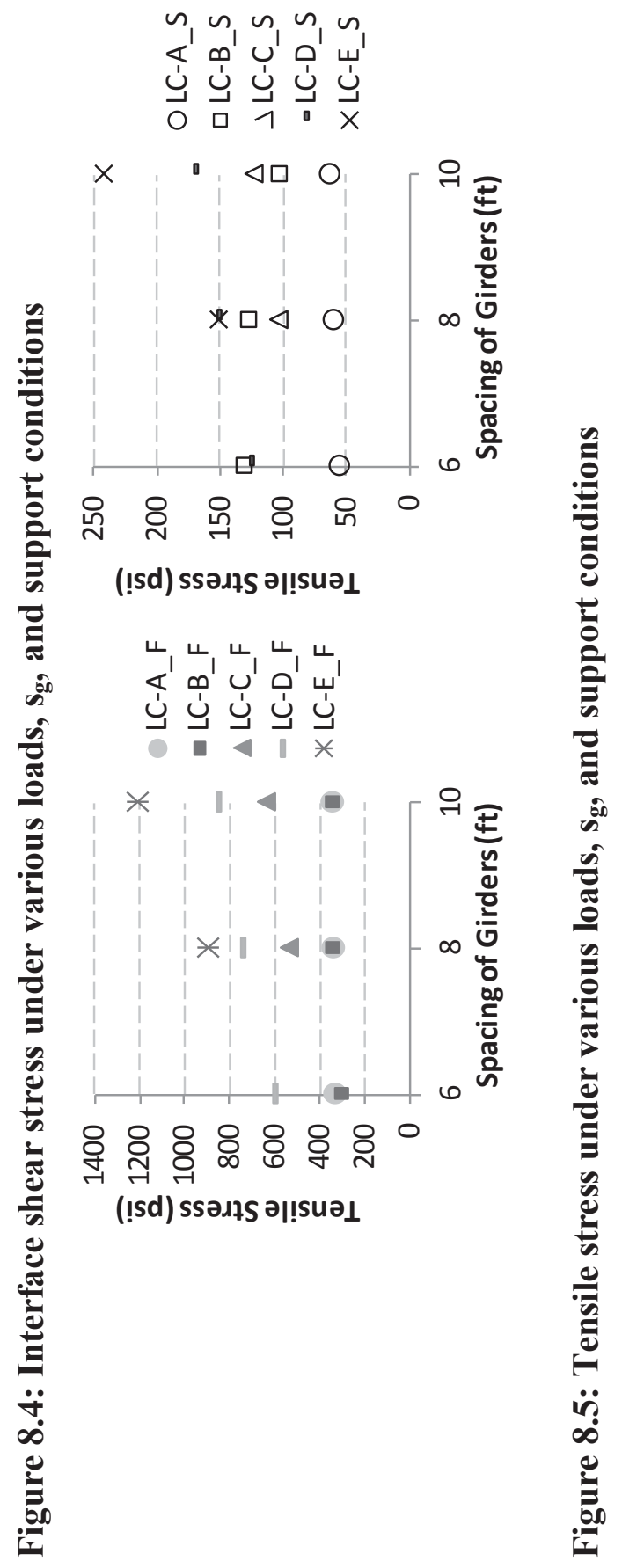

132 